\title{
Nuclear Hybrid Energy Systems - Regional Studies: West Texas \& Northeastern Arizona
}

Humberto E. Garcia Jun Chen Jong S. Kim Michael G. McKellar Wesley R. Deason

Richard B. Vilim Shannon M. Bragg-Sitton Richard D. Boardman

April 2015

The INL is a

U.S. Department of Energy

National Laboratory

operated by

Battelle Energy Alliance

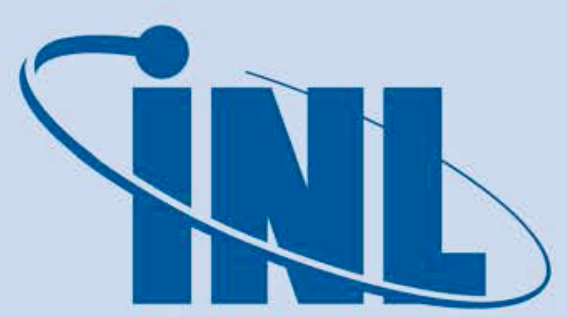

Idaho National Laboratory

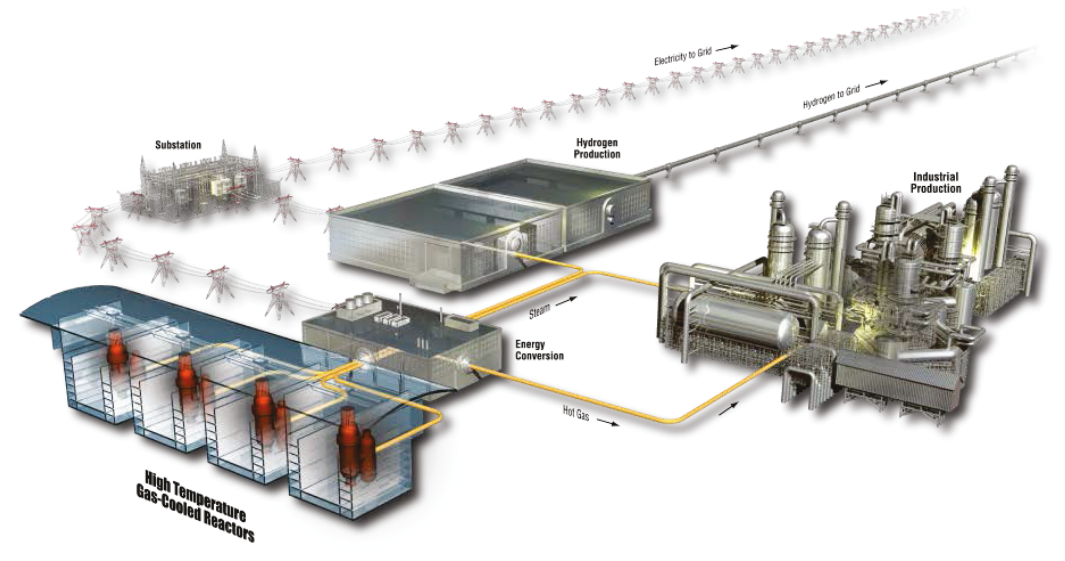




\section{DISCLAIMER}

This information was prepared as an account of work sponsored by an agency of the U.S. Government. Neither the U.S. Government nor any agency thereof, nor any of their employees, makes any warranty, expressed or implied, or assumes any legal liability or responsibility for the accuracy, completeness, or usefulness, of any information, apparatus, product, or process disclosed, or represents that its use would not infringe privately owned rights. References herein to any specific commercial product, process, or service by trade name, trade mark, manufacturer, or otherwise, does not necessarily constitute or imply its endorsement, recommendation, or favoring by the U.S. Government or any agency thereof. The views and opinions of authors expressed herein do not necessarily state or reflect those of the U.S. Government or any agency thereof. 
INL/EXT-15-34503

Revision 0

\title{
Nuclear Hybrid Energy Systems - Regional Studies: West Texas \& Northeastern Arizona
}

\author{
Humberto E. Garcia \\ Jun Chen \\ Jong S. Kim \\ Michael G. McKellar \\ Wesley R. Deason \\ Richard B. Vilim \\ Shannon M. Bragg-Sitton \\ Richard D. Boardman
}

April 2015
Idaho National Laboratory
INL ART Program
Idaho Falls, Idaho 83415
http://www.inl.gov

Prepared for the

U.S. Department of Energy

Office of Nuclear Energy

Under DOE Idaho Operations Office

Contract DE-AC07-05ID14517 

INL ART Program

Nuclear Hybrid Energy Systems - Regional Studies: West Texas \& Northeastern Arizona

INL/EXT-15-34503

Revision 0

April 2015

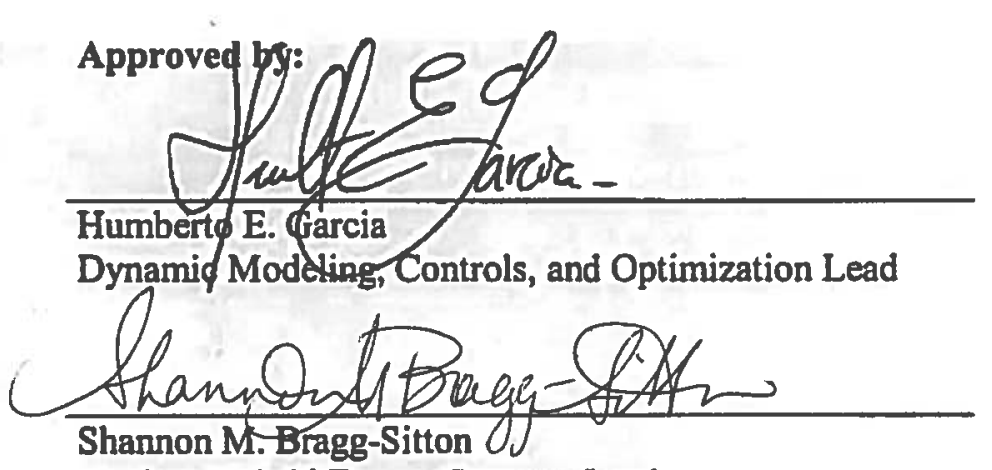

Sham non MEBrag-Sitt Nuclear Hybrid Energy Systems Lead

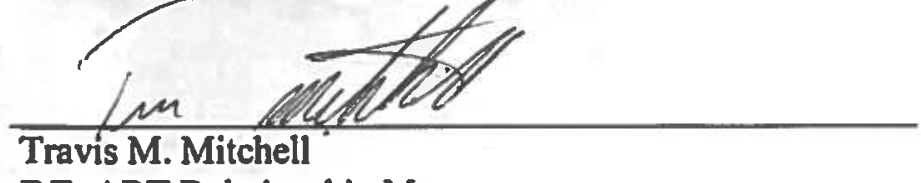

INL ART Relationship Manager

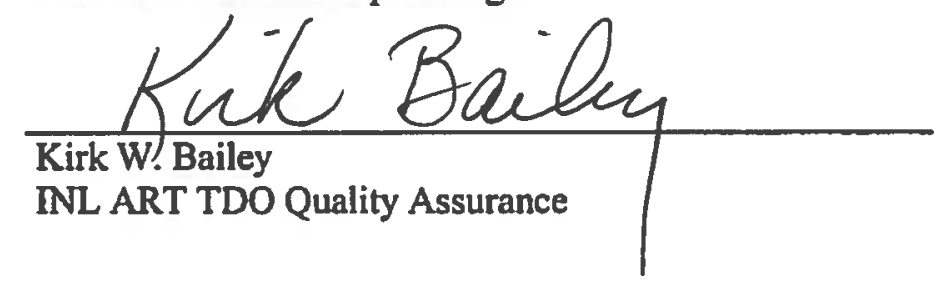

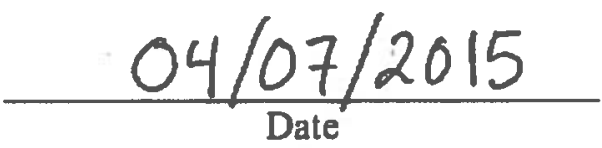
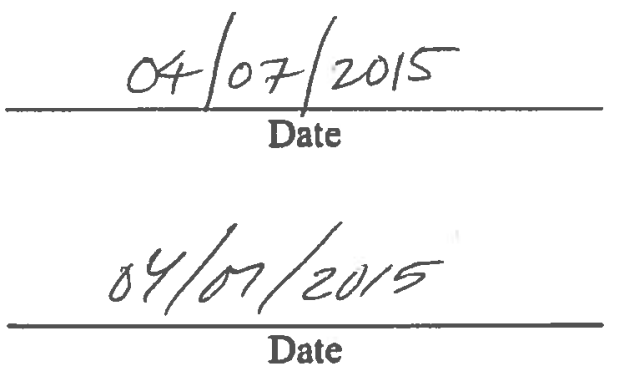

$$
\frac{4 \cdot 7 \cdot 2015}{\text { Date }}
$$





\section{EXECUTIVE SUMMARY}

The primary objective of this study is to conduct a preliminary dynamic analysis of two realistic hybrid energy systems (HES) including a nuclear reactor as the main baseload heat generator (denoted as nuclear HES or nuclear hybrid energy systems [NHES]) and to assess the local (e.g., HES owners) and system (e.g., the electric grid) benefits attainable by the application of NHES in scenarios with multiple commodity production and high penetration of renewable energy. It is performed for regional cases - not generic examples - based on available resources, existing infrastructure, and markets within the selected regions. This study also briefly addresses the computational capabilities developed to conduct such analyses, reviews technical gaps, and suggests some research paths forward.

\section{E.1 Nuclear HES can be designed to exhibit dynamic characteristics to best meet specific regional needs and constraints}

In support of more efficient utilization of clean energy generation sources, including renewable and nuclear options, NHES can be designed and operated as flexible energy resources (FER) to meet both electrical and thermal energy needs in the electric grid and industrial sectors. These conceptual systems could effectively and economically be utilized, for example, to manage the increasing levels of dynamic variability and uncertainty introduced by variable energy resources (VER) such as renewable sources (e.g., wind, solar), distributed energy resources, demand response (DR) schemes, and modern energy demands (e.g., electric vehicles) with their ever changing usage patterns. HES typically integrate multiple energy inputs (e.g., nuclear and renewable generation) and multiple energy outputs (e.g., electricity, gasoline, and fresh water) using complementary energy conversion processes. Consequently, multiple NHES configurations may be deployed to best satisfy particular regional requirements and constraints in the context of both the NHES owners and the electric grid. Potentially available in various designs, NHES can be designed to meet diverse technical specifications (e.g., achieved by their particular arrangement of multiple components) and to accommodate various business models (e.g., achieved by the production of multiple commodities) - making NHES an attractive clean energy solution.

This report discusses the technical and economic performance of two potential NHES configurations selected based on the specific needs and available resources in two U.S. regions. These cases are only examples and do not represent the full extent of the possibilities associated with NHES designed to meet region-specific needs. The two NHES cases selected for initial dynamic analysis are:

1. West Texas

Inputs: Nuclear, Wind, Natural Gas, Water

Outputs: Electricity, Gasoline

Denoted as NHES_Texas, this NHES configuration integrates a small modular nuclear reactor (SMR) and a wind turbine farm as energy generation sources and produces electricity and gasoline. Including a flexible thermal load, NHES_Texas could be operated as a flexible generation resource (FGR).

\section{Northeastern Arizona}

Inputs: Nuclear, Solar, Saline Water

Outputs: Electricity, Fresh Water

Denoted as NHES_Arizona, this NHES configuration integrates a SMR and a solar photovoltaic (PV) station as energy generation sources and produces electricity and fresh water. Including a flexible electrical load, NHES_Arizona could be operated as both a FGR and flexible load resource (FLR).

These NHES configurations include both traditional energy components that produce electricity and additional components to yield multiple forms of energy commodities in addition to electricity. Such advanced energy configurations enable flexible energy management to effectively and economically address the high variability and uncertainty arising from integrating renewable energy and variable thermal and electrical loads into the electric grid. These advanced energy solutions may also provide 
ancillary services to the electric grid. The attractive performance of NHES is further magnified when considering the significant reduction in $\mathrm{CO}_{2}$ emissions that can be achieved using a nuclear reactor as the baseload unit.

While diverse design criteria and metrics for evaluation can be considered, the particular economic figures of merit (FOM) considered are those typically relevant for economic analysis of energy systems:

- Pre-tax Gross Profit (PGP)

- $\quad$ Net Present Value (NPV)

- Payback time

- Internal Rate of Return (IRR)

Likewise, technical FOM considered herein are those typically relevant for electric grid applications:

- Electric power frequency stability

- Maximum renewable penetration that can be accommodated

- Maximum renewable variability that can be accommodated

- Minimum storage requirement

- Response time and ramp-rate

- Load following response

- Operating reserve capacity

- Minimum turndown of integrated systems

- Startup/shutdown time

Other FOM such as greenhouse gas emissions, resiliency, and security (in the sense of national assurance of energy supply) will be considered in future work.

\section{E.2 Nuclear HES require flexible physical and computational capabilities for their effective design, operation, optimization, and demonstration}

In order to effectively design, evaluate, operate, and optimize multi-domain energy system solutions, innovative physical and computational capabilities are needed so that prototype demonstration and eventual deployment are successfully achieved at minimum cost and risk. Given the intrinsic dynamic nature of the energy resources involved, the design, control, analysis, and optimization of these energy solutions should be conducted within a dynamic setting. To this end, this report also briefly reviews the gaps between the existing and novel capabilities needed to develop these modern energy solutions and to achieve the anticipated benefits. In the graded, multi-layer hierarchical approach envisioned, analysis efforts are expected to initially encompass the exploratory technical and economic assessment of multiple HES alternatives via the use of computational capabilities (such as models and co-simulations) to then be progressively integrated with real-time capabilities and actual physical hardware in hardware-in-the-loop (HiL) demonstrations. 


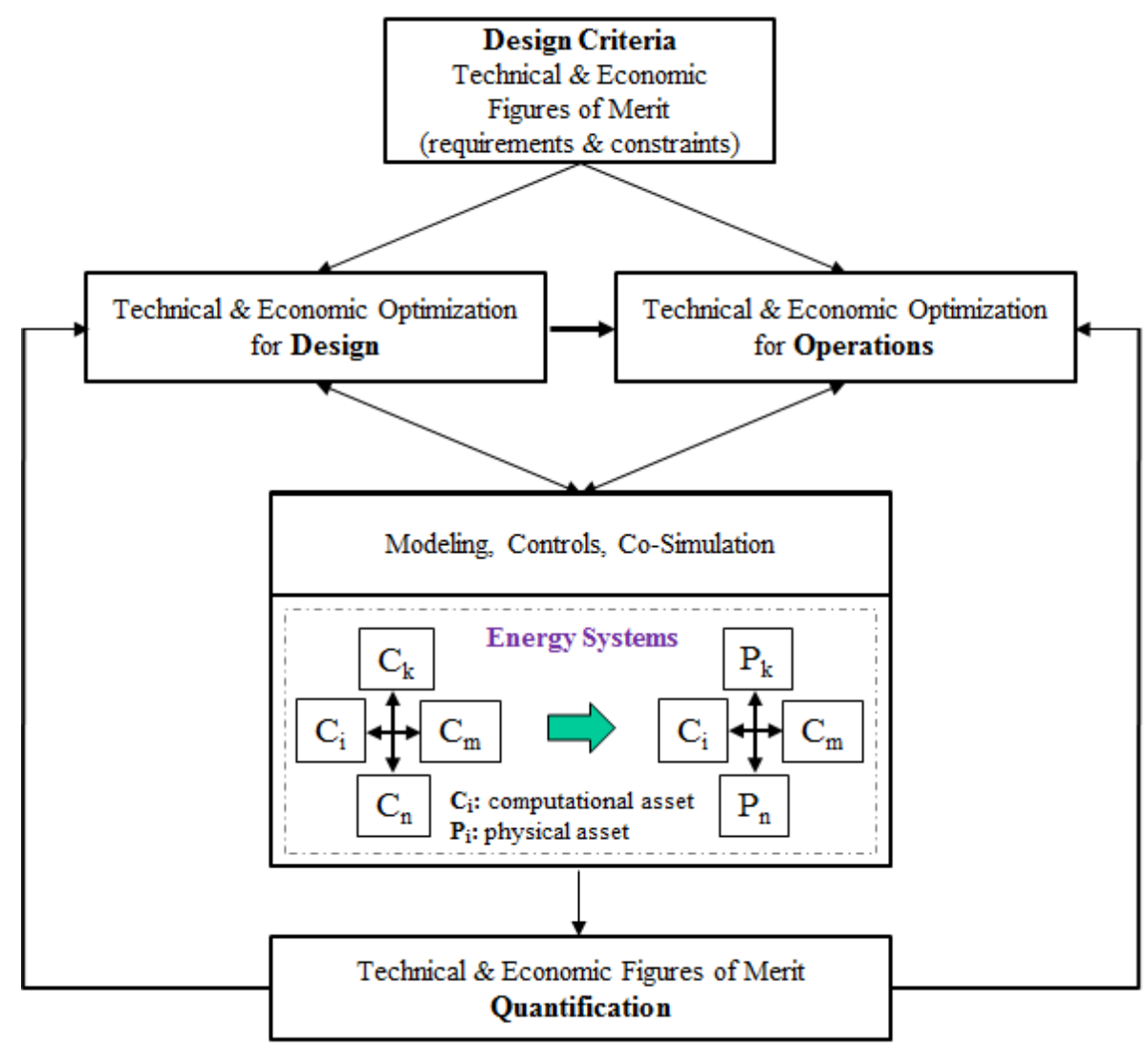

Figure 1. High-level diagram conveying the design, analysis, and optimization framework for HES.

Figure 1 partially illustrates the guiding framework employed in this study for the design, control, analysis, and optimization of HES. In particular, technical and economic design criteria and FOM are identified to characterize, quantify, and compare key performance metrics for NHES alternatives. These FOM are used to optimize the "design" (e.g., component types and sizes) and the "operations" (e.g., optimal mixture of commodity production) of NHES alternatives. In conducting these optimization activities, modeling, control, and co-simulation capabilities, with appropriate levels of granularity and accuracy, are used to estimate system performance. Thus, a number of computational capabilities (denoted by $\mathrm{C}_{\#}$ in Figure 1) and physical assets (denoted by $\mathrm{P}_{\#}$ in Figure 1) emulating the HES alternatives and the connected power/energy grids are accordingly integrated and co-simulated to compute their performance characteristics and limitations. Quantification of selected FOM can be repeated iteratively to refine system design and operation. Figure 1 also illustrates the possibility of initially utilizing only computational $\mathrm{C}_{\#}$ assets (e.g., models), as in the present study, then progressively moving to experimental ensembles consisting of both computational $\mathrm{C}_{\#}$ and physical $\mathrm{P}_{\#}$ (e.g., hardware) assets integrated within non-real-time and real-time environments. The latter is referred to as hardware-in-the-loop studies.

\section{E.3 Nuclear HES can be designed as flexible energy resources to increase reliability, efficiency, and resiliency}

Preliminary technical and economic performance evaluations are presented for the selected NHES configurations to quantify key dynamic characteristics. Evaluation results allow preliminary determination of the attractiveness of these configurations to support the future energy grid and increased penetration of variable (renewable) generation sources. The initial dynamic analyses discussed herein suggest that NHES can: 
- Lead to optimized energy use for the combined commodity, electric grid, and industrial manufacturing sectors.

- Be operated in a flexible manner towards optimizing given economic metrics.

- Achieve high operating reserve capacity values by reapportioning excess thermal and/or electrical energy for production of alternative commodities.

- Provide flexibility at the generation and load side to respond to variations in supply and demand.

- Operate as flexible energy resources (FER) to smooth the variability and reduce uncertainty within electric grid balancing regions by rapidly increasing or decreasing electricity outputs. As opposed to conventional single-output generators that could require variation in baseload power generation, NHES units could maintain baseload generation by diverting energy to produce alternative commodities at times of reduced grid demand or high renewable generation.

- Respond quickly, settle fast, and maintain the required change for large time periods in response to large net demand variations in support of renewable integration and grid ancillary needs.

- Be viewed as in standby, exhibiting zero start up/shut down times from the electric grid perspective, while avoiding operation at a minimum operating point where units tend to be less efficient.

\section{E.4 Nuclear HES exhibit attractive technical and economic characteristics for both their owners and the electric grid}

The dynamic characteristics identified in this preliminary analysis for the two case studies selected suggest many opportunities for NHES, including the following:

- NHES can be designed in numerous configurations, meeting diverse technical specifications, and possibly accommodating various business and financial models.

- NHES can lead to energy use optimization and carbon use reduction for the combined commodity, electric grid, and industrial manufacturing sectors.

- Preliminary results show that higher economic value is achieved by operating the selected NHES configurations to produce alternative commodities while participating in the electric grid market.

- Preliminary findings suggest that the payback time for NHES_Texas and NHES_Arizona would be approximately 8 and 16 years, while the internal rate of return would be $14.5 \%$ and $8.2 \%$ for 30 years of operation, respectively.

- NHES enable flexible operations to support FOM optimization, uncertainty planning, and real-time energy management.

- Technical and economic FOM may drive the design and operations optimization of selected NHES solutions. This report only considers economic optimization for operations. Efforts to optimize NHES designs are in-progress.

- NHES production of electricity and additional commodities can be controlled to yield maximum economic value to the owner; such evaluations consider operational costs, feedstock costs, and real-time commodity pricing.

- $\quad$ NHES can address high penetration, variability, and uncertainty levels in VER, which are challenging to accommodate using traditional energy systems that produce electricity only.

- $\quad$ NHES_Texas can accept levels of renewable penetration and ramp rates greater than $20 \%$ and 0.3 $\mathrm{MWe} / \mathrm{s}$, respectively, with these values being $14 \%$ and $2.1 \mathrm{MWe} / \mathrm{s}$ for NHES_Arizona. 
- $\quad$ NHES can provide operating reserves to stabilize the electric grid while maintaining the electric grid inertia even with increased renewables penetration, thus supporting more robust transient grid response and addressing the anticipated near term power production transitions in the U.S.

- NHES can flexibly provide grid services over various time horizons.

- Comparison of NHES transient performance with the requirements for participating in the wholesale electricity service market suggests that the selected NHES configurations can participate in most ancillary service markets, while providing additional economic benefits through the sale of alternative products (such as gasoline or fresh water).

- Selected NHES configurations can initiate to change their energy distribution quickly following a change in the required electricity generation and settle on the order of seconds.

- NHES can increase or decrease its electricity generation over a large range and maintain the change for long time periods.

- NHES_Texas and NHES_Arizona have a capacity of $45 \mathrm{MWe}$ and $30 \mathrm{MWe}$, respectively, for participation in operating reserve services. Higher capacity values can be achieved by expanding their existing flexible load resource (FLR) and/or installing additional FLR.

- NHES can significantly reduce $\mathrm{CO}_{2}$ emissions through the use of a nuclear baseload unit and renewables to meet grid demand and the thermal and electrical needs of industrial plants.

- An annual reduction of 1.4 million metric tons in $\mathrm{CO}_{2}$ emission is achieved by using a nuclear reactor as the baseload unit as opposed to using a NG-fired baseload unit.

\section{E.5 Nuclear HES will gain from continued RD\&D activities}

Preliminary dynamic analysis results indicate that NHES are technically practical and economically attractive clean energy solutions that can also facilitate high levels of renewable penetration. Results also suggest key areas for additional research, development, and demonstration activities to enable NHES:

- Completion and integration of components shown in the framework illustrated in Figure 1, including algorithms for controls and local to global energy optimization, interfaces for intra- and inter-component communication, methods for probabilistic applications including risk assessments, and experimental testbeds for prototype demonstration.

- Identification, analysis, and optimization of NHES for additional regions and markets.

- Modeling of key operational modes and accident cases to evaluate, understand, and include corrective passive and active measures under diverse normal and off-normal scenarios.

- Although the dynamic models applied in these preliminary analyses exhibit an adequate level of granularity for initial dynamic studies, the level of details currently incorporated in some of the models may need to be increased to more realistically characterize critical governing dynamics under both normal and off-normal conditions. This effort includes the modeling of degradation and failure modes and phenomena in key components.

- Synthesis of more effective control strategies within comprehensive operational scenarios.

- Development of enhanced methods for technical and economic optimization of NHES designs.

- Development of enhanced methods for technical and economic optimization of NHES operations.

- Development of local and coordination control methodologies and algorithms with improved generation and load forecasting for active control of distributed energy resources.

- Development and evaluation of data analytics, big and distributed control paradigms, and intelligent automation approaches for online health assessment, advanced diagnostics/prognostics, flexible, 
resilient and coordinated controls, and market accommodation under normal and off-normal conditions resulting from natural disturbances and cyber-attacks.

- Integration of the developed modeling and simulation, controls, and optimization capabilities with physical assets and computational modules running on real-time frameworks and evaluation of the integrated systems under more realistic scenarios. 


\section{CONTENTS}

EXECUTIVE SUMMARY

vii

E.1 Nuclear HES can be designed to exhibit dynamic characteristics to best meet specific regional needs and constraints ........................................................................... vii

E.2 Nuclear HES require flexible physical and computational capabilities for their effective design, operation, optimization, and demonstration .. viii

E.3 Nuclear HES can be designed as flexible energy resources to increase reliability, efficiency, and resiliency ix

E.4 Nuclear HES exhibit attractive technical and economic characteristics for both their owners and the electric grid ..... . X

E.5 Nuclear HES will gain from continued RD\&D activities .................................................... xi

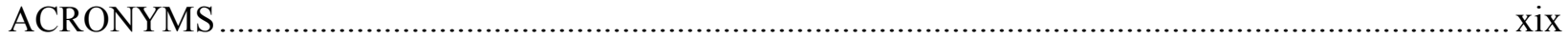

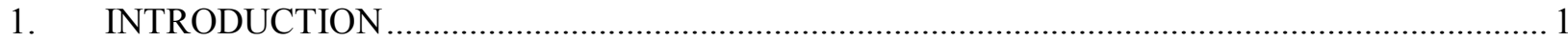

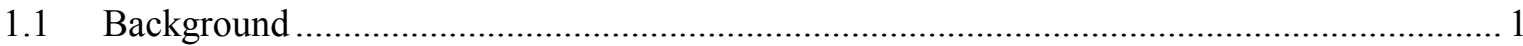

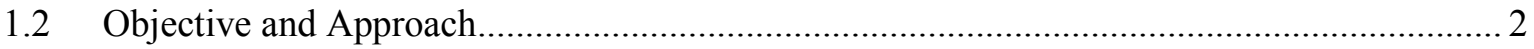

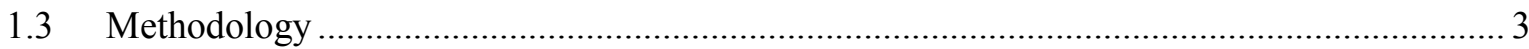

1.4 Dynamic Modeling, Simulation, Controls, and Optimization Framework ............................ 3

1.4.1 Dynamic modeling and simulation ...................................................................... 4

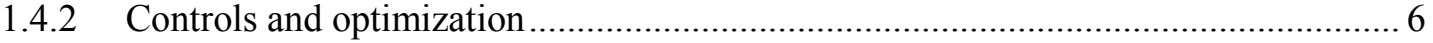

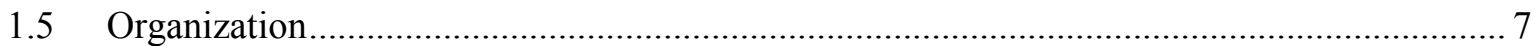

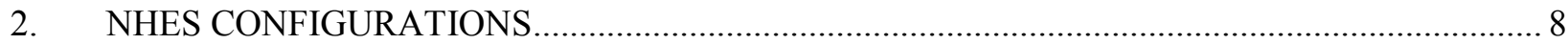

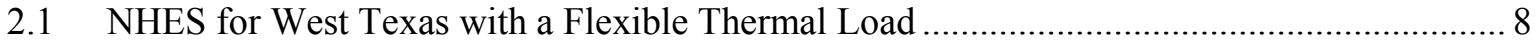

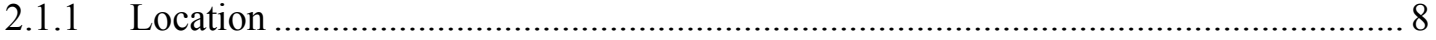

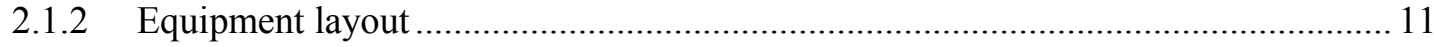

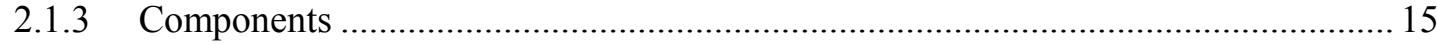

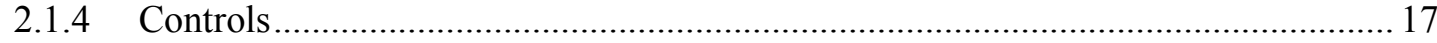

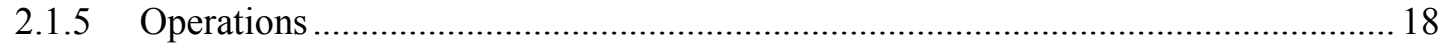

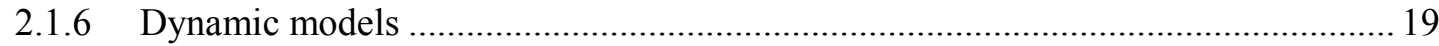

2.2 NHES for Northeastern Arizona with a Flexible Electrical Load......................................... 26

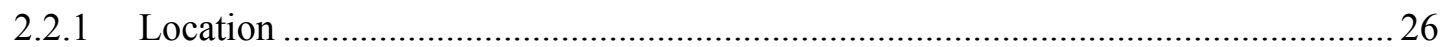

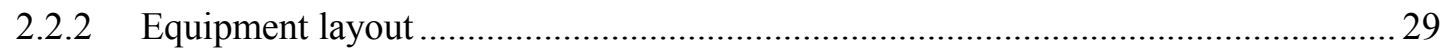

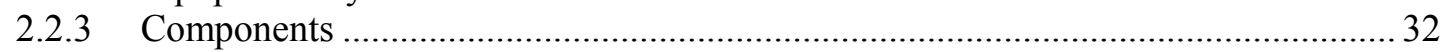

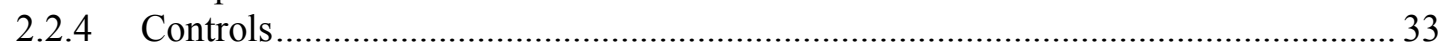

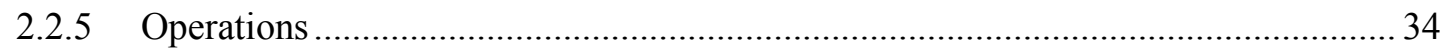

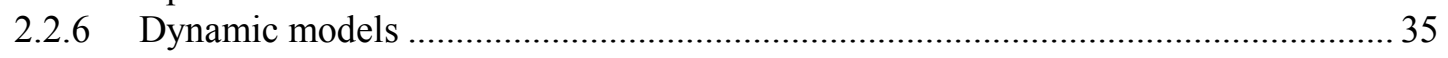

3. TECHNICAL AND ECONOMIC PERFORMANCE ANALYSIS .............................................. 41

3.1 Figures of Merit and Economic Optimization for Operations .............................................. 41

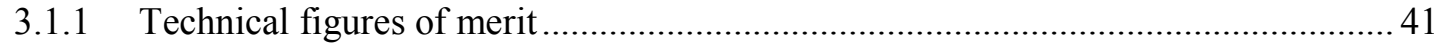

3.1.2 Economic figures of merit and optimization for operations ................................ 42

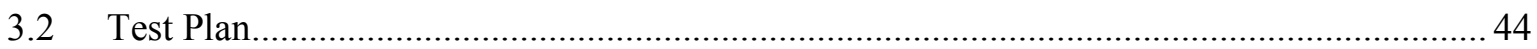

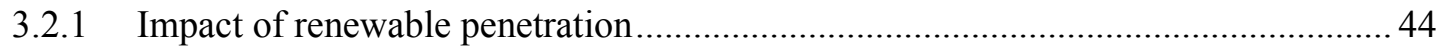

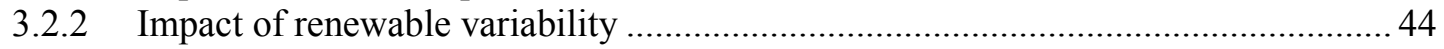




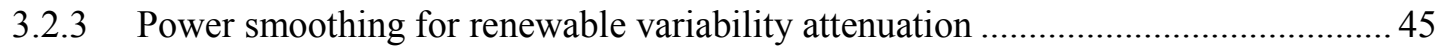

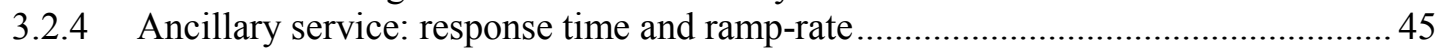

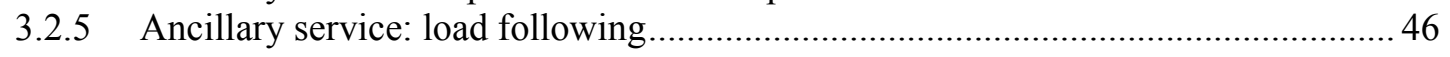

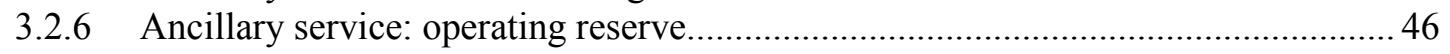

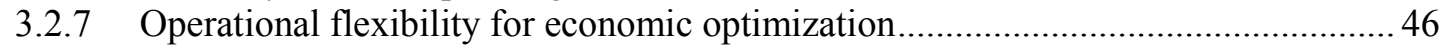

3.3 Renewable and Demand Assumptions and Simulation Setup …............................................5 50

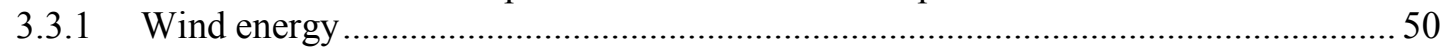

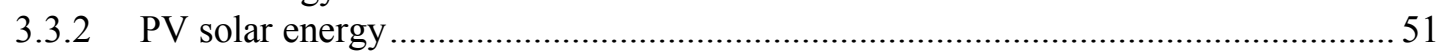

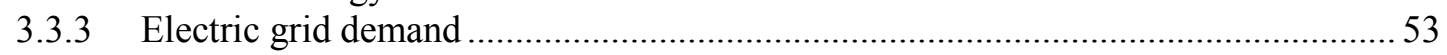

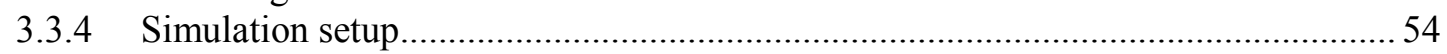

4. PRELIMINARY TECHNICAL AND ECONOMIC ESTIMATES ............................................. 55

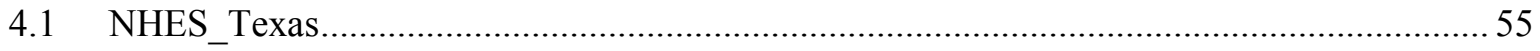

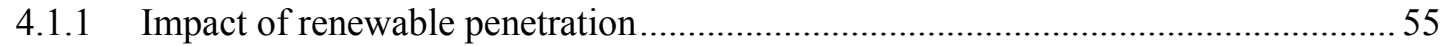

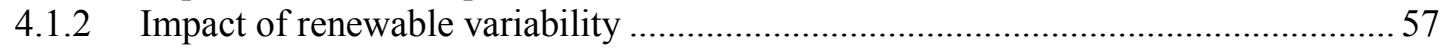

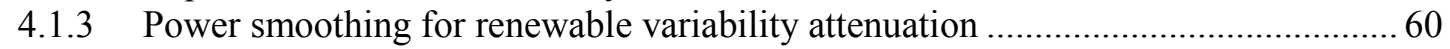

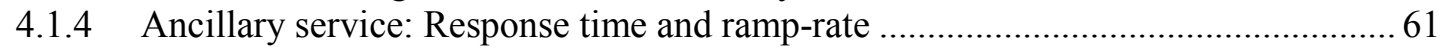

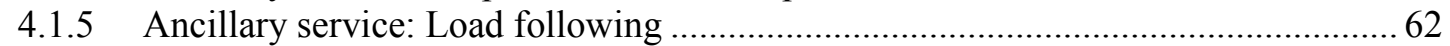

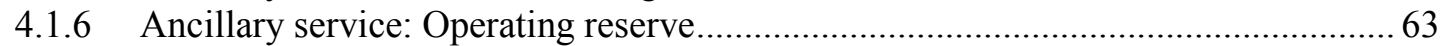

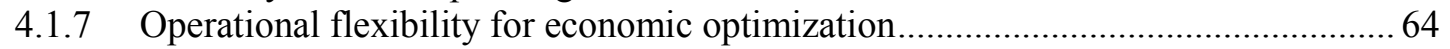

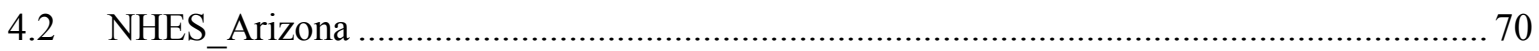

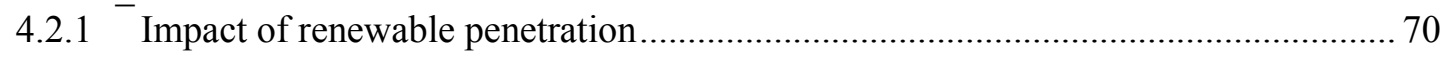

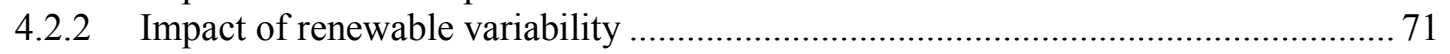

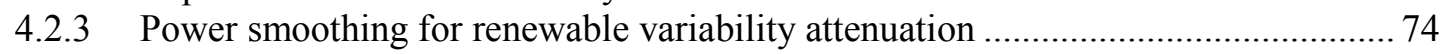

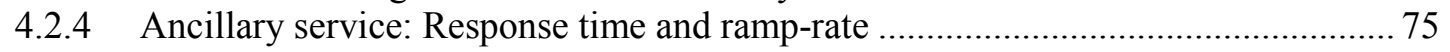

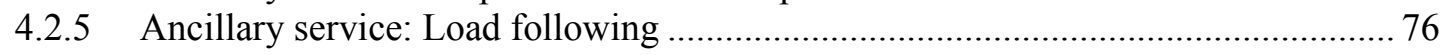

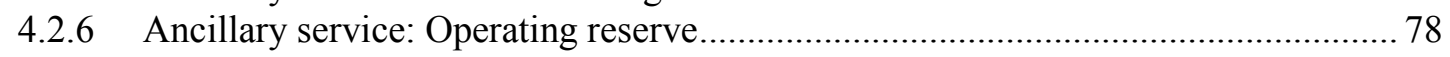

4.2.7 Operational flexibility for economic optimization................................................. 79

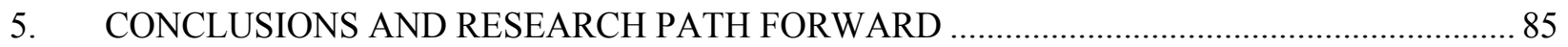

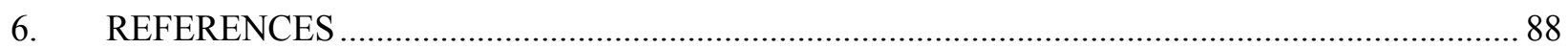

APPENDIX A Formulation of Economic Optimization of Operations................................................ 92

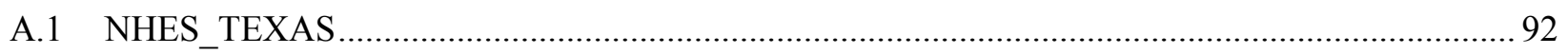

A.1.1 Economic PGP Optimization: Analytical Approach.......................................................... 92

A.1.2 Economic NPV Optimization: Analytical Approach …............................................... 93

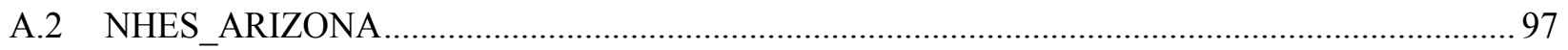

A.2.1 Economic PGP Optimization: Numerical Approach ….................................................. 97

A.2.2 Economic NPV Optimization: Numerical Approach....................................................... 98 


\section{FIGURES}

Figure 1. High-level diagram conveying the design, analysis, and optimization framework for HES. ix

Figure 2. High-level diagram of developed analysis capability.......................................................... 3

Figure 3. Hierarchy of computational architecture for studying hybrid energy systems.......................... 5

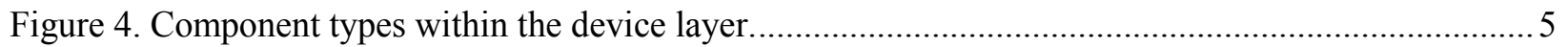

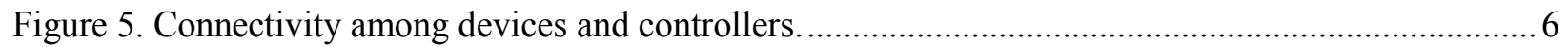

Figure 6. Hierarchical control strategy used in the evaluated NHES configurations................................. 6

Figure 7. North American Electric Reliability Corporation Interconnections [18] ................................ 9

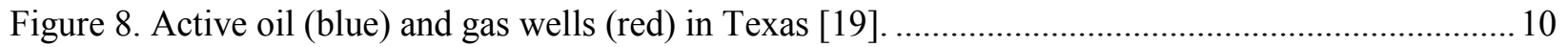

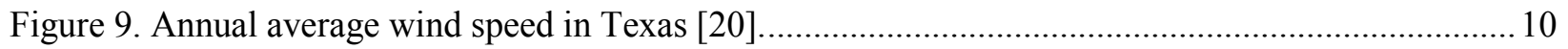

Figure 10. Network topology of NHES_Texas with a flexible thermal load.......................................... 12

Figure 11. Process flow diagram for NHES_Texas: nuclear, power cycle, and thermal distribution....

Figure 12. Process flow diagram for NHES_Texas: steam conditioning and gasoline production. ........... 14

Figure 13. Process flow diagram for NHES_Texas: wind, battery, electric grid..................................... 15

Figure 14. Top-level model for NHES_Texas in Modelica..................................................................2

Figure 15. Top-level model for gasoline production plant used in NHES_Texas in Modelica..................22

Figure 16. Top-level model for the nuclear reactor used in NHES_Texas, NHES_Arizona in

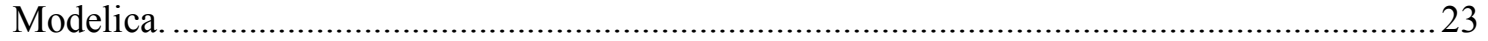

Figure 17. Model of the once-through steam generator in Modelica......................................................25

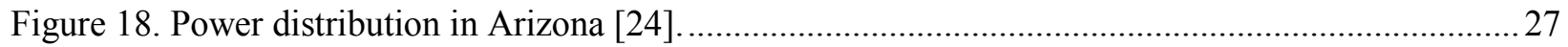

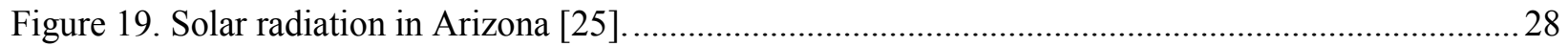

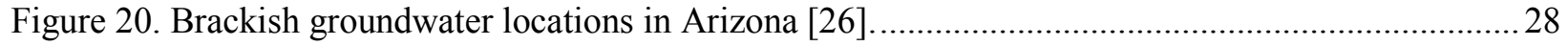

Figure 21. Network topology for NHES_Arizona with a flexible electrical load.................................... 30

Figure 22. Process flow diagram for NHES_Arizona: nuclear and power cycle ..................................... 31

Figure 23. Process flow diagram for NHES_Arizona: PV solar, battery, desalination plant, grid............. 32

Figure 24. Top-level model for NHES_Arizona in Modelica................................................................... 37

Figure 25. Top-level model for FWPP used in NHES_Arizona in Modelica........................................... 38

Figure 26. BWRO desalination process: (a) Process flow diagram for a two-stage BWRO plant.

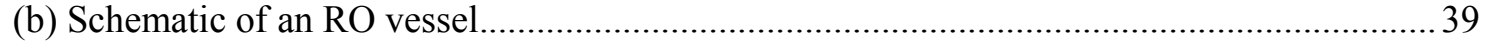

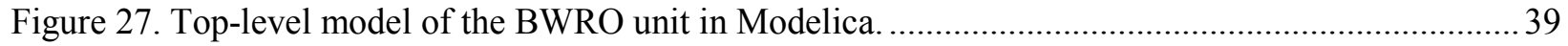

Figure 28. Trapezoidal input signal used for renewable generation.................................................... 45

Figure 29. Ramp signal as electrical generation to the electric grid...................................................... 46

Figure 30. Price trends for natural gas and electricity for a selected 14 day period (Texas) .................... 47

Figure 31. Wholesale price trend for gasoline for a whole year. ........................................................... 48 
Figure 32. Price trend for electricity for a selected 14 day period (Arizona). ......................................... 49

Figure 33. Price trend for water for a whole year (Arizona)............................................................... 49

Figure 34. Wind speed and turbine power for a period of seven days in NHES_Texas...........................50

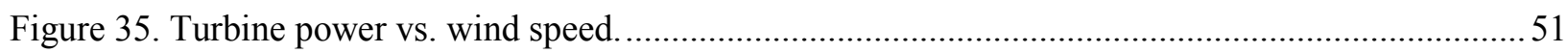

Figure 36. Solar irradiation and PV solar power for a period of seven days in NHES_Arizona................52

Figure 37. Hourly electricity demand considered for NHES_Texas. ....................................................... 53

Figure 38. Hourly electricity demand considered for NHES_Arizona. ..................................................... 54

Figure 39. Steam turbine shaft speed for: (a) 8 wind turbines; (b): 12 wind turbines

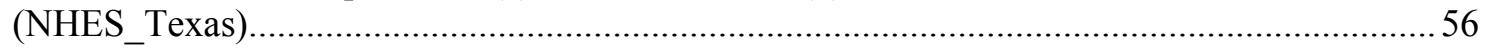

Figure 40. Nuclear (PHG), NG-fired boiler (AHG), and header steam flows used for gasoline production for: (a) 8 wind turbines; (b) 12 wind turbines (NHES_Texas)................................ 57

Figure 41. Steam flow diverted for gasoline production under a renewable ramp rate of: (a) 0.03

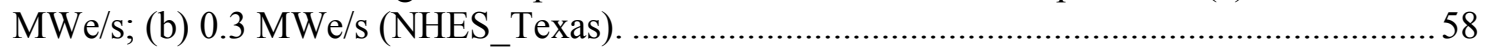

Figure 42. Steam turbine shaft speed under a renewable ramp rate of: (a) $0.03 \mathrm{MWe} / \mathrm{s}$; (b): 0.3 MWe/s (NHES_Texas)

Figure 43. Renewable generation before and after power smoothing with a time constant of $1800 \mathrm{~s}$

(NHES_Texas)

Figure 44. Renewable generation before and after power smoothing with a time constant of $9000 \mathrm{~s}$

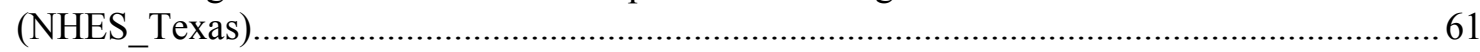

Figure 45. Electrical and mechanical torque at the steam turbine shaft (NHES_Texas)..........................6 62

Figure 46. Steam flows to steam generator, secondary boiler, and from the NG-fired boiler

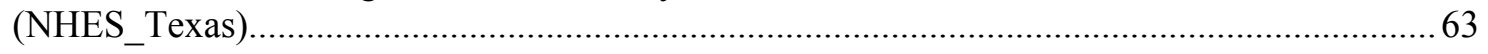

Figure 47. Steam flows to the three 15\%, 30\%, 60\% turbines (NHES_Texas)....................................... 64

Figure 48. Temperature at steam generator outlet flow (NHES_Texas).................................................. 64

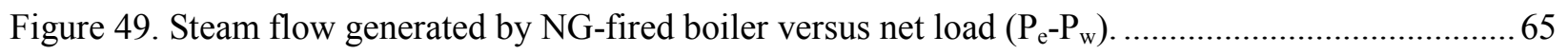

Figure 50. Optimal electricity production for a selected 14 day period for PGP and price trend

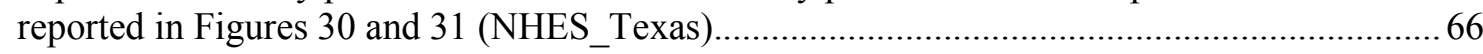

Figure 51. Optimal electricity production for a selected 14 day period for NPV and price trend reported in Figures 30 and 31 (NHES_Texas).

Figure 52. Electrical generation delivered to the electric grid by the nuclear reactor under (a):

PGP and (b): NPV optimization for a selected 14 day period.

Figure 53. Cumulative NPV as a function of time using cost parameters in Table 9

(NHES_Texas).

Figure 54. Payback time as a function of price change rate assuming constant operational mode

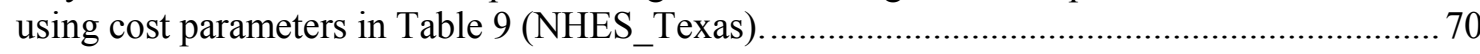

Figure 55. Steam flows entering the three turbines for 5 and 8 PV solar units (NHES_Arizona)............. 71

Figure 56. Electrical power frequency for 5 and 8 PV solar units (NHES_Arizona).............................. 71

Figure 57. Electric power consumed by desalination plant under renewable ramp rate of: (a) 0.21 $\mathrm{MWe} / \mathrm{s}$; (b) $2.1 \mathrm{MWe} / \mathrm{s}$ (NHES_Arizona). 
Figure 58. Steam turbine shaft speed for renewable ramp rates of 0.21 and $2.1 \mathrm{MWe} / \mathrm{s}$

(NHES_Arizona).

Figure 59. Renewable generation before and after power smoothing with a time constant of 900s

(NHES_Arizona).

Figure 60. Renewable generation before and after power smoothing with a time constant of $1800 \mathrm{~s}$

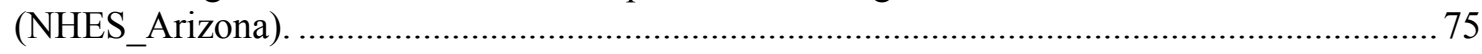

Figure 61. Electrical and mechanical torque at the steam turbine shaft (NHES_Arizona)........................76

Figure 62. Outlet flow and temperature at steam generator (NHES_Arizona)......................................... 77

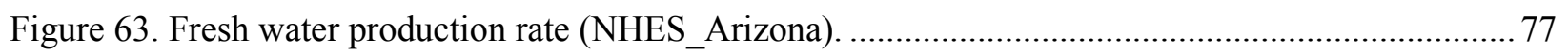

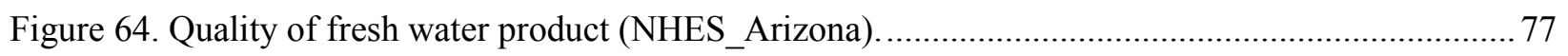

Figure 65. Power consumed by fresh water production plant (NHES_Arizona)...................................... 78

Figure 66. Pressure at steam generator outlet flow (NHES_Arizona)..................................................... 79

Figure 67. Relationship between power consumed and fresh water produced by the desalination

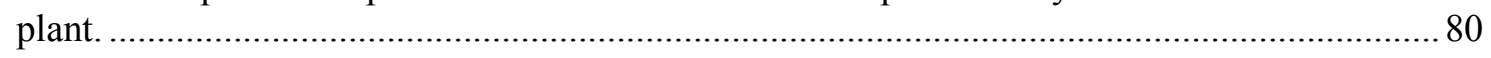

Figure 68. Optimal electricity production for a selected 14 day period for PGP optimization and

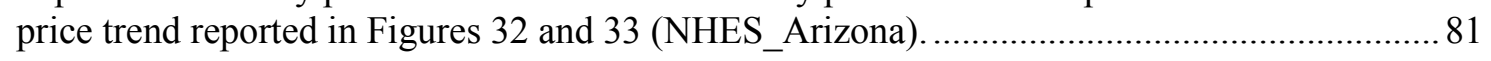

Figure 69. Optimal electricity production for a selected 14 day period for NPV and price trend reported in Figures 32 and 33 (NHES_Arizona).

Figure 70. Electrical contribution delivered to the electric grid by the nuclear reactor for (a): PGP and (b) NPV optimization.

Figure 71. Cumulative NPV as a function of time using cost parameters in Table 10

(NHES_Arizona). 84 


\section{TABLES}

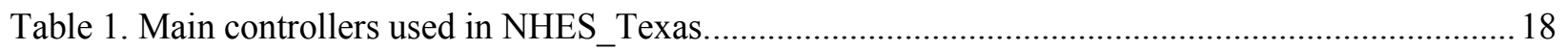

Table 2. Partial list of signals communicated via control bus in NHES_Texas.......................................... 20

Table 3. Full-power conditions for pressurized-water nuclear small modular reactor. ............................. 24

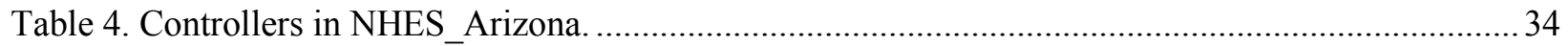

Table 5. Partial list of signals communicated via control bus in NHES_Arizona. ..................................... 36

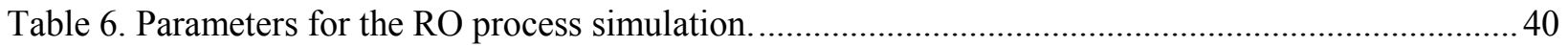

Table 7. Variables used in the economic optimization for operations: NHES_Texas............................... 42

Table 8. Variables used in the economic optimization for operations: NHES_Arizona............................ 43

Table 9. Cost parameter values for NHES_Texas. ................................................................................... 47

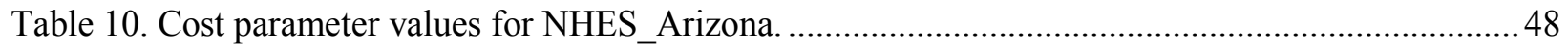

Table 11. Parameters in wind-power mapping Eq. (8) ............................................................................ 51

Table 12. Geometric fact about the solar data collection site. .................................................................51

Table 13. Parameters in Solar-Power Mapping Eq. (10). ........................................................................ 52

Table 14. Simulation setup for NHES_Texas: Impact of RP test........................................................55

Table 15. Simulation setup for NHES_Texas: Impact of renewable variability test...............................58

Table 16. Simulation setup for NHES_Texas: Impact of renewable variability test................................60

Table 17. Simulation setup for NHES_Texas: Response time test........................................................ 61

Table 18. Simulation setup for NHES_Texas: Load following test....................................................... 62

Table 19. Simulation setup for NHES_Texas: Operating reserve test..................................................63

Table 20. Simulation setup for NHES_Texas: Economic optimization for operations test......................65

Table 21. Economic values for first year of operation (NHES_Texas)..................................................6 67

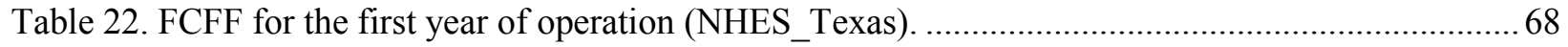

Table 23. Simulation setup for NHES_Arizona: Impact of RP test........................................................ 70

Table 24. Simulation setup for NHES_Arizona: Impact of renewable variability test..............................72

Table 25. Simulation setup for NHES_Arizona: Impact of renewable variability test............................. 74

Table 26. Simulation setup for NHES_Arizona: Response time test..................................................... 75

Table 27. Simulation setup for NHES_Arizona: Load following test. ................................................... 76

Table 28. Simulation setup for NHES_Arizona: Operating reserve test................................................ 78

Table 29. Simulation setup for NHES_Arizona: Economic optimization for operations test. ................... 79

Table 30. Economic values for first year of operation (NHES_Arizona) ............................................... 81

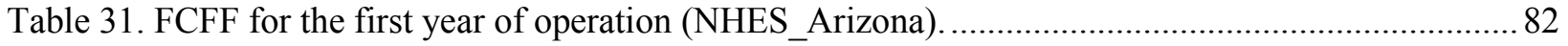




\section{ACRONYMS}

AHG auxiliary heat generation

ANL Argonne National Laboratory

BCVTB Building Controls Virtual Test Bed

BOP balance of plant

BWRO Brackish Water Reverse Osmosis

CAES compressed air energy storage

CAPEX Capital Expenditure

DA depreciation amortization

DME dimethyl ether

DNI direct normal irradiance

DR demand response

ERCOT Electric Reliability Council of Texas

ESE energy storage element

EV electric vehicles

FCFF (real discounted) free cash flow to firm

FCV flow control valve

FER flexible energy resource

FGR flexible generation resource

FLR flexible load resource

FMI functional mockup interface

FOM figures of merit

FWPP fresh water production plant

GE General Electric

GHG Greenhouse Gas

GPP Gasoline Production Plant

HES Hybrid Energy Systems

INL Idaho National Laboratory

IRR internal rate of return

ISO Independent System Operator

LBNL Lawrence Berkeley National Laboratory

LPG liquefied petroleum gas

LWR light water reactor

M\&S Modeling and Simulation 


\begin{tabular}{|c|c|}
\hline MGPD & million gallons per day \\
\hline MIMO & multiple input multiple output \\
\hline MIT & Massachusetts Institute of Technology \\
\hline MSF & multi-stage flash \\
\hline MSL & Modelica Standard Library \\
\hline MTG & methanol-to-gasoline \\
\hline NCSU & North Carolina State University \\
\hline NG & natural gas \\
\hline NHES & Nuclear Hybrid Energy Systems \\
\hline NPV & net present value \\
\hline NREL & National Renewable Energy Laboratory \\
\hline NSSS & Nuclear Steam Supply System \\
\hline O\&M & operations and maintenance \\
\hline ORNL & Oak Ridge National Laboratory \\
\hline PCV & pressure control valve \\
\hline PGP & pre-tax gross profit \\
\hline PHG & primary heat generation \\
\hline PV & photovoltaic \\
\hline PWR & pressurized water reactor \\
\hline REN & renewable \\
\hline RG & required generation \\
\hline $\mathrm{RO}$ & reverse osmosis \\
\hline RTO & Regional Transmission Organization \\
\hline SISO & single input single output \\
\hline SMR & Small Modular Reactor \\
\hline SPP & Southwest Power Pool \\
\hline $\mathrm{TCV}$ & temperature control valve \\
\hline TDS & total dissolved solids \\
\hline TEC & thermal to electrical conversion \\
\hline UNM & University of New Mexico \\
\hline VER & variable energy resource \\
\hline ZEV & zero emission vehicles \\
\hline
\end{tabular}




\section{INTRODUCTION}

\subsection{Background}

Energy generation and utilization in the U.S. has historically exhibited one-to-one source-use pairings [1]. Each major natural energy source is primarily used for one purpose; e.g., nuclear and coal for electricity, natural gas for heating (with a fraction going to electricity), and petroleum for transportation fuels. This constricted architecture may lead to undesired consequences or externalities if any one of these sources is disrupted. The upsets might also be in the uses of energy, for instance, if fuel cell and electrical vehicles or plug-in hybrid vehicles running primarily on electricity become predominant. The consequences of these types of events can be social, economic, geopolitical, or environmental in nature.

Although expected to provide important benefits, it has been largely recognized that increasing renewable penetration and inclusion of time-varying loads, such as electric vehicles (EV), fuel cell electric vehicles, and zero-emission vehicles (ZEV), poses significant technical and economic challenges in terms of electric grid integration, stability, and modernization [2]. This is due to the unpredictability, non-dispatchability, and high variability associated with renewable energy sources, such as wind and solar power, and the variability in modern loads. Although small levels of renewable penetration and variable loads have tolerable effects on grid operation, high levels can require significant changes in the traditional energy systems topology and grid infrastructure architecture. If this variability is not mitigated by engineering solutions, then it must be accommodated by the electric grid. In general, it may be more cost-effective and less complex to attenuate the variability introduced by renewable energy and modern demands via both electrical and thermal means. This power smoothing effect may be accomplished by using energy storage devices such as electric batteries and flywheel systems (e.g., [2,3]), or by extending the architecture of traditional energy systems to enable multiple energy commodity exchanges, including dispatchable electricity, other energy storage products, such as hydrogen and chemicals, and basic products, such as fresh water. In addition to facilitating the incorporation of high levels of renewable penetration, it is equally important for the proposed energy solutions to be economically attractive while minimizing environmental impacts.

In order to increase the robustness, resiliency, adaptability, and flexibility of the U.S. and world energy network towards more effectively responding to resource costs and market drivers or conditions, a more flexible, distributed energy flow landscape and infrastructure is needed to combine various energy generation sources and multiple energy users. This leads to the notion of a hybrid energy system (HES): multiple energy inputs converted to multiple energy products using complementary energy conversion processes. By adding non-traditional energy sources, such as renewable generation, and non-electricity products, such as transportation fuels, energy system hybridization is a promising strategy to achieve energy security and resilience through diversification and integration of energy portfolios. In this manner, not only undesirable economic conditions but also environmental concerns can be resolved. In order to reduce pollution and dependence on foreign fossil resources, a coordinated energy strategy may aim to derive electricity from clean-energy sources (e.g., nuclear and renewable energy) and to produce transportation fuels from regional carbon resources (e.g., natural gas, coal, and biomass). Higher levels of renewable energy penetration in the current energy portfolio are a desirable goal as a means of attaining improved resource utilization and environmental sustainability.

Multiple efforts (e.g., [4-6]) have explored, to various degrees, the idea of closely combining multiple energy sources with diverse energy utilization paths. There are also examples of HES being proposed to act in a stand-alone manner at off-the-grid locations. The selection of the particular Nuclear Hybrid Energy Systems (NHES) configurations studied herein, and the potential locations for their deployment (discussed in Sections 2.1.1 and 2.2.1), were motivated by the efforts and findings reported in [7], which set the foundation for the current regional studies. Small Modular Reactors (SMRs) are selected for the baseload generation system integrated within the selected NHES configurations due to their anticipated technical and economic advantages, including: 
- Scalability/multi-unit operations management

- Incremental capital investment with phased installation

- Complementary in energy output with renewable generators

- Modularity

- Topologically distributed energy solution

- Simple/safer/sealed

- Improved load following

While the primary objective of this report is to investigate the performance characteristics of two selected NHES configurations, the dynamic modeling, control, simulation, and optimization capabilities developed to support such dynamic analysis is also discussed.

\subsection{Objective and Approach}

The goal herein is to evaluate the value proposition of HES that incorporate nuclear and renewable energy. The objective of this study is to devise and analyze NHES that can:

- enable greater penetration of renewable energy in a more cost-effective manner, while providing energy for commodity production and grid services comparable to traditional electricity generation;

- support smooth integration of diverse energy sources and products within existing power and energy infrastructures, while also reducing greenhouse gas (GHG) emissions;

- change the manufacture and delivery of trade-able energy commodities (e.g., hydrogen, oxygen, methanol, ammonia, and fuel/fuel additives);

- enhance the use of carbon resources for the production of chemical commodities (e.g., fertilizers and transportation fuel) and consumer products (e.g., textiles, polyethylene, and plastics);

- promote conversion of non-consumable resources, such as brackish, salty, and waste water, to essential commodities, such as fresh water;

- provide an approach to produce and deliver energy that is constrained by local markets, geography, water availability, and transportation/delivery systems;

- improve the thermodynamic efficiency and work productivity through coordinated dynamic control of energy conversion systems;

- enhance both power and energy quality and management, in addition to improving reliability, security, and value optimization;

- provide sustainable energy security;

- $\quad$ provide ancillary services ${ }^{\mathrm{a}}$ as needed by the electric grid.

This report considers two types of renewable energy sources (i.e., wind and solar photovoltaic [PV] energy), as well as two non-electric commodities (i.e., gasoline and fresh water). Two distinct NHES configurations are considered, both of which include a nuclear SMR plant as the primary energy source and are connected to the electric grid at a point of common coupling.

\footnotetext{
${ }^{a}$ Ancillary services are functions performed by generation (and possibly responsive load) to support the basic services of the electric grid, including balance of generation and load in near real-time.
} 


\subsection{Methodology}

The implications of variability and uncertainty in the time-varying renewable energy generation and electricity demand can only be effectively understood in a dynamic setting. Hence, the current work adopts dynamic performance analysis to characterize tightly-coupled HES. A flexible dynamic modeling and simulation (M\&S), control, and optimization capability was developed to integrate and control component models. This report addresses only a portion of the computational capabilities employed in this study; namely, the technical and economic optimization components, the modeling, control, and co-simulation components, and the figures of merit (FOM) quantification components. Figure 2 illustrates the dynamic M\&S, control, and optimization capability developed. This analytical tool was utilized to explore the operational flexibility of the two NHES configurations considered under different scenarios in order to better understand their dynamic properties and key potentials. Simulation results are quantitatively analyzed in light of selected technical and economic FOM, including operational requirements to participate in the regulatory and/or wholesale electricity market services.

Inputs to the dynamic computational analysis tool include: grid service needs; renewable generation profiles (e.g., wind, solar PV); relevant time-dependent commodity prices (e.g., electricity, gasoline, fresh water); and relevant time-dependent feedstock prices (e.g., natural gas, water). Given this input to the integrated component models, an HES configuration can then be analyzed under two distinct modes. First, when analyzing its participation in the ancillary service market, the HES is operated in a manner in which the electric grid requirements are satisfied as a priority. Second, when analyzing its participation in the commodity sale market, the HES is operated (as determined by an operations optimizer) to support the economic optimization of the system. In the latter case, the goal is to optimize a given (economic) objective value (e.g., net present value [NPV]). Time series of numerous (over 6500) variables are then computed, including emissions, commodity production, and feedstock consumption, and utilized to quantify the selected technical and economic FOM.

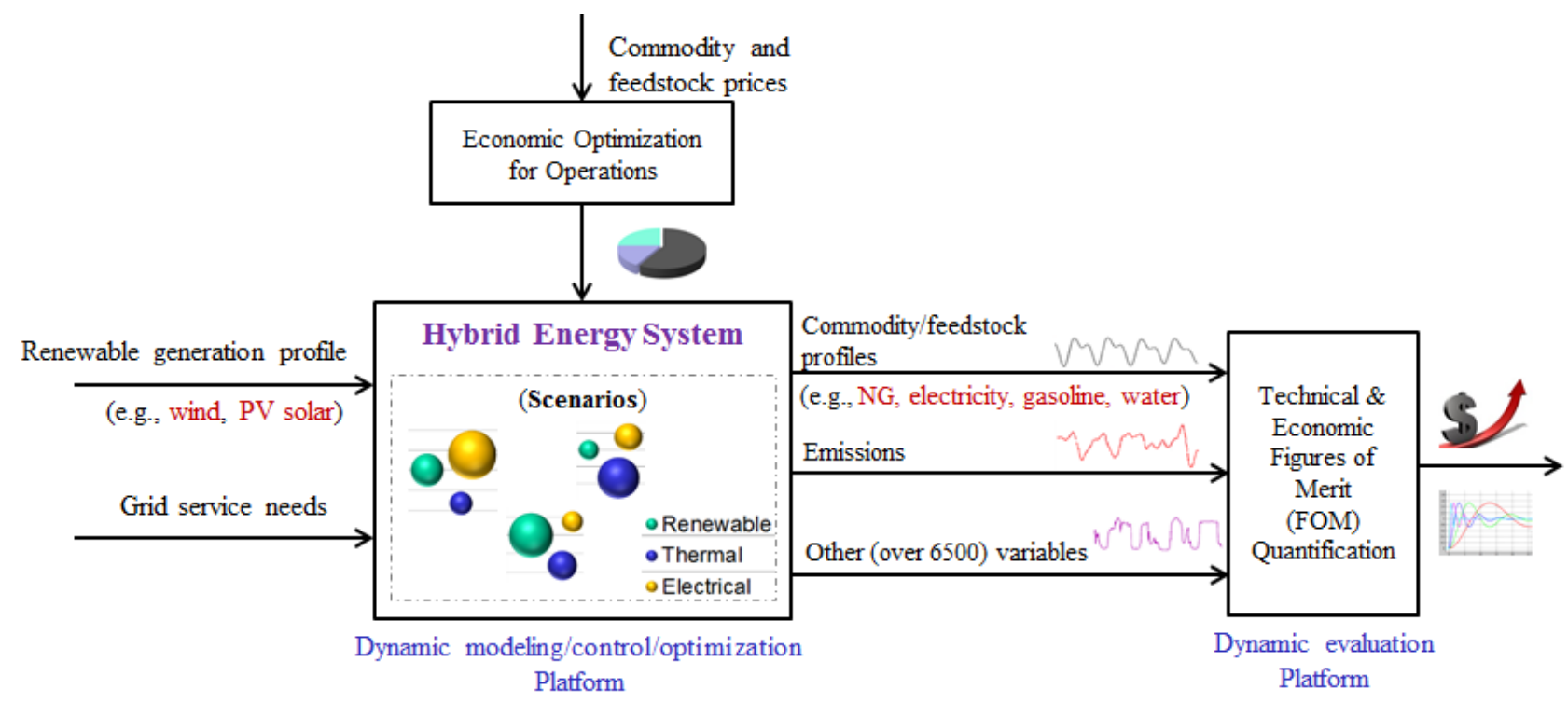

Figure 2. High-level diagram of developed analysis capability.

\subsection{Dynamic Modeling, Simulation, Controls, and Optimization Framework}

Development and analysis of HES solutions should involve collaboration of experts across multiple engineering disciplines. Hence, the selected methods should be amenable to sharing among experts that may be located at multiple institutions and requiring minimal effort to accommodate differing data and 
model formats. The Modelica language was selected for the initial dynamic system analyses as it is well suited for collaborative programming. Modelica-based computational technologies are currently being used at many institutions, including national laboratories (e.g., INL, ANL, ORNL, NREL, LBNL), universities (e.g., Georgia Tech, MIT, NCSU, UNM) and industry (e.g., GE, Siemens). The Modelica-related capabilities include a large number of libraries of open-source code for modeling and co-simulating a wide variety of engineering systems. The existing libraries include modules for nuclear, mechanical, electrical, thermal, chemical, renewable, and industrial processes as well as model exchange and co-simulation tools (e.g., functional mockup interface [FMI]) to simplify coupling to other physical and computational assets. The brief description included in this report focuses on the initially adopted Modelica computational architecture and framework. Other related activities have also been conducted, and continue to be conducted, to integrate computational and physical assets running in non-real-time and real-time environments.

\subsubsection{Dynamic modeling and simulation}

The computational architecture for HES analysis is comprised of six hierarchical layers, as illustrated in Figure 3. The Device Layer is further divided into four categories according to the functionalities of each device; namely, Generation, Loads, Distribution, and Storage, as shown in Figure 4. The other five layers in Figure 3 that sit on top of the Device Layer include the Local Control Layer, Cyber Layer, System Control Layer, Market Layer and Regulatory Layer. These additional layers perform Integration, through which the HES components grouped in the Device Layer are properly connected, integrated, and operated.

The Modelica modeling language is used with Dymola [8] as the M\&S environment to construct and simulate the dynamic models of the selected NHES. The Modelica modeling language is used in the analysis performed due to its supports of physic-based, acausal modeling, while Dymola supports multi-domain model exchange and co-simulation with interactions with other simulation environments such as Matlab/Simulink via numerous mechanisms and tools including Functional Mockup Interface (FMI) and Building Controls Virtual Test Bed (BCVTB).

The level of modeling detail varies from mapping functions to more detailed models (i.e., representative physics-based modeling). In-house developed packages and open-source libraries were utilized to facilitate M\&S. In particular, the Modelica Standard Library (MSL) version 3.2.1 and ThermoPower version 2.1 are utilized. Modelica models were implemented using the commercially available Modelica-language software Dymola, version 2015. The computational models introduced in this report were developed at a level of granularity and accuracy adequate for conducting preliminary reliability studies. Reduced order characterizations of these more detailed models may be more appropriate for grid-level system optimization studies; these will be derived in future work.

It is important to mention that the modeling of water needs is limited in this preliminary study, although it can be critical to consider in detailed analyses. While water usage in support of thermal transport and conversion processes is adequately modeled, there is currently no consideration of modeling it in supporting unit operations such as cooling systems; this will be included in future work. 


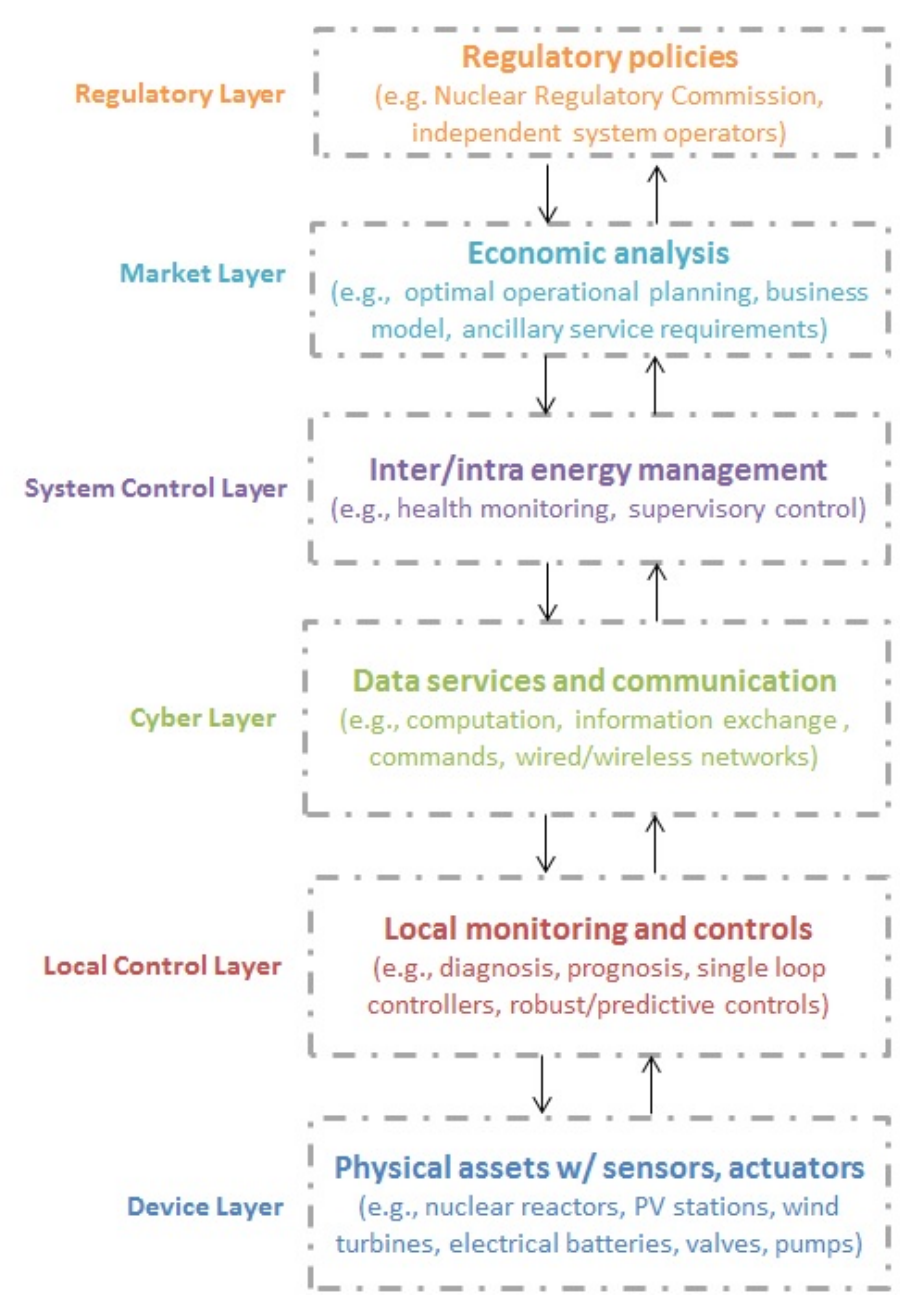

Figure 3. Hierarchy of computational architecture for studying hybrid energy systems.

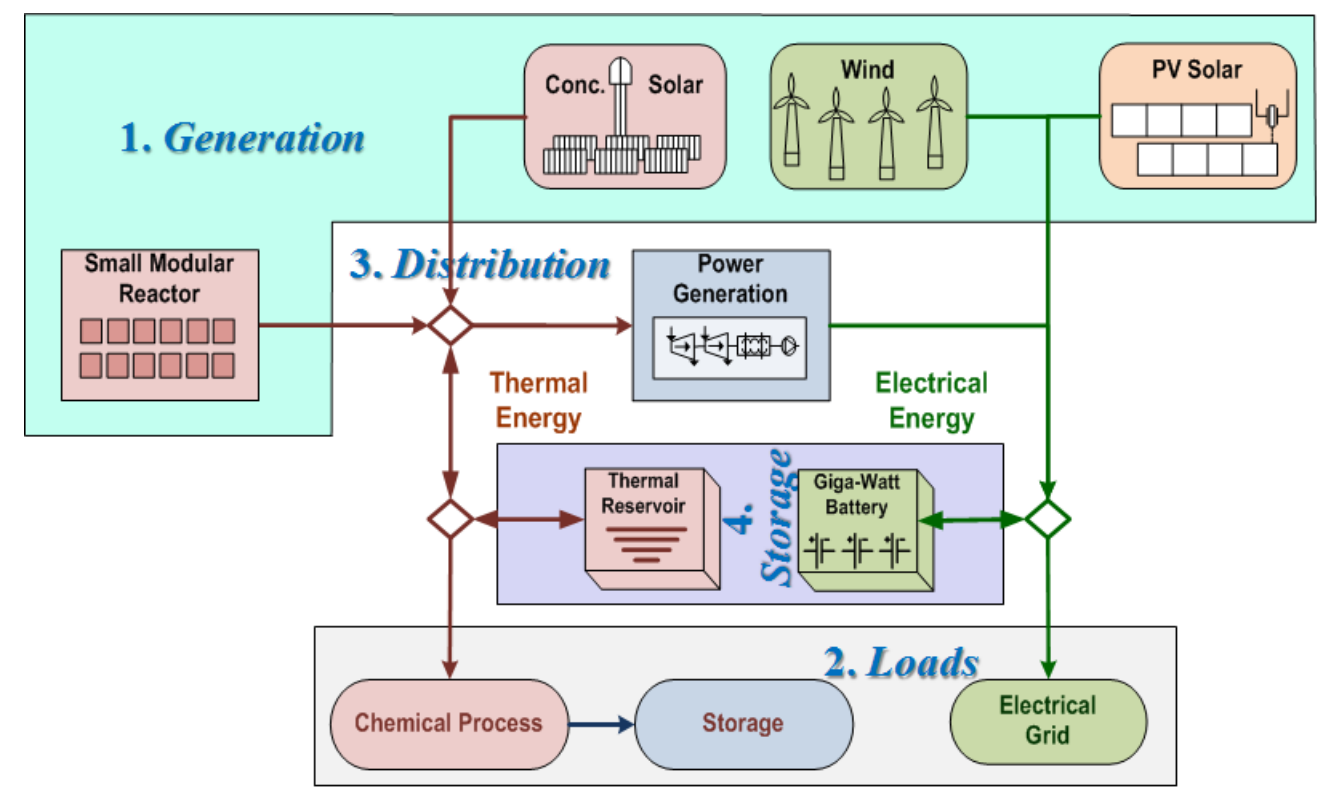

Figure 4. Component types within the device layer. 


\subsubsection{Controls and optimization}

As shown in Figure 5, devices grouped in the device layer are connected via pre-defined and self-compatible connectors (named 'flanges') and connections (blue lines, such as electrical wires and pipe, for example), which carry physical entities including steam, natural gas, water, or electricity. Devices are regulated by local and supervisory controllers (and observers) and are connected via control busses (yellow lines) that transmit control signals, such as sensor measurements and control commands. Consequently, the feature named ControlBus provided by Modelica is largely utilized herein. The separation between controllers and devices, as well as between control busses and physical connections, significantly ease system management and control reconfiguration. In order to ease evaluation of constructed energy configurations, the module called "systemEvaluation" is also incorporated, which defines and sets up the different scenarios being considered.

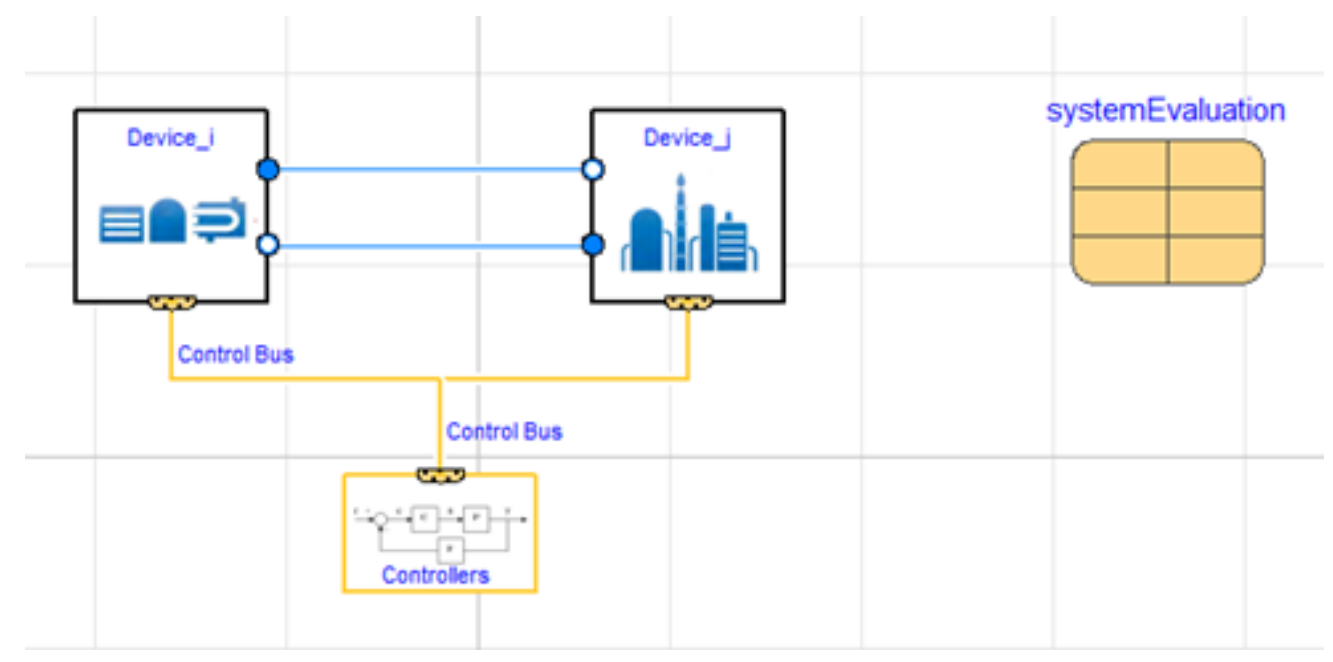

Figure 5. Connectivity among devices and controllers.

The selected NHES configurations exploit the hierarchal control strategy illustrated in Figure 6.

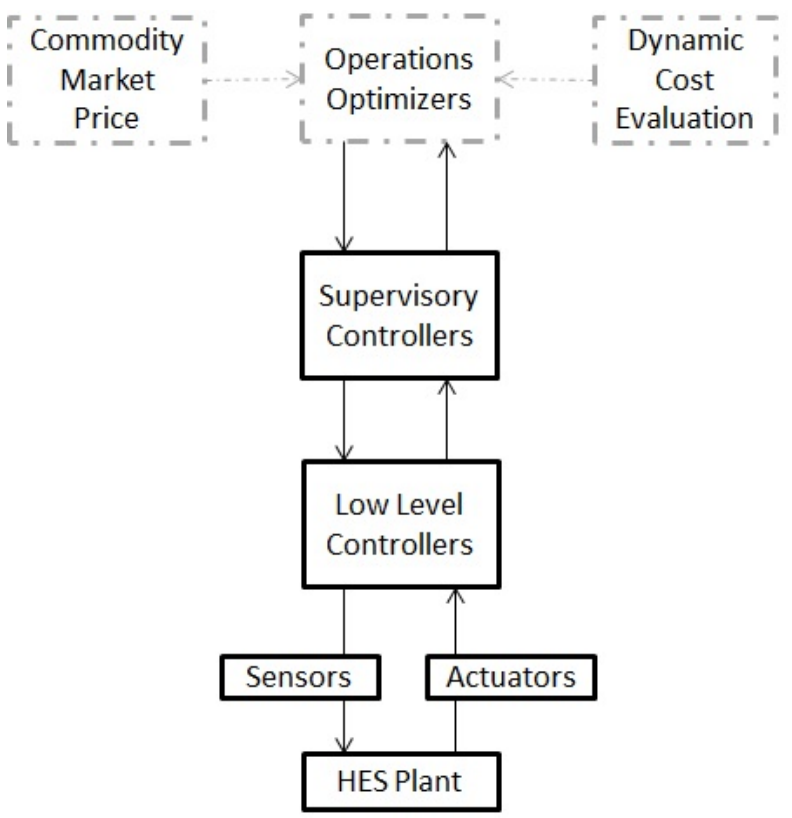

Figure 6. Hierarchical control strategy used in the evaluated NHES configurations. 
In the case illustrated in Figure 6, the operations optimizer (supporting economic optimization for operations) monitors commodity market prices and performs online optimization, considering both commodity price and operational costs to the system, to determine the optimal operation strategy to maximize a goal function (e.g., NPV). The optimal operational conditions are then passed to the supervisory controller which, based on the information received from the operations optimizer and the renewable generation profile, dynamically determines the electricity generation delivered to the electric grid and the amount of corresponding thermal or electrical energy flow diverted to the variable thermal or electrical load particular for the given NHES configuration considered. This information updates the low level controllers accordingly (e.g., change the set point, update the control gain) to ensure that the energy diverted to these loads meets the requirement imposed by the operations optimizer. In its current configuration, the operations optimizer is assumed to have perfect predictive capability related to the renewable resources. A more realistic operations optimizer will be developed in future efforts.

\subsection{Organization}

The remainder of this report is organized into four additional sections. Section 2 describes the two regional NHES configurations selected for this study, as well as their dynamic modeling. Test plans for analysis of dynamic technical and economic performance are described in Section 3. Preliminary results are presented in Section 4. Section 5 provides a summary of the current findings, including a discussion of the existing technology gaps and proposed future research paths. An appendix is also included describing primary formulations derived for implementing economic optimization for operations of the NHES considered. 


\section{NHES CONFIGURATIONS}

The NHES configurations considered in this report include energy components typically utilized for producing electricity and several operations yielding multiple forms of energy commodities including electricity. Specifically, two different NHES configurations are considered. The first configuration, referred to as NHES_Texas, includes a flexible thermal load. This configuration employs a nuclear plant and a series of wind turbines for energy generation, and produces electricity and converts carbon resources to gasoline using excess thermal capacity. The second configuration, referred to as NHES_Arizona, includes a flexible electrical load. This configuration employs a nuclear plant and solar PV stations for energy generation, and yields electricity to meet grid demand and to produce fresh water using excess electrical capacity. In both cases, the NHES is connected to the electric grid at a point of common coupling. This section briefly describes the detailed configurations and their dynamic modeling and simulation. The important phenomena for accurate simulation of their dynamic behavior are characterized in these models. However, this report does not describe, in detail, the specific governing equations included in each model. Details are more briefly presented via summary descriptions of key models and screen-captures to better illustrate the selected configurations.

\subsection{NHES for West Texas with a Flexible Thermal Load}

NHES_Texas can be operated as a flexible generation resource (FGR) via flexible use of the generated thermal energy.

\subsubsection{Location}

This case study was developed based on options considered in [7]. A primary goal of the Texas case study is to utilize the state's large oil and gas industry and wind capacity. The selected process application refines natural gas into gasoline for transportation. Since 2001, wind generation in Texas has increased nearly $1200 \%$, reaching a wind capacity of over $12 \mathrm{GW}$ in 2013 . This is approximately one fifth of the total wind capacity in the United States, making Texas the largest producer of wind energy $[9,10]$. Texas is also the United States' largest crude oil producing state, producing just over one third of total crude oil production in 2013, and the largest natural gas producing state, producing just under one third of total natural gas production in 2013 [11,12].

Selecting an attractive location for an integrated nuclear-renewable HES is nearly as important as selecting its marketable product to ensure profitability and usefulness to society. While a location must be both amenable to the selected renewable generation and to marketing co-products, it must also be able to deliver the electricity generated without significant modification to available infrastructure. In Texas, it is possible to sell electricity to either the Eastern Interconnection or to Electricity Reliability Council of Texas (ERCOT) Interconnection depending on the specific location in the state, as depicted in Figure 7. Co-location of traditionally independent plants is dependent on many factors. Three Texas locations were considered for this study; namely, the Permian Basin of West Texas, the area near the city of Abilene, and the Texas panhandle.

The Permian Basin of West Texas has the highest concentration of oil wells in Texas, as shown in Figure 8. Just south of the Odessa-Midland area within the Permian Basin are a few wind farms with a total capacity of over $400 \mathrm{MWe}$. This area is marked with a green circle in Figures 8 and 9. Oil wells, in addition to producing oil, also produce natural gas, albeit at levels that are not profitable to sell to market. Although venting and flaring of natural gas is the preferred practice, regulations require producers to capture natural gas for environmental reasons [13]. Vented natural gas could be an inexpensive source of natural gas in regions with a high concentration of oil wells. During 2013, an average of 62 million cubic feet per day of natural gas was vented in the Permian Basin [14], which could provide 8,000 barrels of liquid fuel. A typical natural gas to liquid fuel plant requires 290 million cubic feet per day of natural gas [15]. The Permian Basin is part of the ERCOT Interconnection, as shown in Figure 7. 
Five of the largest wind farms in the world are found in the area near the City of Abilene: Roscoe Wind Farm with 781 MWe, Horse Hollow Wind Energy Center with 735.5 MWe, Capricorn Ridge Wind Farm with 662.5 MWe, Sweetwater Wind Farm with 585.3 MWe, and the Buffalo Gap Wind Farm with 523.3 MWe [16]. As expected, wind energy generation is high in this area (Figure 9), but oil wells are scarcer than in the Permian Basin (Figure 8). This area is marked with a red circle in Figures 8 and 9. The area is also a part of the ERCOT interconnection, as shown in Figure 7.

The Texas panhandle location contains natural gas wells and has adequate average wind speed (see the blue circles in Figures 8 and 9). The Wildorado Wind Ranch is located in this region and has a capacity of 161 MWe [17]. This area is part of the Eastern Interconnection.

Considering the carbon resource of interest to the gas-to-liquids plant, natural gas, the availability of renewable wind energy, and the available electric interconnections, the panhandle location is chosen for the initial Texas case study. The close proximity of natural gas wells can provide the needed carbon source for the liquid fuel and the wind speeds are sufficient to use existing or to build additional wind farms for the hybrid system. In this location the electricity would likely be sold to the Southwest Power Pool (SPP) of the Eastern Interconnection, rather than the ERCOT Interconnection.

\section{North American Electric Reliability Corporation Interconnections}

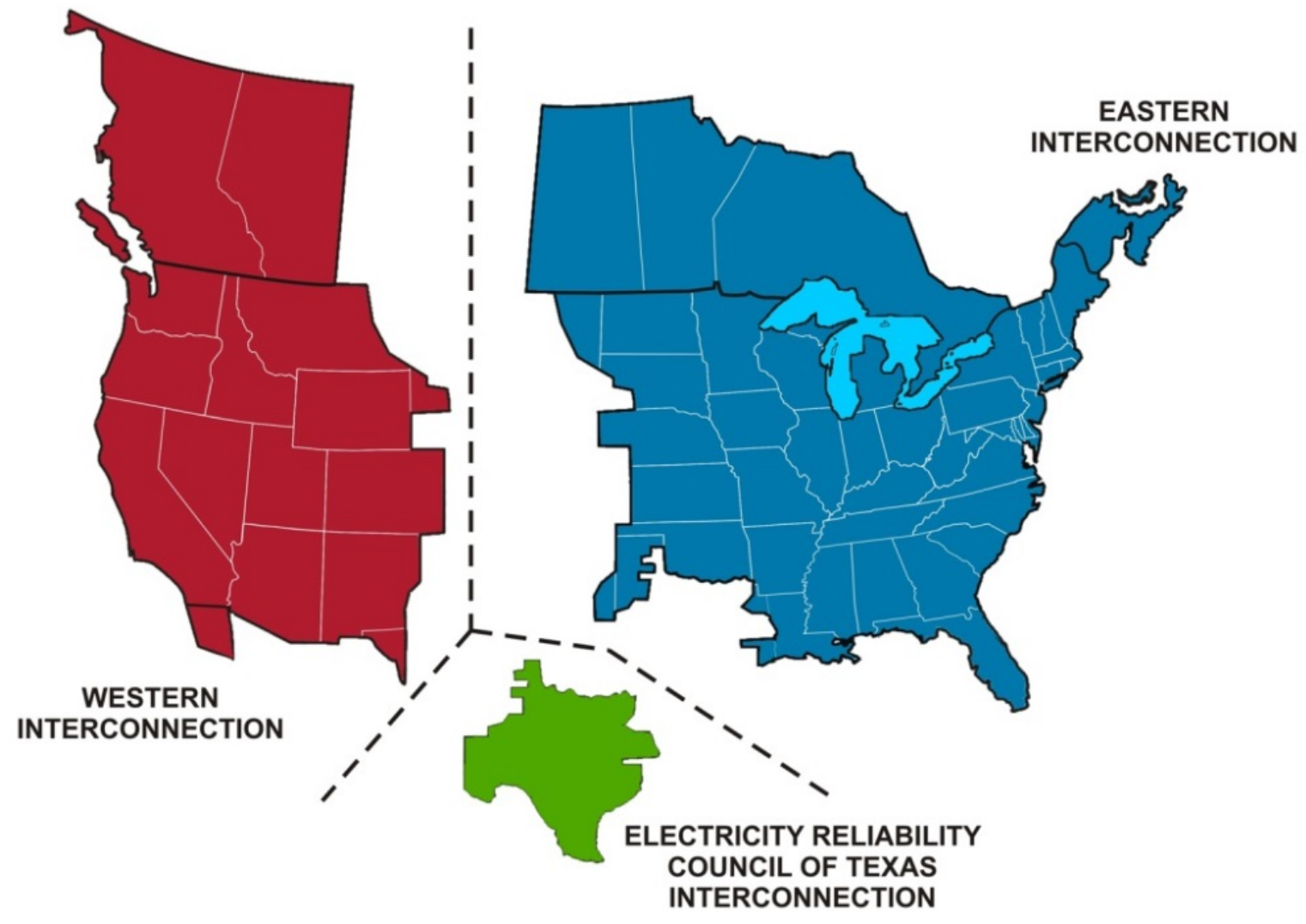

Figure 7. North American Electric Reliability Corporation Interconnections [18]. 


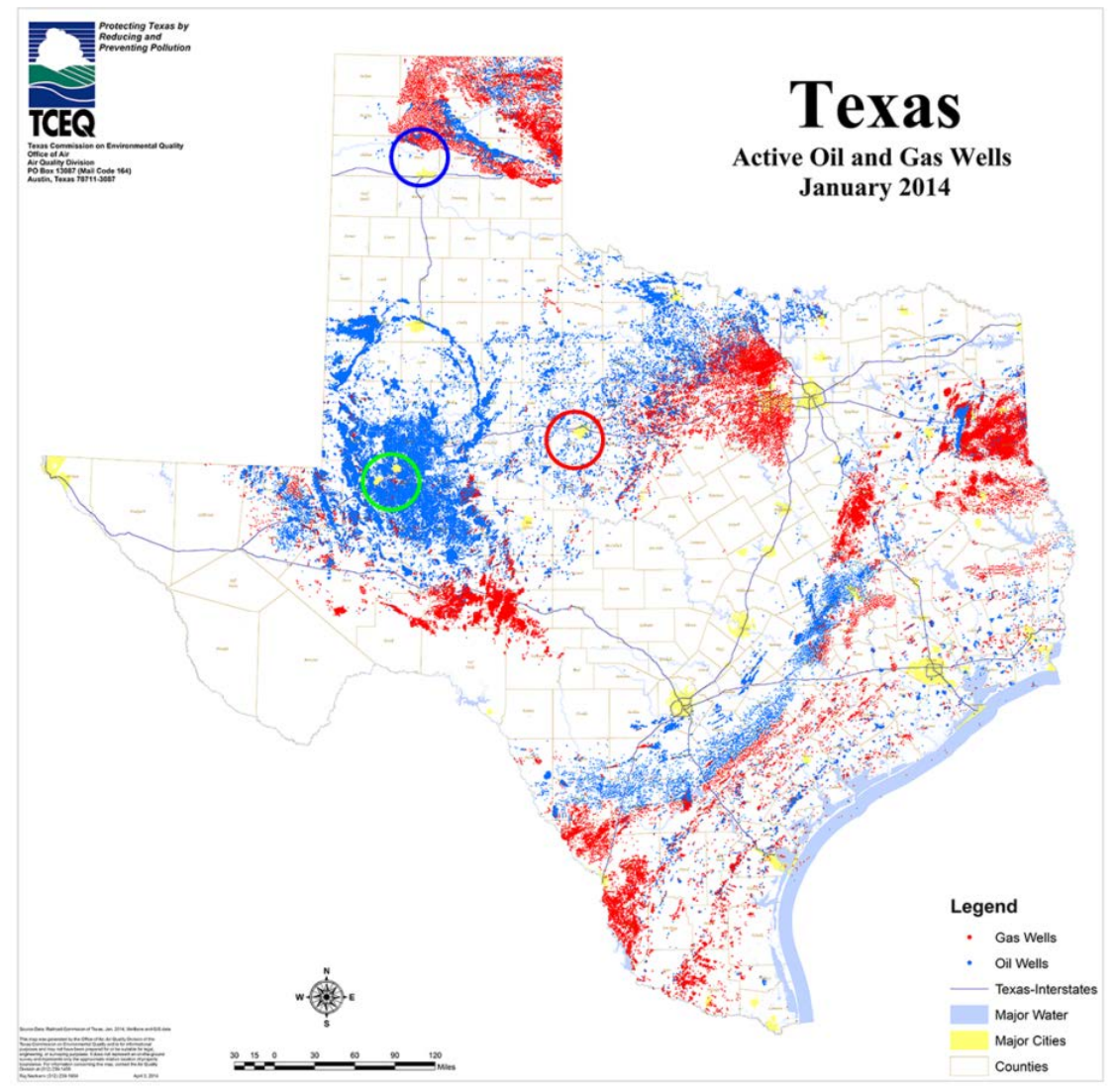

Figure 8. Active oil (blue) and gas wells (red) in Texas [19].

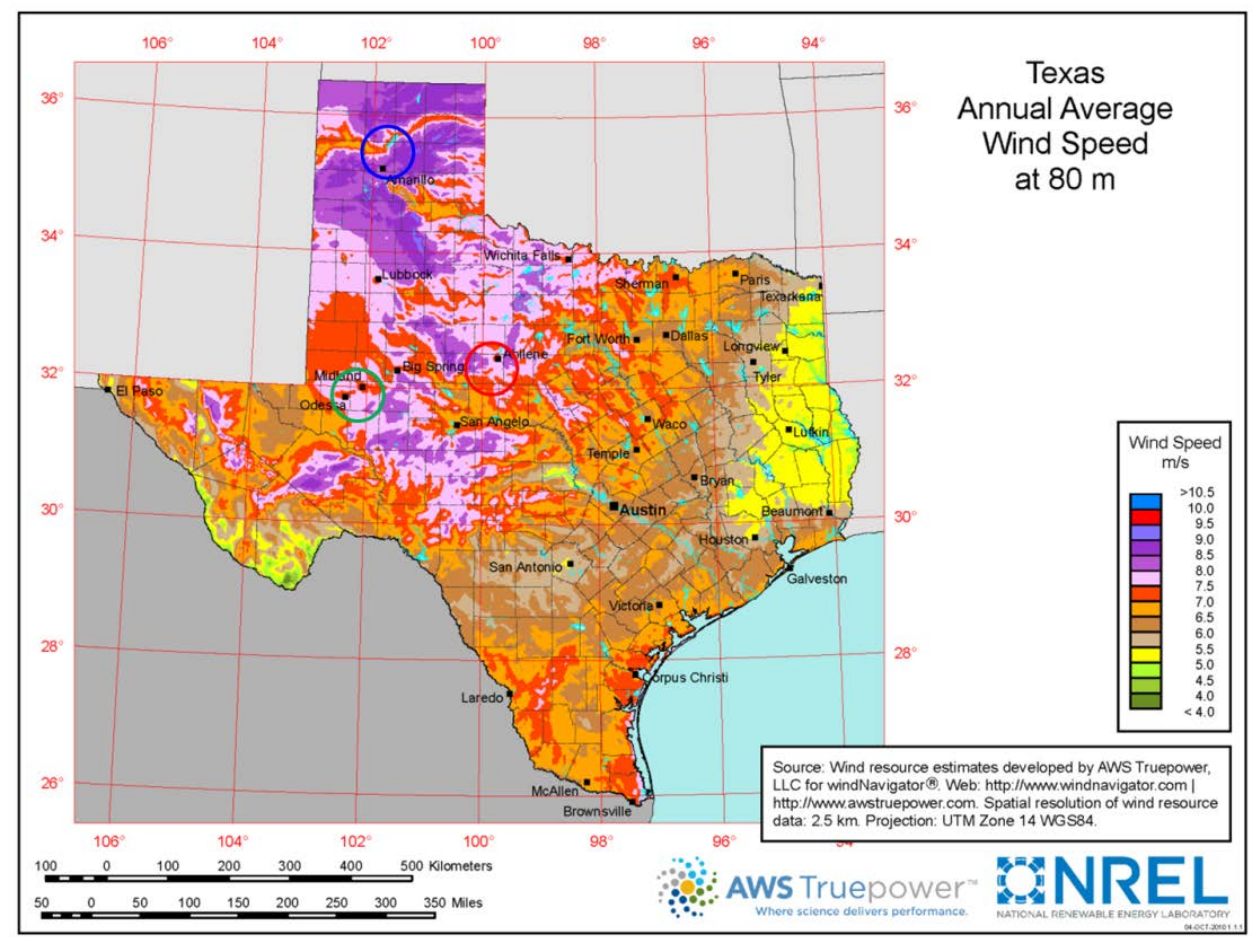

Figure 9. Annual average wind speed in Texas [20]. 


\subsubsection{Equipment layout}

Figures 10-13 show the process diagrams of NHES_Texas, which include the following primary components:

- $600 \mathrm{MWt}$ heat generation plant, consisting of an SMR and a steam generator that provides steam for both electricity generation and for gasoline products; this subsystem is denoted as primary heat generation (PHG).

The balance of plant (BOP) is modeled as follows:

- series of three steam turbines on a single shaft, paired with an electric generator that converts steam into electricity; denoted as thermal to electrical conversion (TEC),

- renewable power generation source consisting of a series of wind turbines, with total wind plant capability of up to $45 \mathrm{MWe}$, denoted as REN (renewable). This relatively-small renewable power generation was selected to accordingly correspond to the selected nominal capacity for the gasoline production plant (GPP). Greater levels of renewable integration is possible by accordingly modifying this initial NHES configuration,

- electrical storage (i.e., a system-scale battery set) used for power smoothing of the electricity generated by the renewable source; denoted as energy storage element (ESE),

- secondary boiler (shown in Figure 11) that transfers heat produced by the SMR to the gasoline production plant, which is located approximately $1 \mathrm{~km}$ from the nuclear reactor site,

- auxiliary heat generation (AHG) plant (i.e., a NG-fired steam generator boiler plant) of up to $150 \mathrm{MWt}$ capacity that generates additional on-demand steam,

- heat distribution header that distributes process steam to various locations of GPP, according to supervisory and low level controllers,

- chemical plant complex able to utilize up to $150 \mathrm{MWt}$ and convert NG and water into gasoline (and liquefied petroleum gas [LPG]) at GPP,

- $\quad$ sufficient carbon resources (e.g., NG) to support chemical production of gasoline,

- electric grid connected to NHES_Texas at a point of common coupling and consuming electricity up to $180 \mathrm{MWe}$.

An inspection of Figure 10 indicates a mis-match in component scale (e.g., a SMR of $180 \mathrm{MWe}$, assuming a 30\% thermal-to-electrical efficiency, pairing with a wind farm of $45 \mathrm{MWe}$ ). This particular component scale was selected considering commercially available gasoline production plant designs; the system capacity can be expanded as renewable energy is phased in. 


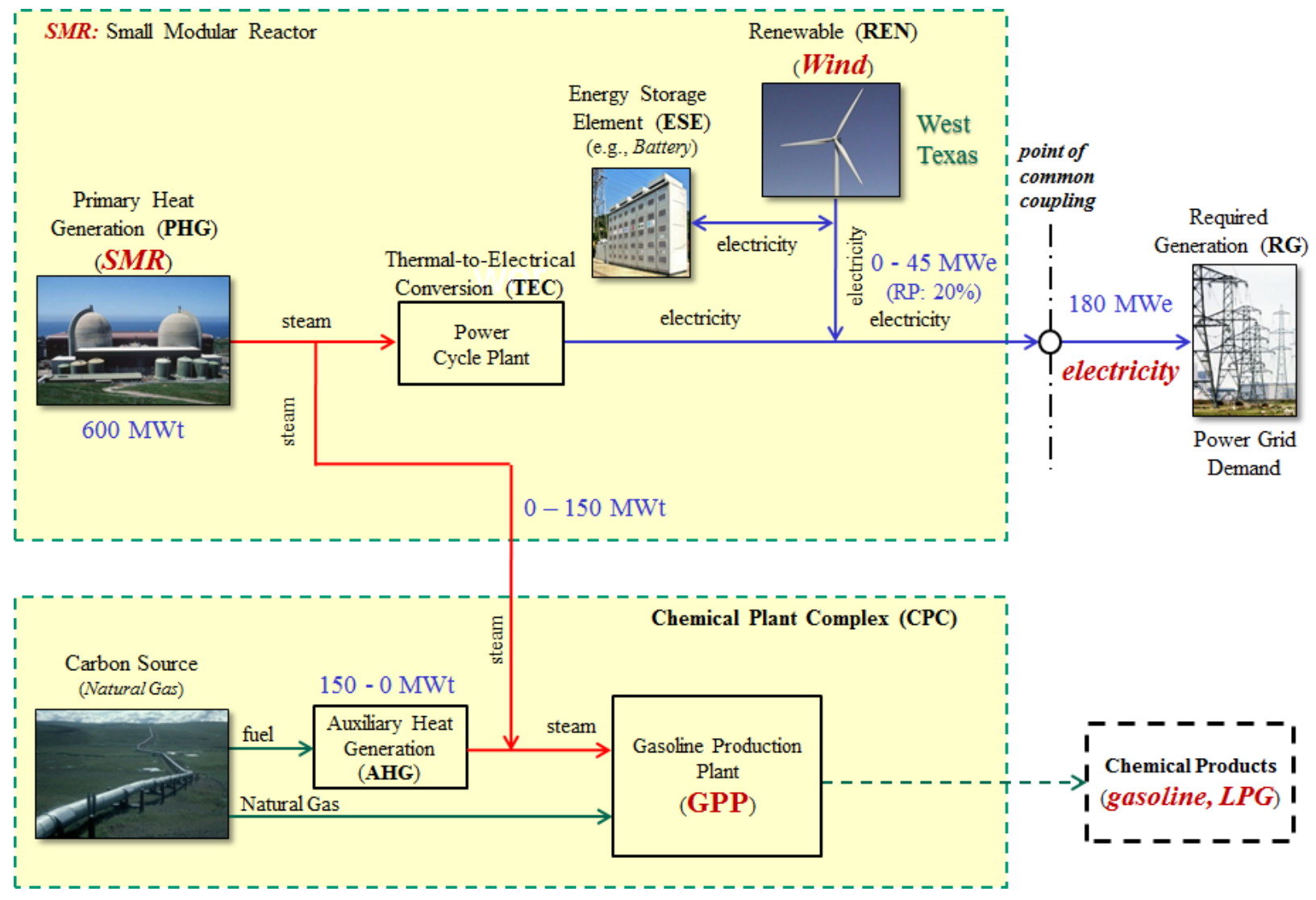

Figure 10. Network topology of NHES_Texas with a flexible thermal load.

While sufficient for this preliminary analysis, a closer inspection of Figure 11 reveals the relative simplicity of the equipment configuration in the power cycle selected for modeling NHES_Texas, as compared to a typical equipment configuration for an actual design. For example, a typical power cycle would include a series of feedwater heaters and pumps whereas the model for this study essentially incorporates only one of each. Furthermore, heating of the feedwater flow may be more often accomplished using bleed steam tapped from the steam turbines. While the simple strategy shown in Figure 11 for heating the feedwater flow was selected in order to use models already available in the toolset, thus allowing more time to focus on the integration of the various component models, it does result in a significant penalty in the overall thermal-to-electrical efficiency for the modeled power cycle. Having demonstrated the integration of component models, improved models and more realistic and thermally efficient configurations are envisioned for future efforts. It is important to notice though that the dynamic technical performance of NHES_Texas is anticipated to remain essentially unchanged after incorporating an improved feedback heating strategy. A consequence of using an improved strategy will manifest in a more favorable economic performance as more thermal energy would become available for producing electricity and gasoline (or, alternatively, in the ability of using a smaller nuclear reactor with accordingly lower capital and operational costs). 


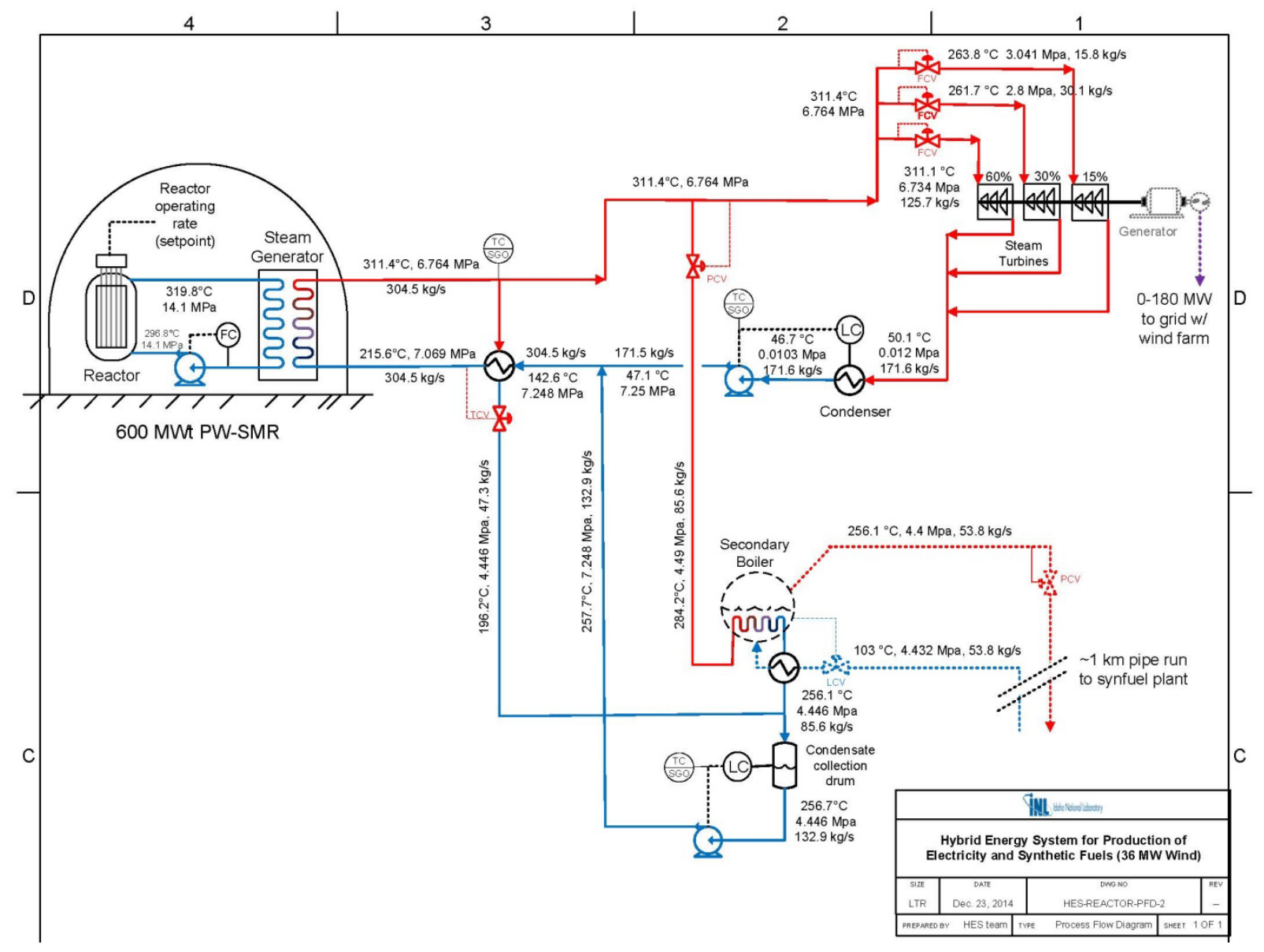

Figure 11. Process flow diagram for NHES_Texas: nuclear, power cycle, and thermal distribution. 


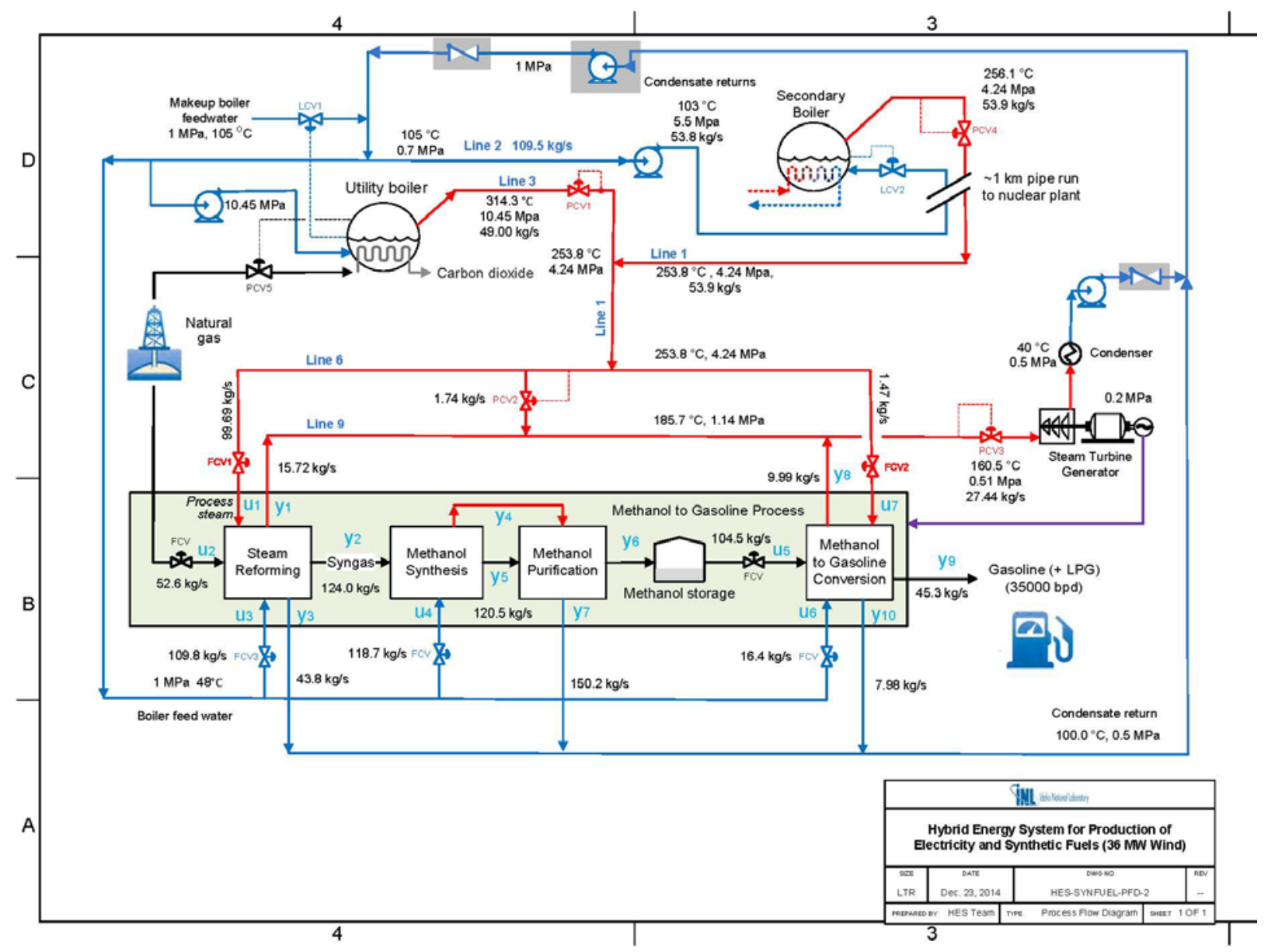

Figure 12. Process flow diagram for NHES_Texas: steam conditioning and gasoline production. 


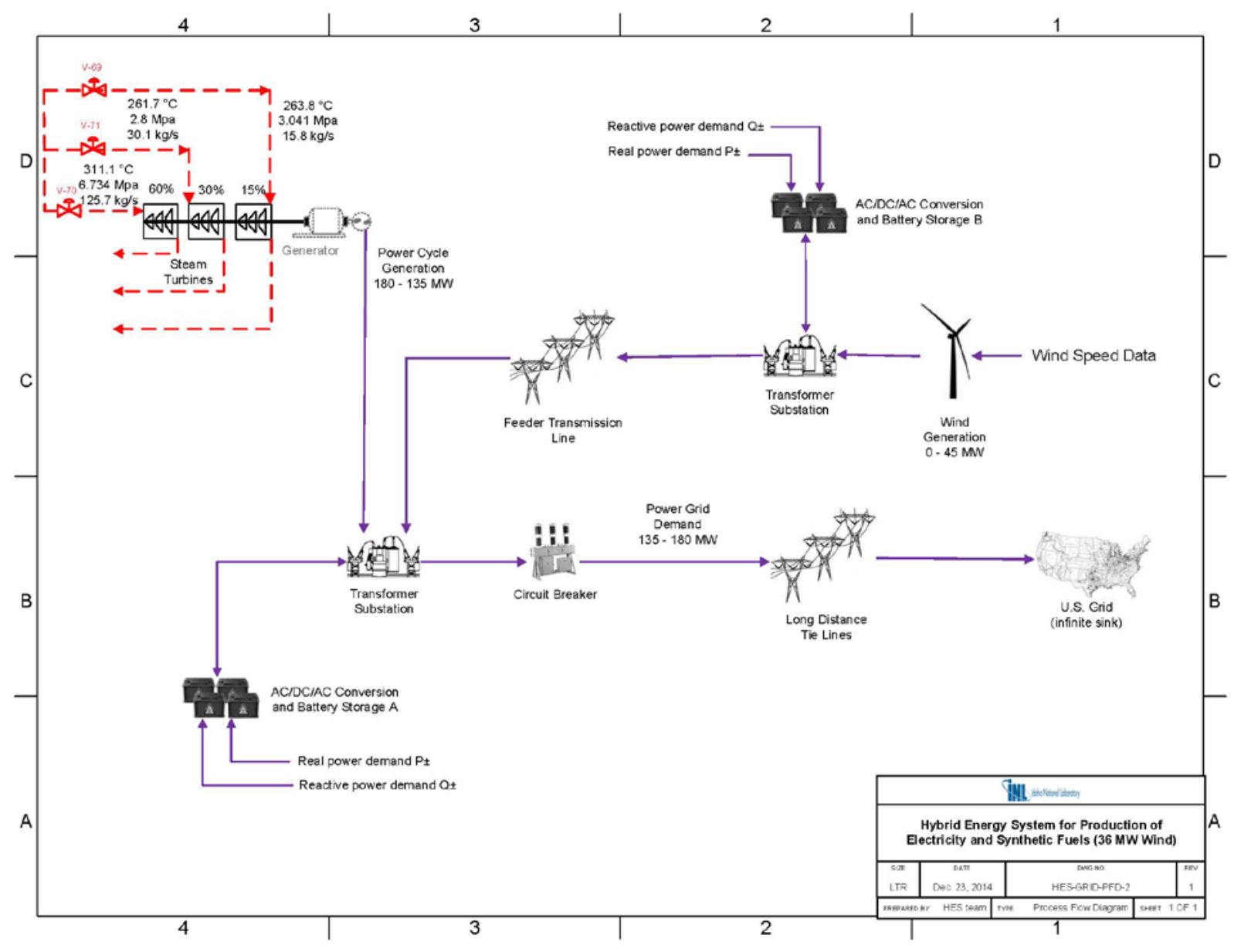

Figure 13. Process flow diagram for NHES_Texas: wind, battery, electric grid.

As shown in Figures 10-12, there are two steam cycles. For thermal energy conversion and transfer, the process steam coming out of the steam generator is modulated (by a pressure control valve [PCV]) for distribution into two locations - one for use by the power cycle to generate electricity and the other for use by the secondary boiler to transfer thermal energy to the gasoline production plant. The process steam through the power cycle and the path through the secondary boiler are merged together, after being condensed into water, which is utilized as feedwater to the steam generator. Each steam flow rate is controlled by a corresponding main pump to maintain the required quality of superheated steam coming out of the steam generator. This path forms the first steam cycle in which the water flow mass is preserved. The second steam cycle is formed by the steam going through GPP and that generated by the secondary boiler. However, as steam is consumed for gasoline production, makeup water enters this water system.

\subsubsection{Components}

PHG is the primary source of energy for NHES_Texas, consisting of a nuclear reactor generating heat according to its nameplate capacity (see Figures 10 and 11), and a steam generator, which transfers heat to the feedwater coming from the BOP. The outflow of the steam generator (i.e., superheated steam) is then delivered to: 
1. Power cycle to drive a series of three steam turbines paired with an electrical generator in order to produce the required additional electricity for meeting grid demand, considering the contribution received from renewable sources (i.e., wind turbines in this case);

2. Gasoline production plant for synthesizing gasoline from natural gas.

As suggested in [4], [5], and [6], the strategy for efficient energy utilization is to build the nuclear reactor with a capacity that meets the peak electrical load, with the remaining process steam accordingly diverted to the production of chemicals or other products. In this report, the nuclear reactor is sized for and operated at its nominal capacity, i.e., $600 \mathrm{MWt}$.

The thermal to electrical conversion (TEC) system is a Rankine power cycle and the primary source of electricity in NHES_Texas. It includes the following components:

- $\quad$ PCV to maintain the desired pressure of the steam supplied to the steam turbines,

- $\mathrm{TCV}$ to maintain the temperature of the feedwater flow entering the steam generator at a given value via an associated feedwater heater;

- three (3) throttle flow control valves (FCV) to ensure that mechanical power generated by the turbines matches the required electricity generation imposed by a supervisory controller;

- $\quad$ series of three (3) steam turbines, each designed at different rated capacities, paired with an electrical generator,

- two (2) condensers for steam-to-water conversion,

- two (2) variable-speed pumps,

- electrical generator.

Note that as shown in Figures 10 to 13, NHES_Texas is operated in a manner such that the electricity produced by the power cycle and the wind turbines is managed by a supervisory controller and distributed to the electric grid according to the electric grid's needs or an optimal electric generation strategy decided by an operations optimizer (supporting economic optimization for operations) based on multiple factors including market price of each product. Because their fuel is free, renewable sources of energy are typically held at maximum available output and are not required to operate at lower-than-maximum output as this otherwise would not be cost effective for renewable generation plants under current energy market rules. Therefore, the renewable energy (i.e., wind energy) is treated in this study as a must-take input (i.e., no renewable curtailment) to NHES_Texas and consists of a series of wind turbines with a maximum generation capacity of $45 \mathrm{MWe}$. This renewable generation is usually characterized by high variability, intermittency, and non-dispatchability. Consequently, as shown in Figures 10 to 13, it is introduced via an electric battery performing power smoothing, thus partially mitigating the renewable's high variability. The effect of this power smoothing action is similar to a low-pass filter. The degree of variability removal (or degree of smoothing) can be characterized by a smoothing time constant. For example, the bigger the smoothing time constant, the higher the variability attenuation. The smoothing time constant in turn defines the following two characteristics of the battery:

1. charge/discharge power provided by the battery to either discharge or accept charge,

2. charge/discharge storage (capacity) representing the total amount of energy during a single charge or discharge period.

In particular, a bigger time constant relates to a larger charge/discharge power and capacity specification for the battery. Therefore, a battery with larger charge/discharge power and capacity can in general achieve a higher degree of smoothing (i.e., variability attenuation). Although there are many other candidates for ESE, such as compressed air energy storage (CAES) and flywheel, a system-scale electric battery is assumed in this study. Other electrical energy storage technologies that could be used for power 
smoothing will require different design specifications. However, the analysis approach and results are expected to be similar. Thermal energy storage technologies may also be modeled in future work.

The gasoline production plant consists of the following unit operations:

- steam reforming plant utilizing steam to convert natural gas into syngas;

- methanol synthesis and purification plant producing methanol;

- methanol storage container, and

- methanol- to-gasoline (MTG) conversion plant requiring thermal energy from steam and outputting gasoline (and a small fraction of LPG).

The GPP utilizes process steam produced by the nuclear reactor (and possibly complemented with steam generated by auxiliary heat generation [AHG]) as shown in Figures 10 and 13 to convert carbonaceous fuels (natural gas) into chemical products (gasoline and LPG). A secondary boiler is used to transfer the thermal energy contained in superheated steam produced by PHG into the steam entering a header. This header distributes steam into various locations of GPP according to supervisory and low level controllers.

The (auxiliary heat generation) AHG system is a natural gas (NG)-fired boiler with capacity of 150 MWt and generates steam solely for the gasoline production plant to meet its steam demand if the steam coming from the nuclear reactor is not sufficient to maintain the desired constant gasoline production level. By generating additional steam to compensate for variability in the steam coming from PHG, AHG enables GPP to operate at a given constant production mode even under variability of renewable generation and grid demand. The sources of carbon and hydrogen to support GPP operations are assumed to be sufficiently large to support the required gasoline production goal.

NHES_Texas is connected to the electric grid via a point of common coupling. The electricity generation profile that must be delivered to the electric grid by NHES_Texas is termed Required Generation (RG), which is typically assigned by an Independent System Operator (ISO) or a Regional Transmission Organization (RTO). In general, ISO/RTO may solicit a time-varying generation profile, according to the net load ${ }^{\mathrm{b}}$ variation and the market price fluctuation. The inherent assumption is that the nuclear reactor can generate sufficient energy to meet the required generation profile.

\subsubsection{Controls}

Numerous feedback controllers are augmented as low-level controllers to maintain the desired process conditions, such as temperature, pressure, and mass flow rates at various locations in the given NHES. As seen in Figures 10 and 11, the temperature of the superheated steam coming out of the steam generator is controlled by two variable-speed control pumps, which maintain the temperature at approximately $311.4^{\circ} \mathrm{C}$, a set point calculated by considering the thermal power efficiency as well as the operational conditions of the steam turbines in the power cycle. The pressure in the power cycle is controlled by a PCV, which regulates the steam flow diverted to the secondary boiler. The flow into the steam turbines is, in turn, controlled by three FCV, one valve for each steam turbine. The FCVs are simultaneously regulated by a governor responsible for maintaining the speed of the turbine shaft at the specified equivalent $60 \mathrm{~Hz}$ that is demanded by the electric grid. These three FCV work accordingly to guarantee that the power cycle generates the exact amount of electricity as needed by the electric grid. The steam going through the steam turbines and the steam going through the secondary boiler are merged together, after they are condensed into water, which is then heated to $215.6^{\circ} \mathrm{C}$ before feeding it into the steam generator. This is accomplished by a heat exchanger being regulated by a temperature control valve (TCV).

\footnotetext{
${ }^{\mathrm{b}}$ Net load is the remaining demand that must be met by conventional generation sources after variable generation is subtracted from the total load (demand).
} 
The conditions of the other steam cycle are also controlled by multiple flow, pressure, and level control valves. It is worth noting that, due to the variability of the renewable generation, the thermal energy sent to GPP is also subject to high variability. In order for GPP to operate at constant production, supplemental steam is provided by an AHG, whose operation is controlled by a PCV. This PCV is present to make sure that the steam flow resulting from combining the steam flow from the secondary boiler and the steam flow produced by AHG is provided to GPP at a constant pressure, which in turn guarantees the constant thermal energy that is needed by GPP to operate at full mode.

Table 1 partially summarizes the main low-level controllers and supervisors used in NHES_Texas. While the controllers listed in Table 1 are often basic (e.g., single input single output [SISO] controllers), advanced controllers (e.g., multiple input multiple output [MIMO] controllers) are anticipated for future inclusion.

Table 1. Main controllers used in NHES_Texas.

\begin{tabular}{|l|l|c|}
\hline Name & Functionality & \# of Use \\
\hline Feedwater Pump Control & Regulate steam temperature & 2 \\
\hline Flow Control Valve (FCV) & Regulate flow rate & 8 \\
\hline Pressure Control Valve (PCV) & Regulate flow pressure & 6 \\
\hline Temperature Control Valve (TCV) & Regulate flow temperature & 1 \\
\hline Level Control & Regulate vessel level & 3 \\
\hline Power Control & Regulate SMR power & 1 \\
\hline Pump Supervisor & Regulate primary pumps & 1 \\
\hline Turbine Admission Valve Governor & Regulate throttle valves & 1 \\
\hline Power cycle Supervisor & Regulate power cycle & 1 \\
\hline
\end{tabular}

\subsubsection{Operations}

There are two units for electricity generation in NHES_Texas, namely, TEC, which includes a series of three steam turbines pairing with an electrical generator, and REN, which is a series of wind turbines coupled with an electrical battery. Under supervisory control, these two electricity generation units are operated accordingly to deliver the electricity generation requested by the electric grid operator (e.g., an ISO, RTO) or by the operations optimizer (supporting economic optimization for operations). In either case, the power delivered to the electric grid is assumed to be less than or equal to $180 \mathrm{MWe}$. This electricity production is the first output of NHES_Texas. The second output is chemical products (i.e., gasoline), which is produced from carbon sources (i.e., NG), steam generated by the nuclear reactor and, if needed, AHG. Note that the nuclear reactor is sized for full load operation (i.e., $600 \mathrm{MWt}$ ); therefore, it is capable of generating (without renewable contribution) sufficient process steam to meet the maximum electric grid demand of $180 \mathrm{MWe}$. This amounts to an overall thermal-to-electrical efficiency of $30 \%$. When a more realistic and thermally efficient feedwater heating strategy is modeled, this efficiency is anticipated to significantly increase as mentioned before.

Under the extreme situation that the requested electricity generation is $180 \mathrm{MWe}$ and no renewable contribution is present, a small amount of steam (i.e., $9.67 \mathrm{~kg} / \mathrm{s}$ ) generated by the steam generator is still directed to the gasoline production plant, with the remaining majority of the steam duty being met by AHG. In the event of non-zero renewable contribution, the amount of electricity generated by the power cycle is determined by a supervisory controller based on the renewable contribution, and the remaining thermal energy produced by the nuclear reactor operating at full-load is sent to GPP in the form of heated steam via the secondary boiler. If the steam coming from the nuclear reactor is not sufficient to maintain the desired gasoline production goal, AHG is accordingly regulated to provide the required additional steam. By enabling the gasoline production plant to utilize steam generated from the nuclear reactor, NHES_Texas provides additional opportunities for flexible energy management, for providing various types of ancillary services, such as operating reserves (e.g., regulating, ramping, load following, and 
supplemental reserves), and for enabling operational flexibility for value (technical and/or economic) optimization.

In order to provide ancillary service, NHES_Texas can increase or decrease electricity production when requested. For example, if the electricity production is $170 \mathrm{MWe}$ at a given time with $10 \mathrm{MWe}$ coming from the wind turbines, then NHES_Texas can potentially increase or decrease its electricity production to as high as $190 \mathrm{MWe}$ or as low as $145 \mathrm{MWe}$, respectively. In the first case, GPP would be solely supported by AHG, while in the second case no steam is needed from AHG. In other words, assuming a $10 \mathrm{MWe}$ constant wind contribution, NHES_Texas can accept a change of $45 \mathrm{MWe}$ (or more if an additional GPP is installed or the power setpoint for the nuclear reactor is accordingly reduced) in its electricity production - this operating capacity is large enough to bid into the ancillary service market. Furthermore, since AHG is utilized to compensate the thermal energy supplied to GPP, NHES_Texas can maintain a given change in its electrical production for large time periods.

\subsubsection{Dynamic models}

Figure 14 shows the top-level model for NHES_Texas. As seen from this screen capture, nineteen main subsystems can be identified as follows:

\section{Physical devices}

1. Nuclear SMR

2. Feedwater heater and thermal distribution center

3. Power generation

4. Secondary boiler

5. Thermal conditioning

6. Thermal transmission lines

7. Auxiliary NG-fired boiler

8. Header network

9. Auxiliary steam turbine generator

10. Chemical gasoline production plant

11. Wind generation

12. Battery-based power smoothing

13. Electric grid

\section{Control devices}

14. Main pumps supervisor

15. Governor

16. Power cycle supervisor

17. Many low-level controllers (embedded within corresponding subsystems, not shown)

18. Control bus

\section{Evaluation Module}

19. System evaluation (used to facilitate ease evaluation of multiple scenarios) 
Each of these subsystems includes a number of components. Detailed subsystem description is beyond the scope of this report. Additional details will be available in associated publications that are in progress.

Table 2 provides a partial list of the sensor signals and control commands being communicated through the control bus.

Table 2. Partial list of signals communicated via control bus in NHES_Texas.

\begin{tabular}{|l|l|l|l|}
\hline Signal name & Signal type & Source Module & Destination Module \\
\hline Battery on/off command & command & Power cycle supervisor & $\begin{array}{l}\text { Battery-based power } \\
\text { smoothing }\end{array}$ \\
\hline $\begin{array}{l}\text { Amount of renewable } \\
\text { generation }\end{array}$ & measurement & $\begin{array}{l}\text { Battery-based power } \\
\text { smoothing }\end{array}$ & Power cycle supervisor \\
\hline Amount of grid consumption & measurement & Electric grid & Power cycle supervisor \\
\hline Turbine generation set point & command & Power cycle supervisor & $\begin{array}{l}\text { Governor \& } \\
\text { Power generation }\end{array}$ \\
\hline Actual turbine generation & measurement & Power generation & Governor \\
\hline Electricity frequency & measurement & Power generation & Governor \\
\hline Valve opening set points & command & Governor & Power generation \\
\hline Pump level measurements & measurement & Turbine generator \& pump & Main pumps supervisor \\
\hline Temperature at reactor outlet & measurement & $\begin{array}{l}\text { Feedwater heater and } \\
\text { thermal distribution center }\end{array}$ & Main pumps supervisor \\
\hline Amount of desired flow & command & Main pumps supervisor & Power generation \\
\hline
\end{tabular}




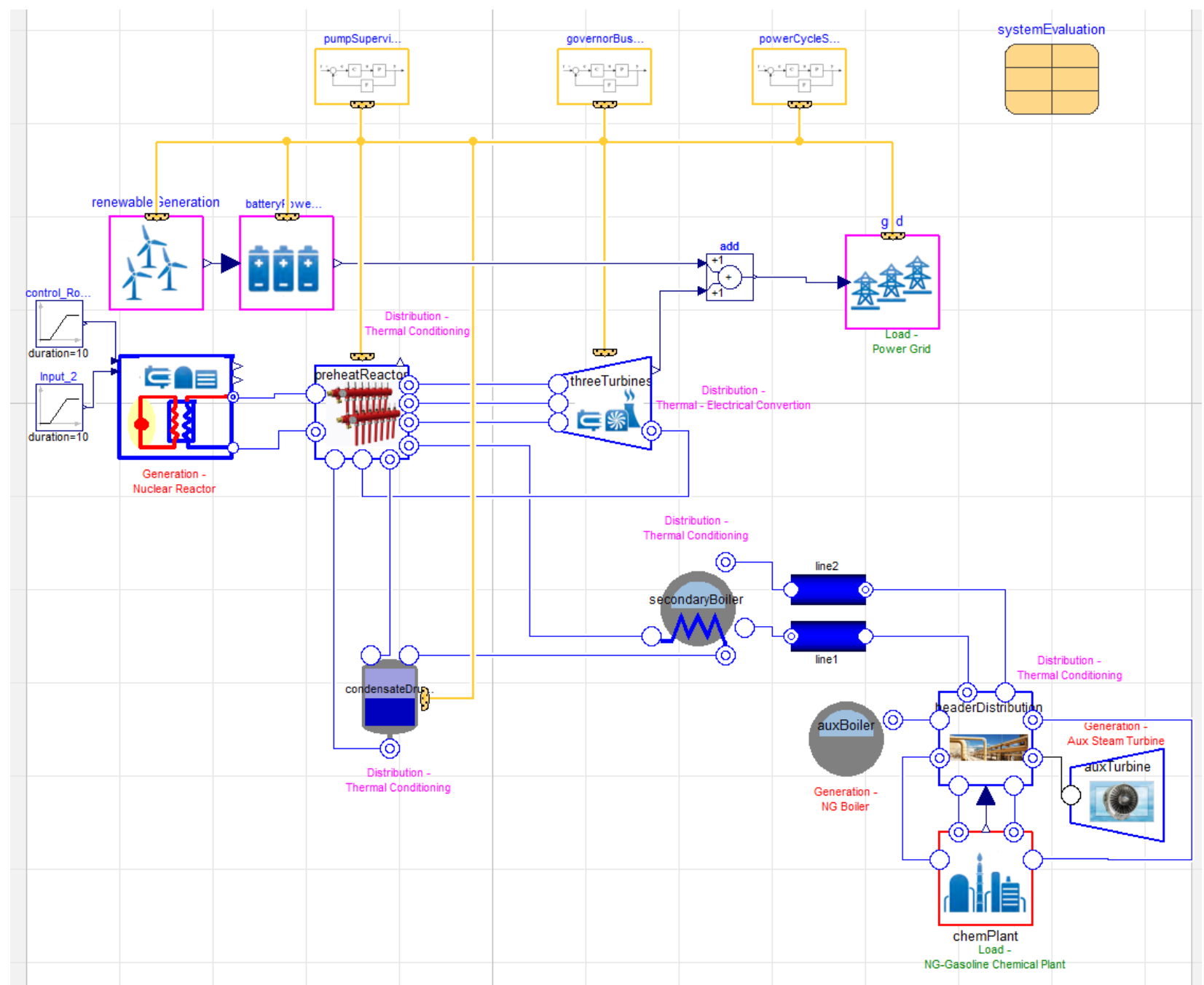

Figure 14. Top-level model for NHES_Texas in Modelica.

In order to provide a brief description of two of the subsystems implemented for NHES_Texas, Figure 15 shows the top-level model for the gasoline production plant. As mentioned previously, the thermal energy produced by the nuclear reactor is used to supply the process heat (in the form of steam) to the natural gas-to-methanol-to-gasoline (MTG) process. There is an auxiliary natural gas-fired utility steam boiler that burns natural gas and generates the additional steam necessary to keep GPP running at constant production capacity. The combined process steam is directed to a steam methane reforming step. 


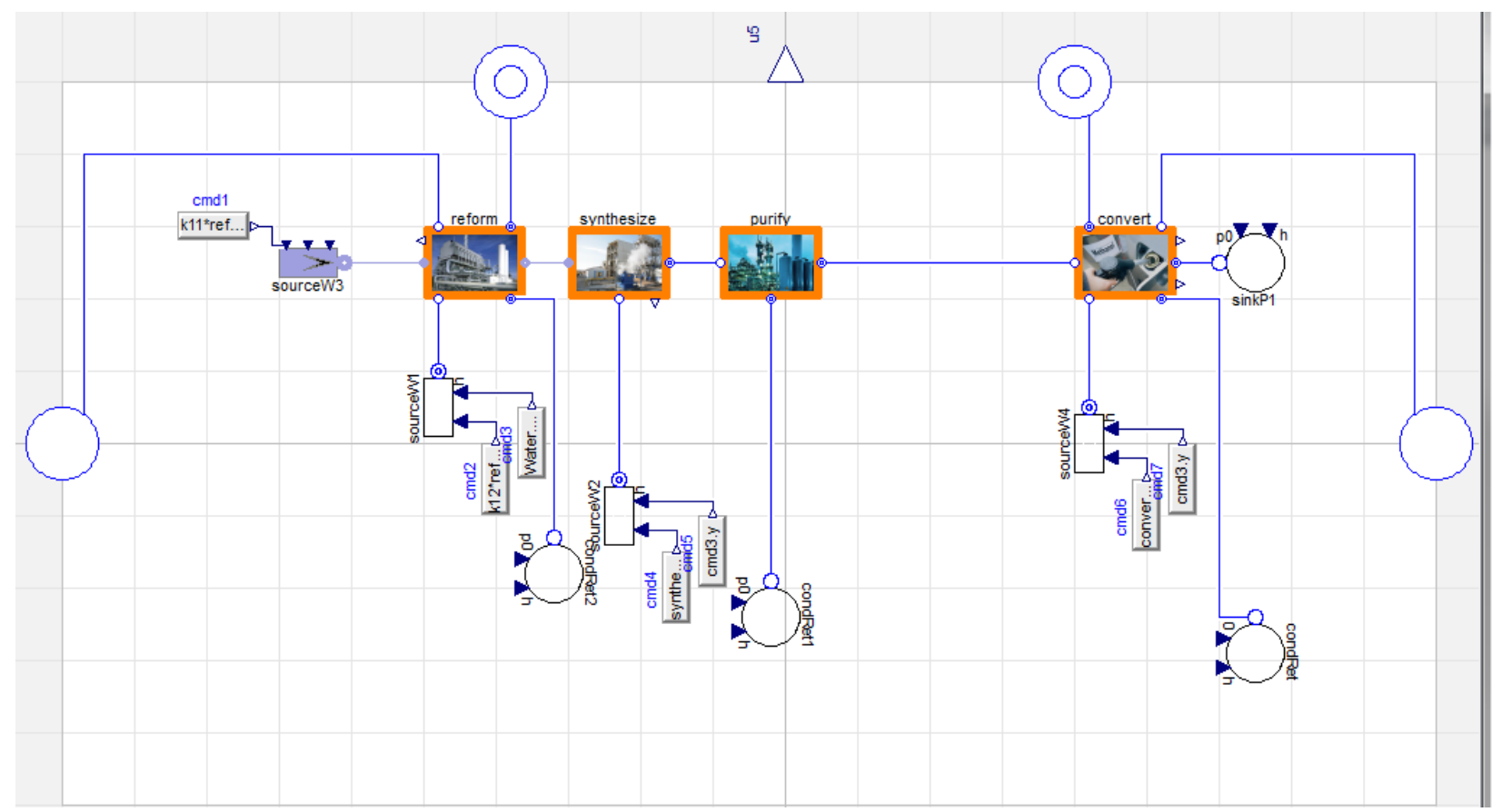

Figure 15. Top-level model for gasoline production plant used in NHES_Texas in Modelica.

Before entering a steam methane reformer, the natural gas is compressed, heated, saturated with hot water, and mixed with a small amount of hydrogen. Subsequently, sulfur is removed from the gas and mixed with process steam to achieve the desired steam-to-carbon ratio. The natural gas/steam mixture is fed to a steam methane reformer consisting of primary steam reforming followed by secondary autothermal reforming, where syngas $\left(\mathrm{CO}\right.$ and $\left.\mathrm{H}_{2}\right)$ is produced. The syngas is fed to a methanol synthesis reactor, from which methanol is produced. Methanol product is purified in a distillation column to remove light gases prior to storage in the methanol intermediate product tank. This storage tank has a capacity of 24-48 hours of design flow and is held at about 50\% full to allow it to compensate for 12-24 hours of high or low flow imbalance. Finally, methanol is converted to gasoline using ExxonMobil's patented process. First, methanol is exothermically converted to an equilibrium concentration of dimethyl ether (DME), water, and methanol in the DME reactor. Next, the product of this reactor is mixed with recycle gas to cool the stream before it is introduced to the ZSM-5 catalytic MTG reactor. In this reactor, methanol and $\mathrm{DME}$ are converted to hydrocarbons ranging from $\mathrm{C}_{1}$ (methane) to $\mathrm{C}_{11}$ (1-naphtha) according to the following generic reaction:

$n \mathrm{CH}_{3} \mathrm{OCH}_{3} \rightarrow \mathrm{C}_{X} \mathrm{H}_{Y}+\mathrm{zH}_{2} \mathrm{O}$

The overall reaction from DME and MTG is exothermic, so the crude gasoline product is cooled via recuperation and by raising steam, followed by condensation. Finally, crude liquid gasoline is purified using several distillation columns (de-ethanizer, de-propanizer, and de-waxing), resulting in the final gasoline product as well as LPG product [15]. Detailed governing equations and models of these processed were initially developed and analyzed using ASPEN and then simplified formulations were implemented in Modelica.

As another example of the dynamic models developed, Figure 16 shows the top-level model for the nuclear SMR used in both NHES_Texas and NHES_Arizona. 


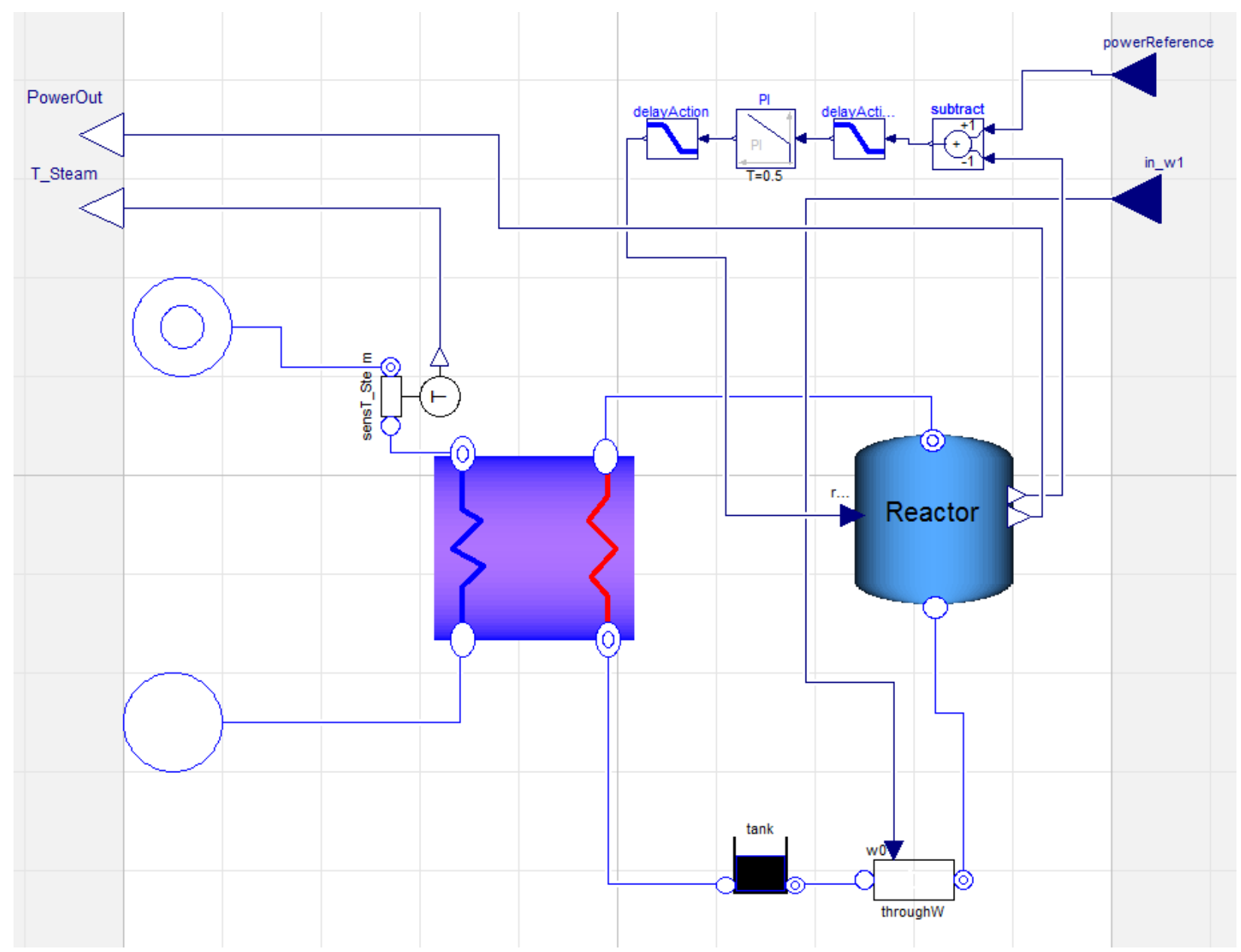

Figure 16. Top-level model for the nuclear reactor used in NHES_Texas, NHES_Arizona in Modelica.

In particular, the developed nuclear steam supply system (NSSS) provides on-demand steam to multiple energy conversion processes that produce commodities for regional markets. The NSSS is based on pressurized-water reactor (PWR) technology, which is regarded as commercially mature, although SMR technology is currently under development. The steam conditions are typical of light water reactor (LWR) technology with a temperature of $320^{\circ} \mathrm{C}$ and a pressure of $7.0 \mathrm{MPa}$. The plant is representative in size and design of a light water cooled SMR.

As shown in Figure 16, the NSSS includes the reactor, primary system, and steam generator. It couples to the balance of plant at the main steam line and the feed water inlet line. The NSSS is of an integrated design, where the primary system components are all located within the primary vessel. The primary coolant enters the reactor core where it is heated. It exits the core and flows up a riser to the reactor coolant pumps where it then reverses direction and flows down through the shell side of a once-through steam generator before returning to the core inlet. The pressurizer is located at the top of the riser. Subcooled feed water enters the tube side of the steam generator and rises up the tubes where heat is transferred from the shell side primary coolant. The secondary coolant exits the tubes as superheated vapor. 
The NSSS model is capable of representing plant behavior during normal steam production, which was adapted from the requirements for commercial light water reactor technology as follows:

- Steam production range: 25 to 100 percent power

- Maximum steam power time-rate-of-change: Ten percent step and five percent per minute ramp.

- Stable regulation of process variables.

The values of process variables at full power are given in Table 3.

Table 3. Full-power conditions for pressurized-water nuclear small modular reactor.

\begin{tabular}{|c|c|c|c|c|}
\hline $\begin{array}{c}\text { Reactor Nominal } \\
\text { Power }[\mathrm{MWt}]\end{array}$ & $\begin{array}{c}\text { Primary Loop } \\
\text { Flowrate }[\mathrm{kg} / \mathrm{s}]\end{array}$ & $\begin{array}{c}\text { Primary Loop } \\
\text { Pressure }[\mathrm{bar}]\end{array}$ & $\begin{array}{c}\text { Reactor Coolant } \\
\mathrm{T}_{\text {out }}\left[{ }^{\circ} \mathrm{C}\right]\end{array}$ & $\begin{array}{c}\text { Reactor Coolant } \\
\mathrm{T}_{\text {in }}\left[{ }^{\circ} \mathrm{C}\right]\end{array}$ \\
\hline 600 & 4500 & 140.7 & 319.8 & 296.8 \\
\hline $\begin{array}{c}\text { Steam } \mathrm{T}_{\text {out }} \\
{\left[{ }^{\circ} \mathrm{C}\right]}\end{array}$ & Feedwater $\mathrm{T}_{\text {in }}\left[{ }^{\circ} \mathrm{C}\right]$ & $\begin{array}{c}\text { Steam Outlet } \\
\text { Pressure }[\mathrm{MPa}]\end{array}$ & $\begin{array}{c}\text { Feedwater Inlet } \\
\text { Pressure }[\mathrm{MPa}]\end{array}$ & $\begin{array}{c}\text { Feedwater Mass } \\
\text { Flowrate }[\mathrm{kg} / \mathrm{s}]\end{array}$ \\
\hline 311.5 & 215.6 & 6.8 & 7.1 & 304.4 \\
\hline
\end{tabular}

The nuclear SMR model features the main phenomena that govern operation of a PWR during normal operation. However, the model is simplified in as much as it does not include phenomena that appear only during off-normal operational. The assumptions that enter into the model are described below for each component.

Pressurizer - The pressurizer operates to maintain primary system coolant at the design pressure during normal operation, which includes normal load maneuvering. The pressurizer is designed to deliver on a pressure setpoint with minimal error. In this work where only normal operation is considered, the pressurizer is assumed to be capable of carrying out its function. In that case, it is then acceptable to represent operation of the pressurizer with an imposed primary system pressure boundary condition.

Main Coolant Pump - The primary system pump delivers the required coolant flow rate to the reactor. During normal operational transients, the time rates of change of process variables in the primary system are such that the primary pump is able to deliver on its flow rate setpoint with minimal error. In this work where only normal operation is considered, it is not necessary to model the dynamics of the pump, but it is sufficient to represent its operation with an imposed coolant mass flow rate. For off-normal transients, however, where pump rotor and coolant inertia are important, it would be necessary to solve the equations of motion for the pump and fluid and include the pump performance maps.

Reactor Core - The thermal-hydraulic behavior of the core is represented by a single average fuel pin and its associated coolant channel. The fuel pin axial power profile is assumed to be uniform. The fuel pin is divided into ten axial nodes and the fuel pellet into three radial nodes. The energy equations for the fuel pin are solved for temperatures. The coolant channel is assembled from the water_tube element in the ThermoPower library. An extension is created to link it to the cladding exterior temperature.

The core neutronics is driven by reactivity that is communicated to the core through changes in reactor inlet temperature, reactor coolant mass flow rate, and control rod position. For normal electric power operation, the greatest rate of reactivity change occurs for the 10 percent electric load change over $10 \mathrm{~s}$ (so-called 10\% step, but actually a ramp). The average of the multi-group delayed neutron precursor decay half-lives is approximately $13 \mathrm{~s}$, comparable to the time scale of reactivity addition. This addition does not significantly excite the fastest precursors (half-lives $<2.4 \mathrm{~s}$ ) so there is not a need to model their dynamics (i.e. their behavior can be regarded as quasi-static). The slower precursors (half-lives $>6 \mathrm{~s}$ ), however, are excited. They are represented reasonably well by a $13 \mathrm{~s}$ value for the average half-life parameter. Hence, the reactor neutronic response to changes in reactivity during normal electric power production can be reasonably well represented by one-group point kinetics. 
The main temperature reactivity feedbacks are temperature-dependent coolant moderation and fuel Doppler. These are represented through temperature coefficients of reactivity. Unlike the case for liquid-metal and gas reactors, structural feedbacks such as control rod thermal expansion are not significant since the average temperature of the core is near-constant and the core full-power temperature rise is less than $50{ }^{\circ} \mathrm{C}$. Structural feedbacks can therefore be neglected.

Once-through Steam Generator - The once-through steam generator is marked on the secondary side by three heat different transfer regimes (subcooled, nucleate boiling, and superheat) and by a relatively small coolant inventory, from an energy capacitance standpoint. As this component is the interface between the main energy source, the reactor, and other hybrid-energy system sinks, it is important that its thermal-hydraulic phenomena be well represented. It is also important that dynamic effects in the steam generator (mass and energy storage) are adequately modeled since the instantaneous heat rate is closely linked to the relative lengths of the heat transfer regimes and that these lengths can change quickly given the small energy capacitance. The steam generator model is assembled from basic elements in the ThermoPower library. Figure 17 is a schematic of the steam generator showing the ThermoPower icons for these elements connected in a manner that models the thermal-hydraulic processes.

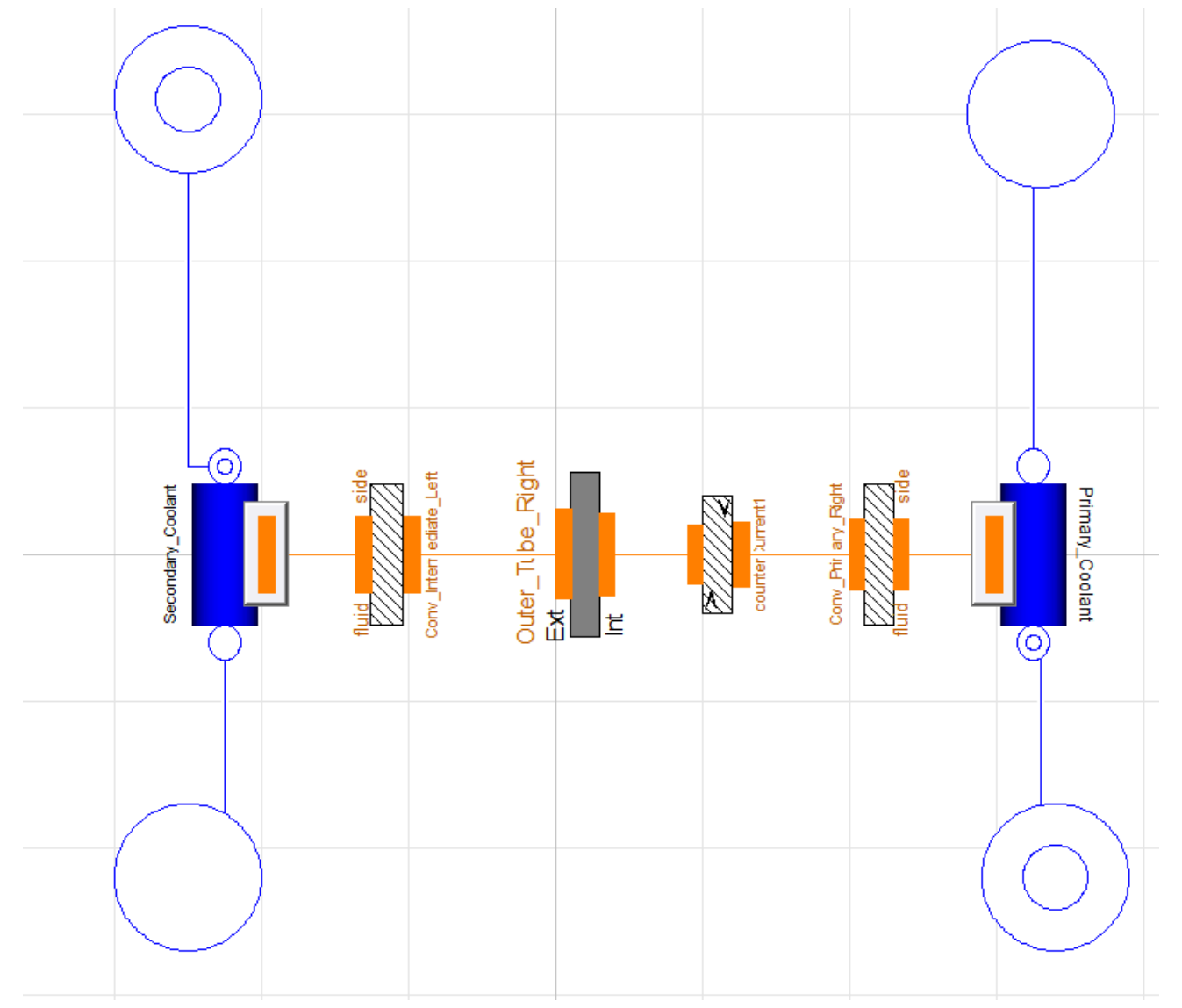

Figure 17. Model of the once-through steam generator in Modelica.

In this initial effort, the reactor control system is basic, operating to control reactor thermal power by adjusting control rod reactivity. The controller compares measured reactor power to a user-supplied set point power to generate an error signal for input to a controller. The controller outputs control rod reactivity that drives the error in power to zero over time. The reactor control system should be extended as regional cases dictate such that it acts to additionally maintain constant reactor core average temperature while at load, for example. In addition, the overall NSSS control system will need to be tailored to address the BOP control issues that are unique to each regional NHES. 


\subsection{NHES for Northeastern Arizona with a Flexible Electrical Load}

NHES_Arizona can be operated as a both FGR and flexible load resource (FLR).

\subsubsection{Location}

This case study was developed based on options considered in [7]. The specific location in northeast Arizona for this system was determined by consulting with the Arizona Governor's Office of Energy Policy and the Arizona Collaboratory for Advanced Energy Solutions. These meetings were attended by Arizona state legislators, business developments leaders, and university representatives.

Arizona is expecting increased power and water needs over the next 15 to 20 years. The Arizona Public Service, the largest electric utility in Arizona, projects their peak power requirement to increase from 8,124 MWe in 2014 to $12,982 \mathrm{MWe}$ by 2029. The renewable component of the Arizona energy mix is anticipated to increase from 3,182 GW-hr in 2014 to 6,944 GW-hr by 2029 [21]. Estimated population growth in Arizona is expected to be 10.5, 13.3 and 18.3 million people for the years 2035, 2060, and 2110 , respectively. The annual water demands are projected to grow from the 2014 volume of 6.9 million acre-feet to between 8.2 and 8.6 million acre-feet in 2035; between 8.6 and 9.1 million acre-feet in 2060, and between 9.9 and 10.5 million acre-feet in 2110 [22]. Figure 18 shows the current energy distribution within Arizona. Nine gigawatts of power is currently provided by coal fired plants in the northeast corner of the state. Fifty percent of those coal fired plants are predicted to be retired by 2020 due to EPA emission regulations $[15,23]$ and/or regional power generation preferences.

An integrated nuclear-renewable HES could benefit the northeast corner of Arizona. While other suitable locations for the NHES-Arizona configuration may be identified within Arizona and elsewhere, this energy solution could replace the coal fired power plant on the Navajo reservation in the northeast corner of the state, enabling it to use existing high-voltage lines to transport electricity within Arizona and to California. The plant also sits above an aquifer that contains brackish water. By using a reverse osmosis (RO) desalination plant, potable water can be produced for use on the reservation and/or piped to other areas within Arizona, New Mexico, Colorado, and Utah. The selected NHES could aid the penetration of additional renewable energy by diverting power to desalinate brackish water in the area during times of excess power production. 


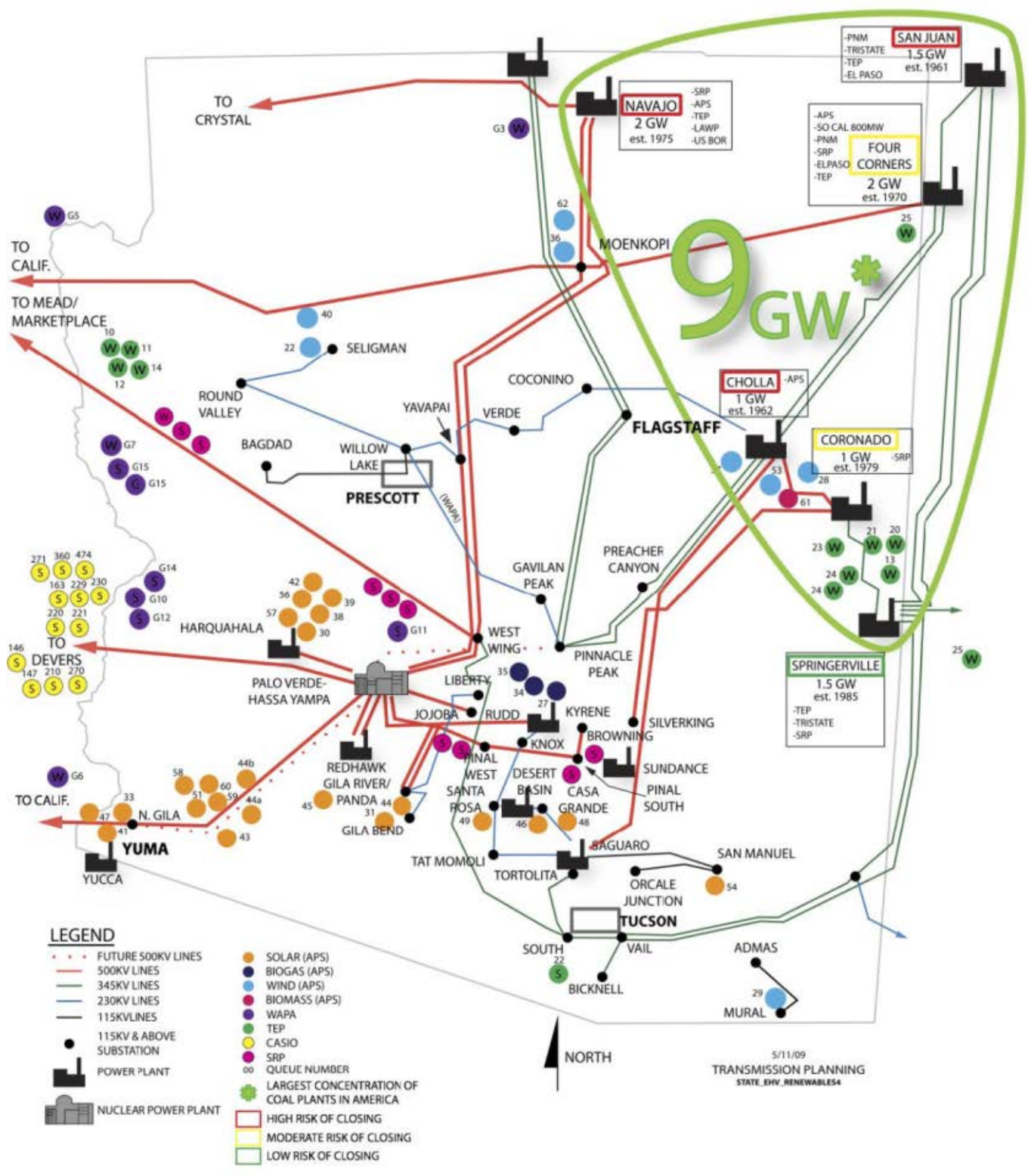

Figure 18. Power distribution in Arizona [24].

As shown in Figure 19, solar power plants are the largest renewable resource in Arizona, with the plants located primarily in the southwest corner of the state due to higher solar radiation and high population density. The aquifer in the northeast side of the state shown in Figure 20 contains 250 million acre-feet of brackish ground water. This aquifer could potentially provide up to 180 million acre-feet of fresh water. For this study, a $600 \mathrm{MWt}$ PWR and a 45 MWe reverse osmosis desalination plant are assumed to be constructed in the northeast region of Arizona. The selected renewable energy source is solar PV power co-located near the nuclear power plant. The RO desalination plant can fluctuate between 15 to $45 \mathrm{MWe}$ to enable the penetration of the same amount of solar energy. This will produce 22,425 to $56,377 \mathrm{~m}^{3} / \mathrm{hr}$ of water, which provides the daily water needs for 0.95 to 2.85 million people. Furthermore, if the candidate NHES is built, replacement of coal power plants with nuclear could provide high quality jobs with a corresponding need for higher education for those on the reservation. 


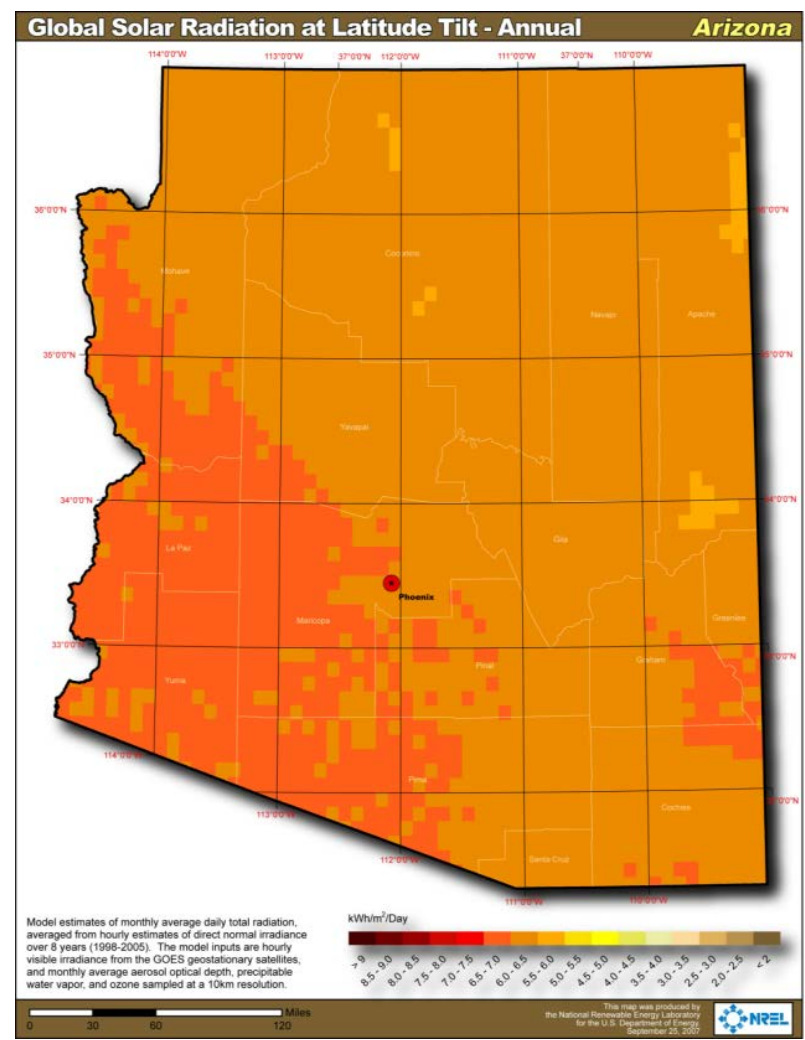

Figure 19. Solar radiation in Arizona [25].

ERROL L. MONTGOMERY \& ASSOCIATES, INC.

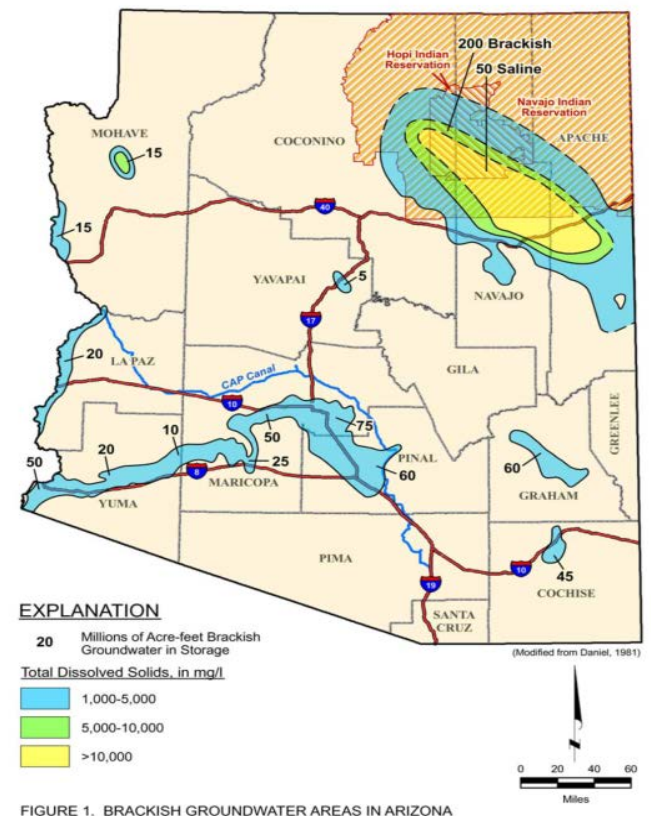

FIGURE 1. BRACKISH GROUNDWATER AREAS IN ARIZONA

Figure 20. Brackish groundwater locations in Arizona [26]. 


\subsubsection{Equipment layout}

Figures 21 to 23 show the process diagrams of NHES_Arizona, which include the following main components:

- $600 \mathrm{MWt}$ heat generation plant, consisting of a nuclear SMR and a steam generator that generates steam for electricity generation, denoted as PHG;

and $\mathrm{BOP}$ as follows:

- series of three steam turbines paired with an electrical generator that converts steam into electricity, denoted as TEC,

- renewable power generation produced by PV solar stations, with capability of up to $30 \mathrm{MWe}$, denoted as REN (renewable). This relatively-small renewable power generation was selected to accordingly correspond to the selected nominal capacity for the fresh water production plant (FWPP). Greater levels of renewable integration is possible by accordingly modifying this initial NHES configuration

- electrical storage (i.e., a system-scale battery set) used for power smoothing of the electricity generated by the renewable source (i.e., PV solar power), denoted as ESE,

- FWPP able to utilize electricity up to $45 \mathrm{MWe}$, and convert saline or brackish water into fresh water and brine,

- enough saline or brackish feedwater to support the fresh water production plant,

- electric grid connected to the NHES at a point of common coupling and consuming electricity up to 165 MWe.

An inspection of Figure 21 indicates a mis-match in component scale (e.g., a SMR of $180 \mathrm{MWe}$, assuming 30\% thermal-to-electrical efficiency, pairing with a wind farm of $45 \mathrm{MWe}$ ). This particular component scale was selected considering the anticipated water needs in the Arizona region. FWPP can be expanded as the need for fresh water increases and renewable energy is phased in. 


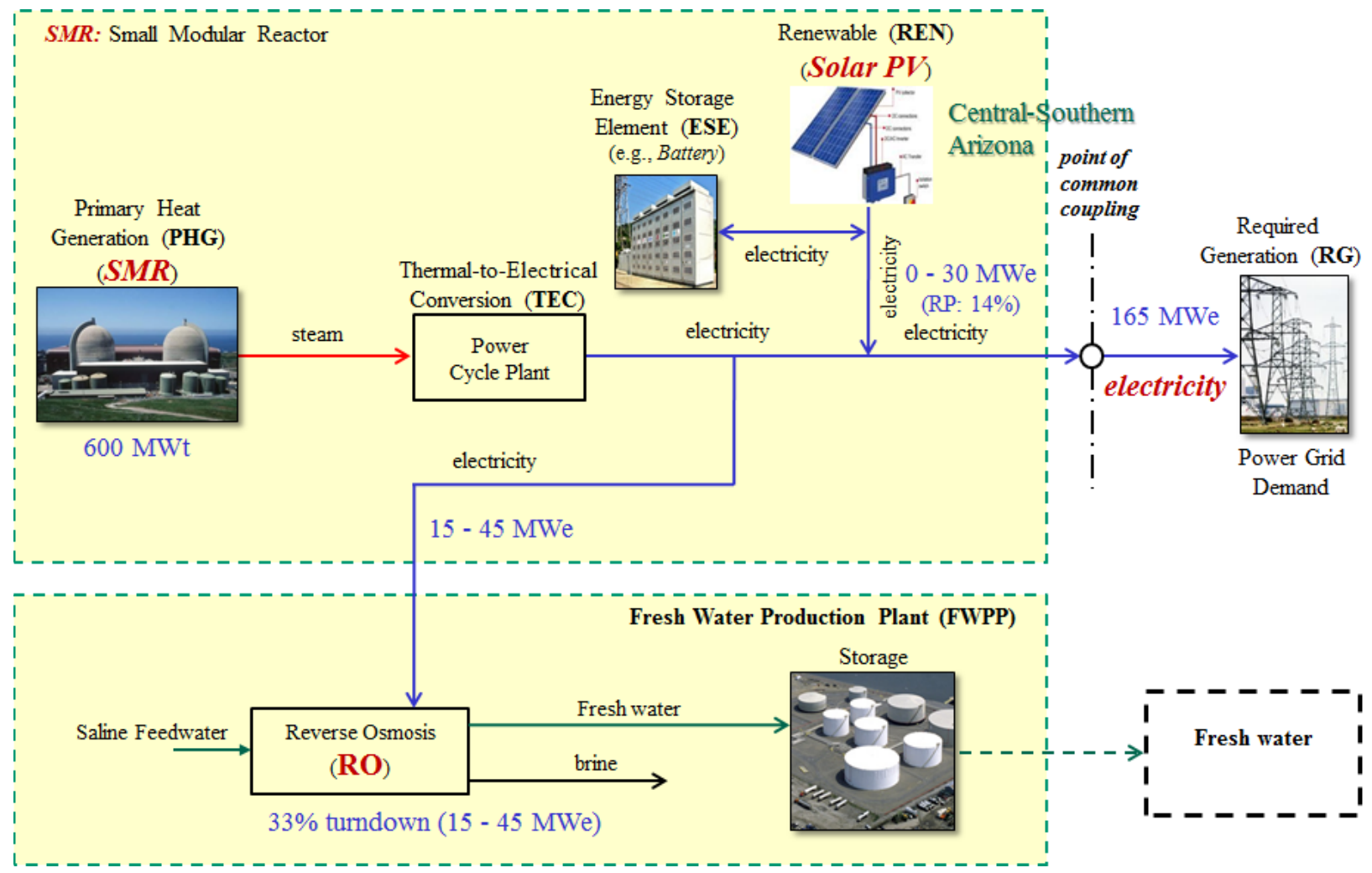

Figure 21. Network topology for NHES_Arizona with a flexible electrical load.

While sufficient for this preliminary analysis, a closer inspection of Figure 22 reveals the relative simplicity of the equipment configuration in the power cycle selected for modeling NHES_Arizona, as compared to a typical equipment configuration for an actual design. For example, a typical power cycle would include a series of feedwater heaters and pumps whereas the model for this study incorporates only one of each. Furthermore, heating of the feedwater flow may be more often accomplished using bleed steam tapped from the steam turbines. While the simple strategy shown in Figure 22 for heating the feedwater flow was selected in order to use models already available in the toolset, thus allowing more time to focus on the integration of the various component models, it does result in a significant penalty in the overall thermal-to-electrical efficiency for the modeled power cycle. Having demonstrated the integration of component models, improved models and more realistic and thermally efficient configurations are envisioned for future efforts. It is important to notice though that the dynamic technical performance of NHES_Arizona is anticipated to remain essentially unchanged after incorporating an improved feedback heating strategy. A consequence of using an improved strategy will manifest in a more favorable economic performance as more thermal energy would become available for producing electricity and fresh water (or, alternatively, in the ability of using a smaller nuclear reactor with accordingly lower capital and operational costs). 


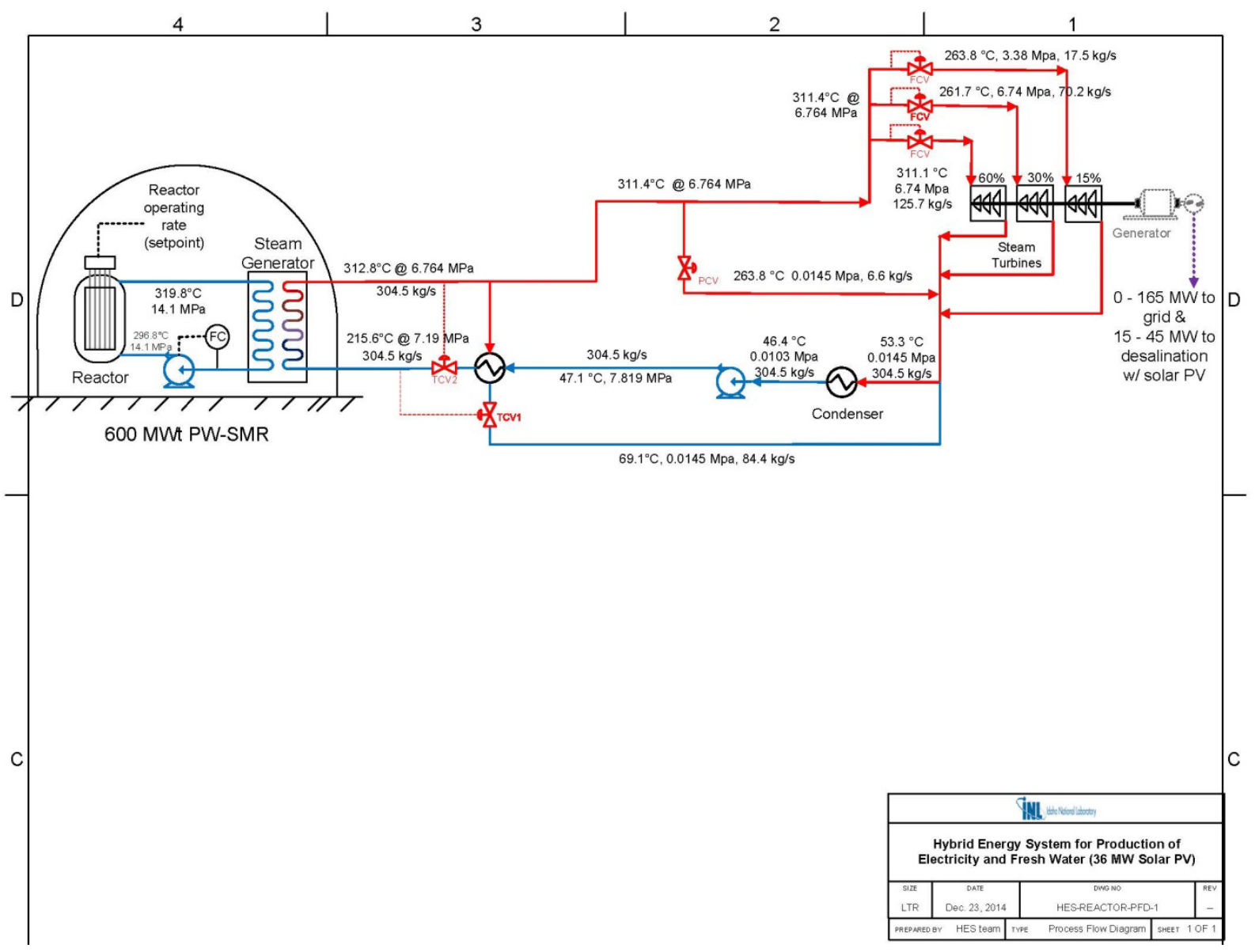

Figure 22. Process flow diagram for NHES_Arizona: nuclear and power cycle. 


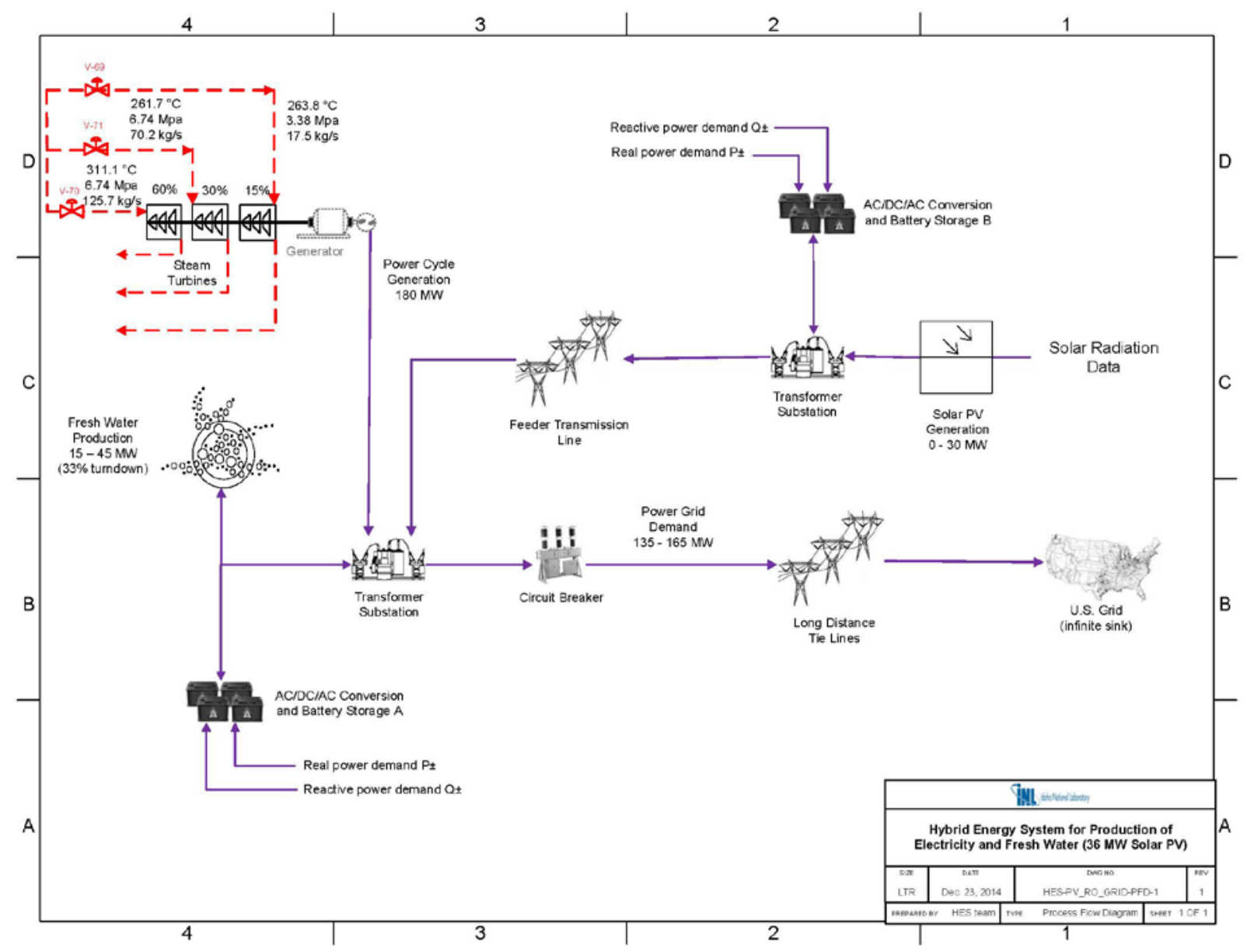

Figure 23. Process flow diagram for NHES_Arizona: PV solar, battery, desalination plant, grid.

As indicated in Figures 21 and 22, the current configuration differs from NHES_Texas in that there is only one steam generation cycle in NHES_Arizona. The process steam coming out of the steam generator is exclusively directed to the power cycle for electricity production, with a typically small amount bypassed through a PCV in case of pressure deviation, both of which are merged together before being condensed into water, and delivered as feedwater to the steam generator. These form the only steam cycle in NHES_Arizona, preserving the steam flow mass in the system.

\subsubsection{Components}

PHG is the primary source of energy in NHES_Arizona. PHG includes a nuclear reactor generating heat according to the reactor operating rate (see Figures 21 and 22), and a steam generator, which transfers heat to the feedwater coming from the BOP. The outflow of the steam generator (i.e., superheated steam) is then delivered to the power cycle to drive a series of three steam turbines paired with an electrical generator in order to produce the required additional electricity to meet the demands from both the electric grid and the water desalination plant, considering contribution from the renewable generation. As indicated previously, the superheated steam is wholly directed into the power cycle unless there is pressure deviation, in which case a small amount of steam is diverted through a PCV, bypassing the TEC system. Similar to the case of NHES_Texas, the nuclear reactor is sized for full-load operation, i.e., $600 \mathrm{MWt}$. 
The TEC system is the primary source of electricity generation in NHES_Arizona. It includes the following components:

- $\quad \mathrm{PCV}$ to maintain the desired pressure of the steam supplied to the steam turbines;

- two (2) TCV to maintain the temperatures of the steam generator inlet and outlet flows, with associated feedwater heater;

- $\quad$ three (3) throttle FCV to ensure that mechanical power generated by the turbines matches the required electricity generation imposed by a supervisory controller;

- $\quad$ series of three (3) steam turbines, each designed at different rated capacities, paired with an electrical generator,

- condenser for steam-to-water conversion,

- electrical generator.

Note that as shown in Figures 21 to 23, NHES_Arizona is operated in a manner such that the electricity produced by the power cycle and the PV solar stations are managed by a supervisory controller and distributed to the electric grid and the water desalination plant according to their individual needs and an optimal strategy determined by an operations optimizer (supporting economic optimization for operations) based on multiple factors including market price of each product. Because their fuel is free, renewable energy sources are typically held at maximum available output and are not required to operate at lower-than-maximum output, as this would not be cost effective for renewable generation plants under current energy market rules. Therefore, the renewable energy (i.e., PV solar energy) is treated in this study as a must-take input (i.e., no renewable curtailment) to NHES_Arizona and consists of a series of PV solar units with a maximum generation capacity of $30 \mathrm{MWe}$. This renewable generation is usually characterized by high variability, intermittency, and non-dispatchability. Consequently, as shown in Figures 21 to 23, it is introduced via an electric battery to perform power smoothing, thus mitigating the renewable's high variability.

As shown in in Figures 21 and 23, the FWPP uses electricity produced by the power cycle and the PV solar units to convert saline or brackish water into fresh water. The required electricity consumption set point sent to FWPP is regulated by a supervisory controller according to the individual need and an optimal strategy selected based on multiple factors, such as market price of each commodity. In particular, the FWPP considered in NHES_Arizona consists of the following unit operations:

- pre-process unit to coarsely remove impurities in saline water,

- $\quad$ set of tanks and pumps to push water towards reverse osmosis (RO) membranes,

- RO membranes to diffuse water from brine,

- $\quad$ post-process unit for fresh water treatment.

The connection of NHES_Arizona to the electric grid is similar to that devised for NHES_Texas; hence, no additional description is provided here.

\subsubsection{Controls}

NHES_Arizona exploits the same hierarchal control strategy as that described for NHES_Texas, as illustrated in Figure 6. This strategy dynamically determines the amount of electricity that needs to be diverted to the water desalination plant and updates the local controller accordingly (e.g., change the set point, update the control gain) to ensure the electricity distributions into the electric grid versus the FWPP meet the supply requirements.

Numerous feedback controllers are augmented as low-level controllers to maintain desired conditions, such as temperature, flow rate, or pressure of steam flows in various parts of the steam cycle. As can be 
seen in Figure 22, the pressure in the steam cycle is controlled by a PCV, regulating the steam flow that is bypassing the TEC system. The flow into the steam turbines is controlled by three FCV, one for each steam turbine. These three FCV work accordingly to guarantee the power cycle generates the precise amount of electricity needed, which is full load production in this case. The steam going through the steam turbines and the steam bypassing the TEC system are merged together, before it is condensed into water, which is heated to $215.6^{\circ} \mathrm{C}$ before feeding it into the steam generator. This is accomplished by a heat exchanger under temperature control valve (TCV1) regulation. The feedwater flow into the steam generator is regulated by a second temperature control valve (TCV2), which maintains the temperature of the outflow steam of the steam generator at desired value of $312.8^{\circ} \mathrm{C}$. Table 4 partially summarizes the low level controllers and supervisors used in NHES_Arizona.

Table 4. Controllers in NHES_Arizona.

\begin{tabular}{|l|l|c|}
\hline Name & Functionality & \# of Use \\
\hline Feedwater Pump Control & Maintain necessary pressure head & 1 \\
\hline Flow Control Valve (FCV) & Regulate flow rate & 4 \\
\hline Pressure Control Valve (PCV) & Regulate flow pressure & 2 \\
\hline Temperature Control Valve (TCV) & Regulate flow temperature & 1 \\
\hline Power Control & Regulate SMR power & 1 \\
\hline Turbine Admission Valve Governor & Regulate throttle valves & 1 \\
\hline Power cycle Supervisor & Regulate power cycle & \\
\hline
\end{tabular}

\subsubsection{Operations}

There are two units for electricity generation in NHES_Arizona; namely, the TEC system, which includes a series of three steam turbines pairing with an electrical generator, and REN, which is a set of PV solar units coupled with an electrical battery. These two electricity generation units are operated accordingly to deliver the electricity generation requested by the electric grid operator (e.g., an ISO, RTO) or by the operations optimizer (supporting economic optimization for operations). In either case, the power delivered to the electric grid is assumed to be less than or equal to $165 \mathrm{MWe}$. This electricity production is the first output of NHES_Arizona. The second output is fresh water, which is produced by the desalination plant from electricity distributed by the supervisory controller. Unlike the case of NHES_Texas where an AHG is used to compensate for the variability of the steam flow delivered by the nuclear reactor to the chemical plant, here the electricity consumed by the water desalination plant is supplied by the nuclear power plant transmission system. The water desalination plant has a capacity of $45 \mathrm{MWe}$, but is operated to maintain a minimum electricity consumption of $15 \mathrm{MWe}$. The nuclear reactor is sized for full load operation, i.e., $600 \mathrm{MWt}$, such that it is capable of generating (without renewable contribution) sufficient process steam to meet the maximum electric grid demand (i.e., $165 \mathrm{MWe}$ ) plus the minimum consumption for desalination operations (i.e., $15 \mathrm{MWe}$ ). This amounts to an overall thermal-to-electrical efficiency of $30 \%$. Recall that when a more realistic and thermally efficient feedwater heating strategy is modeled, this efficiency is anticipated to significantly increase as mentioned before. Under the extreme situation that the electric grid requests from this NHES a constant electricity generation of $165 \mathrm{MWe}$ in the absence of renewable contribution, the electrical power provided to the water desalination plant is just $15 \mathrm{MWe}$; in the event of non-zero renewable contribution, the desalination plant may be then operated beyond the minimum of $15 \mathrm{MWe}$ under the guidance of a supervisory controller. 
In summary, the power cycle and PV solar units generate electricity accordingly to meet the demand imposed by the electric grid as well as by the variable electrical load consumed by the water desalination plant. The distribution of electricity to the electric grid versus FWPP is subject to a supervisory controller and varies with respect to the renewable generation. In the worst case scenario, the water desalination plant would produce approximately $40 \%$ of its maximum fresh water production. This is contrary to the NHES_Texas case, in which the gasoline production plant is maintained at a full production mode regardless of the absence of the renewable contribution. By enabling the water desalination plant to use excess electricity, NHES_Arizona provides opportunities for flexible energy management, providing various ancillary services, such as operating reserves (e.g., regulating, ramping, load following, and supplemental reserves), and attractive operational flexibility for value (technical and/or economic) optimization.

NHES_Arizona can increase or decrease its electricity production when requested in order to provide ancillary services. For example, if the electricity production is $160 \mathrm{MWe}$ at a given time with $10 \mathrm{MWe}$ coming from the PV solar units, then NHES_Arizona can potentially increase or decrease electricity production to as high as $175 \mathrm{MWe}$ or as low as $145 \mathrm{MWe}$, respectively. Accordingly, the water desalination plant would be operated at its minimum or full production mode consuming $15 \mathrm{MWe}$ to $45 \mathrm{MWe}$. In other words, assuming a $10 \mathrm{MWe}$ constant PV solar contribution, NHES_Arizona can accept a change of up to $30 \mathrm{MWe}$ in its electricity production, a capacity that is large enough to bid into ancillary service market. Furthermore, since the water desalination plant can be operated at its minimum turndown for as long as requested, NHES_Arizona can maintain the change in its electrical production for large time periods.

\subsubsection{Dynamic models}

Similar to NHES_Texas, the Modelica modeling language, the MSL, and the ThermoPower library are used, with Dymola used as M\&S environment, to build the dynamic model of the selected NHES Arizona.

Figure 24 shows the top-level model for NHES_Arizona. As seen from this screen-capture, twelve main subsystems can be identified as follows:

\section{$\underline{\text { Physical devices }}$}

1. Nuclear SMR

2. Feedwater heater and thermal distribution center

3. Power generation

4. Reverse osmosis water desalination plant

5. PV solar generation

6. Battery-based power smoothing

7. Electric grid

Control devices

8. Governor

9. Power cycle supervisor

10. Many low-level controllers (embedded within corresponding subsystems; not shown)

11. Control bus

Evaluation Module

12. System evaluation (used to facilitate evaluation of multiple scenarios 
Each of these subsystems includes a number of components. Detailed subsystem description is beyond the scope of this report. Additional details will be available in associated publications that are currently in progress.

Table 5 provides a partial list of the sensor signals and control commands that are communicated through the control bus.

Table 5. Partial list of signals communicated via control bus in NHES_Arizona.

\begin{tabular}{|l|l|l|l|}
\hline Signal name & Signal type & Source Module & Destination Module \\
\hline Battery on/off command & command & Power cycle supervisor & $\begin{array}{l}\text { Battery-based power } \\
\text { smoothing }\end{array}$ \\
\hline $\begin{array}{l}\text { Amount of renewable } \\
\text { generation }\end{array}$ & measurement & $\begin{array}{l}\text { Battery-based power } \\
\text { smoothing }\end{array}$ & Power cycle supervisor \\
\hline Amount of grid consumption & measurement & Electric grid & Power cycle supervisor \\
\hline Turbine generation set point & command & Power cycle supervisor & $\begin{array}{l}\text { Governor \& } \\
\text { Power generation }\end{array}$ \\
\hline Actual turbine generation & measurement & Turbine generator & Governor \\
\hline Electricity frequency & measurement & Turbine generator & Governor \\
\hline Valve opening set points & command & Governor & Power generation \\
\hline $\begin{array}{l}\text { RO power consumption set } \\
\text { point }\end{array}$ & command & Power cycle supervisor & $\begin{array}{l}\text { Reverse osmosis } \\
\text { desalination plant }\end{array}$ \\
\hline RO power consumption & measurement & $\begin{array}{l}\text { Reverse osmosis } \\
\text { desalination plant }\end{array}$ & Power cycle supervisor \\
\hline
\end{tabular}




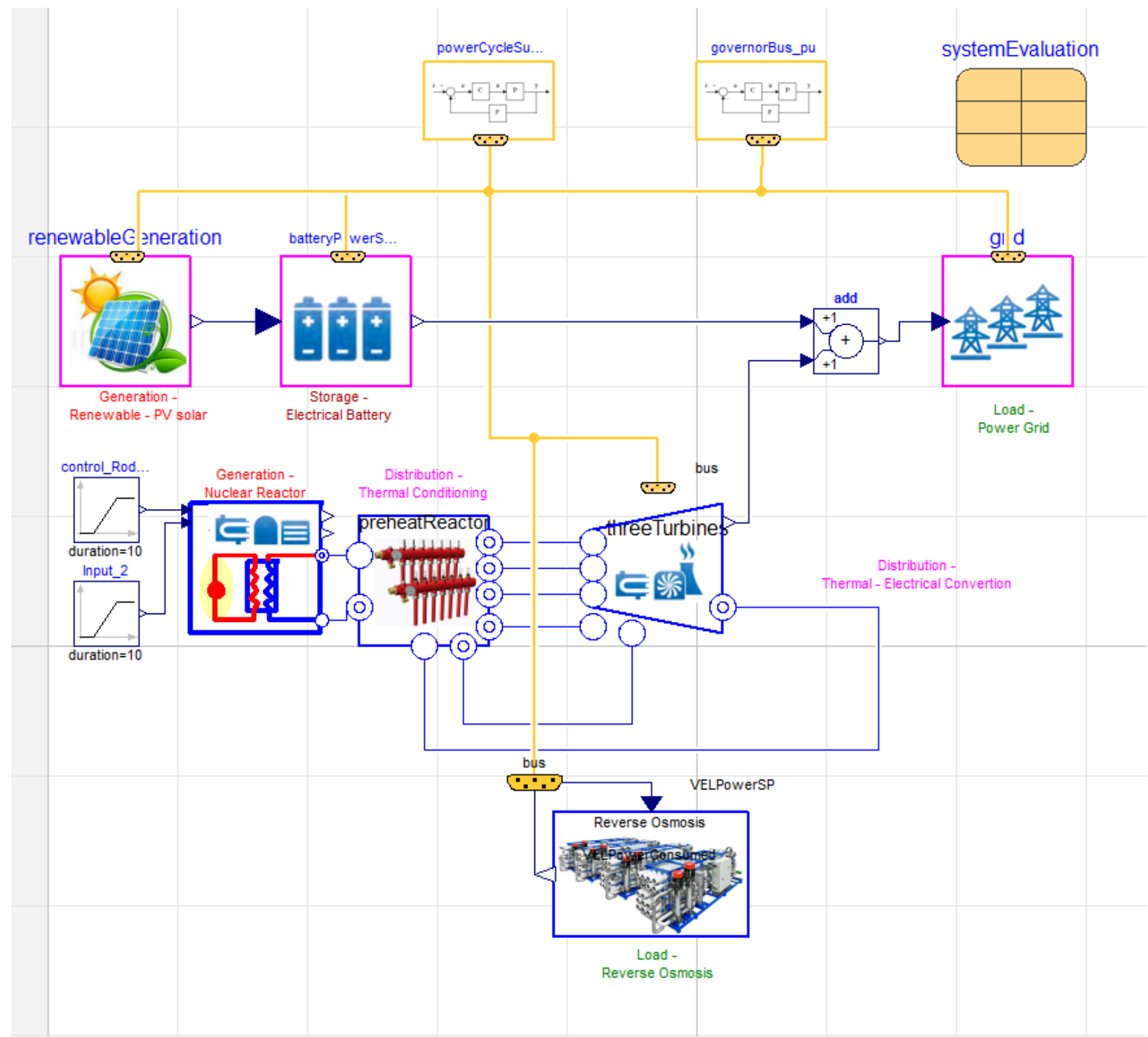

Figure 24. Top-level model for NHES_Arizona in Modelica.

Figure 25 shows the top-level for FWPP to provide a brief description of one of the subsystems implemented for NHES_Arizona. 


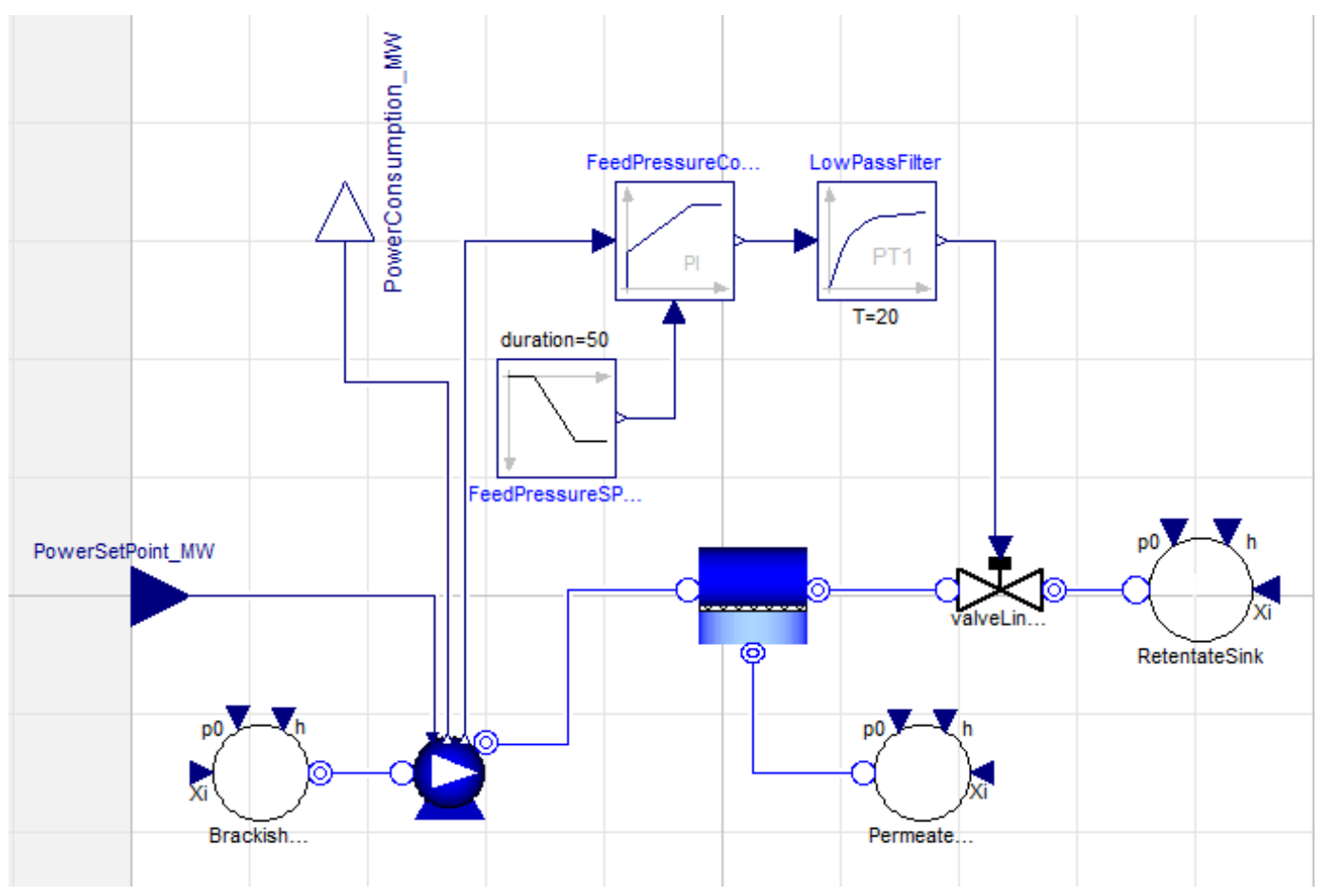

Figure 25. Top-level model for FWPP used in NHES_Arizona in Modelica.

In particular, desalination is one of the solutions to bridge the gap between drinking water supply and demand. Desalination technologies can be broadly categorized as thermal (phase change) and membrane (non-phase change) processes. Within those two types, there are sub-categories depending on different techniques, including multi-stage flash (MSF), multi-effect, and vapor compression distillations, electro-dialysis, and reverse osmosis (RO). Of the various methods used for desalination, RO is the predominant means of producing fresh water throughout the world. In the Middle East, however, MSF is the mainstream method due to advantages in operating cost and its low energy requirements.

The RO process uses a semi-permeable membrane, which allows water to pass through but not salts, to separate the fresh water from the saline feed water. As illustrated in Figure 26(a), a typical brackish water reverse osmosis (BWRO) plant consists of four main components: feed water pre-treatment, high-pressure pumping, membrane separation, and permeate post-treatment. In this work, the modeling efforts are focused on the two components (i.e., high-pressure pumping and membrane separation) enclosed in the dashed box shown in Figure 26(a). Figure 26(b) depicts the configuration of an RO vessel used in BWRO, which is typically comprised of six to eight membrane models connected in series. These pressure vessels are arranged in rows in each membrane stage, with two-stage membrane separation being typical. Each stage has a recovery of 50-60\%, achieving an overall system recovery of $70-85 \%$. Figure 27 shows the Modelica model of the BWRO unit. 


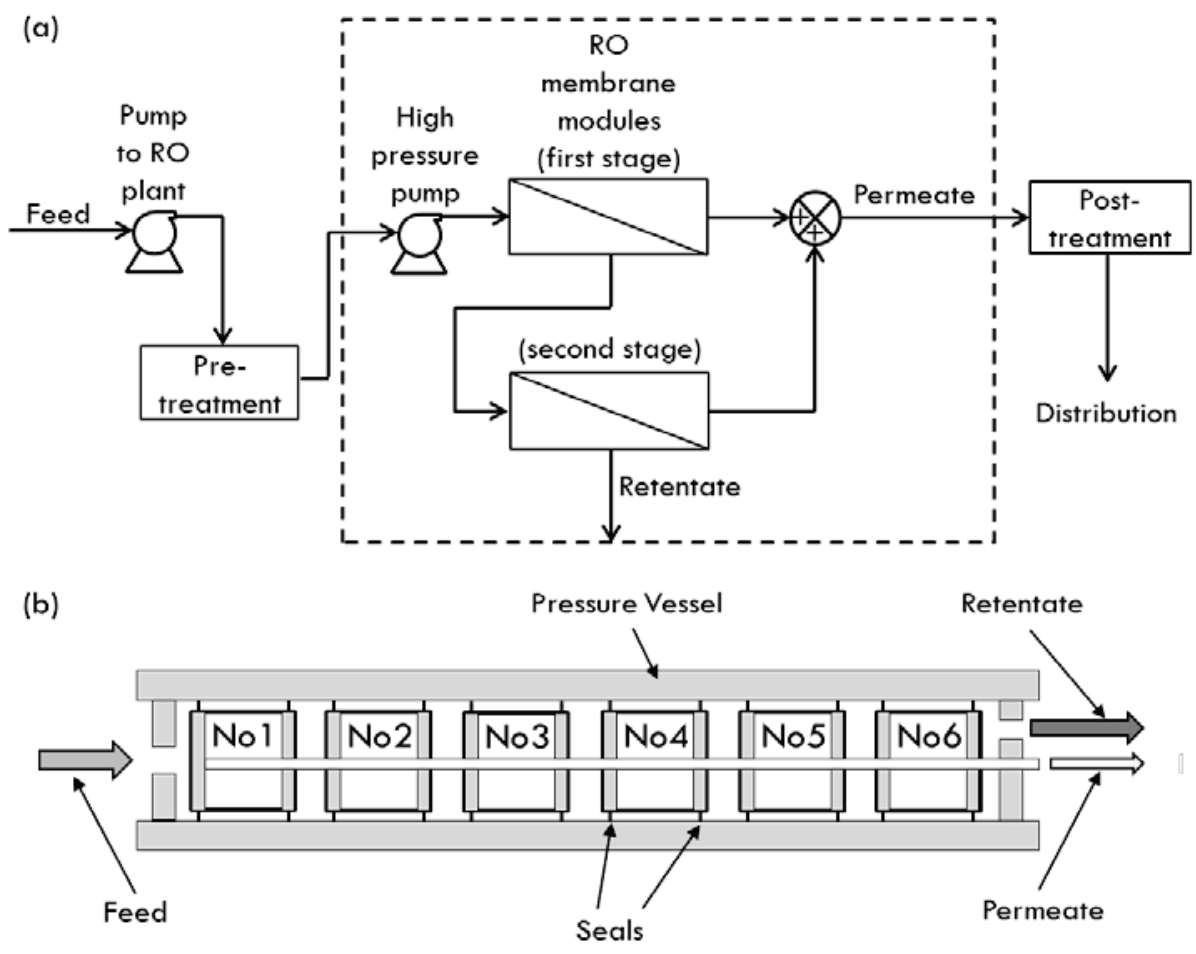

Figure 26. BWRO desalination process: (a) Process flow diagram for a two-stage BWRO plant. (b) Schematic of an RO vessel.

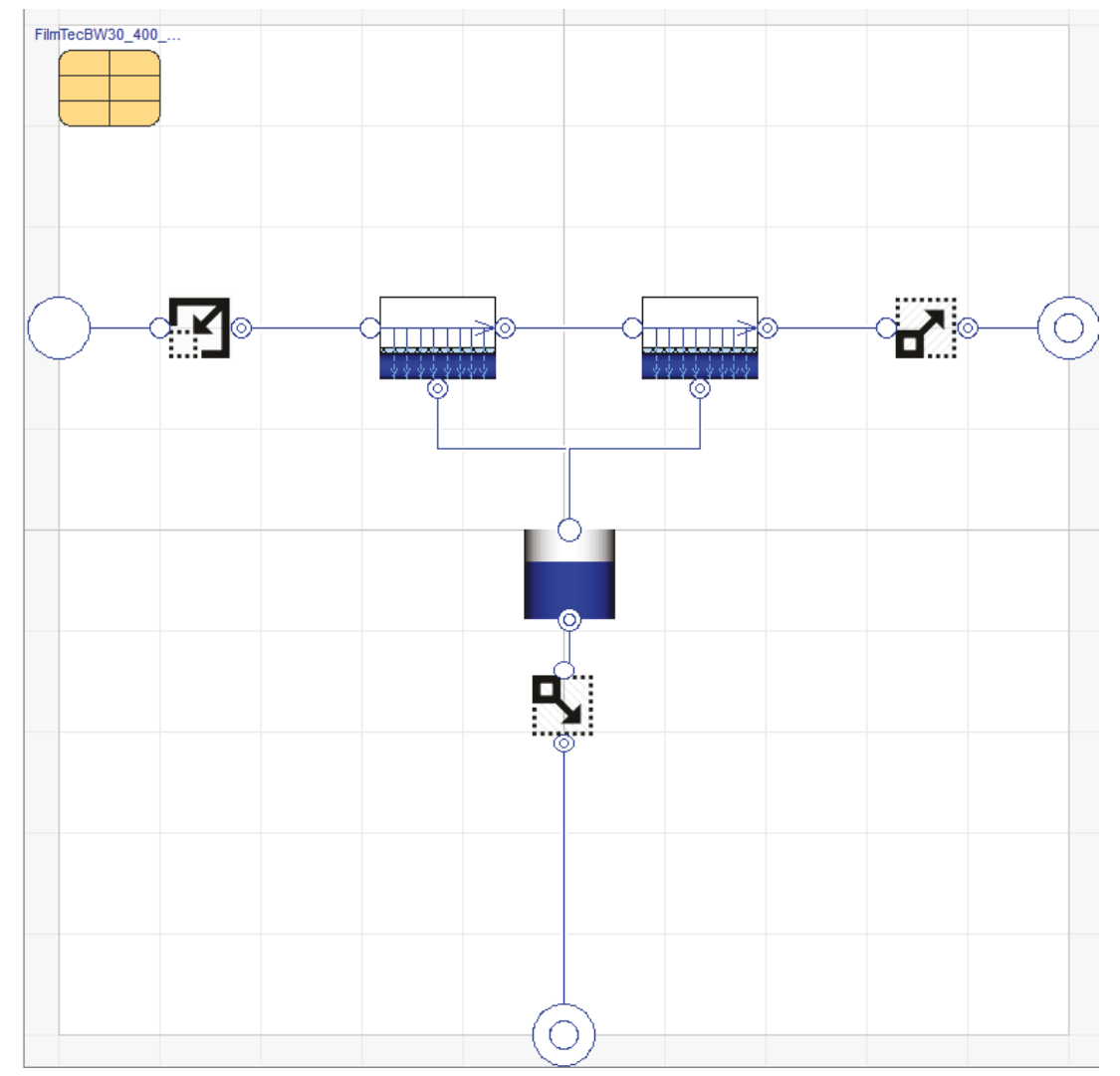

Figure 27. Top-level model of the BWRO unit in Modelica. 
The BWRO desalination plant is sized for $56,380 \mathrm{~m}^{3} / \mathrm{hr}$ (357 million gallons per day [MGPD]) capacity, about four times the size of one of the current largest seawater RO desalination systems [27]. At this capacity, the plant consumes $45 \mathrm{MWe}$ of electrical power to generate the required feed pressure (16.5 barg) for desalting the brackish water, containing 3,500 part per million (ppm) of total dissolved solids (TDS). The assumed values for the simulation parameters used in the case study are listed in Table 6. The FilmTech BW30-400 membrane, a spiral-wound membrane manufactured by Dow Chemical, is chosen for simulation; its specifications can be found in [28].

Table 6. Parameters for the RO process simulation.

\begin{tabular}{|l|l|}
\hline Parameter & Value \\
\hline Number of HP feed pumps, each of which is rated at 1MWe & 45 \\
\hline Pump efficiency & 0.8 \\
\hline Pump speed [RPM] & 1,800 \\
\hline Number of stages & 2 \\
\hline Number of pressure vessels & 9,900 \\
\hline Number of RO elements in a pressure vessel & 6 \\
\hline Fouling of an RO membrane due to scale formation [\%] & 5 \\
\hline Feed temperature $\left[{ }^{\circ} \mathrm{C}\right]$ & 25 \\
\hline Feed salinity ${ }^{2}[\mathrm{ppm}]$ & 3,500 \\
\hline Feed pressure $[\mathrm{barg}]$ & 16.5 \\
\hline Permeate flow rate $\left[\mathrm{m}^{3} / \mathrm{hr}\right](\mathrm{MGPD})$ & $56,380(357)$ \\
\hline Average permeate salinity [ppm] & 60 \\
\hline Recovery ratio (ratio of permeate flow rate to feed flow) [\%] & 72 \\
\hline
\end{tabular}

${ }^{a}$ Of the various possible dissolved components in feed stream, the only components considered in this study were $\mathrm{Na}^{+}$and $\mathrm{Cl}$, i.e., in the feed stream, the mass concentration of TDS is the same as that of $\mathrm{NaCl}$.

In this work, the emphasis is on dynamic simulation and control of RO desalination process over the full range of operating conditions. A 1-D dynamic model was developed to describe flow in the axial direction for both the feed and permeate sides by incorporating the overall fluid and solute mass balance equations as follows:

$$
\begin{aligned}
& V_{B} \frac{d \rho_{b}}{d t}=Q_{f} \rho_{f}-Q_{r} \rho_{r}-Q_{p} \rho_{p} \\
& V_{B} \frac{d C_{b}}{d t}=Q_{f} C_{f}-Q_{r} C_{r}-Q_{p} C_{p}
\end{aligned}
$$

where $Q, C$, and $\rho$ refer to the volumetric flow rate, salt concentration, and density of the solution, respectively. Subscripts $f, r, p$, and $b$ refer to the feed, retentate, permeate, and bulk (average between the feed and retentate) streams, respectively. $V_{B}$ is the brine channel volume of an RO element. Also, the solution-diffusion model modified with the concentration polarization theory is applied to predict RO performance [28].

Note that, as in the NHES_Texas case, since the power smoothing effect of the electric battery is modeled as a first order different equation, the smoothing frequency discussed earlier can be represented as the inverse of the time constant of the battery power smoothing, i.e., $\tau_{E S E}$, which is selected as a variable in the dynamic performance analysis presented in the following sections. 


\section{TECHNICAL AND ECONOMIC PERFORMANCE ANALYSIS}

Numerous tests were carried out to characterize the dynamic technical and economic properties of the two regional HES configurations, to compute several technical and economic FOM, and to demonstrate their capability to manage high levels of renewable penetration, while supporting multiple commodity production and ancillary services. Such enhanced understanding of the dynamic characteristics of these advanced energy systems can assist policy makers, as well as designers and engineers, to best devise practical solutions for accommodating the high variability of renewable generation and for effectively working towards increased use of clean energy.

\subsection{Figures of Merit and Economic Optimization for Operations}

\subsubsection{Technical figures of merit}

The technical FOM considered in this preliminary dynamic study are those typically relevant for electric grid applications. These include:

- Electric power frequency stability

- Maximum renewable penetration that can be accommodated

- Maximum renewable variability that can be accommodated

- Minimum storage requirement

- Response time and ramp-rate

- Load following response

- Operating reserve capacity

- Minimum turndown of integrated systems

- Startup/shutdown time

In particular, the system technical performance is evaluated in terms of the FOM listed above, observing in all cases the variation of the electric power frequency. Consequently, time series of the electric power frequency (or equivalently, turbine shaft speed) are analyzed and at times plotted when deemed productive to show the high quality of electrical frequency regulation provided by the NHES configurations. Furthermore, the production rate of alternative commodities and/or their quality (e.g., salinity of the fresh water product) are also used as performance indicators. Dynamic characteristics of the NHES configurations are also measured in terms of response time and other metrics relevant to ancillary services. For instance, the response time by which the considered NHES configuration is capable of redistributing energy following a renewable/demand change is tested and compared to the operational requirements for participation in wholesale market services.

Likewise, the ancillary service markets explored in this report also include load following, spinning and non-spinning reserves, and supplemental reserves [29-31]. Regulation provides real-time adjustments to maintain the desired frequency and requires response time and ramp-rate on the minute timescale and must be maintained for 15 minutes at a time [31]. Load following matches the real time demand, requires roughly 10 minutes response time and must be maintained for 10 minutes to several hours [31]. Spinning reserve and non-spinning reserve are additional capacity that is available in the event of a generator failure or other contingency. Spinning reserve requires immediate response and a total response time less than 10 minutes and must be maintained for up to 2 hours [31]. Non-spinning reserve does not require immediate response but has the same requirements in total response time and duration as spinning reserve [31]. Supplemental reserve must respond in less than 30 minutes and be maintained for 3 hours. As shown in this report, the selected NHES configurations can respond sufficiently fast and for sufficiently long duration, to participate in the ancillary service market. 


\subsubsection{Economic figures of merit and optimization for operations}

The economic FOM considered are those typically relevant for economic analysis of energy systems:

- Pre-tax Gross Profit (PGP)

- $\quad$ Net Present Value (NPV)

- Payback time

- Internal Rate of Return (IRR)

As discussed previously, the selected NHES configurations can be controlled during operation to optimize under operational control for optimizing a given technical and/or economic value. In this report, only economic optimization during operations is considered. Depending on which economic metrics and NHES configurations are considered, different approaches for economic optimization for operations were devised, as it will be discussed. In particular, PGP for NHES_Texas $\left(\mathrm{PGP}_{\mathrm{TX}}\right)$ is defined as shown in Eq. (4), where Table 7 lists the variables used in the optimization problem formulation.

$P G P_{T X}=P_{e} \beta_{e}+M_{g} \beta_{g}-\left(M_{N G_{-} A H G}+M_{N G \_G P P}\right) \beta_{N G}-M_{W} \beta_{W}-M_{C} \beta_{C}$

Table 7. Variables used in the economic optimization for operations: NHES_Texas.

\begin{tabular}{|l|l|l|}
\hline PHG generation & $\mathrm{P}_{\mathrm{phg}}$ & $\mathrm{MW}$ \\
\hline Renewable contribution & $\mathrm{P}_{\mathrm{w}}$ & $\mathrm{MW}$ \\
\hline Electricity production & $\mathrm{P}_{\mathrm{e}}$ & $\mathrm{MW}$ \\
\hline Electricity price & $\beta_{\mathrm{e}}$ & $\$ / \mathrm{MW}-\mathrm{s}$ \\
\hline Gasoline production & $\mathrm{M}_{\mathrm{g}}$ & $\mathrm{kg} / \mathrm{s}$ \\
\hline Gasoline price & $\beta_{\mathrm{g}}$ & $\$ / \mathrm{kg}$ \\
\hline GPP rated power & $\mathrm{P}_{\mathrm{g}}$ & $\mathrm{MW}$ \\
\hline PHG contribution to GPP & $\mathrm{P}_{\mathrm{T}}$ & $\mathrm{MW}$ \\
\hline NG consumption by AHG & $\mathrm{M}_{\mathrm{NG}_{\_} \mathrm{AHG}}$ & $\mathrm{kg} / \mathrm{s}$ \\
\hline NG consumption by GPP & $\mathrm{M}_{\mathrm{NG}_{-} \mathrm{GPP}}$ & $\mathrm{kg} / \mathrm{s}$ \\
\hline NG price & $\beta_{\mathrm{NG}}$ & $\$ / \mathrm{kg}$ \\
\hline Water consumption & $\mathrm{M}_{\mathrm{W}}$ & $\mathrm{kg} / \mathrm{s}$ \\
\hline Water price & $\beta_{\mathrm{W}}$ & $\$ / \mathrm{kg}$ \\
\hline GHG emission (CO ${ }_{2}$ in this case) & $\mathrm{M}_{\mathrm{C}}$ & $\mathrm{kg} / \mathrm{s}$ \\
\hline GHG penalty & $\beta_{\mathrm{C}}$ & $\$ / \mathrm{kg}$ \\
\hline AHG emission rate & $\gamma$ & 1 \\
\hline Coefficients for NG consumption & $\mathrm{k}_{0}, \mathrm{k}_{1}$ & $\mathrm{~kg} / \mathrm{s}, \mathrm{kg} / \mathrm{s} / \mathrm{MW}$ \\
\hline Real Discounted Free Cash Flow to Firm & $F C F F_{R, k}$ & 1 \\
\hline Discounted rate & $r_{R}$ & 1 \\
\hline Tax rate & $t a x$ & 1 \\
\hline Revenue from sales & $R_{k}$ & $\$$ \\
\hline Operations \& Maintenance & $O \& M_{k}$ & $\$$ \\
\hline Depreciation Amortization & $D A_{k}$ & $\$$ \\
\hline Inflation rate & $i$ & 1 \\
\hline Penalty for Greenhouse Gases & $G H G_{k}$ & $\$$ \\
\hline Capital Expenditure & $C A P E X_{k}$ & $\$$ \\
\hline & & \\
\hline
\end{tabular}


As shown in APPENDIX A the optimization problem related to PGPTX reduces to the analytical solution in Eq. (5),

$P_{e}=\left\{\begin{array}{cc}P_{p h g} & \text { if } \beta_{e}-k_{1} \beta_{N G}-\gamma k_{1} \beta_{C}>0 \\ P_{p h g}+P_{w}-P_{g} & \text { otherwise }\end{array}\right.$

NPV is defined for NHES_Texas (NPV TX) in Eq. (6) ${ }^{\mathrm{c}}$, where Table 7 lists all the variables used in the optimization problem formulation.

$N P V_{T X}=\sum_{k=0}^{N} \frac{F C F F_{R, k}}{\left(1+r_{R}\right)^{k}}$

with

$$
F C F F_{R, k}=\left(R_{k}-O \& M_{k}-D A_{k}(1+i)^{-k}\right)(1-\operatorname{tax})+D A_{k}(1+i)^{-k}-G H G_{k}-C A P E X_{k}
$$

and

$$
D A_{k}=\rho_{d a, k} C A P E X_{0}
$$

As shown in APPENDIX A, the optimization problem related to NPV $\mathrm{TX}_{\mathrm{TX}}$ reduces to the following analytical solution:

$$
P_{e}=\left\{\begin{array}{cc}
P_{p h g} & \text { if }(1-\operatorname{tax})\left(\beta_{e}-k_{1} \beta_{N G}\right)-\gamma k_{1} \beta_{C}>0 \\
P_{p h g}+P_{w}-P_{g} & \text { otherwise }
\end{array}\right.
$$

Similarly, PGP is defined for NHES_Arizona $\left(\mathrm{PGP}_{\mathrm{AZ}}\right)$ in Eq. (7), where Table 8 lists all the variables used in the optimization problem formulation.

$P G P_{A Z}=P_{e} \beta_{e}+M_{f w} \beta_{f w}$

Table 8. Variables used in the economic optimization for operations: NHES_Arizona.

\begin{tabular}{|l|l|l|}
\hline PHG generation & $\mathrm{P}_{\mathrm{phg}}$ & $\mathrm{MW}$ \\
\hline Renewable contribution & $\mathrm{P}_{\mathrm{s}}$ & $\mathrm{MW}$ \\
\hline Electricity production & $\mathrm{P}_{\mathrm{e}}$ & $\mathrm{MW}$ \\
\hline Electricity price & $\beta_{\mathrm{e}}$ & $\$ / \mathrm{MW}-\mathrm{s}$ \\
\hline Fresh water production & $\mathrm{M}_{\mathrm{fw}}$ & $\mathrm{kg} / \mathrm{s}$ \\
\hline Fresh water price & $\beta_{\mathrm{fw}}$ & $\$ / \mathrm{kg}$ \\
\hline RO power consumption & $\mathrm{P}_{\mathrm{RO}}$ & $\mathrm{MW}$ \\
\hline RO power consumption - Lower limit & $\mathrm{P}_{\mathrm{ROL}}$ & $\mathrm{MW}$ \\
\hline RO power consumption - Upper limit & $\mathrm{P}_{\mathrm{ROU}}$ & $\mathrm{MW}$ \\
\hline Coefficients for power to fresh water relationship & $\mathrm{k}_{0}, \mathrm{k}_{1}, \mathrm{k}_{2}$ & $\mathrm{~kg} / \mathrm{s}, \mathrm{kg} / \mathrm{s} / \mathrm{MW}, \mathrm{kg} / \mathrm{s} / \mathrm{MW}^{2}$ \\
\hline
\end{tabular}

As shown in APPENDIX A, the optimization problem related to $\mathrm{PGP}_{\mathrm{AZ}}$ is re-formulated as follows: Maximize

$$
J=\int_{0}^{T} P_{e} \beta_{e}+M_{f w} \beta_{f w} d t
$$

${ }^{\mathrm{c}}$ C. Rabiti, B.S. Cherry, W.R. Deason, P. Sabharwall, S.M. Bragg-Sitton, R.D. Bardman. "Framework for the Economic Analysis of Hybrid Systems based on Exergy Consumption". INL Report, INL/EXT-14-32934. August 2014. 
Subject to (for all time $t$ )

$$
\begin{gathered}
P_{e}-P_{S}+P_{R O}=P_{p h g} \\
M_{f w}=k_{0}+k_{1} P_{R O}+k_{2} P_{R O}^{2} \\
P_{p h g}+P_{S}-P_{R O U} \leq P_{e} \leq P_{p h g}-P_{R O L}
\end{gathered}
$$

NPV is defined for NHES_Arizona $\left(\mathrm{NPV}_{\mathrm{AZ}}\right)$ similarly to NHES_Texas. Consequently and as shown in APPENDIX A, the optimization problem related to $\mathrm{NPV}_{\mathrm{AZ}}$ is reformulated as follows:

Maximize

$$
J=(1-\operatorname{tax}) \int_{0}^{T} P_{e} \beta_{e}+M_{f w} \beta_{f w}-\beta_{-} r o_{-} v M_{f w} d t
$$

Subject to (for all time $t$ )

$$
\begin{gathered}
P_{e}-P_{S}+P_{R O}=P_{p h g} \\
M_{f w}=k_{0}+k_{1} P_{R O}+k_{2} P_{R O}^{2} \\
P_{p h g}+P_{s}-P_{R O U} \leq P_{e} \leq P_{p h g}-P_{R O L}
\end{gathered}
$$

The payback time was determined by recording the time instance when the cumulative NPV for the considered NHES case equals zero. Finally, the IRR was defined herein as the value of discounted rate for which the NPV equals zero assuming an economic life of 30 years [15], excluding construction time.

\subsection{Test Plan}

\subsubsection{Impact of renewable penetration}

The renewable penetration (RP) is defined as the ratio of the maximum power generation delivered by REN (renewable) versus the maximum total power generation produced by both REN and PHG, all converted to the form of electrical power, and is defined as:

$$
R P:=\frac{\max _{\mathrm{t} \geq 0} E_{R E N}(t)}{\max _{\mathrm{t} \geq 0}\left[E_{R E N}(t)+E_{P H G}(t)\right]} \times 100 \%
$$

where $E_{R E N}(t)$ is the renewable power generation and $E_{P H G}(t)$ is power generation in terms of electrical power generated by the nuclear reactor at time $t$. This particular formulation for RP was selected over other possibilities to avoid assigning an ill-defined value whenever the denominator $E_{R E N}(t)+E_{P H G}(t)$ is zero at a given instant $t$.

In order to assess the impact of RP, the value of RP is varied to determine its effect on key process variables (e.g., electrical frequency) and to assess whether the particular NHES can satisfactorily accommodate the maximum level of renewable penetration that it is designed for.

\subsubsection{Impact of renewable variability}

The next test aims to characterize how the NHES responds to variability of the renewable energy source. An adjustable input signal is used to emulate the power generation contributed by the renewable component, which allows a user to manipulate the variability of the renewable integrated, observe its effect on key process variables (e.g., electrical frequency), and assess whether the particular NHES can satisfactorily accommodate fast changing renewable power injections. Specifically, the trapezoid illustrated in Figure 28 is utilized to describe the renewable generation where the width and amplitude are as denoted, and the ramp rate is defined as the ratio of $\Delta \mathrm{P}$ over $\Delta \mathrm{T}$ of the uphill/downhill. 


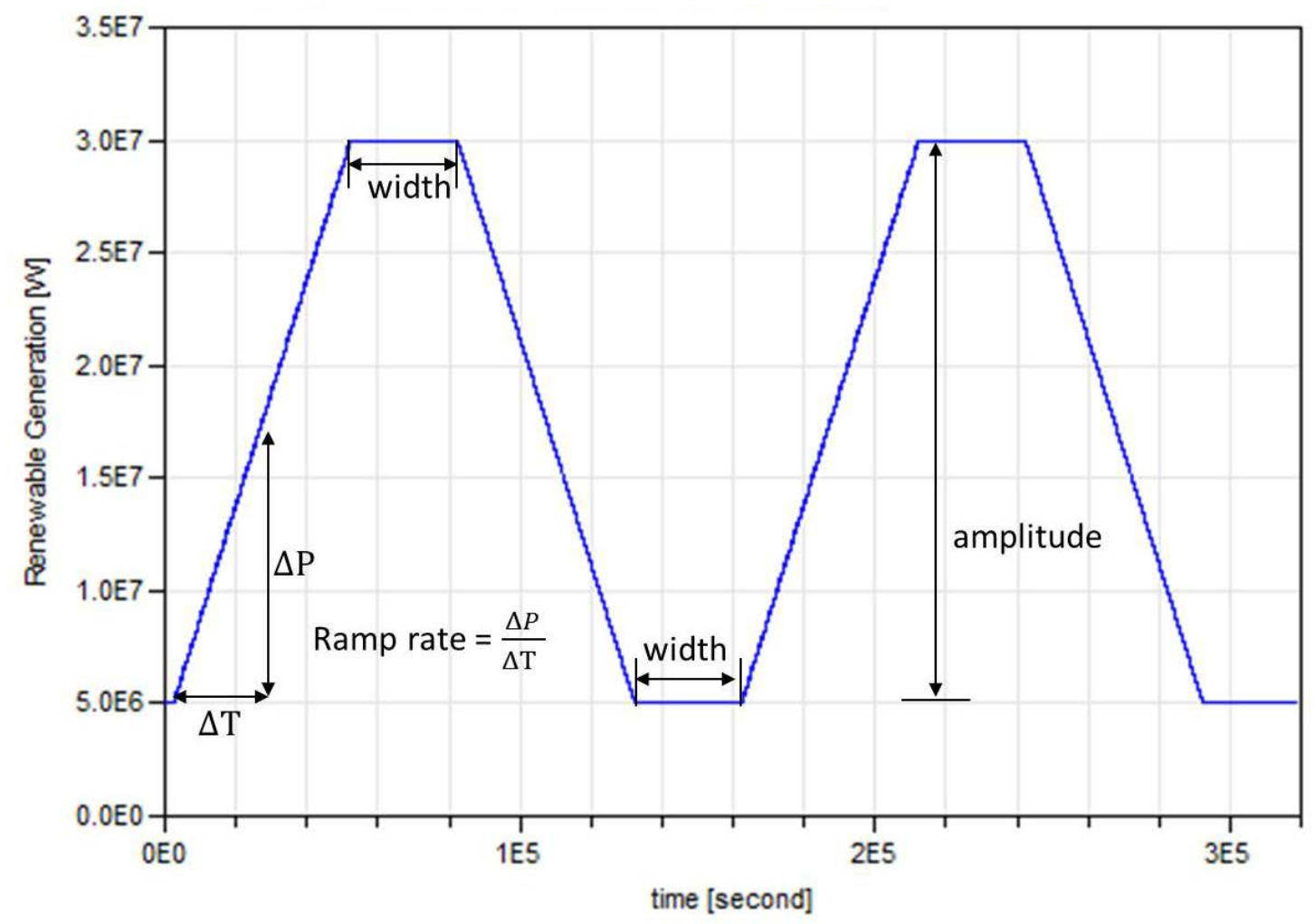

Figure 28. Trapezoidal input signal used for renewable generation.

\subsubsection{Power smoothing for renewable variability attenuation}

Recall from the previous section that in this report an electric battery is used as an ESE to smooth the renewable generation contribution. When used for power smoothing, the battery acts as a low-pass filter with its frequency significantly affecting the degree of variability removal. This test is employed to characterize the NHES dynamic properties in response to different battery selection. The power smoothing effect of batteries is modeled as first order differential equations and hence, the time constant, $\tau_{E S E}$, is used, which is the inverse of its frequency.

\subsubsection{Ancillary service: response time and ramp-rate}

By enabling more than one option for energy utilization, NHES configurations act like a large energy smoothing element for the electric grid, providing more or less electricity generation within a short time when necessary to meet demand. Depending on how quickly the NHES configuration can begin responding, change its response, and deliver the requested change, it can be utilized for various ancillary services such as regulating, ramping and contingency reserve. This test is to demonstrate how fast the NHES configurations can respond to an electrical demand change. In this test, the demand curve has the profile shown in Figure 29, where the parameters startTime, startValue, duration and height are as denoted. Note that, by using this profile, the duration can be made to approach zero (e.g., for simulating a step change), while having the flexibility to generate a less aggressive ramping signal. 


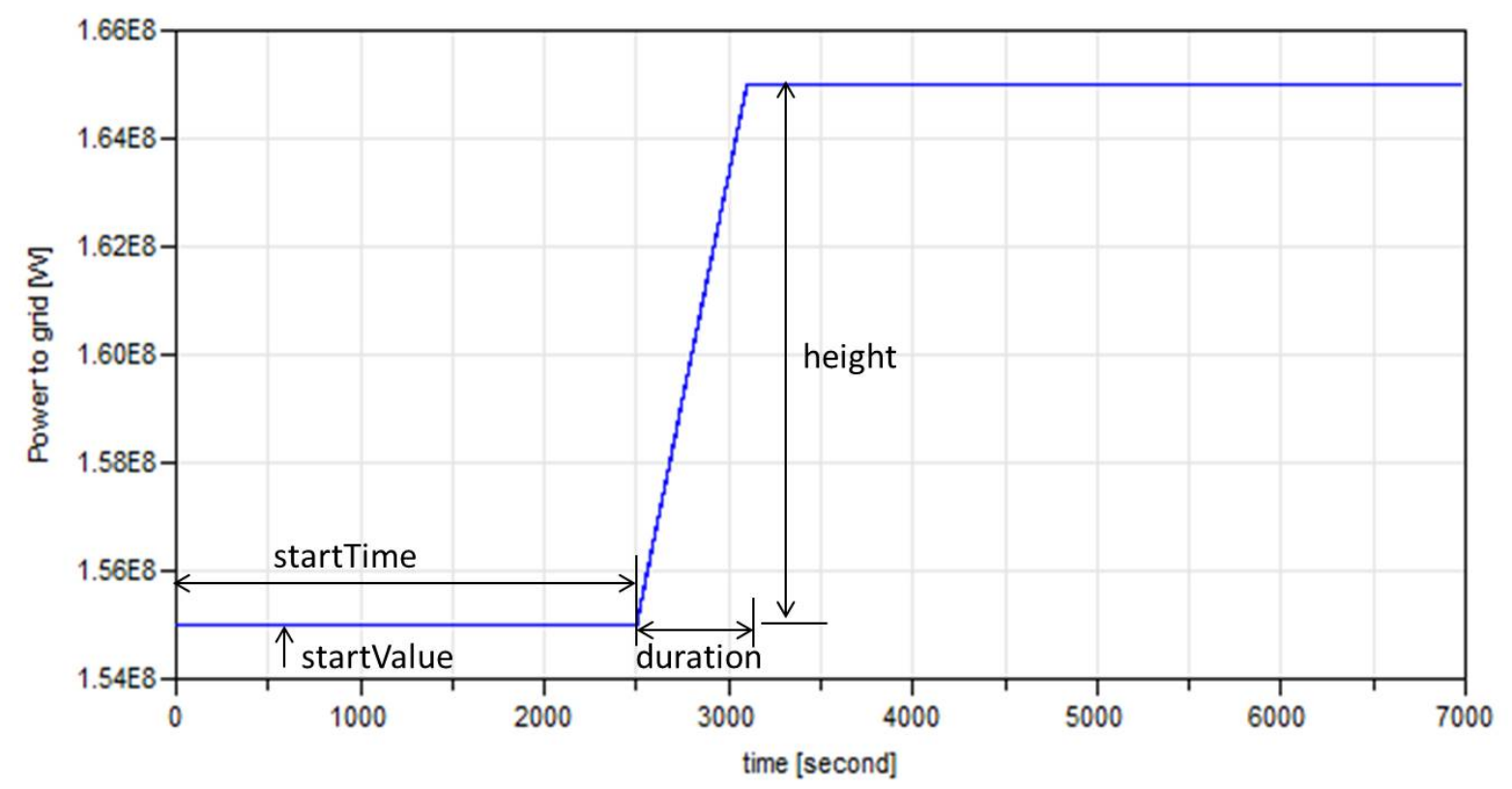

Figure 29. Ramp signal as electrical generation to the electric grid.

\subsubsection{Ancillary service: load following}

In order to demonstrate the capability of the NHES configurations to provide load following reserves, simulations are conducted using actual hourly demand profiles for West Texas and Phoenix Arizona, respectively, to show how the system performance may be affected when the variability to the NHES is introduced from the demand side. However, the demand profiles are accordingly modified in a manner to assure that the maximum electrical generation/load capacities of components within selected NHES are not exceeded.

\subsubsection{Ancillary service: operating reserve}

This test is to evaluate the operating reserve capacity that the selected NHES configurations can provide to the electric grid. In particular, a sharp increase in the electric grid demand is introduced in the simulation. For this test, the demand curve has also the profile shown in Figure 29. Simulation with this type of curve is performed to show the ability of the NHES configurations to meet the sharp demand increase, while providing high quality electricity. This test is also used to evaluate the minimum turndown and startup and shutdown time characteristics of selected NHES solutions.

\subsubsection{Operational flexibility for economic optimization}

As discussed earlier, the selected NHES configurations can be operated under flexible operational control to optimize a given economic FOM, such as PGP, NPV, or IRR. This test is designed to demonstrate the ability of the NHES configurations to generate time varying electric profiles determined by an operations optimizer in response to price variations in electricity, alternative products (i.e., gasoline or fresh water), and feedstock (i.e., NG and water).

Table 9 reports the cost parameter values assumed in the economic analysis for NHES_Texas. Figures 30 and 31 plot the assumed price trends for NG, electricity, and gasoline for selected time periods for NHES_Texas. Note that one year of data is utilized in the simulations. 
Table 9. Cost parameter values for NHES_Texas.

\begin{tabular}{|c|c|c|c|c|}
\hline (2) & Parameter & Value & Unit & Reference \\
\hline \multirow{3}{*}{ Nuclear \& Power Cycle } & $\alpha$ phg & 4718 & $\$ \mathrm{~kW}^{-1}$ & {$[32,33]$} \\
\hline & $\beta$ phg_f(annual) & 27.91 & $\$ \mathrm{MWh}^{-1}$ & [34] \\
\hline & $\beta$ phg_v & 0 & $\$ \mathrm{MWh}^{-1}$ & \\
\hline \multirow{4}{*}{$\begin{array}{l}\text { Auxiliary heat } \\
\text { generation }\end{array}$} & $\alpha \_$ahg & 1057.44 & $\$ \mathrm{~kW}^{-1}$ & {$[35]$} \\
\hline & $\beta$ ahg_f(annual) & 3 & $\%$ & {$[35]$} \\
\hline & $\beta$ ahg $v$ & NG price time series & $\$ \mathrm{~kg}^{-1}$ & Figure 30 \\
\hline & $\beta_{\mathrm{C}}$ & 0.045 & $\$ \mathrm{~kg}^{-1}$ & {$[36]$} \\
\hline \multirow{3}{*}{ Wind Turbines } & $\alpha$ ren & 2339.61 & $\$ \mathrm{~kW}^{-1}$ & [37] \\
\hline & $\beta$ ren_f(annual) & 36.91 & $\$ \mathrm{~kW}^{-1}$ & [37] \\
\hline & $\beta$ ren_v & 0 & & \\
\hline \multirow{3}{*}{ Battery } & $\alpha \_$ese & 81.42 & $\$ \mathrm{kWh}^{-1}$ & {$[6]$} \\
\hline & $\beta$ ese $\mathrm{f}$ & 3 & $\%$ & [6] \\
\hline & $\beta$ ese $v$ & $\mathrm{n} / \mathrm{a}$ & $\$ \mathrm{kWh}^{-1}$ & \\
\hline \multirow{5}{*}{$\begin{array}{l}\text { Gasoline Production } \\
\text { Plant }\end{array}$} & $\alpha \_c p$ & $42,661,291$ & $\$ \mathrm{~kg}^{-1} \mathrm{~s}$ & {$[15]$} \\
\hline & $\beta$ cp f (annual) & 12 & $\%$ & [15] \\
\hline & $\beta \_p \_v n g$ & NG price time series & $\$ \mathrm{~kg}^{-1}$ & Figure 30 \\
\hline & $\beta \_c p \_v \_w$ & $1.06 \mathrm{e}-3$ & $\$ \mathrm{~kg}^{-1}$ & {$[38]$} \\
\hline & $\beta \_c p \_v \_g$ & Gasoline price time series & $\$ \mathrm{~kg}^{-1}$ & Figure 31 \\
\hline Inflation rate & $i$ & 3 & $\%$ & \\
\hline Discount rate (WACC) & $r_{R}$ & 5 & $\%$ & \\
\hline Depreciation rate & $\rho_{d a, k}$ & See footnote $^{\mathrm{d}}$ & $\%$ & [39] \\
\hline Tax & $\operatorname{tax}$ & 35 & $\%$ & {$[40]$} \\
\hline
\end{tabular}

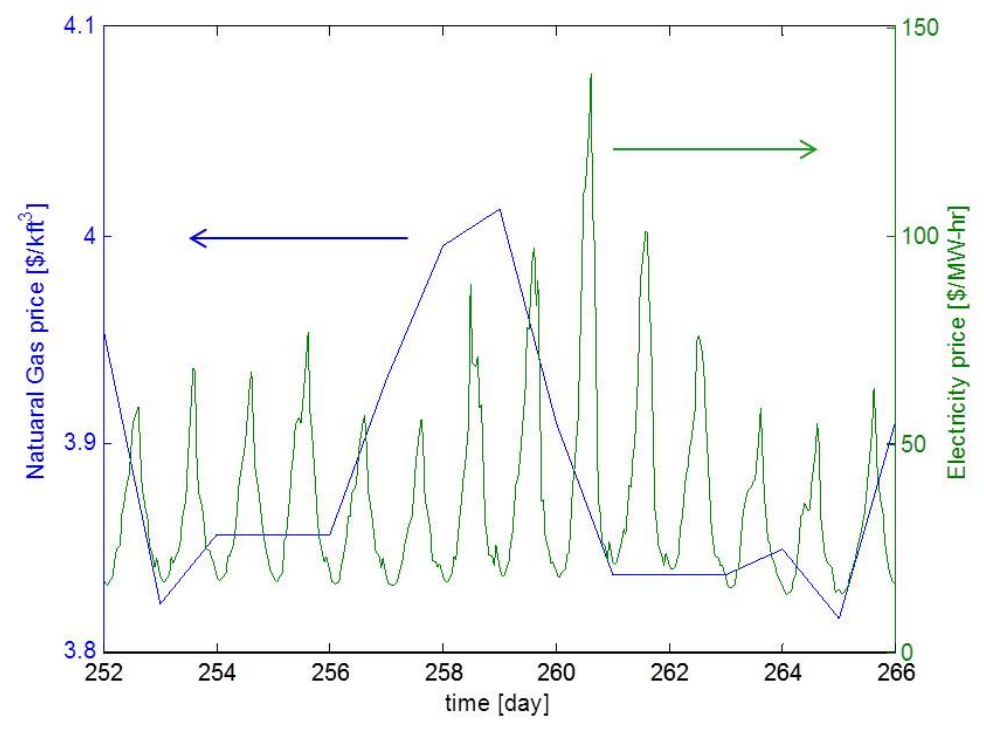

Figure 30. Price trends for natural gas and electricity for a selected 14 day period (Texas) ${ }^{\text {e. }}$

\footnotetext{
${ }^{\mathrm{d}}$ The DA rates for the first 16 years is $5.00 \%, 9.50 \%, 8.55 \%, 7.70 \%, 6.93 \%, 6.23 \%, 5.90 \%, 5.90 \%, 5.91 \%, 5.90 \%, 5.91 \%$, $5.90 \%, 5.91 \%, 5.90 \%, 5.91 \%, 2.95 \%$, respectively, and $0 \%$ afterwards.

e The electricity price is the day-ahead market settlement point price downloaded from ERCOT at http://www.ercot.com/mktinfo/prices/index.html on February 4, 2015. Although the HES_Texas would sell electricity to the
} 
Table 10 reports the cost parameter values assumed in the economic analysis for NHES_Arizona.

Table 10. Cost parameter values for NHES_Arizona.

\begin{tabular}{|c|c|c|c|c|}
\hline (2) & Parameter & Value & Unit & Reference \\
\hline \multirow{3}{*}{$\begin{array}{l}\text { Nuclear \& Power } \\
\text { Cycle }\end{array}$} & $\alpha$ phg & 4718 & $\$ \mathrm{~kW}^{-1}$ & {$[32,33]$} \\
\hline & $\beta$ phg f (annual) & 27.91 & $\$ \mathrm{MWh}^{-1}$ & [34] \\
\hline & $\beta$ phg_v & 0 & $\$ \mathrm{MWh}^{-1}$ & \\
\hline \multirow{3}{*}{ PV station } & $\alpha$ ren & 5385.98 & $\$ \mathrm{~kW}^{-1}$ & [41] \\
\hline & $\beta$ ren f (annual) & 54.28 & $\$ \mathrm{~kW}^{-1}$ & [42] \\
\hline & $\beta$ ren_v & 0 & & \\
\hline \multirow{3}{*}{ Battery } & $\alpha \_$ese & 81.42 & $\$ \mathrm{kWh}^{-1}$ & {$[6]$} \\
\hline & $\beta$ ese $f($ annual $)$ & 3 & $\%$ & [6] \\
\hline & $\beta$ ese $\mathrm{v}$ & $\mathrm{n} / \mathrm{a}$ & $\$ \mathrm{kWh}^{-1}$ & \\
\hline \multirow{3}{*}{$\begin{array}{l}\text { Reverse Osmosis } \\
\text { Desalination Plant }\end{array}$} & $\alpha$ ro & 32076.21 & $\$ \mathrm{~kg}^{-1} \mathrm{~s}$ & [43] \\
\hline & $\beta$ ro_f(annual) & 4841.43 & $\$ \mathrm{~kg}^{-1} \mathrm{~s}$ & [43] \\
\hline & $\beta$ ro_v & $6.6 e-5$ & $\$ \mathrm{~kg}^{-1}$ & [44] \\
\hline Inflation rate & $i$ & 3 & $\%$ & \\
\hline $\begin{array}{l}\text { Discount rate } \\
\text { (WACC) }\end{array}$ & $r_{R}$ & 5 & $\%$ & \\
\hline Depreciation rate & $\rho_{d a, k}$ & See footnote ${ }^{f}$ & $\%$ & [39] \\
\hline Tax & $\operatorname{tax}$ & 40 & $\%$ & {$[40,45]$} \\
\hline
\end{tabular}

Likewise, Figure 32 and 33 plot the assumed price trends for electricity and fresh water over selected time periods. Note that one year of data is utilized in the simulations.

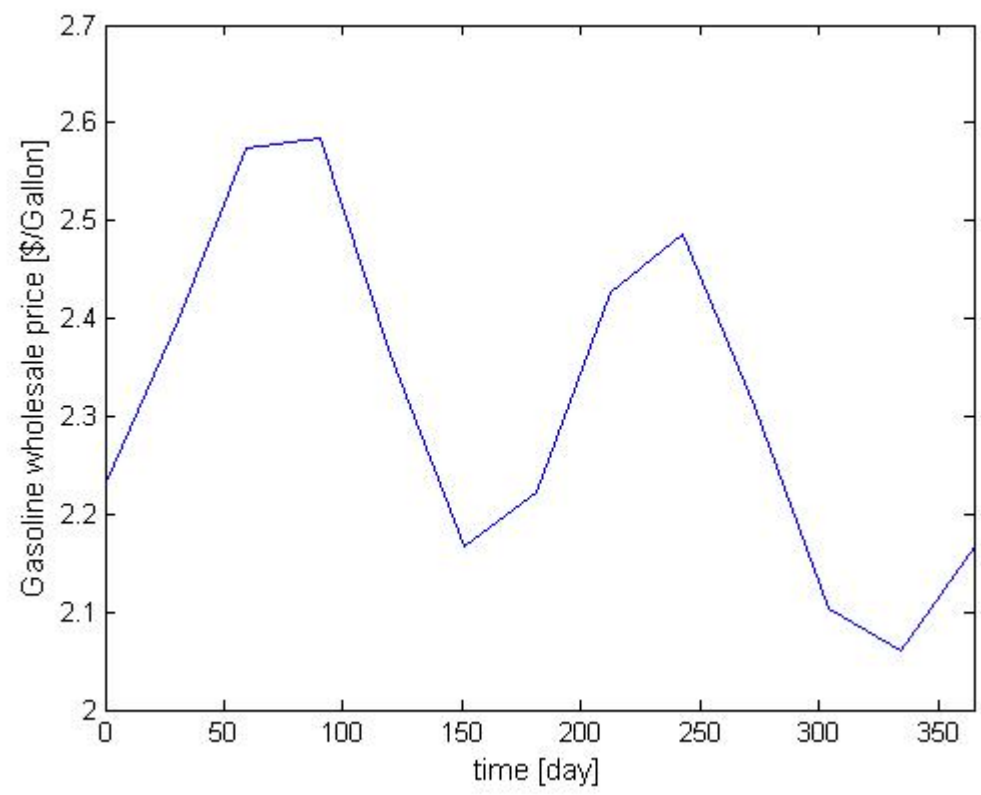

Figure 31. Wholesale price trend for gasoline for a whole yearg.

Southwest Power Pool (SPP) of the Eastern Interconnection, ERCOT data was used here due to initial data availability. The time series is scaled by 0.75 to reflect the conservativeness of the NHES in bidding. The NG price is download from Texas Alliance of Energy Producers at http://texasalliance.org/historical-nymex-natural-gas-prices/ on February 4, 2015.

${ }^{\mathrm{f}}$ The DA rates for the first 16 years is $5.00 \%, 9.50 \%, 8.55 \%, 7.70 \%, 6.93 \%, 6.23 \%, 5.90 \%, 5.90 \%, 5.91 \%, 5.90 \%, 5.91 \%$, $5.90 \%, 5.91 \%, 5.90 \%, 5.91 \%, 2.95 \%$, respectively, and $0 \%$ afterwards. 


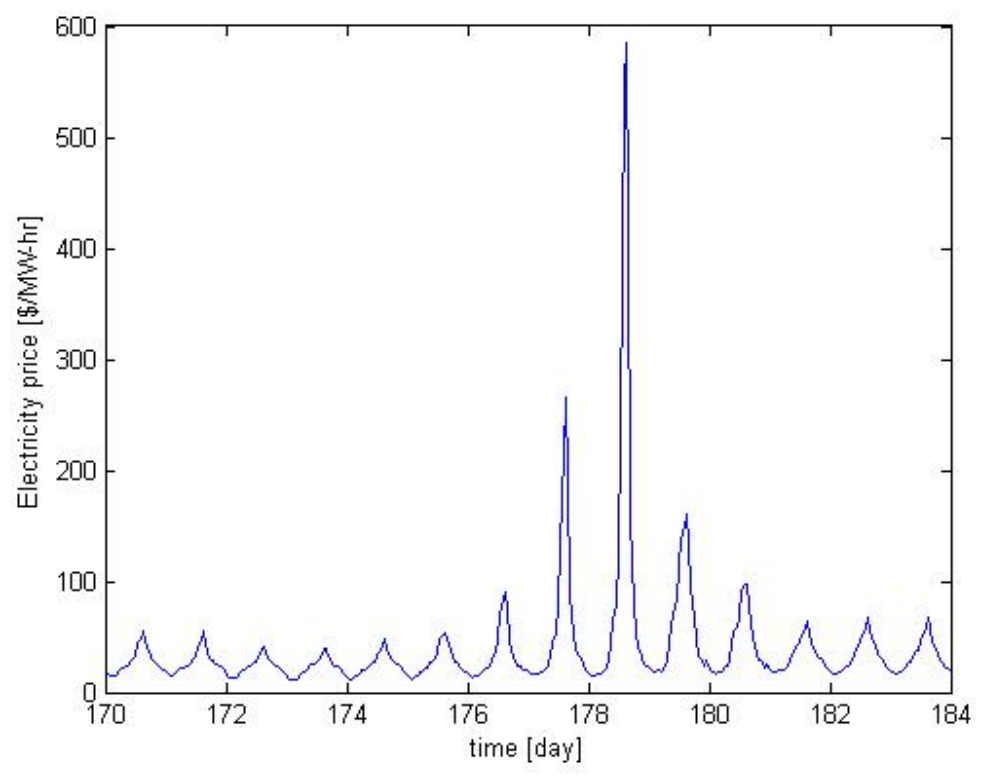

Figure 32. Price trend for electricity for a selected 14 day period (Arizona) $)^{\text {h. }}$

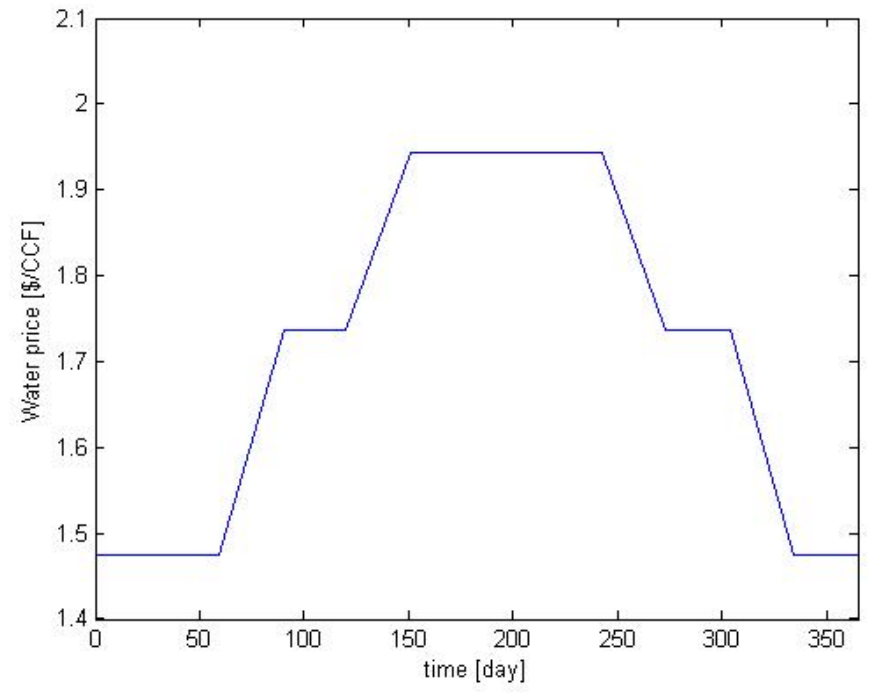

Figure 33. Price trend for water for a whole year (Arizona)i.

${ }^{g}$ The gasoline wholesale price by a refinery in Texas is downloaded from EIA at http://www.eia.gov/dnav/pet/pet pri refmg dcu STX m.htm on February 5, 2015. The time series is scaled so that the mean is 2.4496 /gallon, which corresponds to the average price by refinery in Texas between January 2009 and December 2013.

${ }^{\mathrm{h}}$ The electricity price is based on the day-ahead market settlement point price downloaded from ERCOT at http://www.ercot.com/mktinfo/prices/index.html on February 4, 2015. Although the HES_Arizona would sell electricity to the APS instead, ERCOT data was used here due to initial data availability. This data is scaled so the average of the time series conforms the Annual Average Bilateral Prices of \$36.10 per MW-hr for Palo Verde, Arizona in the year of 2011 (obtained from FERC at http://www.ferc.gov/market-oversight/mkt-electric/southwest/elec-sw-yr-pr.pdf on February 5, 2015). An additional scale by 0.85 is applied to the time series to reflect the conservativeness of the NHES in bidding. 


\subsection{Renewable and Demand Assumptions and Simulation Setup}

\subsubsection{Wind energy}

For long term prediction of wind power, physical models may be utilized; however, they often do not provide sufficient accuracy in short-term prediction for efficient power management. Likewise, while statistical methods may provide accurate short-term results, their reliability in long-term prediction is questionable [46]. In this work, renewable energy generation is modeled as time-series input signals based on wind speed data obtained from the Eastern Wind dataset maintained by NREL (National Renewable Energy Laboratory) ${ }^{j}$. The data series used in this work is for a site in West Texas. Figure 34 shows a representative seven days of the dataset (sampled at every $10 \mathrm{~min}$, with linear interpolation used to fill data gaps) to illustrate the variability of power production, which must be accommodated to make wind power more generally useful. Scaled versions of this time-series are used to model different levels of renewable penetrations.

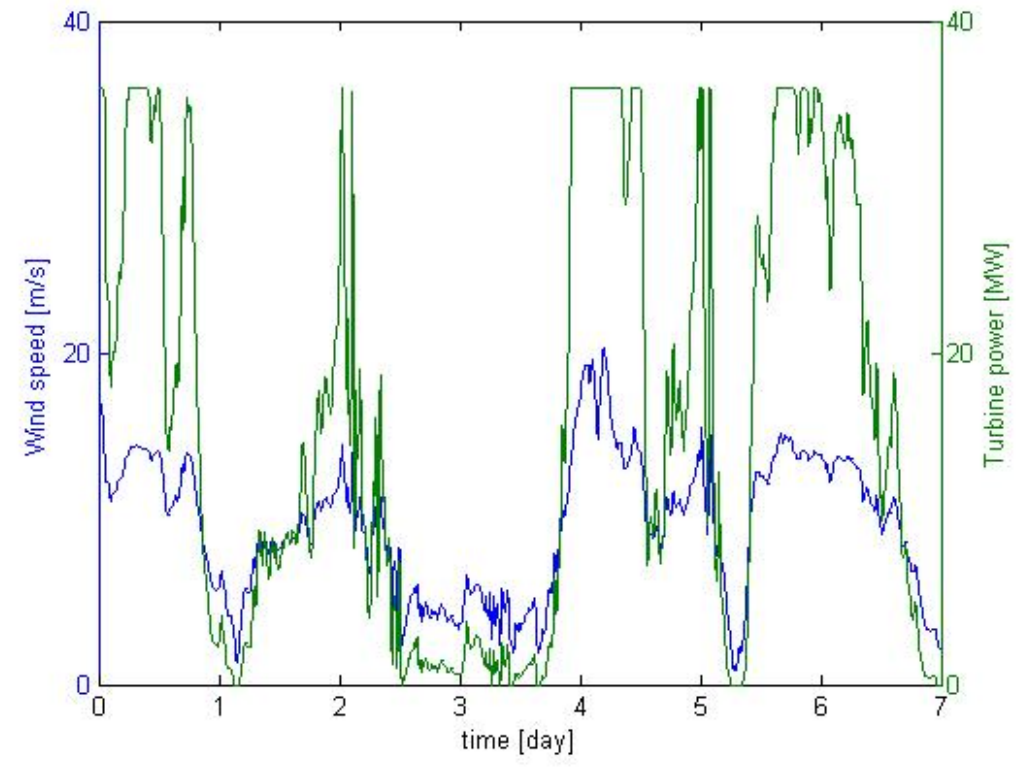

Figure 34. Wind speed and turbine power for a period of seven days in NHES_Texas.

The wind speed data is then converted to wind power input to the battery, assuming a given number of wind turbines, each rated at 3.6 MWe and located on a 2 square kilometer site for a maximum of about $36 \mathrm{MWe}$ generation at full production (hence assuming about ten wind turbines), according to the function shown in Figure 35. There are four operating regimes for a wind turbine, separated by critical wind speed values. At wind speeds below a minimum cut-in velocity, there is insufficient kinetic energy in the wind to cause any rotation, thus no electrical power is produced. At wind speeds above a cut-out velocity, a braking system is activated for safety reasons, and again no power is produced. Between the rated and the cut-out velocity values, the turbine provides a steady maximum power level, also known as the rated power. For the range between the cut-in and rated speeds, the power is calculated using Eq. (8):

\footnotetext{
${ }^{\mathrm{i}}$ The water price is based on the monthly residential price in Phoenix, Arizona, downloaded from https://www.phoenix.gov/waterservices/customerservices/rateinfo on February 5, 2015, which is scaled such that the average of the time series is $\$ 0.6$ per cubic meter, corresponding to the cost for purchasing groundwater or surface water in Arizona (B. G. Colby, D. R. Smith, and K. Pittenger, "Enhancing supply reliability during drought", in Arizona water policy: management innovations in an urbanizing, arid region, 2007).

${ }^{\mathrm{j}}$ Accessed on November 21, 2014 at http://www.nrel.gov/electricity/transmission/eastern_wind_dataset.html
} 


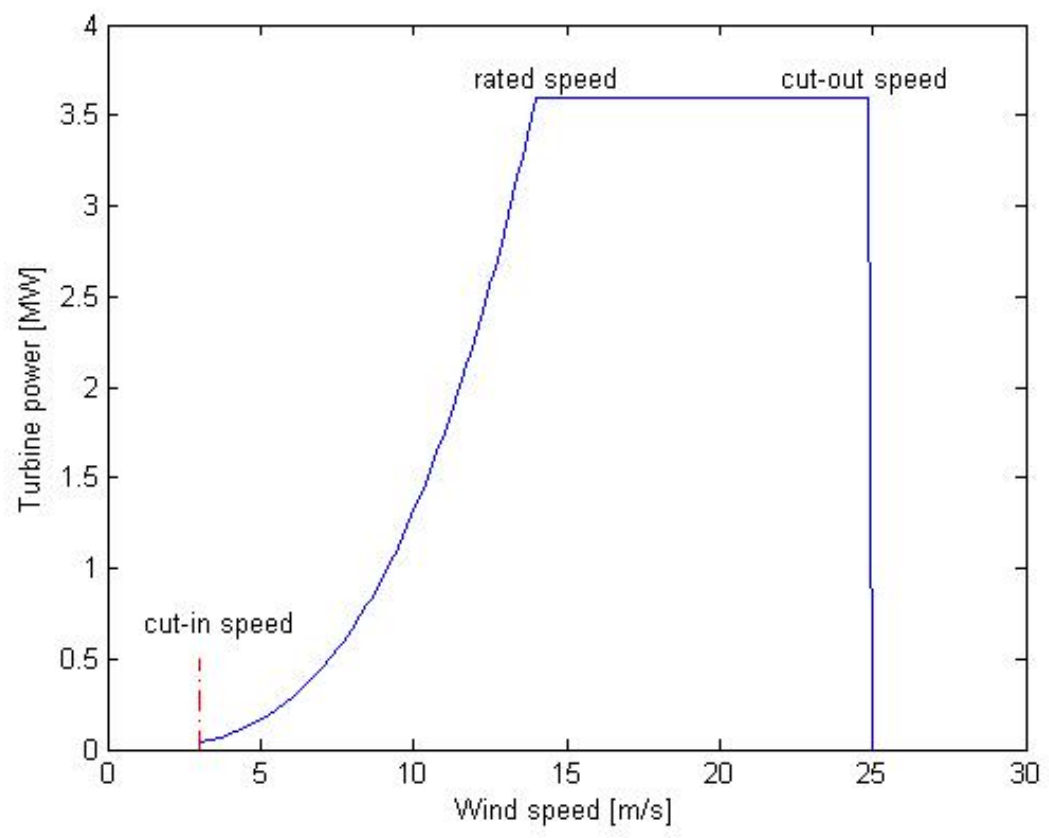

Figure 35. Turbine power vs. wind speed.

$E_{R E N}:=0.5 \eta \rho U^{3} \frac{\pi d^{2}}{4}$

where $\eta$ is the conversion efficiency of the wind turbine, $\rho$ is the density of the air at the site, $U$ is the wind velocity, and $d$ is the diameter of the turbine blades. In essence, Eq. (8) relates the power delivered by the turbine to the amount of kinetic energy available in the wind, via an overall lumped efficiency number. At a typical site, the majority of the turbine operation occurs in this regime. The values for each parameter in Eq. (8) used in the simulations are listed in Table 11.

Table 11. Parameters in wind-power mapping Eq. (8).

\begin{tabular}{|l|l|l|}
\hline$\eta$ & Conversion efficiency of the wind turbine & $35 \%$ \\
\hline$\rho$ & Density of the air at the site & $1.17682 \mathrm{~g} / \mathrm{m}^{3}$ \\
\hline $\mathrm{d}$ & Diameter of the turbine blades & $90 \mathrm{~m}$ \\
\hline
\end{tabular}

Note that Figure 34 also shows a representative seven days of wind power, assuming ten turbines and the above parameters.

\subsubsection{PV solar energy}

The PV solar energy generation is modeled as time-series input signals based on solar irradiation data (i.e., Direct Normal Irradiance, Diffuse Horizontal Irradiance) as well as air temperature data obtained from the Southwest Solar Research Park dataset (Phoenix, Arizona) maintained by NREL ${ }^{\mathrm{k}}$. The site geometrical data is listed in Table 12.

Table 12. Geometric fact about the solar data collection site.

\begin{tabular}{|l|l|}
\hline Latitude & $33.41663^{\circ}$ North \\
\hline Longitude & $112.01875^{\circ} \mathrm{West}$ \\
\hline Time Zone & -7.0 \\
\hline
\end{tabular}

\footnotetext{
${ }^{\mathrm{k}}$ Accessed on November 21, 2014 at http://www.nrel.gov/midc/ssrp/
} 
Given time series data for Direct Normal Irradiance (DNI) and Diffuse Horizontal Irradiance (DHI), the total amount of irradiation received by a PV module, denoted as $\mathrm{G}_{\mathrm{T}}$, is given by Eq. (9) $[47,48]$ :

$G_{T}=D N I * \cos (\beta+\delta-$ lat $)+D H I * \frac{180-\beta}{180}$

where $\beta$ is the tilt angle of the PV module from horizontal whose typical optimal value is slightly less than the site latitude [49], $\delta=23.45^{\circ} \sin (360(284+$ DOY $) / 365)$ is the declination angle [50], lat is the latitude of the site and DOY is the day of the year. Figure 36 is a plot of seven representative days of the irradiation on a PV module and the electrical power generated using the above conversion with parameters as listed in Table 12. Note that while more complex conversion formulas can be found in literature (e.g., [51]), the above formulation is chosen to balance computational complexity and simulation speed.

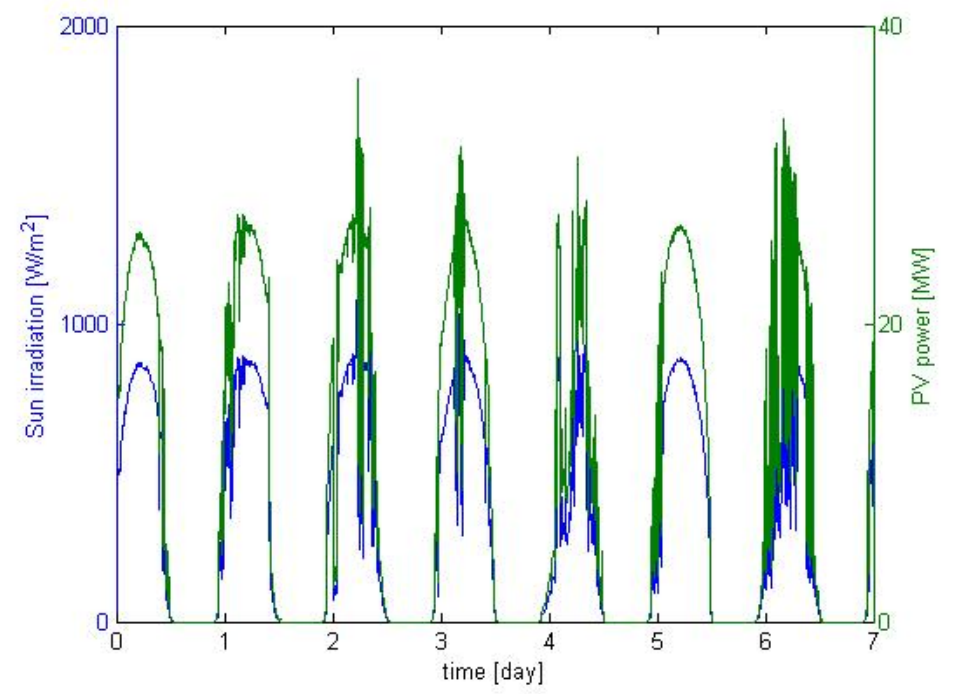

Figure 36. Solar irradiation and PV solar power for a period of seven days in NHES_Arizona.

A PV module receives solar irradiation, and converts it to electrical power. The generated power depends on the amount of irradiation received by the PV module and the ambient temperature at which the PV module is operating. In order to characterize the relationship among the PV power output, solar irradiation, and the ambient temperature, several mapping functions were studied in $[48,52,53]$. In this report, the power output from the PV module is modeled according to:

$P=G_{T} \tau_{p v} \eta_{r e f} A[1-\gamma(T-25)]$

where $\mathrm{G}_{\mathrm{T}}$ is the solar irradiation arriving on the PV module, $\mathrm{T}$ is the ambient temperature, and $\mathrm{A}$ is the total area of the PV module receiving solar irradiation. The values of parameters in Eqs. (9) and (10) used in simulation are listed in Table 13.

Table 13. Parameters in Solar-Power Mapping Eq. (10).

\begin{tabular}{|c|l|l|}
\hline$\tau_{p v}$ & Transmittance of the PV module's outside layer & $90 \%$ \\
\hline$\eta_{r e f}$ & PV module efficiency measured under STC & $15 \%$ \\
\hline$\beta$ & Tilt angle of the PV module & $33.42^{\circ}$ \\
\hline$\gamma$ & Temperature coefficient & $0.45 \%$ \\
\hline
\end{tabular}

\footnotetext{
${ }^{1}$ Standard Test Condition $\left(1000 \mathrm{~W} / \mathrm{m}^{2}\right.$ solar irradiation and $25^{\circ} \mathrm{C}$ ambient temperature [54]) as specified in standards such as IEC 61215 and IEC 61646.
} 
Note that Figure 36 also shows a representative seven days of the PV power output, using parameters as listed in Table 13, and the total area receiving solar irradiation is $\mathrm{A}=2.4 \mathrm{e} 5 \mathrm{~m}^{2}$. The solar irradiation data is thus converted to PV solar power input to the battery, assuming a given number of PV solar stations, each rated at 4 MWe nominal. Assuming eight PV solar stations, a nominal power of approximately $30 \mathrm{MWe}$ is generated at Standard Test Condition.

\subsubsection{Electric grid demand}

Two distinct time series of actual hourly load data collected from Texas and Arizona are used to model the required electric grid generation for the load following tests. The hourly load data for Texas was published by Electric Reliability Council of Texas ${ }^{m}$ and is associated with the west region of Texas. The other hourly load data for Arizona was published by Federal Energy Regulatory Commission ${ }^{\mathrm{n}}$ and corresponds to Phoenix, AZ. Both time series data are scaled so that the peak load is saturated at $180 \mathrm{MWe}$ and $165 \mathrm{MWe}$, respectively, with the variability being preserved for data below their corresponding peak. Figures 37 and 38 show the scaled version of hourly load data from Texas and Arizona, respectively.

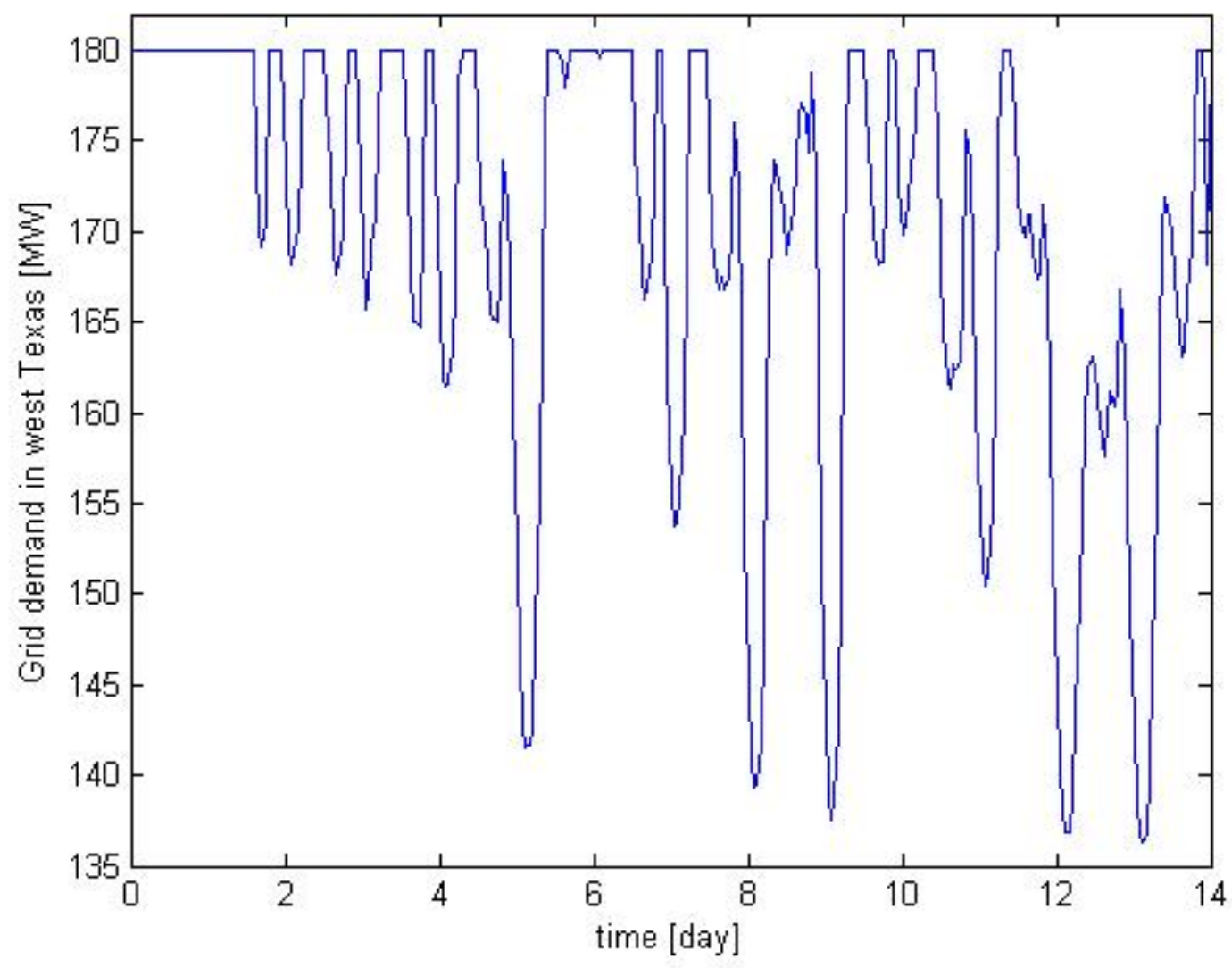

Figure 37. Hourly electricity demand considered for NHES_Texas.

\footnotetext{
${ }^{m}$ Accessed on December 11, 2014 at http://www.ercot.com/gridinfo/load/load hist/

${ }^{\mathrm{n}}$ Accessed on December 19, 2014, 2014 at http://www.ferc.gov/docs-filing/forms/form-714/data.asp
} 


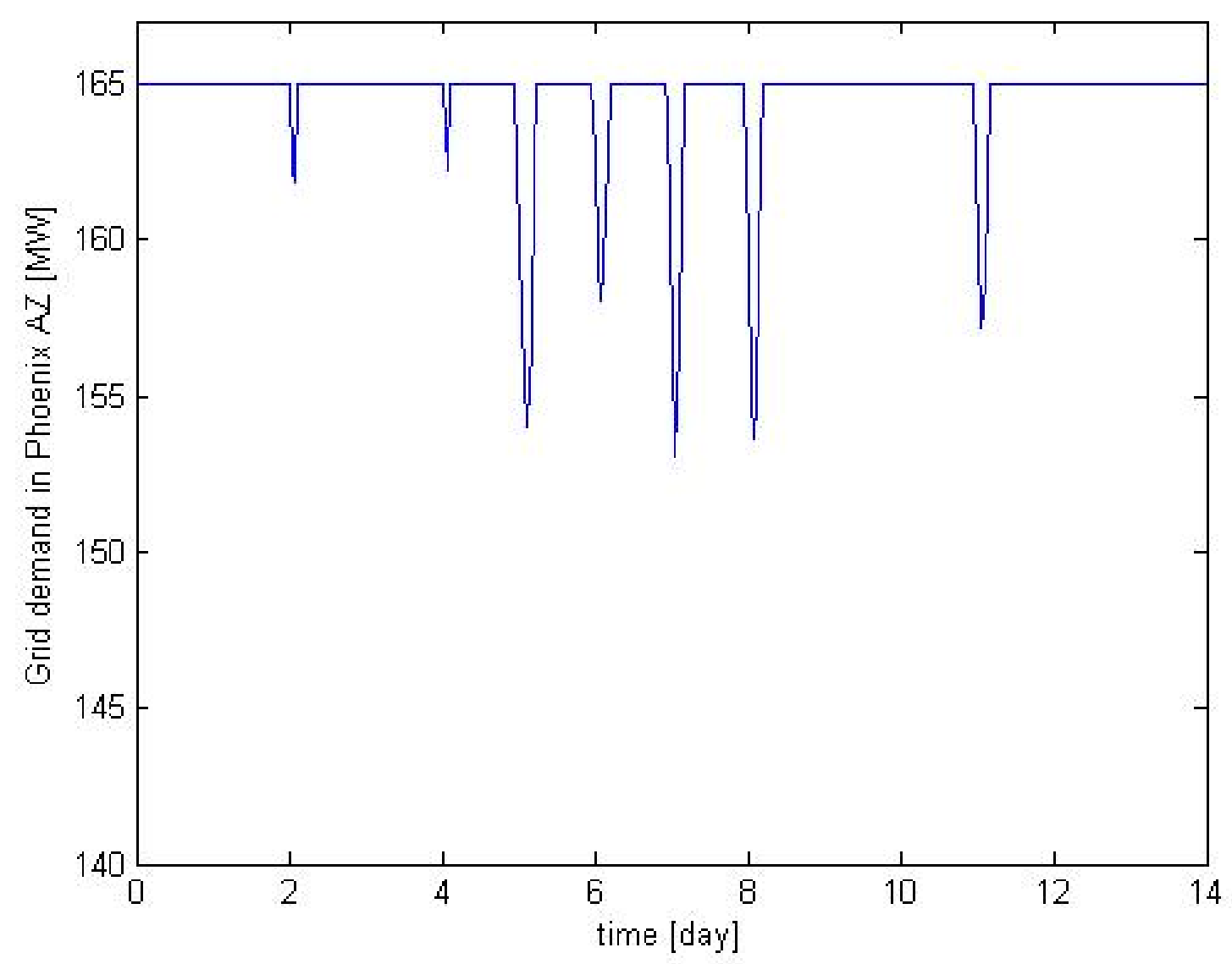

Figure 38. Hourly electricity demand considered for NHES_Arizona.

\subsubsection{Simulation setup}

As indicated in Sections 2.1.6and 2.2.6, the NHES configurations under consideration are modeled in the Modelica language. Modelica provides unique multi-engineering capabilities such that models and libraries may be comprised of components from many different engineering domains such as mechanical, electrical, chemical, control, thermal, pneumatic, hydraulic, power train, thermodynamics, vehicle dynamics, air conditioning, and many more [55]. All the simulations are performed on standard Windows workstations, with simulation times varying according to the particular test under evaluation. Note that a simulation of a two-week period is typically sufficient to capture key dynamic characteristics of the renewable energy and NHES configurations considered. Simulation for longer periods result in higher computational complexity, while providing few, if any, additional insights on the system's dynamic properties. For evaluation considering the operational control responding to a product's actual market value change, a longer period (e.g., 12 months) is selected for simulation, as market prices present less variability over short time intervals. 


\section{PRELIMINARY TECHNICAL AND ECONOMIC ESTIMATES}

This section presents preliminary technical and economic estimates obtained from conducting the various tests described in Section 3. Time series are plotted with time units given in seconds unless otherwise indicated. In order to assess whether a given NHES configuration is capable of satisfactorily responding to the particular test under consideration, a key process variable that should always be observed is the electrical power frequency (or turbine shaft speed) or, equivalently, the corresponding electrical and mechanical torque at the steam turbine shaft. This is because the electrical power frequency (or turbine shaft speed) must be managed in a very tight band of $\pm 0.5 \mathrm{~Hz}$ (or $\pm 3.14 \mathrm{rad} / \mathrm{s}$ ) around the system's design frequency of $60 \mathrm{~Hz}$ (or $377 \mathrm{rad} / \mathrm{s}$ ) to ensure electric grid reliability; otherwise, the particular NHES would be disconnected from the electric grid. There are additional process variables that should be tracked (e.g., steam generator inlet and outlet temperature, pressure, and mass flow rates) to assess whether safety requirements are met as well. On a case-by-case basis, other process variables (e.g., the nuclear-generated steam diverted for gasoline production in NHES_Texas and the concentration of fresh water produced in NHES-Arizona) are important in determining whether the variability introduced by energy sources and/or loads is satisfactorily managed within the given NHES. As plotting all relevant process variables needed to comprehensively assess the behavior of the given NHES under each test is too lengthy, the next sections provide selected time series plots of process variables deemed as most interesting. Regardless of this reporting strategy, all key process variables were accordingly collected and used as necessary to assess whether the dynamic behavior of the given NHES is satisfactory under each test.

\subsection{NHES_Texas}

This section presents preliminary results obtained from conducting the tests described in Section 3 as they apply to the HES with flexible thermal load (NHES_Texas).

\subsubsection{Impact of renewable penetration}

In this test, the system performance is evaluated for increasing renewable penetration. The simulation setup values used in this test are listed in Table 14.

Table 14. Simulation setup for NHES_Texas: Impact of RP test.

\begin{tabular}{|l|l|l|}
\hline Electrical generation to grid & source & $180 \mathrm{MWe}$ (constant) \\
\hline \multirow{3}{*}{ Wind profile } & source & Texas region actual \\
\cline { 2 - 3 } & $\begin{array}{l}\text { no. of turbines }(3.6 \\
\text { MWe each) }\end{array}$ & $\begin{array}{r}\text { a. } 8 \\
\text { b. } 12\end{array}$ \\
\hline Power smoothing time constant $\left(\tau_{E S E}\right)$ & $1800 \mathrm{~s}$ \\
\hline Simulation duration & $604800 \mathrm{~s}(1$ week $)$ \\
\hline Simulation output interval & $60 \mathrm{~s}$ \\
\hline
\end{tabular}

Figure 39 shows the time series of the steam turbine shaft speed when considering eight and twelve wind turbines. Notice that the variation of shaft speed is well within the acceptable band. 
(a)

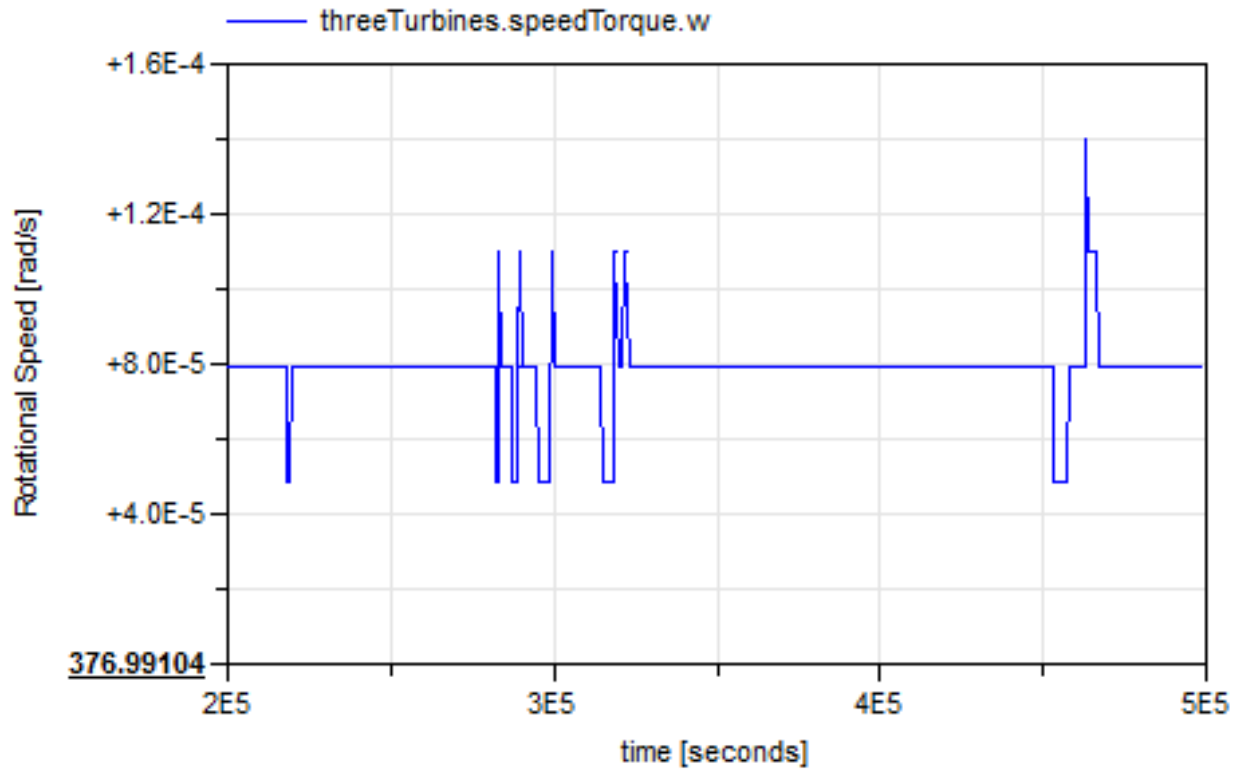

(b)

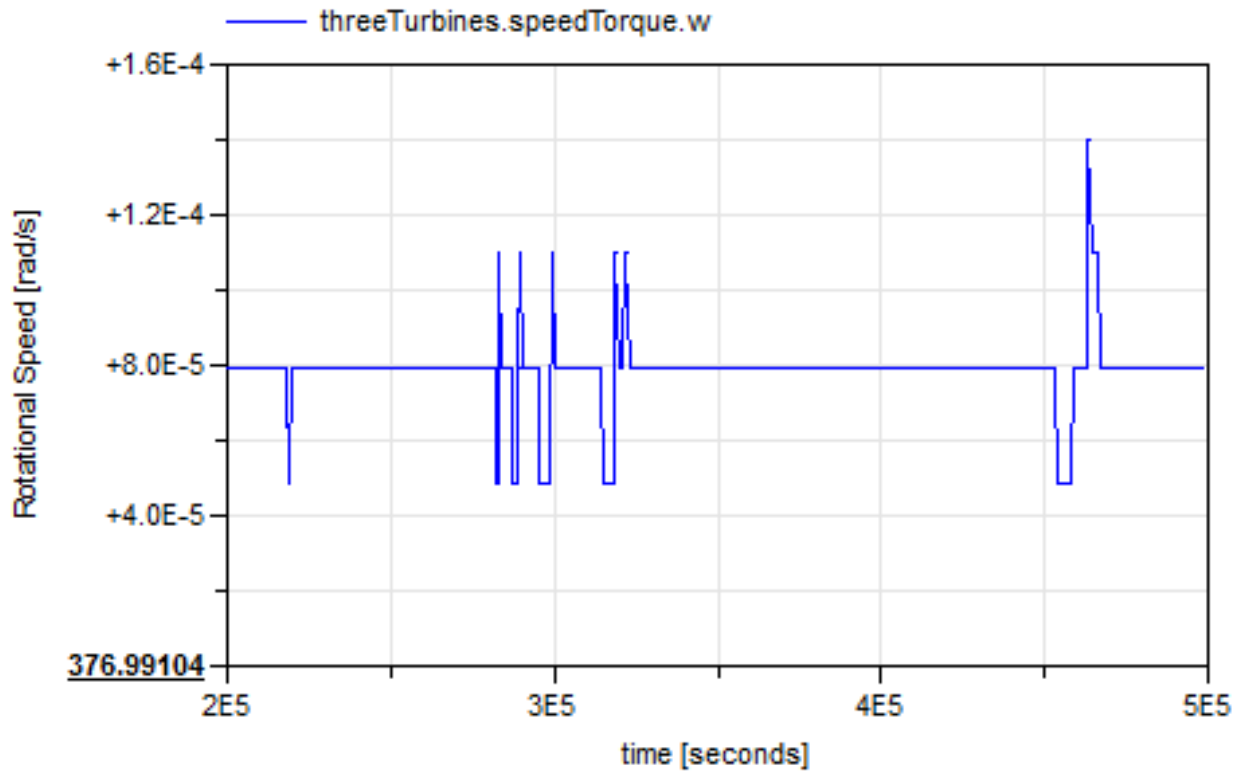

Figure 39. Steam turbine shaft speed for: (a) 8 wind turbines; (b): 12 wind turbines (NHES_Texas).

Likewise, Figure 40 shows the flow rate of the steam produced by the steam generator associated with the nuclear reactor as well as that produced by the NG-fired auxiliary boiler, the latter being used to assure that a constant high-pressure steam flow can be supplied to GPP for gasoline production when considering eight and twelve wind turbines. Due to the complementary action of these two PHG- and AHG-generated steam flows, the gasoline production plant can successfully be operated in a constant full load mode, even though the nuclear reactor delivers a time-varying thermal energy for gasoline production that varies as a function of the variability introduced by the renewable (wind) source. These 
results suggest that high penetration levels of renewable energy can be effectively managed by NHES_Texas, while maintaining adequate dynamic performance.

(a)

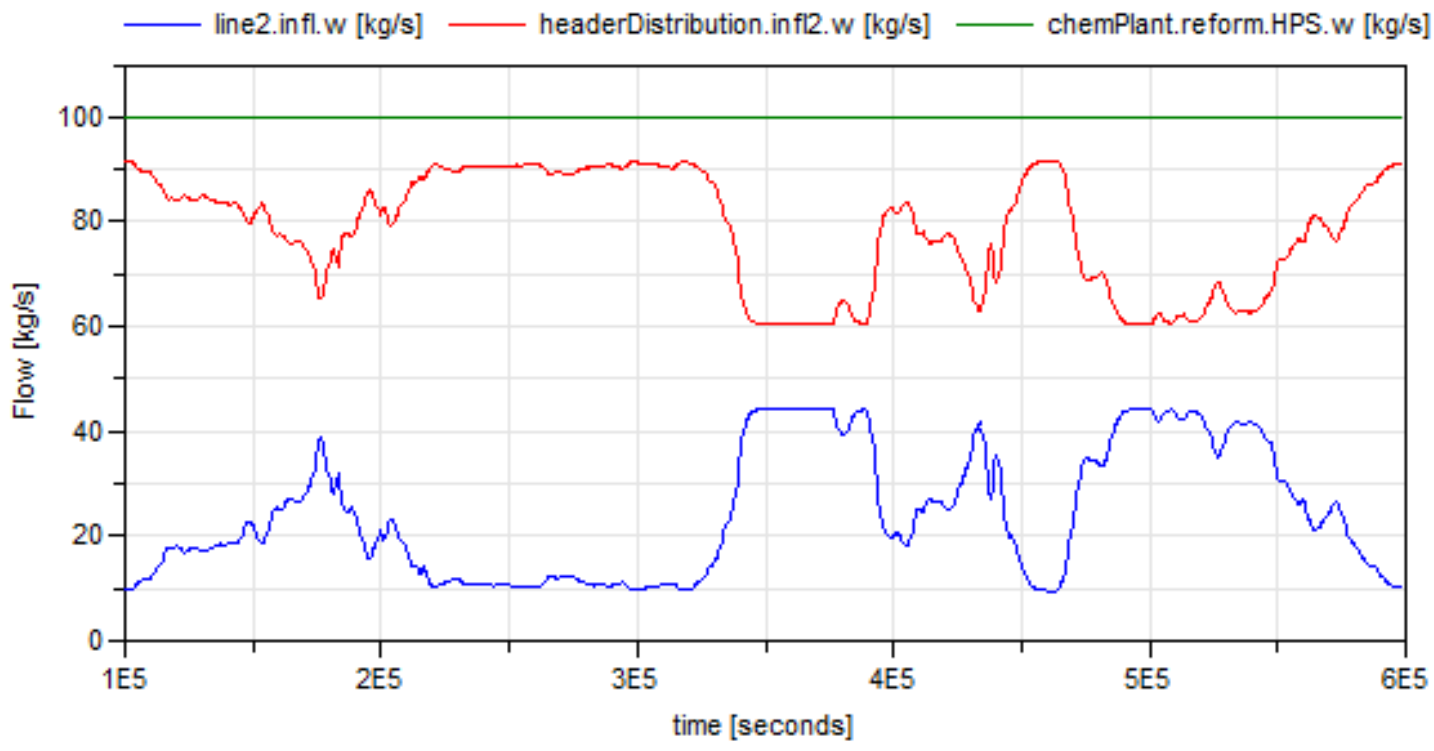

(b)

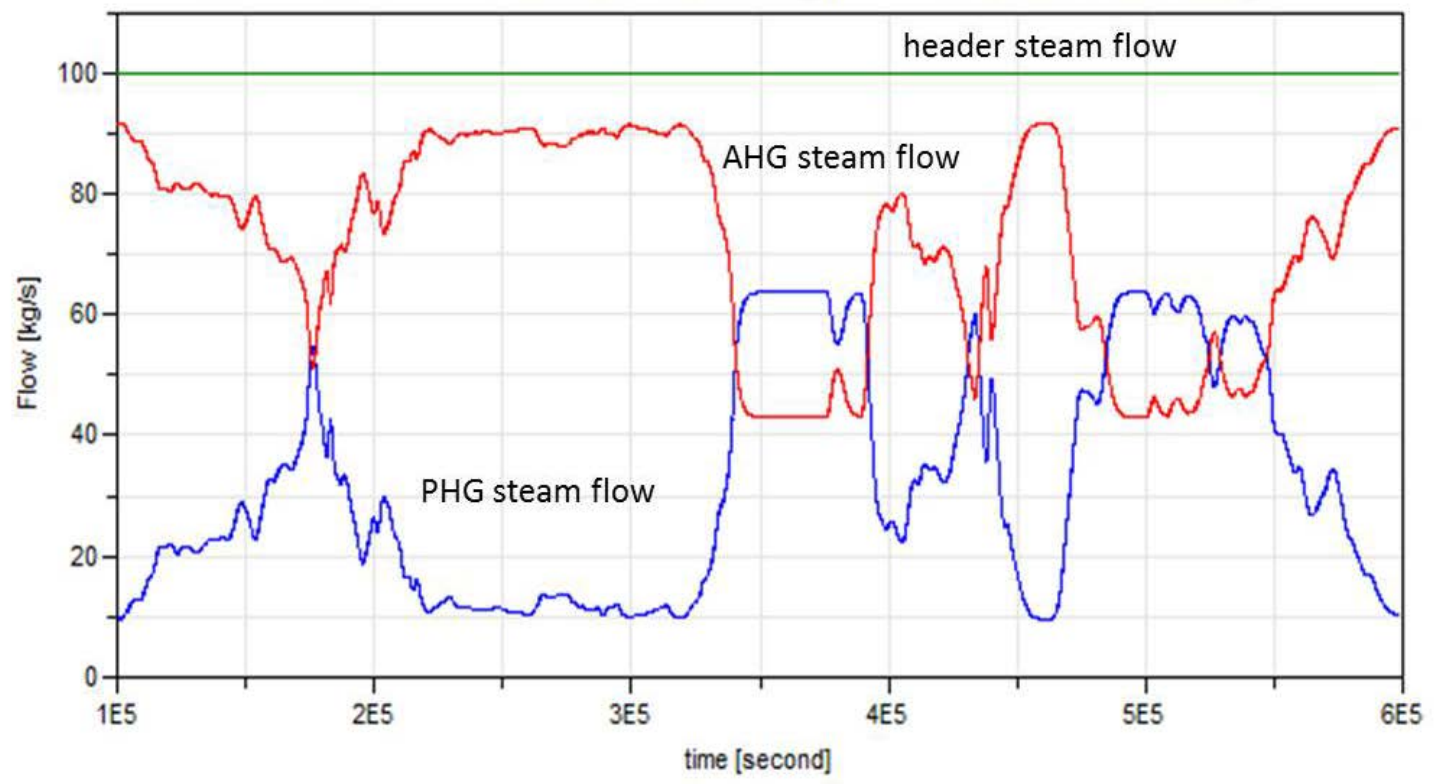

Figure 40. Nuclear (PHG), NG-fired boiler (AHG), and header steam flows used for gasoline production for: (a) 8 wind turbines; (b) 12 wind turbines (NHES_Texas).

\subsubsection{Impact of renewable variability}

In this test, the renewable generation is characterized by a trapezoidal signal as shown in Figure 28, whose amplitude is selected such that the renewable penetration is $12 \%$. The simulation setup values used in this test are listed in Table 15. 
Table 15. Simulation setup for NHES_Texas: Impact of renewable variability test.

\begin{tabular}{|l|l|l|}
\hline Electrical generation to grid & Source & $180 \mathrm{MWe}$ (constant) \\
\hline \multirow{3}{*}{ Wind profile } & source & Figure 28 profile \\
\cline { 2 - 3 } & amplitude & $25 \mathrm{MWe}$ \\
\cline { 2 - 3 } & ramp rate & $\begin{array}{r}\text { a. } 0.03 \mathrm{MWe} / \mathrm{s} \\
\text { b. } 0.3 \mathrm{MWe} / \mathrm{s}\end{array}$ \\
\cline { 2 - 3 } & width & $500 \mathrm{~s}$ \\
\hline Power smoothing time constant $\left(\tau_{E S E}\right)$ & $1800 \mathrm{~s}$ \\
\hline Simulation duration & $10000 \mathrm{~s}$ \\
\hline Simulation output interval & $0.1 \mathrm{~s}$ \\
\hline
\end{tabular}

As indicated in Table 15, the time-varying effect of renewable generation is evaluated by assuming an electrical renewable contribution with a 25 MWe peak and two different large ramp rates: 0.03 and $0.3 \mathrm{MWe} / \mathrm{s}$. These ramp rates were selected after identifying that the maximum ramp rate observed on the actual wind power data collected was $0.05 \mathrm{MWe} / \mathrm{s}$ without power smoothing. Figure 41 shows the time series of the steam flow generated by the steam generator that is diverted for gasoline production in response to a time-varying renewable generation.

(a)

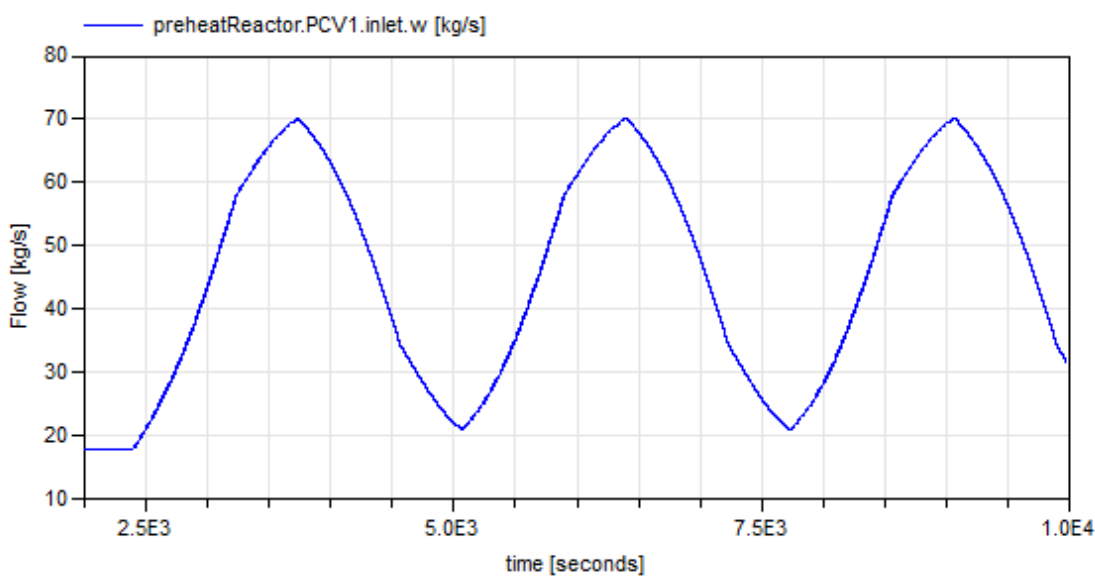

(b)

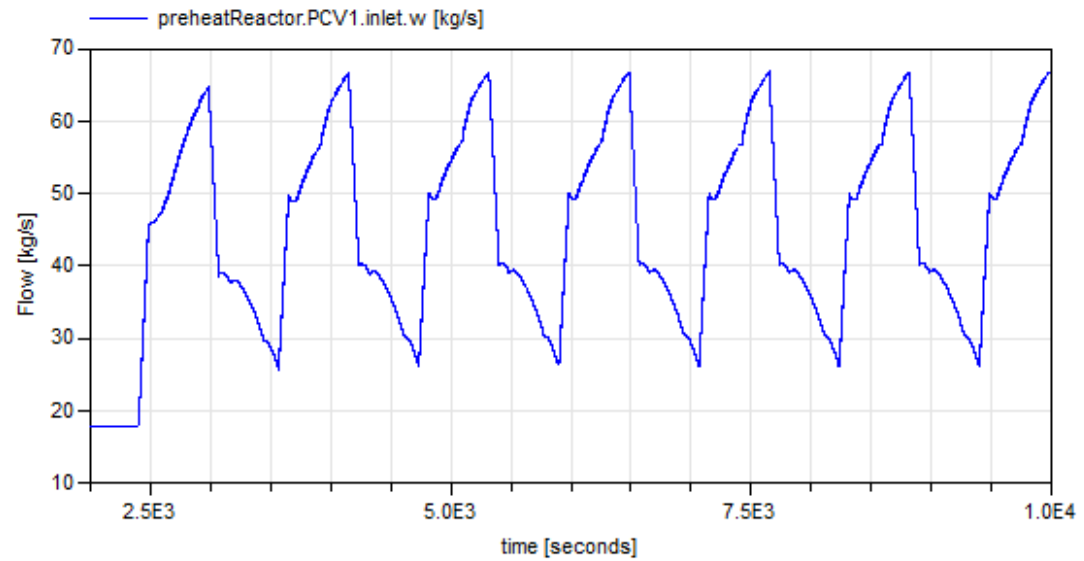

Figure 41. Steam flow diverted for gasoline production under a renewable ramp rate of: (a) $0.03 \mathrm{MWe} / \mathrm{s}$; (b) $0.3 \mathrm{MWe} / \mathrm{s}$ (NHES_Texas). 
Likewise, Figure 42 shows the time series of the turbine shaft speed. As the turbine shaft speed is kept well within the required range by rapidly diverting steam for gasoline production, these results suggest that high variability of renewable energy can be effectively managed by NHES_Texas, while maintaining adequate dynamic performance.

(a)

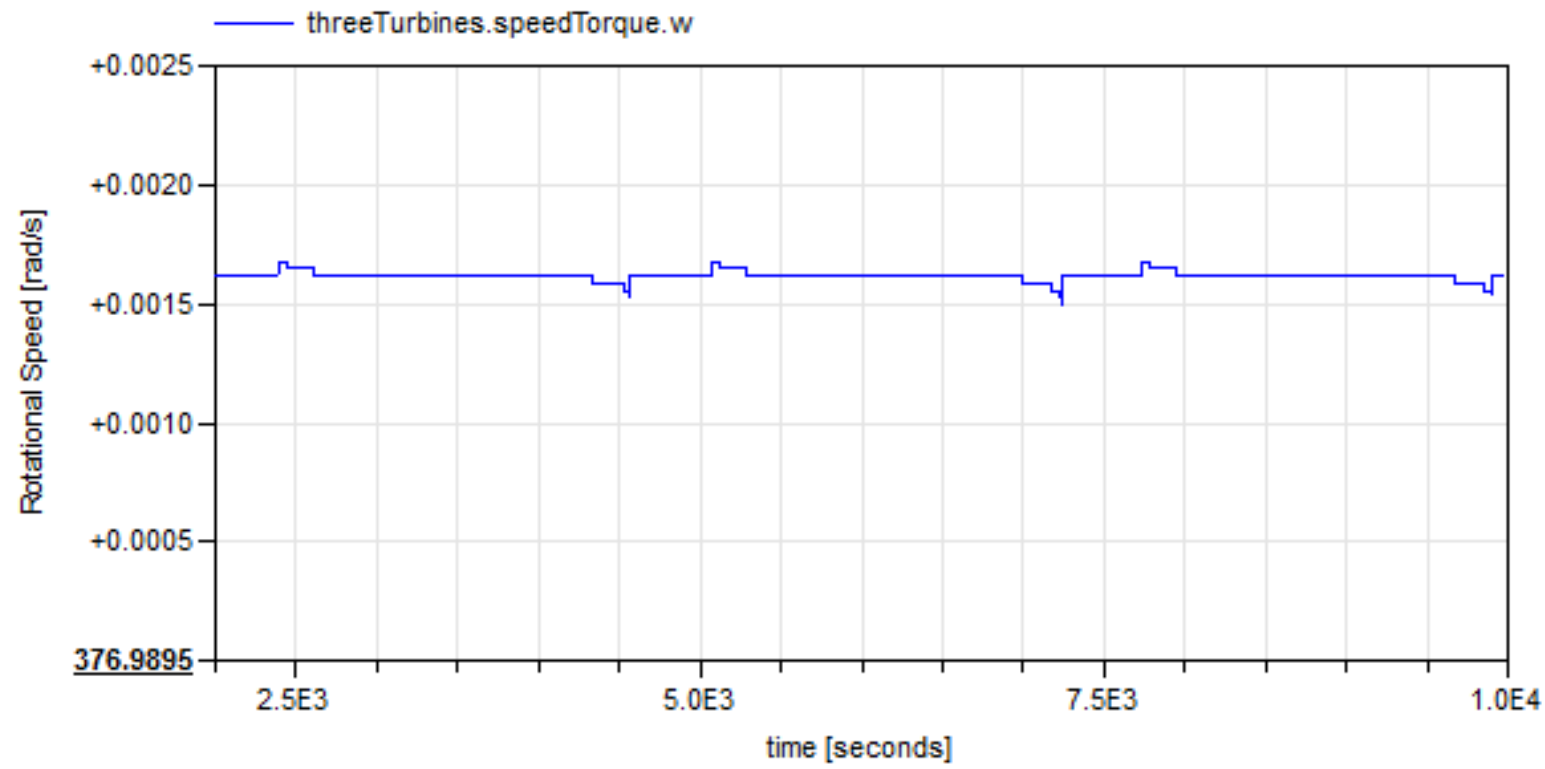

(b)

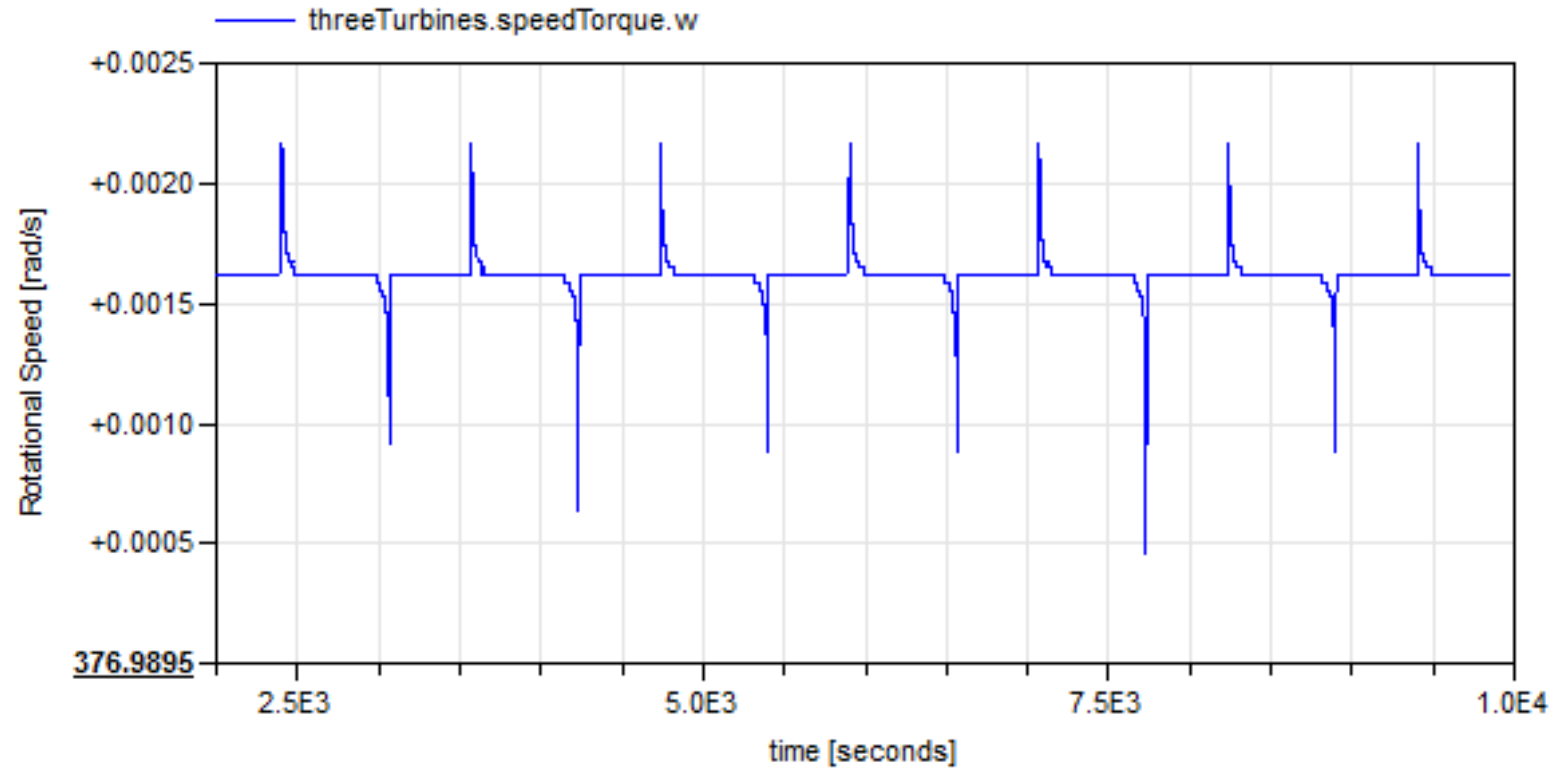

Figure 42. Steam turbine shaft speed under a renewable ramp rate of: (a) $0.03 \mathrm{MWe} / \mathrm{s}$; (b): $0.3 \mathrm{MWe} / \mathrm{s}$ (NHES_Texas). 


\subsubsection{Power smoothing for renewable variability attenuation}

In this test, the system performance is evaluated for two values of power smoothing provided by an electric battery. The simulation setup values used in this test are listed in Table 16.

Table 16. Simulation setup for NHES_Texas: Impact of renewable variability test.

\begin{tabular}{|l|l|l|}
\hline Electrical generation to grid & source & $180 \mathrm{MWe}$ (constant) \\
\hline Wind profile & source & Texas region actual \\
\cline { 2 - 3 } & no. of turbines & 10 \\
\hline Power smoothing time constant $\left(\tau_{E S E}\right)$ & $\begin{array}{r}\text { a. } 1800 \mathrm{~s} \\
\text { b. } 9000 \mathrm{~s}\end{array}$ \\
\hline Simulation duration & $604800 \mathrm{~s}$ \\
\hline Simulation output interval & $600 \mathrm{~s}$ \\
\hline
\end{tabular}

Figures 43 and 44 show the renewable generation profiles before and after the power smoothing effect introduced by the electric battery for different values of power smoothing time constants. For each figure, the instantaneous power output differences and the areas of continuous charge/discharge cycles correspond to the particular charge/discharge power and energy storage values, respectively, accommodated by the battery. While the largest difference in the instantaneous power output corresponds to the minimum charge/discharge power required for the battery, the largest single contiguous area corresponds to its minimum required energy storage capacity. In this case, the battery needs to have a power rating of $17 \mathrm{MWe}$ and storage capacity of $16 \mathrm{MWe}-\mathrm{hr}$ to achieve the smoothing effect reported in Figure 43, and a power rating of $22 \mathrm{MWe}$ and storage capacity of $90 \mathrm{MWe}-\mathrm{hr}$ to achieve the smoothing effect reported in Figure 44. Since the capital and operational costs of the battery are directly related to its size, this test provides a benchmark when considering the trade-off between the benefit of incorporating power smoothing to smooth the variability introduced by the renewable source versus the cost of installing system-scale ESE.

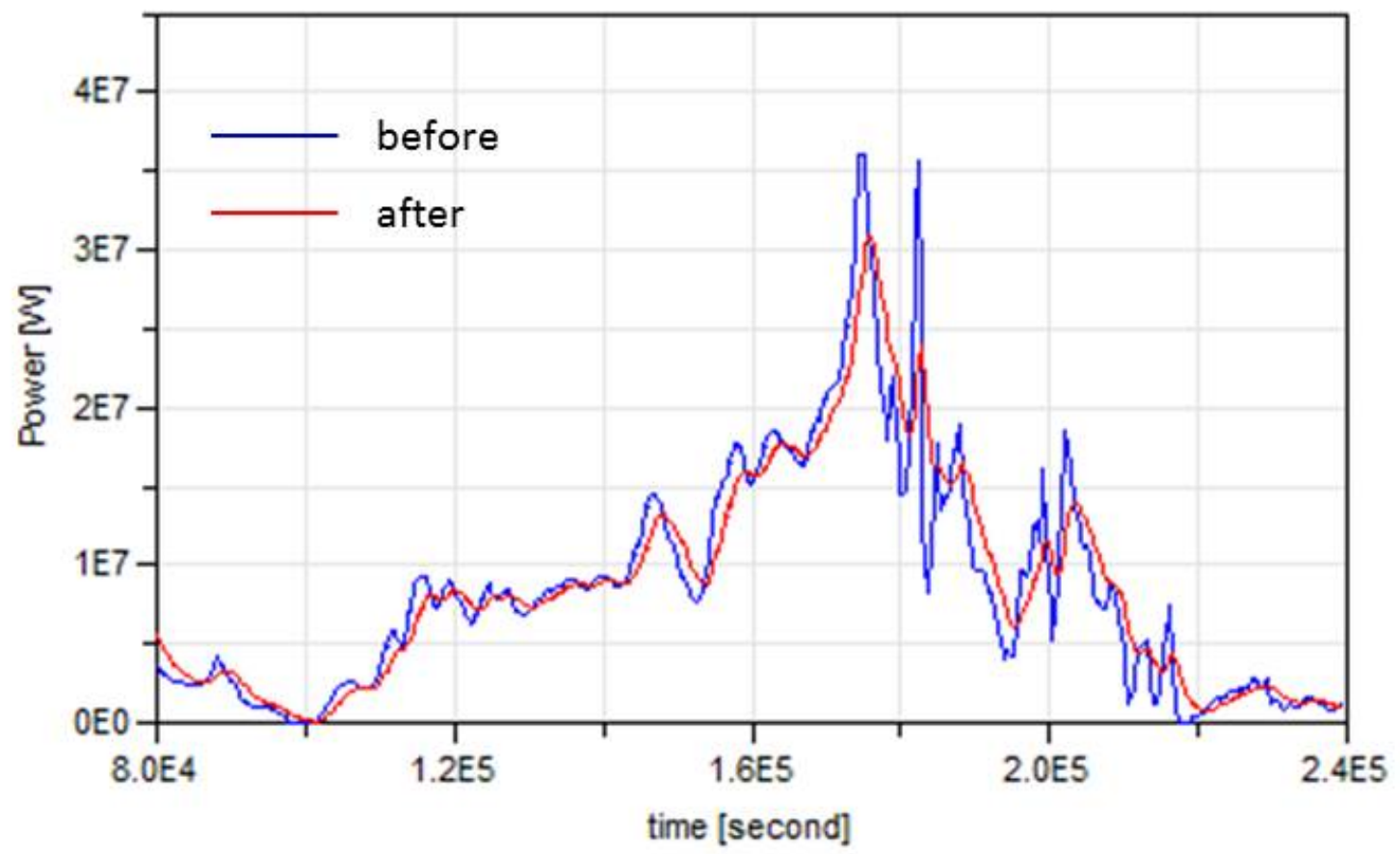

Figure 43. Renewable generation before and after power smoothing with a time constant of $1800 \mathrm{~s}$ (NHES_Texas). 


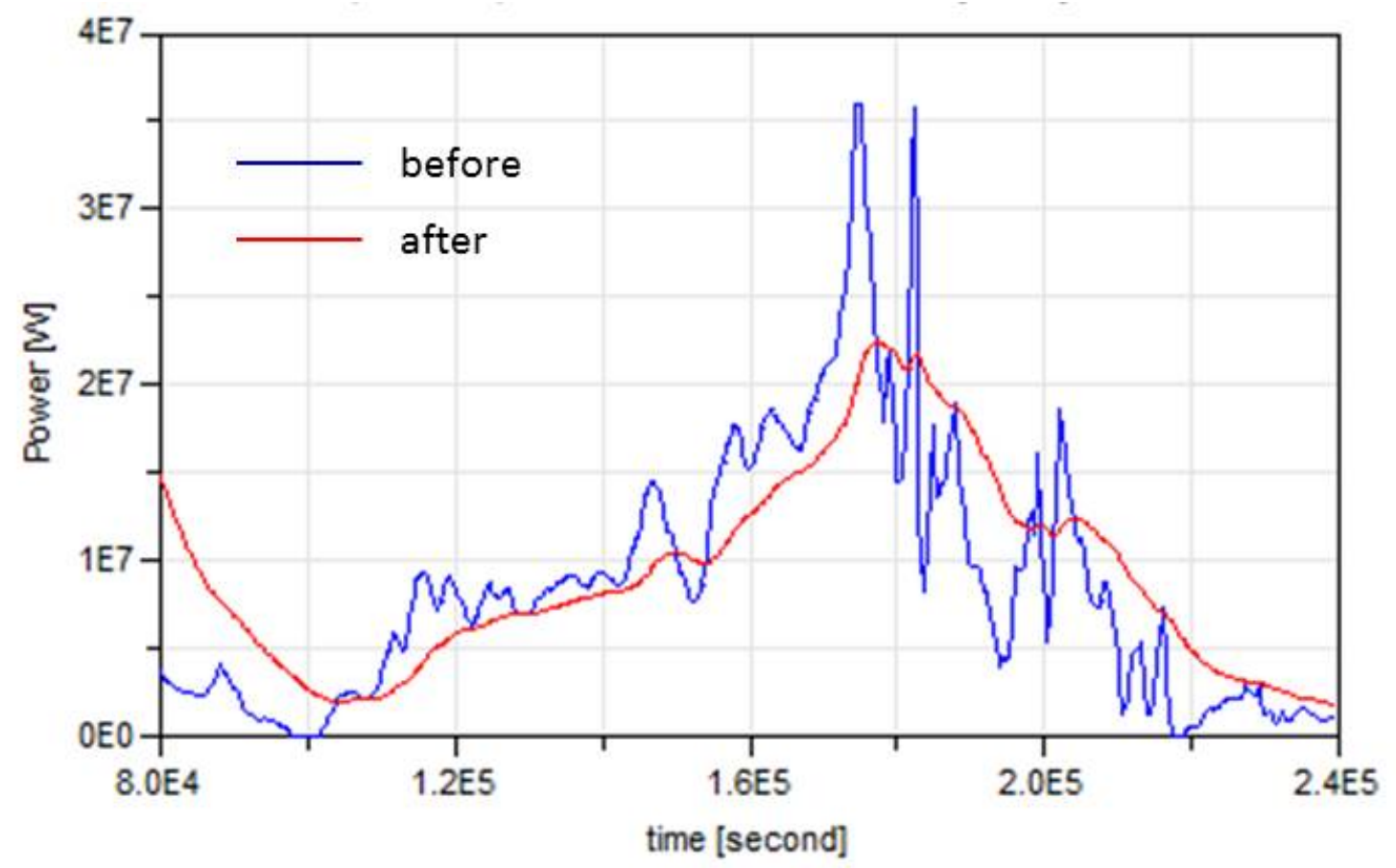

Figure 44. Renewable generation before and after power smoothing with a time constant of $9000 \mathrm{~s}$ (NHES_Texas).

\subsubsection{Ancillary service: Response time and ramp-rate}

In order to assess the response time and ramp-rate characteristics of NHES_Texas, a demand profile with a step change is used. The simulation setup values used in this test are listed in Table 17.

Table 17. Simulation setup for NHES_Texas: Response time test.

\begin{tabular}{|l|l|l|}
\hline \multirow{3}{*}{ Electrical generation to grid } & source & Figure 29 profile \\
\cline { 2 - 3 } & height & $25 \mathrm{MWe}$ \\
\cline { 2 - 3 } & duration & $0.01 \mathrm{~s}$ \\
\cline { 2 - 3 } & startValue & $155 \mathrm{MWe}$ \\
\cline { 2 - 3 } & startTime & $2500 \mathrm{~s}$ \\
\hline Wind profile & source & $18 \mathrm{MWe}$ (constant) \\
\hline Power smoothing time constant $\left(\tau_{E S E}\right)$ & $1800 \mathrm{~s}$ \\
\hline Simulation duration & $3000 \mathrm{~s}$ \\
\hline Simulation output interval & $0.01 \mathrm{~s}$ \\
\hline
\end{tabular}

As indicated in Table 17, the transient is initiated at $2500 \mathrm{~s}$ via a 25 MWe increase in electrical grid demand (from an initial generation level of $155 \mathrm{MWe}$ ). This increase is completed within $0.01 \mathrm{~s}$ (hence a very high ramp-rate). Figure 45 shows the time series for both the electrical and mechanical torques at the steam turbine shaft. As can be seen, it requires 0.6 seconds for the mechanical torque to match the corresponding electrical torque change and settle to its final value. This fast response is likely due to effective control strategies implemented, but may also be attributed to the potential absence of engineered constraints (imposed for safety, for example) in the model that may more realistically characterize all key components of concern. Additional constraints will be implemented in future model refinement. Regardless, this preliminary result strongly suggests that NHES_Texas can begin responding very quickly and change its response fast enough to participate in the electric grid ancillary services considered. 


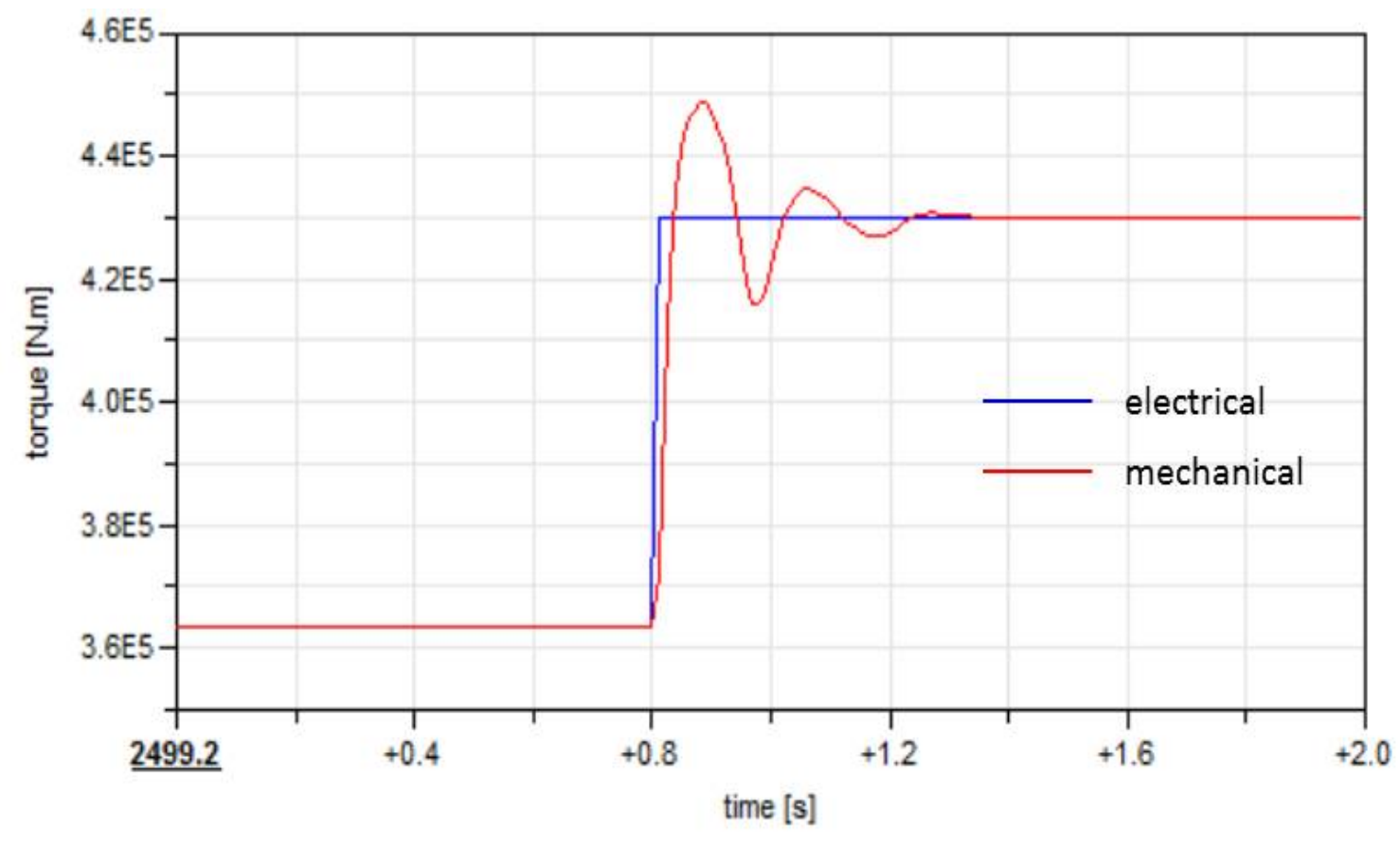

Figure 45. Electrical and mechanical torque at the steam turbine shaft (NHES_Texas).

\subsubsection{Ancillary service: Load following}

As suggested by the previous test, NHES_Texas is predicted to respond fast enough to participate in the ancillary services considered. This test is to further demonstrate the capability of NHES_Texas for load following. The simulation setup values used in this test are listed in Table 18.

Table 18. Simulation setup for NHES_Texas: Load following test.

\begin{tabular}{|l|l|l|}
\hline Electrical generation to grid & source & Texas region actual \\
\hline Wind profile & source & $18 \mathrm{MWe}($ constant $)$ \\
\hline Power smoothing time constant $\left(\tau_{E S E}\right)$ & $1800 \mathrm{~s}$ \\
\hline Simulation duration & $1209600 \mathrm{~s}(2$ weeks $)$ \\
\hline Simulation output interval & $600 \mathrm{~s}$ \\
\hline
\end{tabular}

Figure 46 shows the time series of the flows going to the steam generator and that diverted to the secondary boiler for delivery towards gasoline production, in addition to the steam flow generated by the auxiliary steam boiler for supporting constant gasoline production at the GPP. These results suggest that NHES_Texas can act as a highly responsive device to meet load following needs by accordingly delivering the necessary electricity generation profile demanded by the electric grid, while correspondingly adjusting itself to maintain adequate operating conditions. 


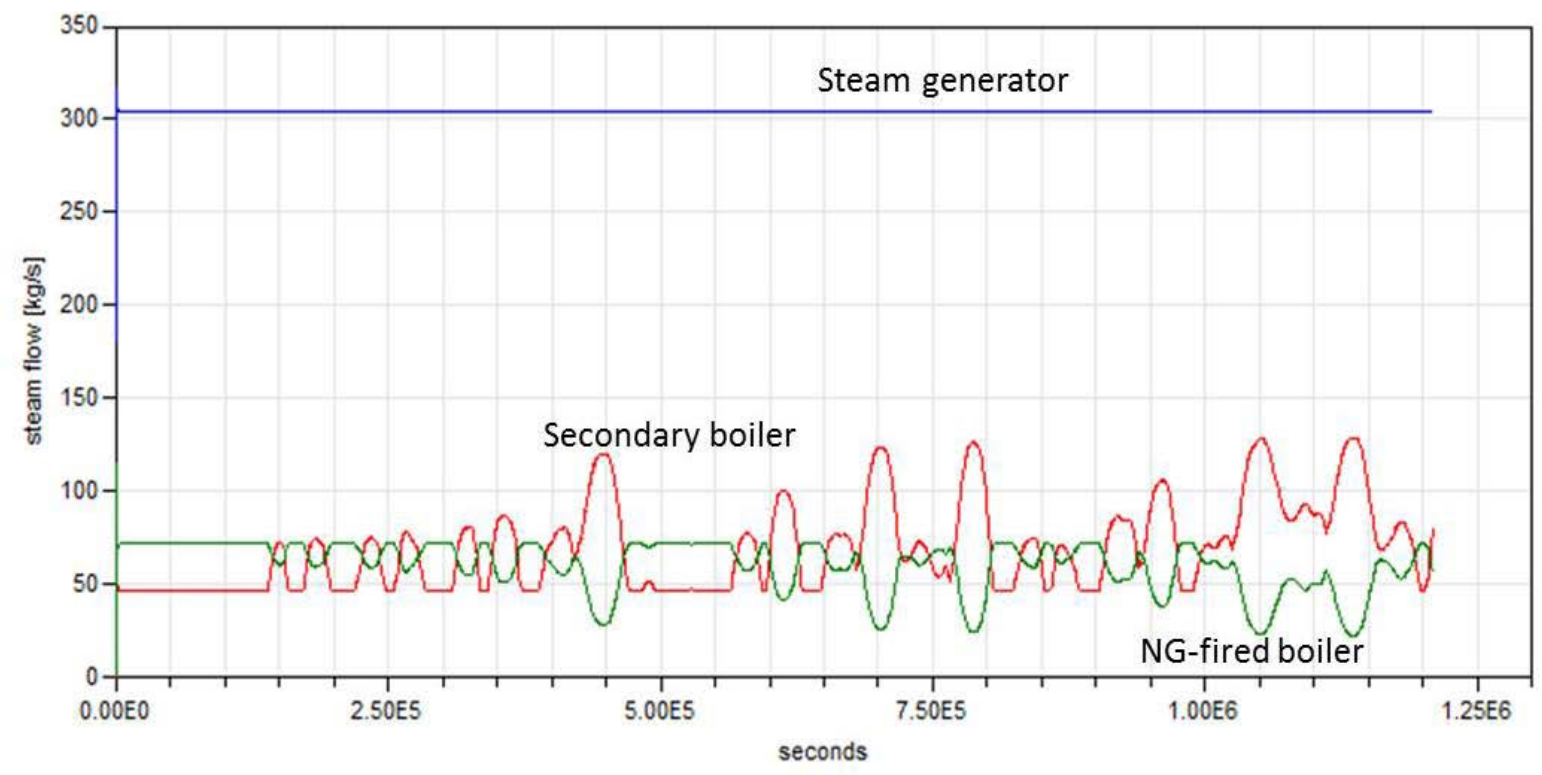

Figure 46. Steam flows to steam generator, secondary boiler, and from the NG-fired boiler (NHES_Texas).

\subsubsection{Ancillary service: Operating reserve}

This test is to further demonstrate the operating reserve capacity that NHES_Texas can provide to the electric grid. The simulation setup values used in this test are listed in Table 19.

Table 19. Simulation setup for NHES_Texas: Operating reserve test.

\begin{tabular}{|l|l|l|}
\hline \multirow{5}{*}{ Electrical generation to grid } & source & Figure 29 profile \\
\cline { 2 - 3 } & height & $10 \mathrm{MWe}$ \\
\cline { 2 - 3 } & duration & $600 \mathrm{~s}$ \\
\cline { 2 - 3 } & startValue & $155 \mathrm{MWe}$ \\
\cline { 2 - 3 } & startTime & $2500 \mathrm{~s}$ \\
\hline Wind profile & source & $18 \mathrm{MWe}$ (constant) \\
\hline Power smoothing time constant $\left(\tau_{E S E}\right)$ & $1800 \mathrm{~s}$ \\
\hline Simulation duration & $5000 \mathrm{~s}$ \\
\hline Simulation output interval & $0.1 \mathrm{~s}$ \\
\hline
\end{tabular}

The electric grid demand in this scenario is reported in Table 19, where the requested electricity increases from $155 \mathrm{MWe}$ at $2500 \mathrm{~s}$ to $165 \mathrm{MWe}$ over 10 minutes, which corresponds to the ancillary service requirement for the considered operating reserve. Figure 47 shows the times series for the steam flows going to each of the three installed turbines, respectively. As shown in this figure, the governor quickly adjusts the steam flows entering each turbine in order to effectively accommodate the increased demand. Likewise, Figure 48 shows the times series for the temperature of the steam flow leaving the steam generator. The temperature response from time zero to $2500 \mathrm{~s}$ corresponds to the system initialization from cold shutdown to full operation. Notice the very small perturbation from $2500 \mathrm{~s}$ and beyond in the temperature response caused by the indicated demand increase.

These results suggest that NHES_Texas can provide a large spinning capacity. Being essentially in standby mode with respect to the electric grid, this configuration does essentially exhibit zero startup and shutdown times to deliver the requested operating reserve services. This is achieved by the fact that NHES_Texas offers more than one energy utilization avenue, allowing steam to be diverted to increase or decrease electricity generation quickly when demanded. 


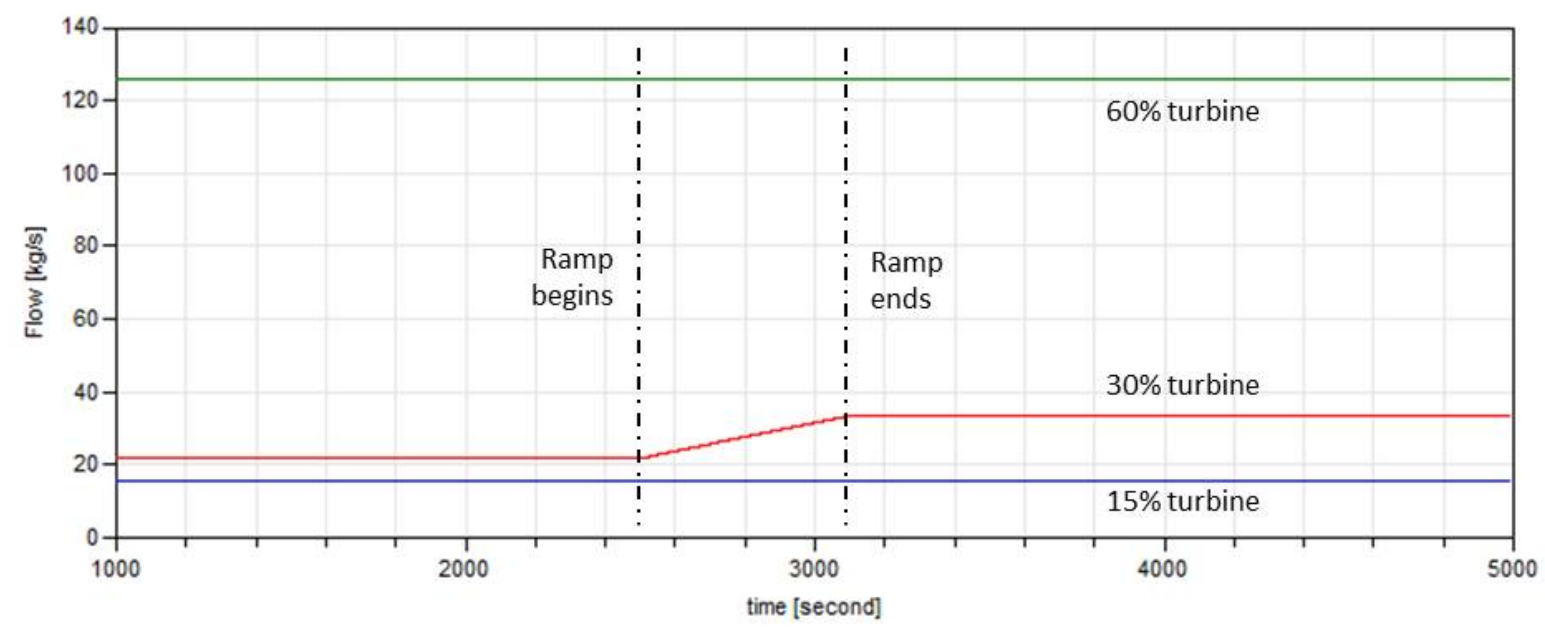

Figure 47. Steam flows to the three 15\%, 30\%, 60\% turbines (NHES_Texas).

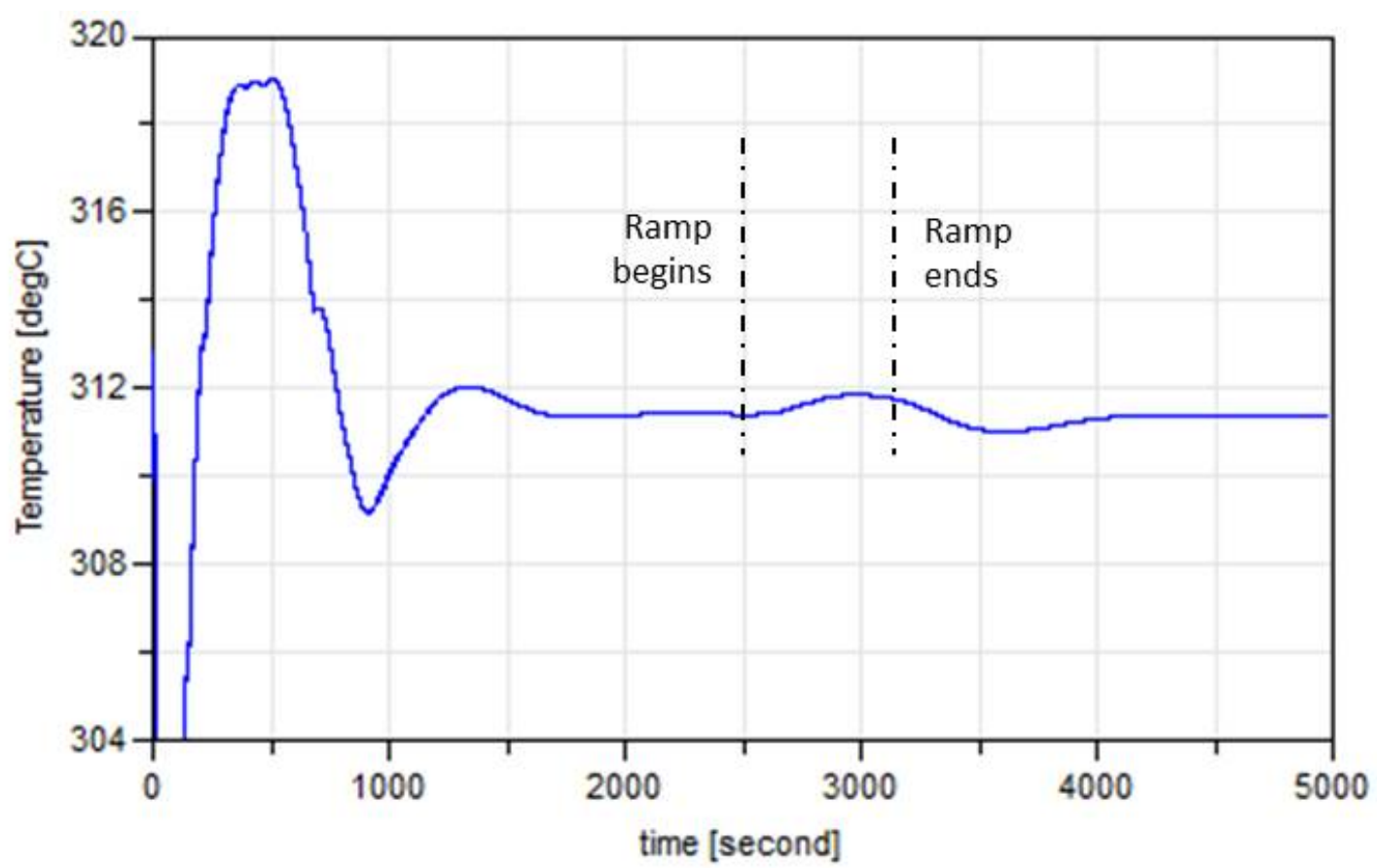

Figure 48. Temperature at steam generator outlet flow (NHES_Texas).

\subsubsection{Operational flexibility for economic optimization}

In order to demonstrate the controllability of NHES_Texas for economic optimization, two scenarios were considered under variable wind power generation. The simulation setup values used in this test are listed in Table 20. 
Table 20. Simulation setup for NHES_Texas: Economic optimization for operations test.

\begin{tabular}{|c|c|c|}
\hline Electrical generation to grid & source & $\begin{array}{ll}\text { 1. } & 171 \mathrm{MWe} \text { (constant) } \\
\text { 2. } & \text { adjusted for PGP } \\
\text { optimization } \\
\text { 3. } \\
\text { adjusted for NPV } \\
\text { optimization }\end{array}$ \\
\hline \multirow[t]{2}{*}{ Wind profile } & source & Texas region actual \\
\hline & $\begin{array}{l}\text { no. of turbines } \\
\text { (3.6 MWe each) }\end{array}$ & 10 \\
\hline \multicolumn{2}{|l|}{ Power smoothing time constant $\left(\tau_{E S E}\right)$} & $1800 \mathrm{~s}$ \\
\hline \multicolumn{2}{|l|}{ Simulation duration } & $31536000 \mathrm{~s}$ (1 year) \\
\hline \multicolumn{2}{|l|}{ Simulation output interval } & $1200 \mathrm{~s}$ \\
\hline
\end{tabular}

The first scenario uses a constant value for electricity generation, representing the case in which the NHES configuration commits to deliver a constant electricity generation to the electric grid without considering the relative pricing of electricity and gasoline. The other scenarios use economic optimization to determine the most advantageous mix of products, resulting in variable electricity generation as a function of the time-dependent commodity and feedstock prices.

In order to compute the value for $\mathrm{k}_{0}$ and $\mathrm{k}_{1}$ which characterize the linear relationship shown in Eq. (11) and Section A.1.1 of APPENDIX A between the steam flow $\mathrm{M}_{\mathrm{NG}}$ generated by the NG-fired boiler and the net load $\left(\mathrm{P}_{\mathrm{e}}-\mathrm{P}_{\mathrm{w}}\right)$, several simulations were conducted to obtain the relationship plotted in Figure 49, where the horizontal axis is the net load, while the vertical axis is the thermal contribution delivered by AHG. Recall that the net load is the remaining demand that must be met by conventional generators (the nuclear reactor in this example) after variable generation is subtracted from the total demand.

$M_{N G}=k_{0}+k_{1}\left(P_{e}-P_{w}\right)$

Assuming that burning $0.06 \mathrm{~kg}$ natural gas would generate $1 \mathrm{~kg}$ of steam [6], then $\mathrm{k}_{0}=-8.07$ [kg/s] and $\mathrm{k}_{1}=7.63 \mathrm{e}-2[\mathrm{~kg} / \mathrm{s} / \mathrm{MW}]$. It also was assumed that $1 \mathrm{~kg}$ of natural gas burned would generate 2.697867 $\mathrm{kg}$ of $\mathrm{CO}_{2}[5]$.

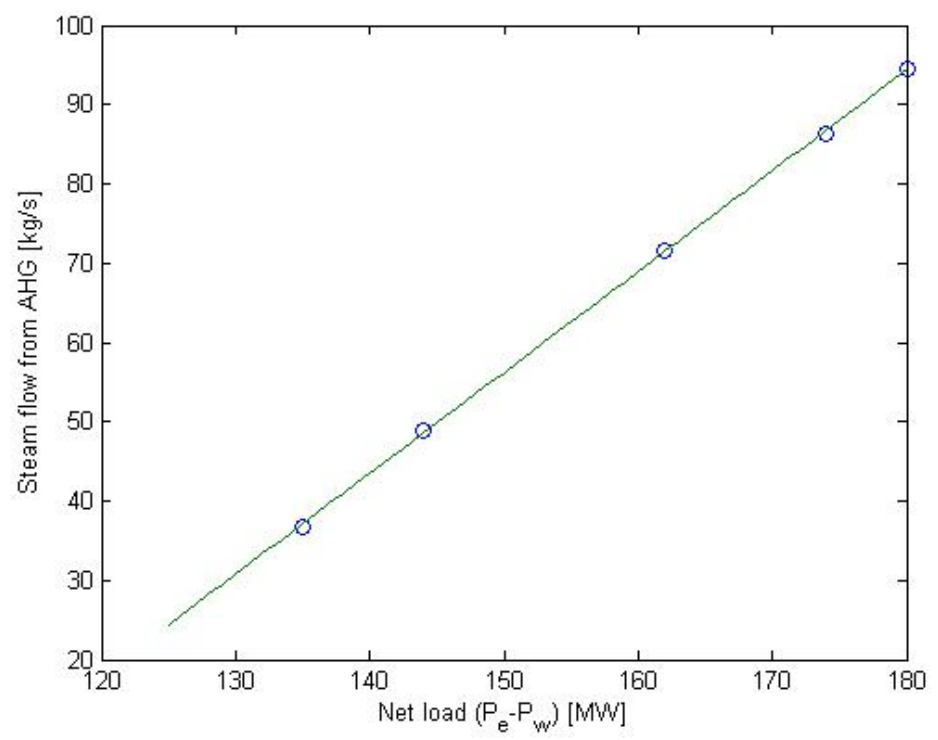

Figure 49. Steam flow generated by NG-fired boiler versus net load $\left(P_{e}-P_{w}\right)$. 


\section{Economic FOM: Pre-tax Gross Profit}

The resulting optimal electricity production for NHES_Texas is shown in Figure 50, corresponding to the maximization of pre-tax gross profit (PGP) and assuming the price trend of Figures 30 and 31 and the wind production rate shown in Figure 34. This adjusted electricity generation profile is then fed to NHES_Texas to test system performance and demonstrate the system's flexibility to operate under this PGP-driven mode. Note that when the natural gas is at a relatively high price, the operations optimizer (supporting economic optimization for operations) prefers to produce less electricity in order to reduce consumption of NG to maintain constant full production mode at the gasoline production plant. When the price for NG decreases, the cost of consuming NG also decreases. In such cases, the operations optimizer chooses to increase the production of electricity to the electric grid by decreasing the amount of thermal energy that is diverted to GPP, which accordingly increases the amount of NG used by AHG. Note that in the latter case the electricity production is at its maximum of $180 \mathrm{MWe}$.

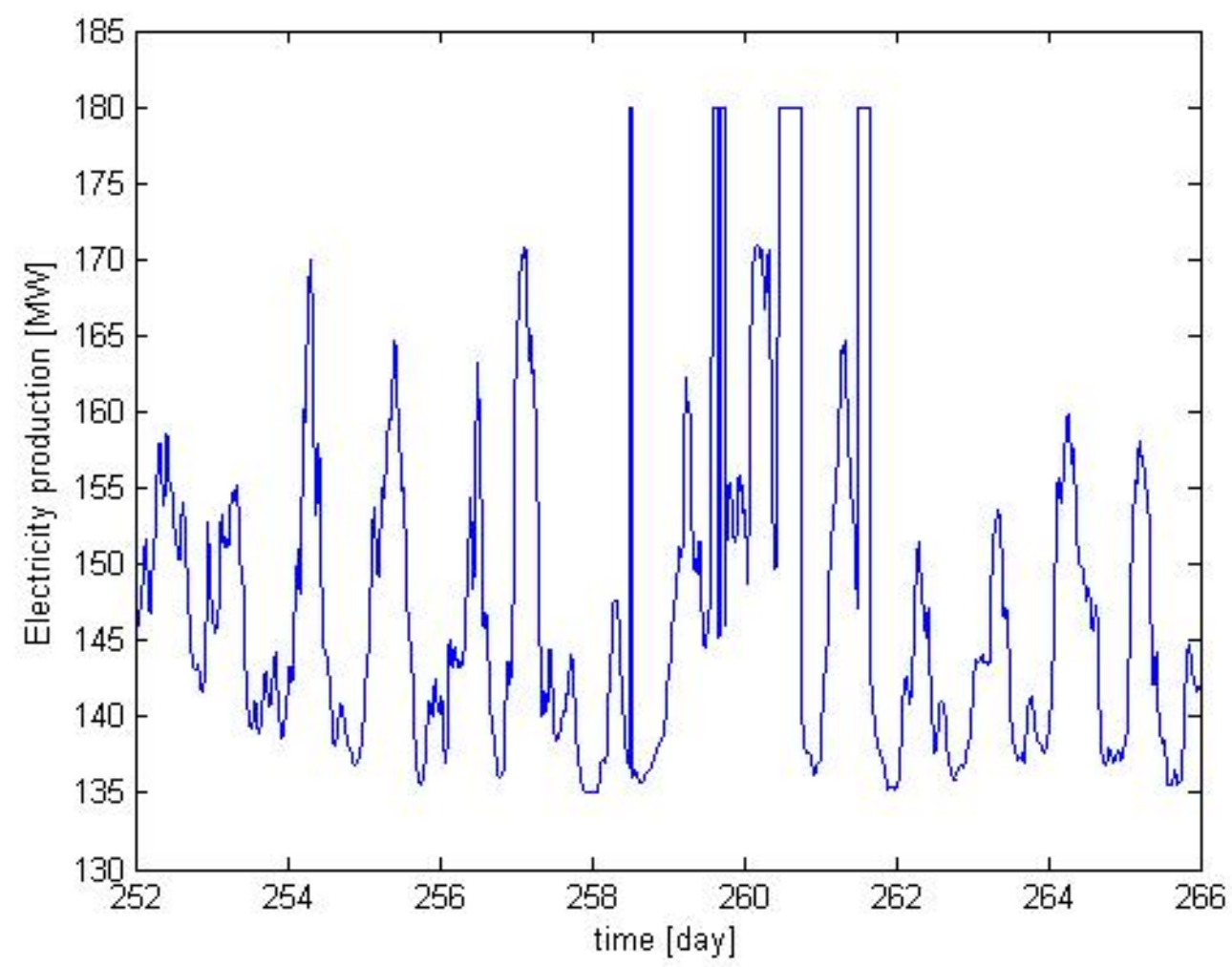

Figure 50. Optimal electricity production for a selected 14 day period for PGP and price trend reported in Figures 30 and 31 (NHES_Texas).

As noted before, the gasoline production rate is held constant such that the revenue from the sale of gasoline is not affected by the operations optimizer. Hence, the simplified objective function under optimization, i.e., $J=\int_{0}^{T} P_{e} \beta_{e}-M_{N G_{-} A H G} \beta_{N G}-M_{C} \beta_{C} d t$, is used to analyze the simulation results.

Based on the cost parameters values reported in Table 9, Table 21 reports economic metrics associated with the first year of operation with and without economic optimization. Excluding the gasoline sales, Table 21 shows that the simplified objective function for NHES_Texas increases from $\$-408,313$ at constant operation mode to $\$ 6,684,607$ when considering the modeled commodity market dynamics. 
Table 21. Economic values for first year of operation (NHES_Texas).

\begin{tabular}{|l|r|r|r|}
\hline Economic value & \multicolumn{1}{l|}{$\begin{array}{l}\text { Optimized Electricity } \\
\text { Generation }\end{array}$} & $\begin{array}{l}\text { Constant Electricity } \\
\text { Generation }\end{array}$ & \multicolumn{1}{l|}{ Gain } \\
\hline Revenue - Electricity & $\$ 37,157,285$ & $\$ 43,181,004$ & $-13.95 \%$ \\
\hline Revenue - Gasoline & $\$ 1,218,743,747$ & $\$ 1,218,743,747$ & $0.00 \%$ \\
\hline Cost - Penalty for CO2 & $(\$ 11,129,636)$ & $(\$ 15,893,894)$ & $\mathbf{- 2 9 . 9 8 \%}$ \\
\hline Cost - NG for boiler & $(\$ 19,343,042)$ & $(\$ 27,695,423)$ & $\mathbf{- 3 0 . 1 6 \%}$ \\
\hline Cost - NG for CP & $(\$ 351,184,318)$ & $(\$ 351,184,318)$ & $0.00 \%$ \\
\hline Cost - Water for CP & $\$ \$ 7,770,339)$ & $(\$ 7,770,339)$ & $0.00 \%$ \\
\hline PGP & $\$ 866,473,697$ & $\$ 859,379,779$ & $0.83 \%$ \\
\hline Simplified Objective Function & $\mathbf{\$ 6 , 6 8 4 , 6 0 7}$ & $\mathbf{- \$ 4 0 8 , 3 1 3}$ & N/A \\
\hline
\end{tabular}

\section{Economic FOM: $N P V$}

The resulting optimal electricity production for NHES_Texas is shown in Figure 51, corresponding to the maximization of NPV and assuming the price trend in Figures 30 and 31 and the wind production in Figure 34 .

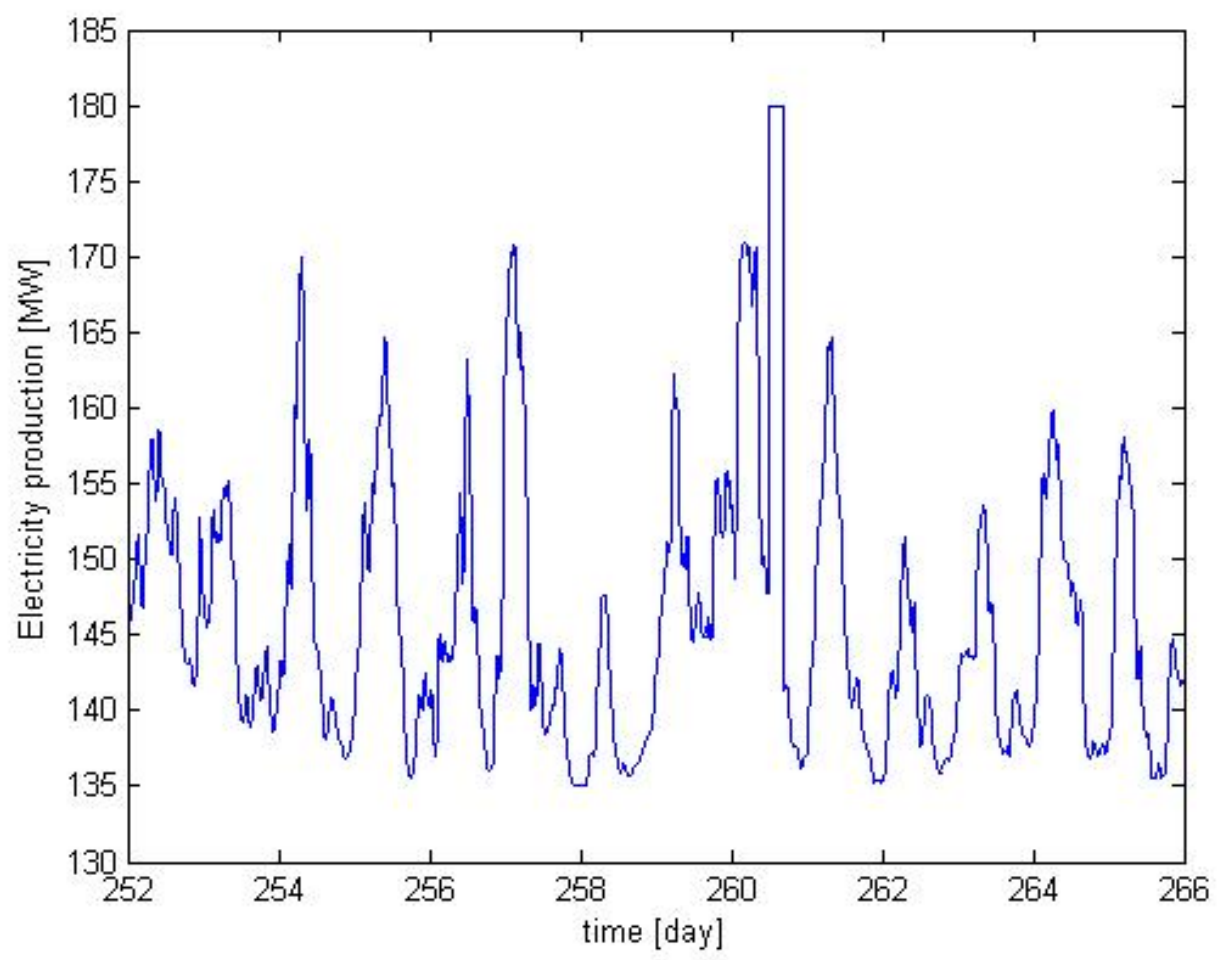

Figure 51. Optimal electricity production for a selected 14 day period for NPV and price trend reported in Figures 30 and 31 (NHES_Texas).

As before, this adjusted electricity generation profile is then fed to NHES_Texas to test system performance and demonstrate the system's flexibility to operate under this NPV-optimization mode. Table 22 shows that the real discounted FCFF for the first year under this NHES configuration increases from $\$ 421,539,071$ at constant operation mode to $\$ 428,728,703$ (a $1.71 \%$ gain) when considering the modeled commodity market dynamics. 
Table 22. FCFF for the first year of operation (NHES_Texas).

\begin{tabular}{|l|r|r|r|}
\hline Economic value & $\begin{array}{l}\text { Optimized Electricity } \\
\text { Generation }\end{array}$ & $\begin{array}{l}\text { Constant } \\
\text { Electricity } \\
\text { Generation }\end{array}$ & \multicolumn{1}{c|}{ Gain } \\
\hline Revenue - Electricity & $\$ 36,898,348$ & $\$ 43,181,004$ & $-14.55 \%$ \\
\hline Revenue - Gasoline & $\$ 1,218,743,760$ & $\$ 1,218,743,760$ & $0.00 \%$ \\
\hline Cost - Penalty for CO2 & $(\$ 10,611,369)$ & $(\$ 15,893,894)$ & $\mathbf{- 3 3 . 2 4 \%}$ \\
\hline Cost - NG for boiler & $(\$ 18,479,768)$ & $(\$ 27,695,423)$ & $\mathbf{- 3 3 . 2 8 \%}$ \\
\hline Cost - NG for CP & $(\$ 351,184,318)$ & $(\$ 351,184,318)$ & $0.00 \%$ \\
\hline Cost - Water for CP & $\mathbf{\$ 4 2 8 , 7 2 8 , 7 0 3}$ & $\mathbf{\$ 4 2 1 , 5 3 9 , 0 7 1}$ & $\mathbf{1 . 7 1 \%}$ \\
\hline FCFF & & & $0.00 \%$ \\
\hline
\end{tabular}

Figure 52 plots the electrical contribution delivered to the electric grid by the nuclear reactor, i.e., the system load minus the output from the renewable generation fleet (or net load, $\mathrm{P}_{\mathrm{e}}-\mathrm{P}_{\mathrm{w}}$ ), under both PGP-optimization and NPV-optimization modes, for a selected 14 day period. These results suggest that under both scenarios, the operations optimizer tends to divert the thermal power from the nuclear reactor from electricity generation to GPP and only increases the electrical contribution when the price for electricity is very high. Considering the fact that the nuclear reactor used in this case study can deliver a maximum rated power of $180 \mathrm{MWe}$, this result suggests that for most of the time NHES_Texas has a capacity of $45 \mathrm{MWe}$ for participation in operating reserve services, generating revenue from providing operating reserve services on top of the sale of electricity. Under the current formulation, the electrical contribution increases only as a response to high electricity prices in the day ahead market. Participation in the ancillary service market is not considered in this report. Notice that this 45 MWe capacity can be used for gasoline production or accordingly diverted to the electric grid as needed. As this operating reserve capacity value is limited by the rated capacity of the associated flexible load resource (GPP in this case), higher capacity values can be achieved by expanding its existing FLR and/or installing additional FLR, such as a hydrogen generation plant.

(a) PGP

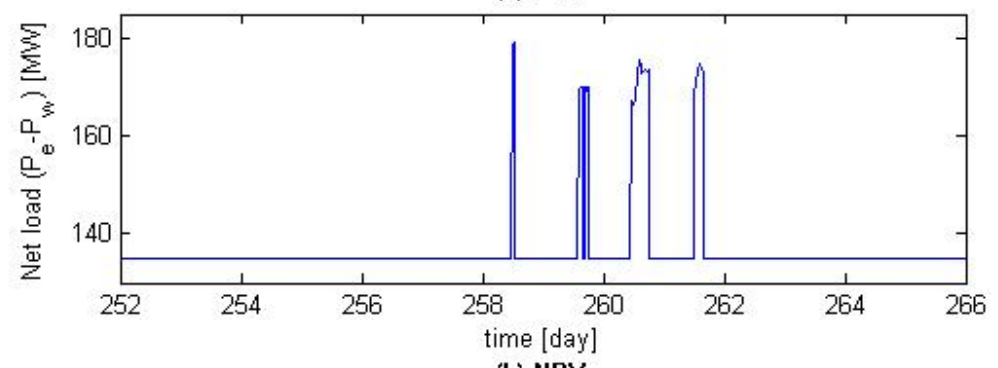

(b) NPV

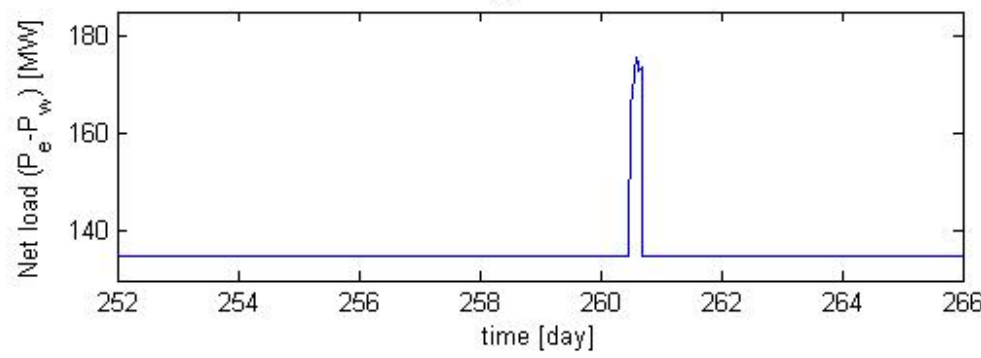

Figure 52. Electrical generation delivered to the electric grid by the nuclear reactor under (a): PGP and (b): NPV optimization for a selected 14 day period. 
Similarly, Figure 53 plots the cumulative NPV as a function of time with and without economic optimization for operations and assuming that the commodity trends (e.g., price, production, and consumption) in subsequent years are the same as those assumed for the first year. Based on the preliminary cost parameter values reported in Table 9, Figure 53 indicates that the payback time for NHES_Texas is about 8.27 and 8.45 years when including NPV optimization or not, respectively. The internal rate of return (IRR) is $14.5 \%$ for 30 years of operation under the optimized case.

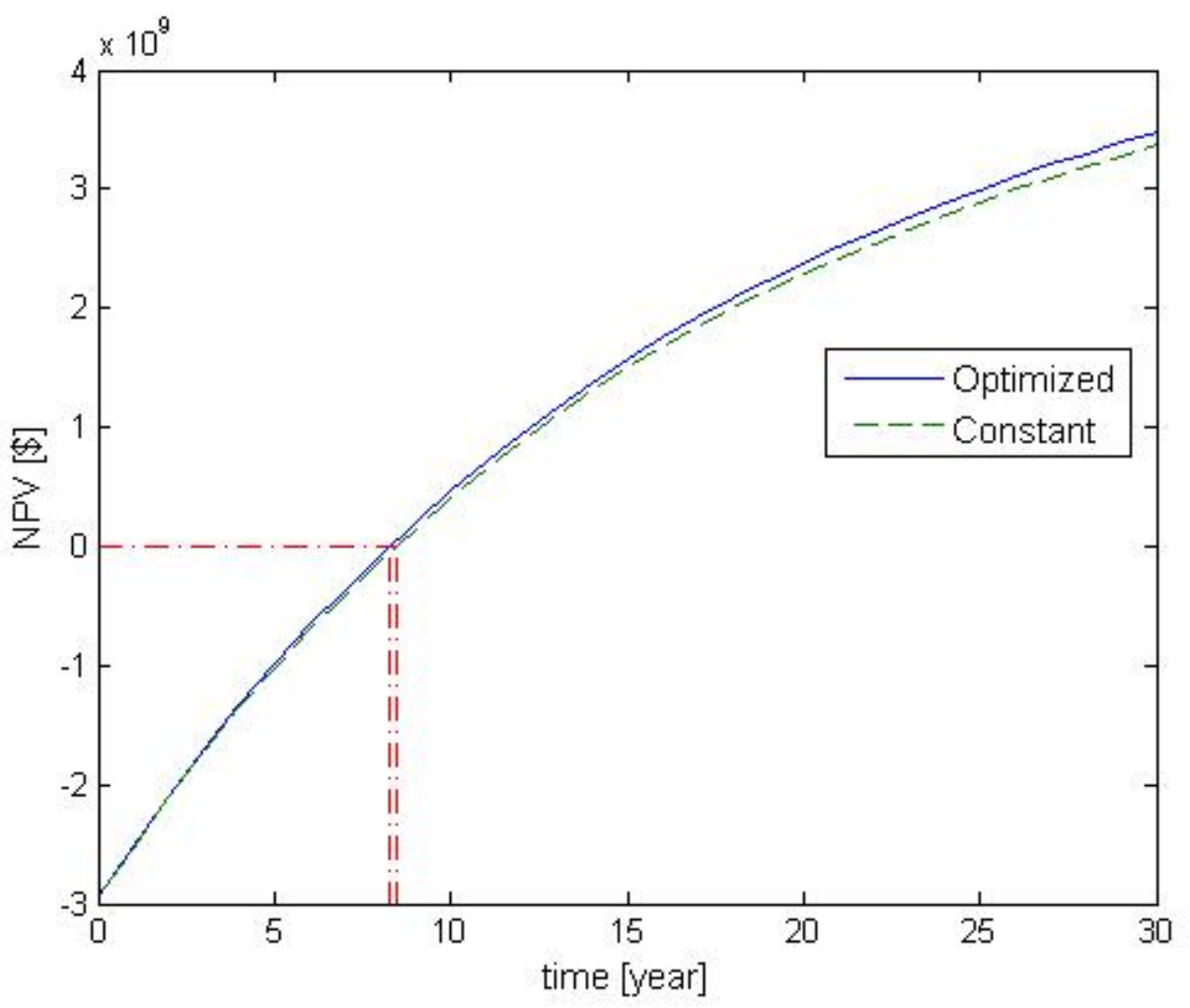

Figure 53. Cumulative NPV as a function of time using cost parameters in Table 9 (NHES_Texas).

In order to measure the sensitivity of the economic effect of the NHES to the commodity prices, analysis is conducted assuming the price of a certain commodity is increasing or decreasing at a steady annual rate. The constant operational mode is also assumed for this analysis. Figure 54 shows the payback time as a function of price change rate. The result suggests that the influence of electricity price on payback time is not significant, while the payback time is sensitive to the prices of NG and gasoline. In particular, if the annual increase rate for NG price is higher than $7 \%$, or the annual decrease rate for gasoline is higher than $4 \%$, then the system may not be economically attractive. Note that this sensitivity study is conducted for NHES_Texas only. A similar analysis for NHES_Arizona will be conducted in a future effort. 


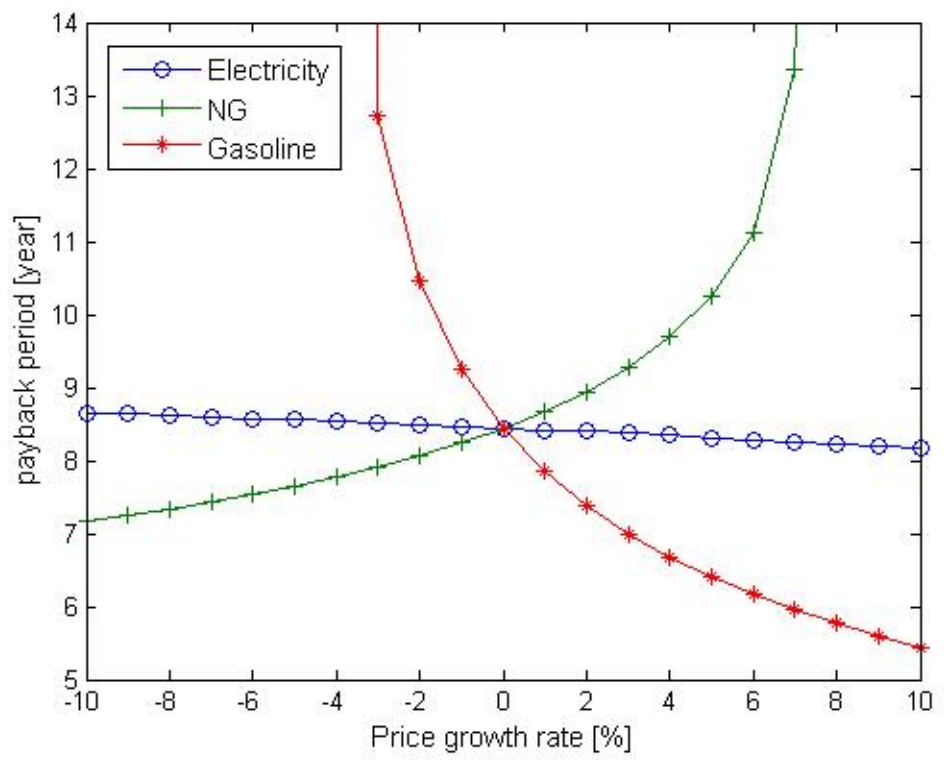

Figure 54. Payback time as a function of price change rate assuming constant operational mode using cost parameters in Table 9 (NHES_Texas).

These results suggest that NHES_Texas has the flexibility to be controlled for economic optimization, for example, while maintaining desired electricity quality and operational requirements. This attractive performance is further magnified when considering that an annual reduction of 1.4 million metric tons in $\mathrm{CO}_{2}$ emission is achieved by using a nuclear reactor as the baseload unit as opposed to using a NG-fired unit, for example.

\subsection{NHES_Arizona}

This section presents preliminary results of the tests described in Section 3, for a hybrid energy system with a flexible electrical load (NHES_Arizona). The values used for the parameters included in Eqs. (9) and (10) regarding renewable (PV solar) generation are listed in Table 13.

\subsubsection{Impact of renewable penetration}

In this test, the system performance is evaluated under several values of renewable penetration. The simulation setup values used in this test are listed in Table 23.

Table 23. Simulation setup for NHES_Arizona: Impact of RP test.

\begin{tabular}{|l|l|l|}
\hline Electrical generation to grid & source & $165 \mathrm{MWe}$ (constant) \\
\hline PV solar profile & source & Arizona region actual \\
\cline { 2 - 3 } & $\begin{array}{l}\text { no. of units }(4 \mathrm{MWe} \\
\text { each) }\end{array}$ & $\begin{array}{l}\text { c. } 5 \\
\text { d. } 8\end{array}$ \\
\hline Power smoothing time constant $\left(\tau_{E S E}\right)$ & $1800 \mathrm{~s}$ \\
\hline Simulation duration & $604800 \mathrm{~s}(1$ week) \\
\hline Simulation output interval & $60 \mathrm{~s}$ \\
\hline
\end{tabular}

Figure 55 shows the times series for the steam flows going to each of the three installed turbines, respectively, when considering five and eight PV units. As shown in this figure, the steam flows entering each turbine are essentially unperturbed by the variability of renewable generation due to the flexible electrical load characteristic offered by the reverse osmosis (RO) desalination plant. 


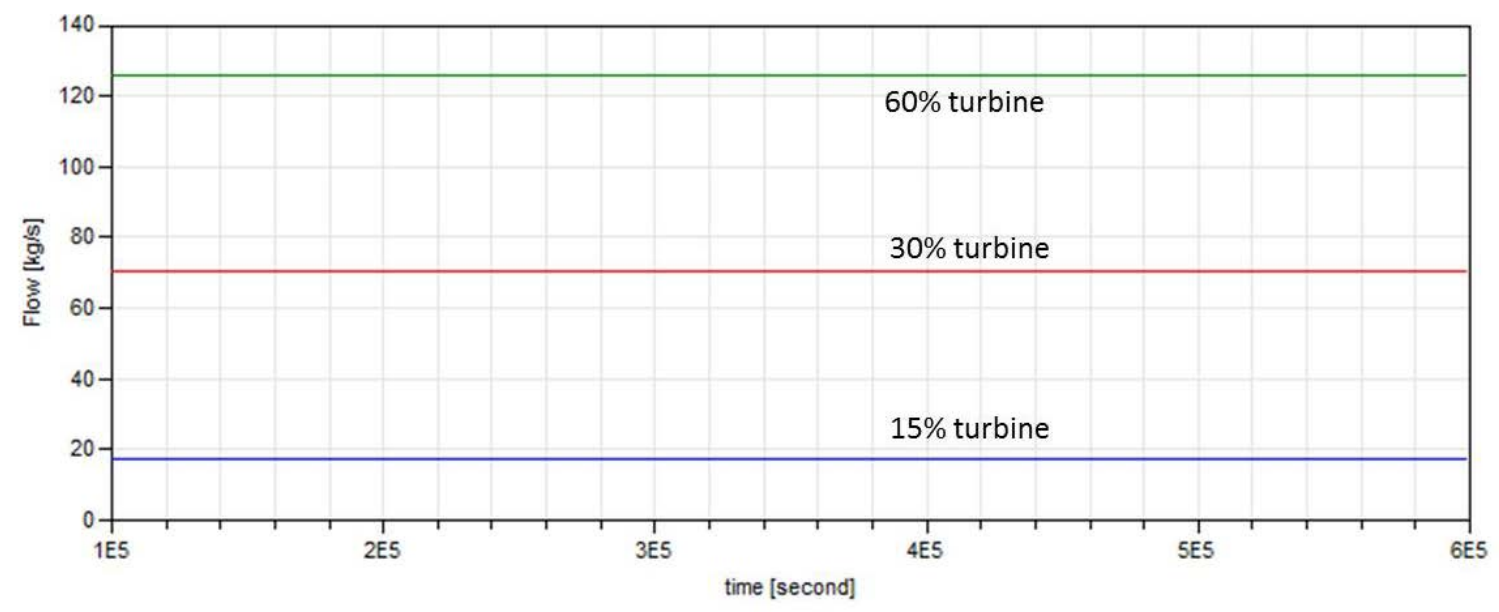

Figure 55. Steam flows entering the three turbines for 5 and 8 PV solar units (NHES_Arizona).

Figure 56 shows the time series of the electrical power frequency when considering five and eight PV solar units. Notice that the electrical power frequency is maintained and does not change even with the inclusion of time-varying renewable generation as determined from actual Arizona data. These results suggest that high penetration levels of renewable energy can be effectively managed by NHES_Arizona, while maintaining adequate dynamic performance.

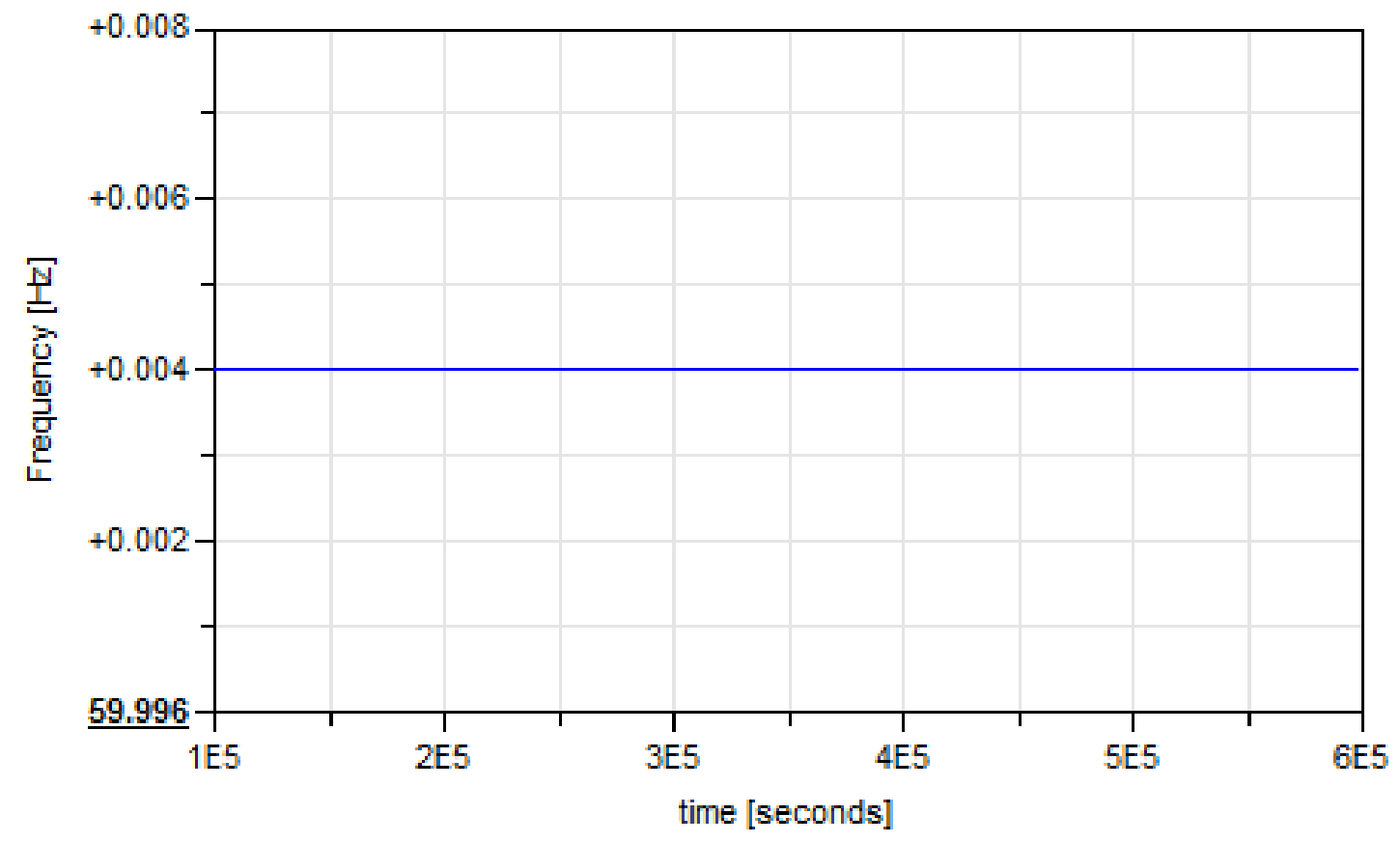

Figure 56. Electrical power frequency for 5 and 8 PV solar units (NHES_Arizona).

\subsubsection{Impact of renewable variability}

In this test, the renewable generation is characterized by a trapezoidal signal as shown in Figure 28, whose amplitude is selected such that the renewable penetration is $12 \%$. The simulation setup values used in this test are listed in Table 24. 
Table 24. Simulation setup for NHES_Arizona: Impact of renewable variability test.

\begin{tabular}{|l|l|l|}
\hline Electrical generation to grid & source & $165 \mathrm{MWe}$ (constant) \\
\hline PV solar profile & source & Figure 28 profile \\
\cline { 2 - 3 } & amplitude & $25 \mathrm{MWe}$ \\
\cline { 2 - 3 } & ramp rate & $\begin{array}{c}\text { c. } 0.21 \mathrm{MWe} / \mathrm{s} \\
\text { d. } 2.1 \mathrm{MWe} / \mathrm{s}\end{array}$ \\
\cline { 2 - 3 } & width & $500 \mathrm{~s}$ \\
\hline Power smoothing time constant $\left(\tau_{E S E}\right)$ & $1800 \mathrm{~s}$ \\
\hline Simulation duration & $10000 \mathrm{~s}$ \\
\hline Simulation output interval & $0.1 \mathrm{~s}$ \\
\hline
\end{tabular}

As indicated in Table 24, the time-varying effect of renewable generation is evaluated by assuming an electrical renewable contribution with a $25 \mathrm{MWe}$ peak and two different large ramp rates: 0.21 and $2.1 \mathrm{MWe} / \mathrm{s}$. These ramp rates were selected after identifying that the maximum ramp rate observed on the actual solar power data collected was $0.35 \mathrm{MWe} / \mathrm{s}$ without power smoothing. Figure 57 shows the time series of the electric power consumed by the desalination plant in response to a time-varying renewable generation. Likewise, Figure 58 shows the time series of the turbine shaft speed. As the turbine shaft speed is essentially unperturbed by rapidly requiring the RO plant to consume power generated by the PV solar plant for water desalination, these results suggest that the high variability of renewable energy can be effectively managed by NHES_Arizona, while maintaining adequate dynamic performance. 
(a)

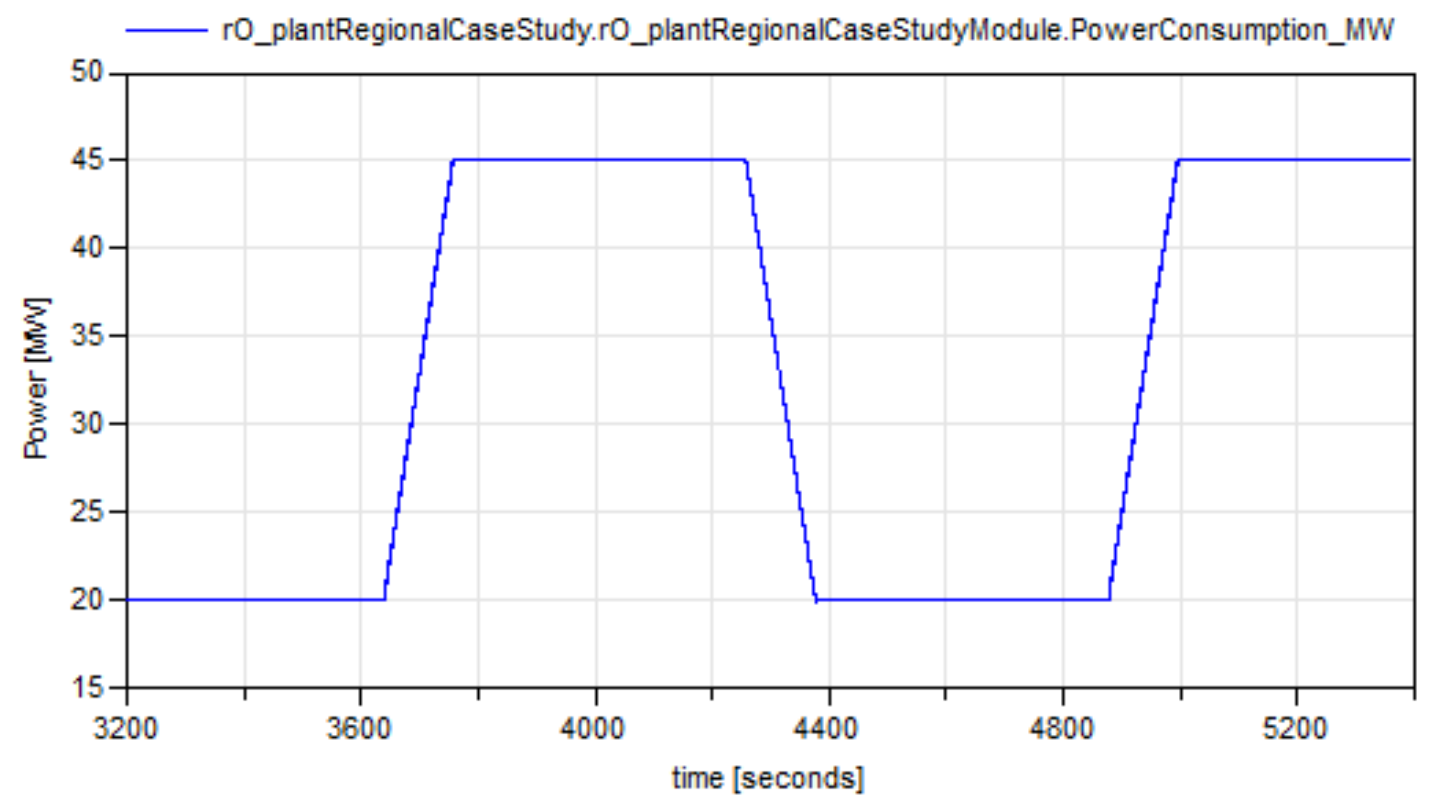

(b)

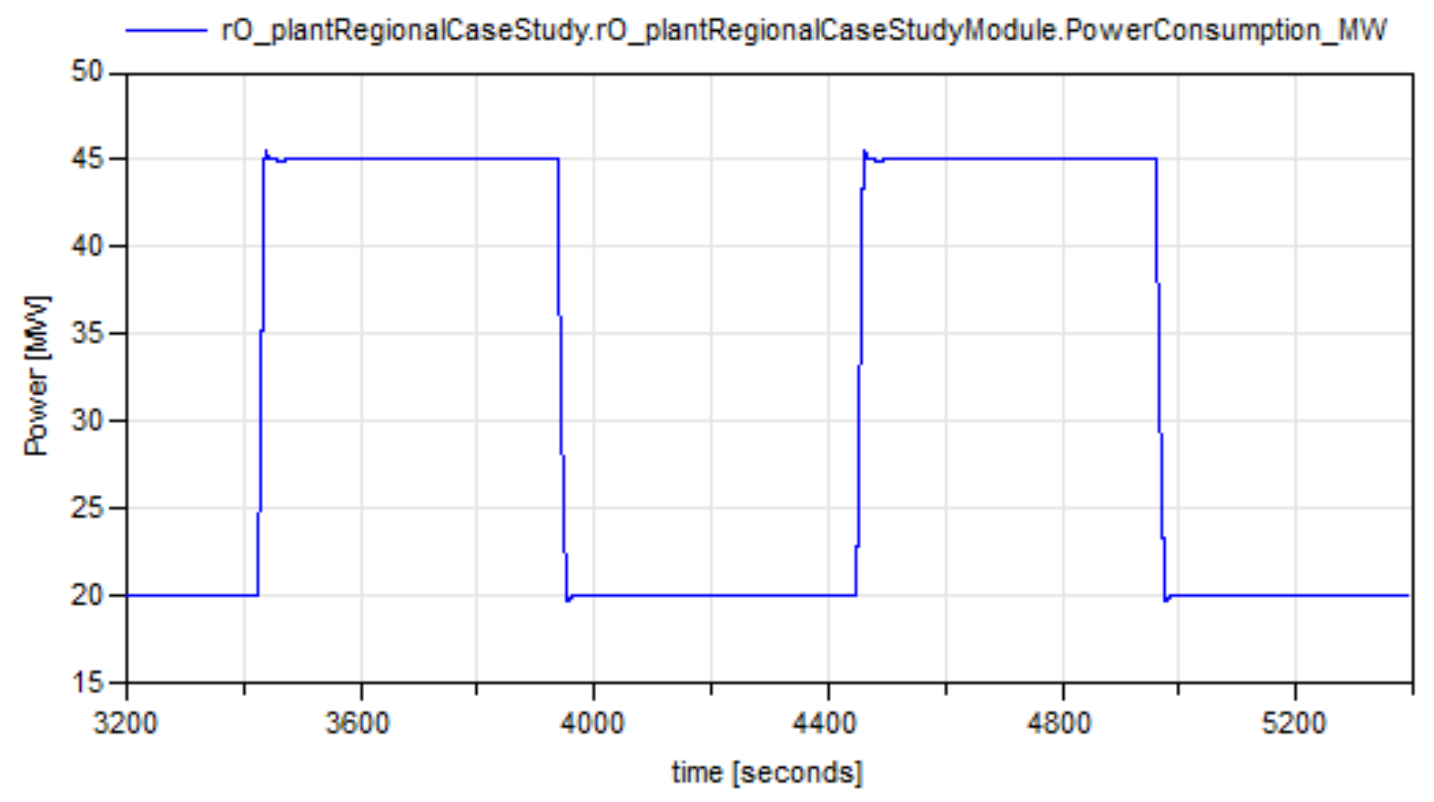

Figure 57 . Electric power consumed by desalination plant under renewable ramp rate of: (a) $0.21 \mathrm{MWe} / \mathrm{s}$; (b) $2.1 \mathrm{MWe} / \mathrm{s}$ (NHES_Arizona). 


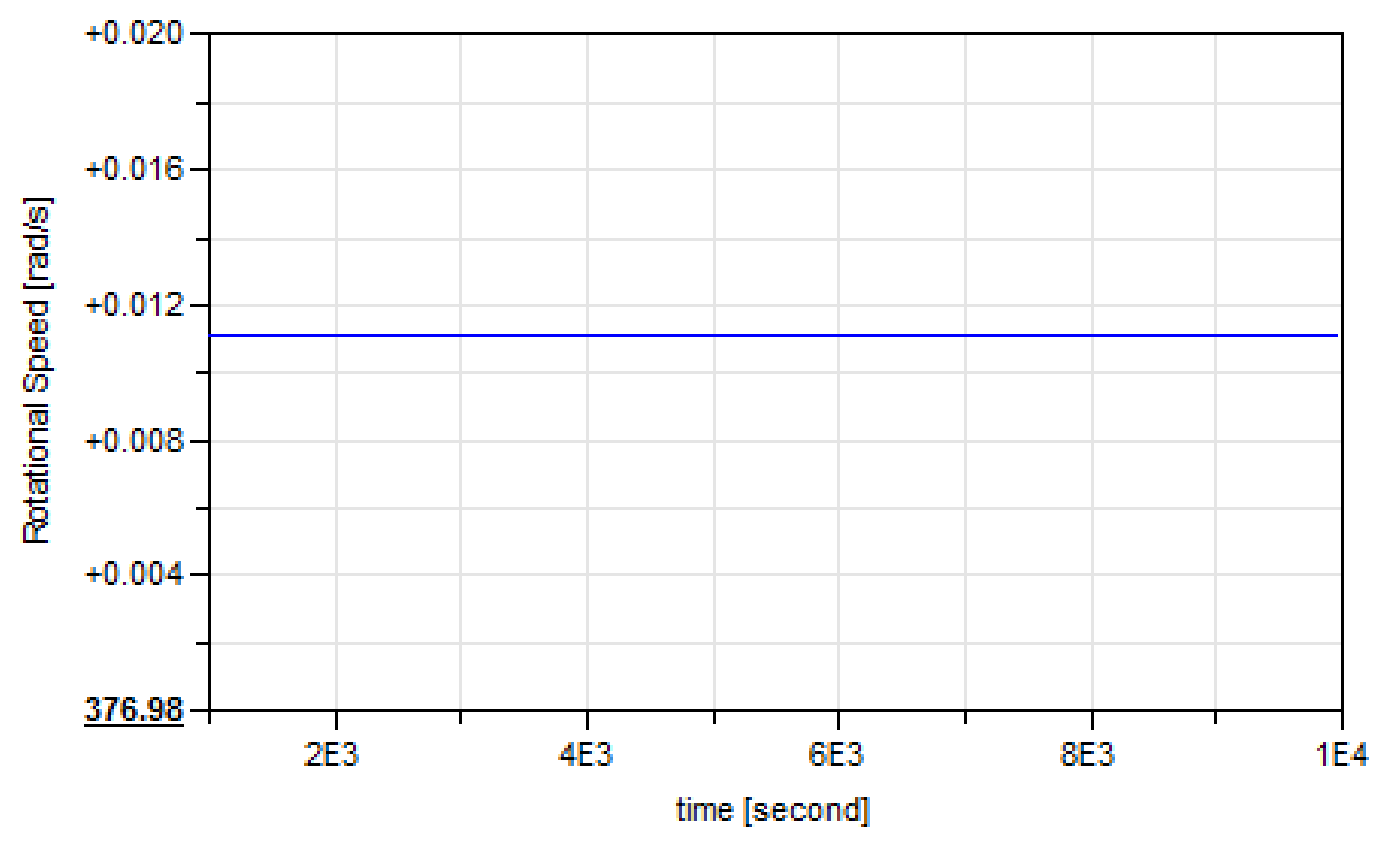

Figure 58. Steam turbine shaft speed for renewable ramp rates of 0.21 and $2.1 \mathrm{MWe} / \mathrm{s}$ (NHES_Arizona).

\subsubsection{Power smoothing for renewable variability attenuation}

In this test, the system performance is evaluated under several values of power smoothing provided by an electrical battery. The simulation setup values used in this test are listed in Table 25 .

Table 25. Simulation setup for NHES_Arizona: Impact of renewable variability test.

\begin{tabular}{|l|l|l|}
\hline Electrical generation to grid & source & $165 \mathrm{MWe}$ (constant) \\
\hline PV solar profile & source & Arizona region actual \\
\cline { 2 - 3 } & no. of units & 6 \\
\hline Power smoothing time constant $\left(\tau_{E S E}\right)$ & $\begin{array}{r}\text { c. } 900 \mathrm{~s} \\
\text { d. } 1800 \mathrm{~s}\end{array}$ \\
\hline Simulation duration & $604800 \mathrm{~s}$ \\
\hline Simulation output interval & $60 \mathrm{~s}$ \\
\hline
\end{tabular}

Figures 59 and 60 show the renewable generation profiles before and after the power smoothing effect introduced by the electric battery for different values of power smoothing time constants. For each figure, the instantaneous power output differences and the areas of continuous charge/discharge cycles correspond to the particular charge/discharge power and energy storage values accommodated by the electric battery. While the largest difference in the instantaneous power output corresponds to the minimum charge/discharge power required for the battery, the largest single contiguous area corresponds to its minimum required energy storage capacity. In this case, the battery needs to have a power rating of 19 MWe and storage capacity of $7 \mathrm{MWe}$-hr to achieve the smoothing effect reported in Figure 59, and a power rating of $21 \mathrm{MWe}$ and storage capacity of $13 \mathrm{MWe}-\mathrm{hr}$ to achieve the smoothing effect reported in Figure 60. Since the capital and operational costs of the battery are directly related to its size, this test provides a benchmark when considering the trade-off between the benefit of incorporating power smoothing to smooth the variability introduced by the renewable source versus the cost of installing system-scale ESE. 


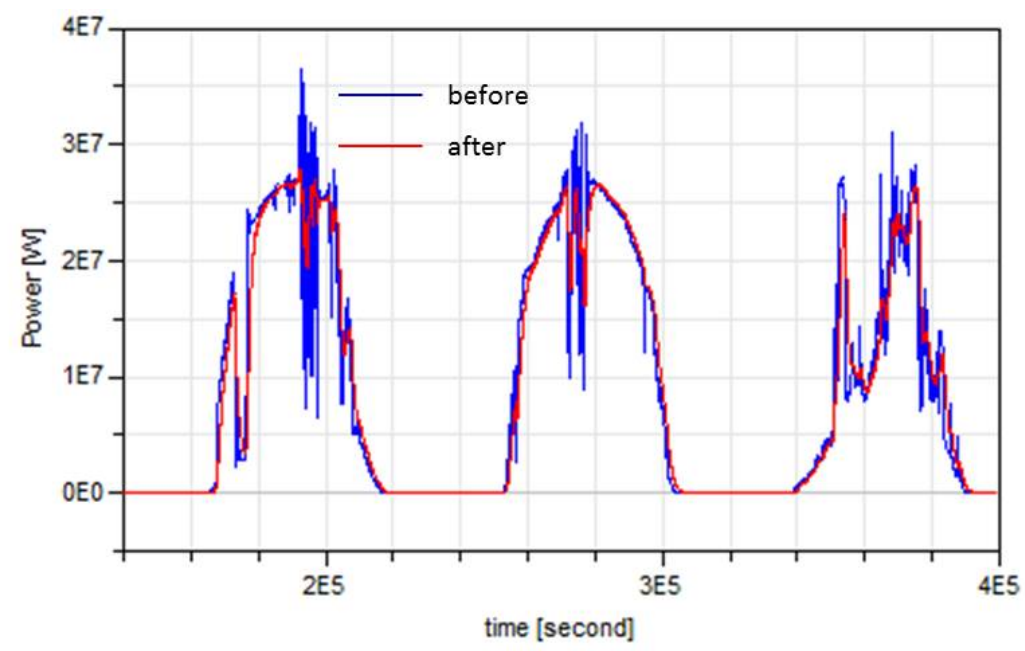

Figure 59. Renewable generation before and after power smoothing with a time constant of $900 \mathrm{~s}$ (NHES_Arizona).

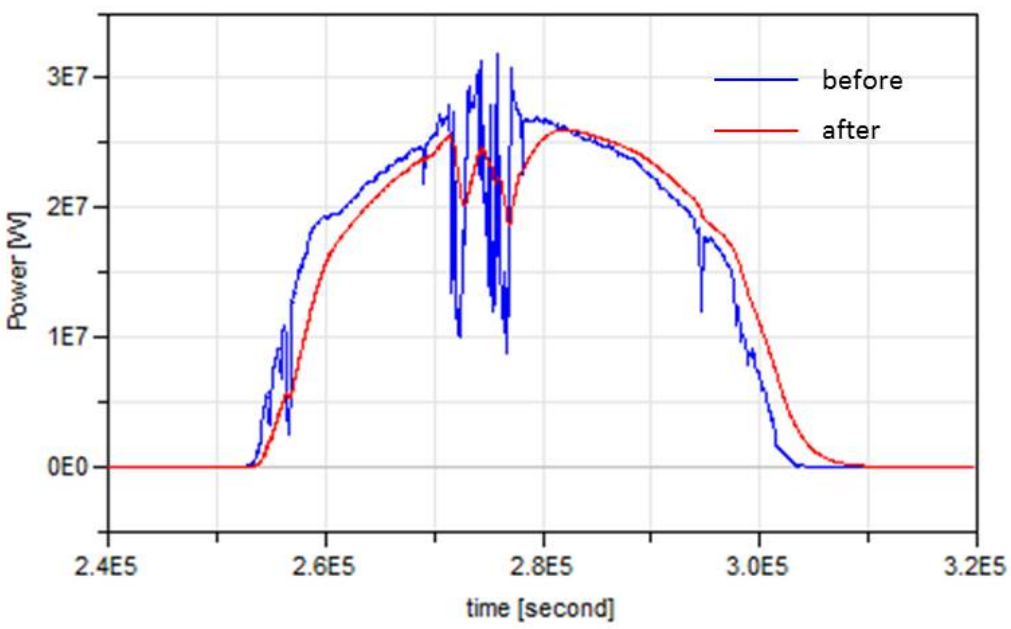

Figure 60. Renewable generation before and after power smoothing with a time constant of $1800 \mathrm{~s}$ (NHES_Arizona).

\subsubsection{Ancillary service: Response time and ramp-rate}

In order to assess the response time and ramp-rate characteristics of NHES_Arizona, a demand profile with a step change is used. The simulation setup values used in this test are listed in Table 26.

Table 26. Simulation setup for NHES_Arizona: Response time test.

\begin{tabular}{|l|l|l|}
\hline \multirow{2}{*}{ Electrical generation to grid } & source & Figure 29 profile \\
\cline { 2 - 3 } & height & $10 \mathrm{MWe}$ \\
\cline { 2 - 3 } & duration & $0.001 \mathrm{~s}$ \\
\cline { 2 - 3 } & startValue & $155 \mathrm{MWe}$ \\
\cline { 2 - 3 } & startTime & $2500 \mathrm{~s}$ \\
\hline PV solar profile & source & $18 \mathrm{MWe}$ (constant) \\
\hline Power smoothing time constant $\left(\tau_{E S E}\right)$ & $1800 \mathrm{~s}$ \\
\hline Simulation duration & $3000 \mathrm{~s}$ \\
\hline Simulation output interval & $0.01 \mathrm{~s}$ \\
\hline
\end{tabular}


As indicated in Table 26, the transient is initiated at $2500 \mathrm{~s}$ via a $25 \mathrm{MWe}$ increase in electrical grid demand (from an initial generation level of $155 \mathrm{MWe}$ ). This increase is completed within $0.001 \mathrm{~s}$ (hence a very high ramp-rate). Figure 61 shows the time series for both the electrical and mechanical torques at the steam turbine shaft. As can be seen, it requires 1.5 seconds for the mechanical torque to match the corresponding electrical torque change and settle to its final value. This fast response is likely due to effective control strategies implemented, but may also be attributed to the potential absence of engineered constraints (imposed for safety, for example) in the model that may more realistically characterize all key components of concern. Additional constraints will be implemented in future model refinement. Regardless, this preliminary result strongly suggests that NHES_Arizona can begin responding very quickly and change its response fast enough to participate in the electric grid ancillary services considered.

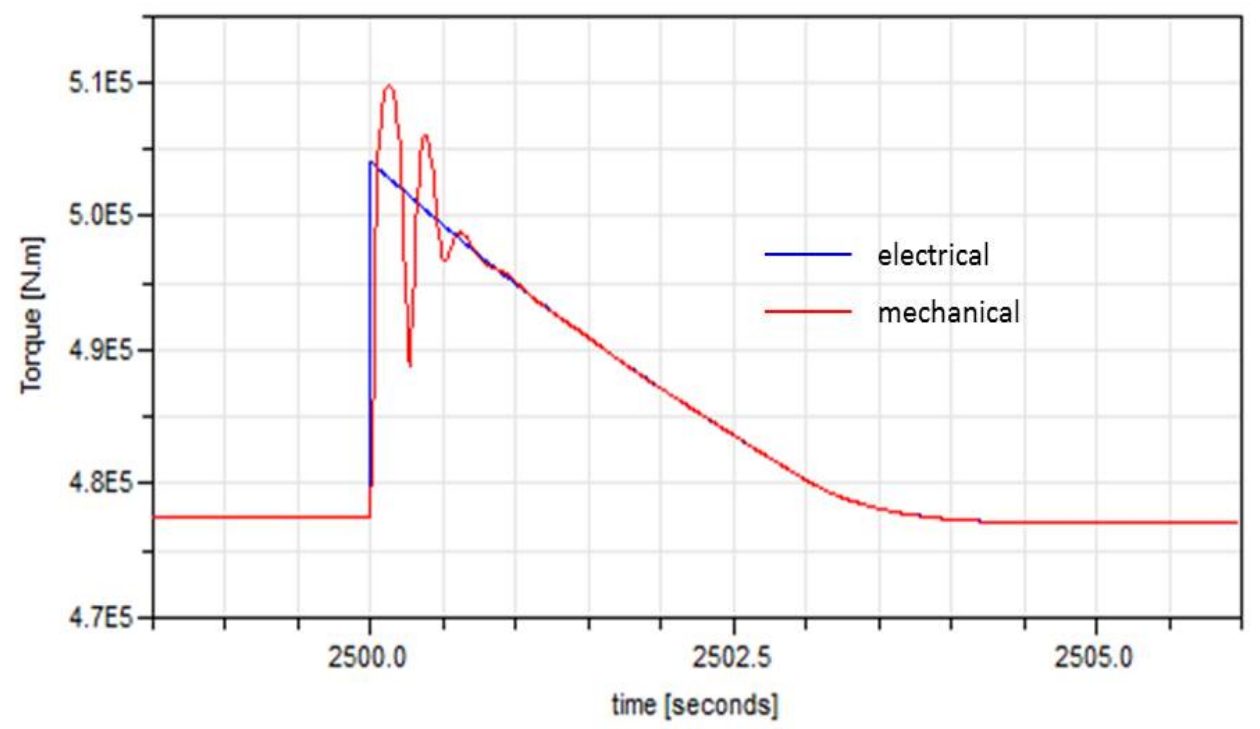

Figure 61. Electrical and mechanical torque at the steam turbine shaft (NHES_Arizona).

\subsubsection{Ancillary service: Load following}

As suggested by the previous test, NHES_Arizona is predicted to respond fast enough to participate in the ancillary services considered. This test is to further demonstrate the capability of NHES_Arizona for load following. The simulation setup values used in this test are listed in Table 27.

Table 27. Simulation setup for NHES_Arizona: Load following test.

\begin{tabular}{|l|l|l|}
\hline Electrical generation to grid & source & Arizona region actual \\
\hline PV solar profile & source & $18 \mathrm{MWe}$ (constant) \\
\hline Power smoothing time constant $\left(\tau_{E S E}\right)$ & $1800 \mathrm{~s}$ \\
\hline Simulation duration & $1209600 \mathrm{~s}(2$ weeks $)$ \\
\hline Simulation output interval & $60 \mathrm{~s}$ \\
\hline
\end{tabular}

Figure 62 shows the time series of the temperature and steam flow at the outlet of the steam generator. Notice that changes in load demand do not lead to changes in these two process variables as these changes are essentially accommodated by the use of the flexible electrical load provided by the RO plant. This adaptation provided by the desalination plant can be observed in Figures 63 and 64. Notice from these figures that while the production and concentration of fresh water vary as the demand varies, the quality of the fresh water produced is well within water purity requirements (i.e., $500 \mathrm{mg} / \mathrm{kg}$ ) at all times. These results suggest that NHES_Arizona can act as a highly responsive device to meet load 
following needs by delivering the necessary electricity generation profile demanded by the electric grid, while correspondingly adjusting operations to maintain adequate operating conditions.

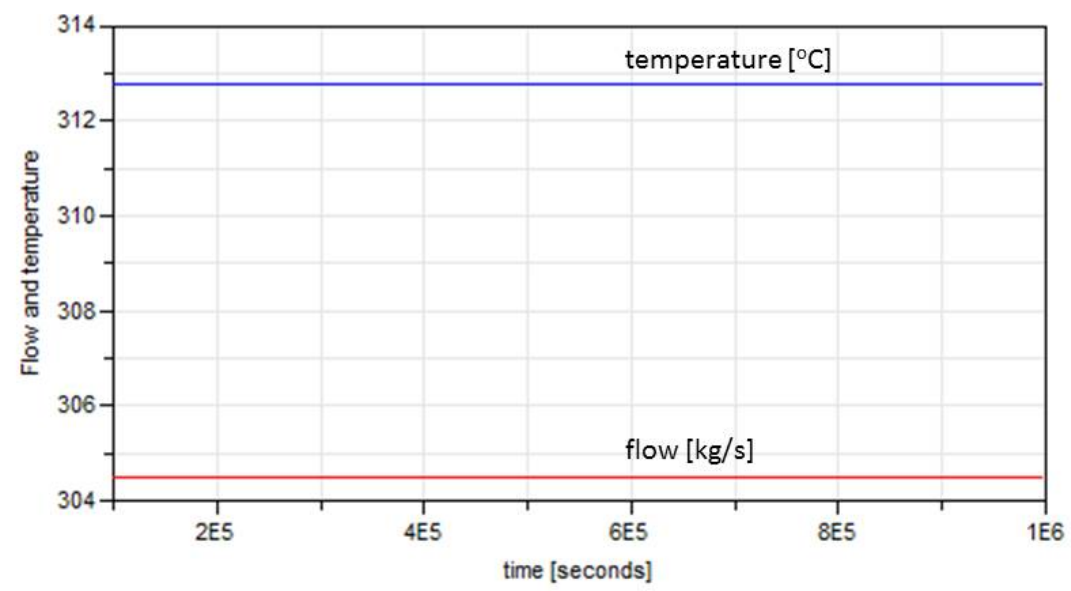

Figure 62. Outlet flow and temperature at steam generator (NHES_Arizona).

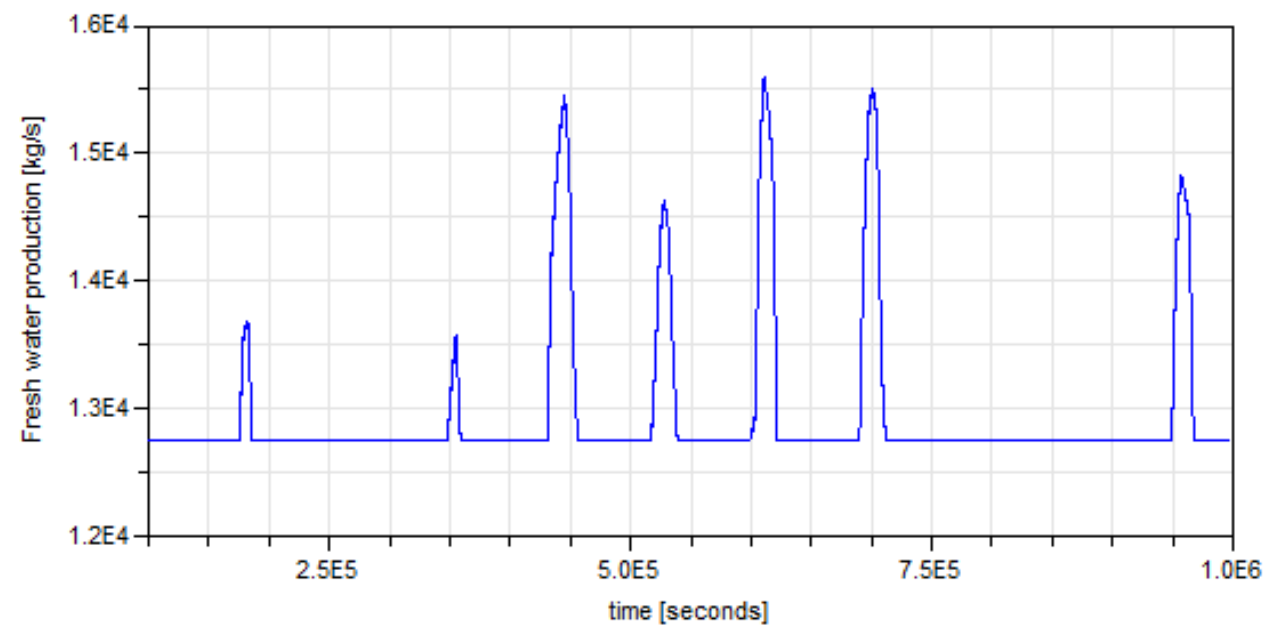

Figure 63. Fresh water production rate (NHES_Arizona).

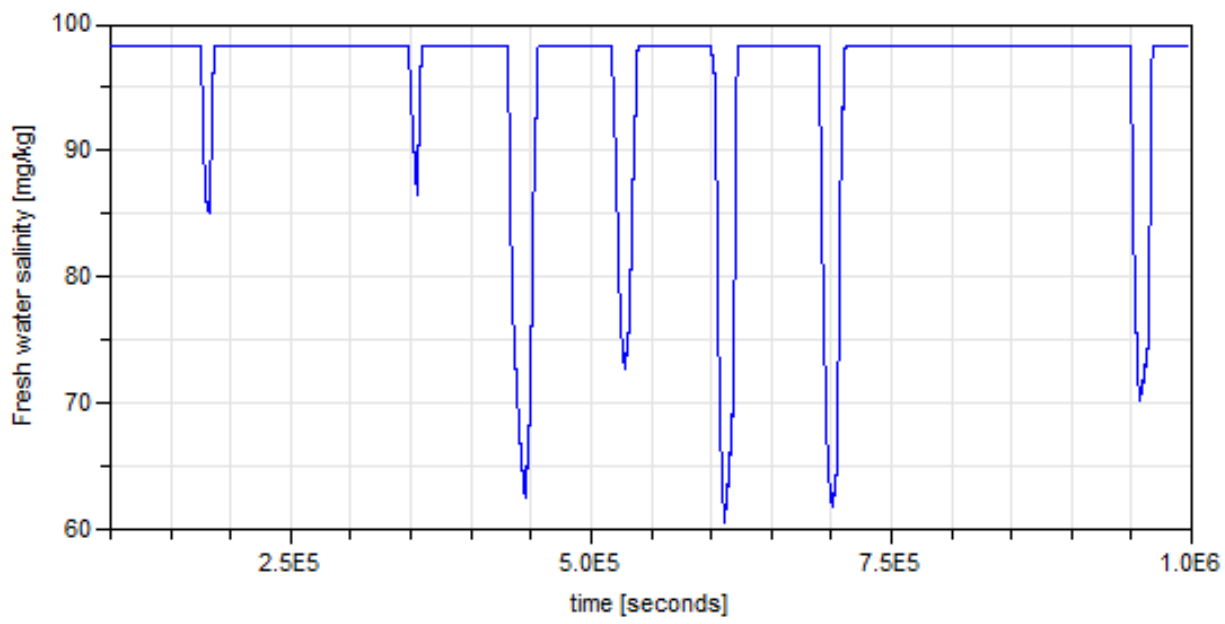

Figure 64. Quality of fresh water product (NHES_Arizona). 


\subsubsection{Ancillary service: Operating reserve}

This test is to further demonstrate the operating reserve capacity that NHES_Arizona can provide to the electric grid. The simulation setup values used in this test are listed in Table 28.

Table 28. Simulation setup for NHES_Arizona: Operating reserve test.

\begin{tabular}{|l|l|l|}
\hline \multirow{3}{*}{ Electrical generation to grid } & source & Figure 29 profile \\
\cline { 2 - 3 } & height & $10 \mathrm{MWe}$ \\
\cline { 2 - 3 } & duration & $600 \mathrm{~s}$ \\
\cline { 2 - 3 } & startValue & $155 \mathrm{MWe}$ \\
\cline { 2 - 3 } & startTime & $2500 \mathrm{~s}$ \\
\hline PV solar profile & source & $18 \mathrm{MWe}$ (constant) \\
\hline Power smoothing time constant $\left(\tau_{E S E}\right)$ & $1800 \mathrm{~s}$ \\
\hline Simulation duration & $5000 \mathrm{~s}$ \\
\hline Simulation output interval & $0.1 \mathrm{~s}$ \\
\hline
\end{tabular}

The electric grid demand in this scenario is reported in Table 28, where the requested electricity increases from $155 \mathrm{MWe}$ at $2500 \mathrm{~s}$ to $165 \mathrm{MWe}$ over 10 minutes, which corresponds to the particular ancillary service requirement for operating reserve. Figure 65 shows the times series for the power consumed by the desalination plant. As shown in this figure, the power supervisor quickly acts by demanding changes in the load to be consumed by the desalination plant to effectively accommodate the increased demand. Likewise, Figure 66 shows the times series for the pressure of the steam flow leaving the steam generator. The pressure response from time zero to $2500 \mathrm{~s}$ corresponds to the system initialization from cold shutdown to full operation. Notice the very small perturbation from $2500 \mathrm{~s}$ and beyond in the pressure caused by the indicated demand increase.

These results suggest that NHES_Arizona can provide a large spinning capacity. Being essentially in standby mode with respect to the electric grid, this configuration essentially exhibits zero startup and shutdown times to deliver the requested operating reserve services. This is achieved by the fact that NHES_Arizona offers more than one energy utilization avenue, allowing electricity to be diverted to the desalination plant to increase or decrease electricity delivered to the electric grid quickly when demanded.

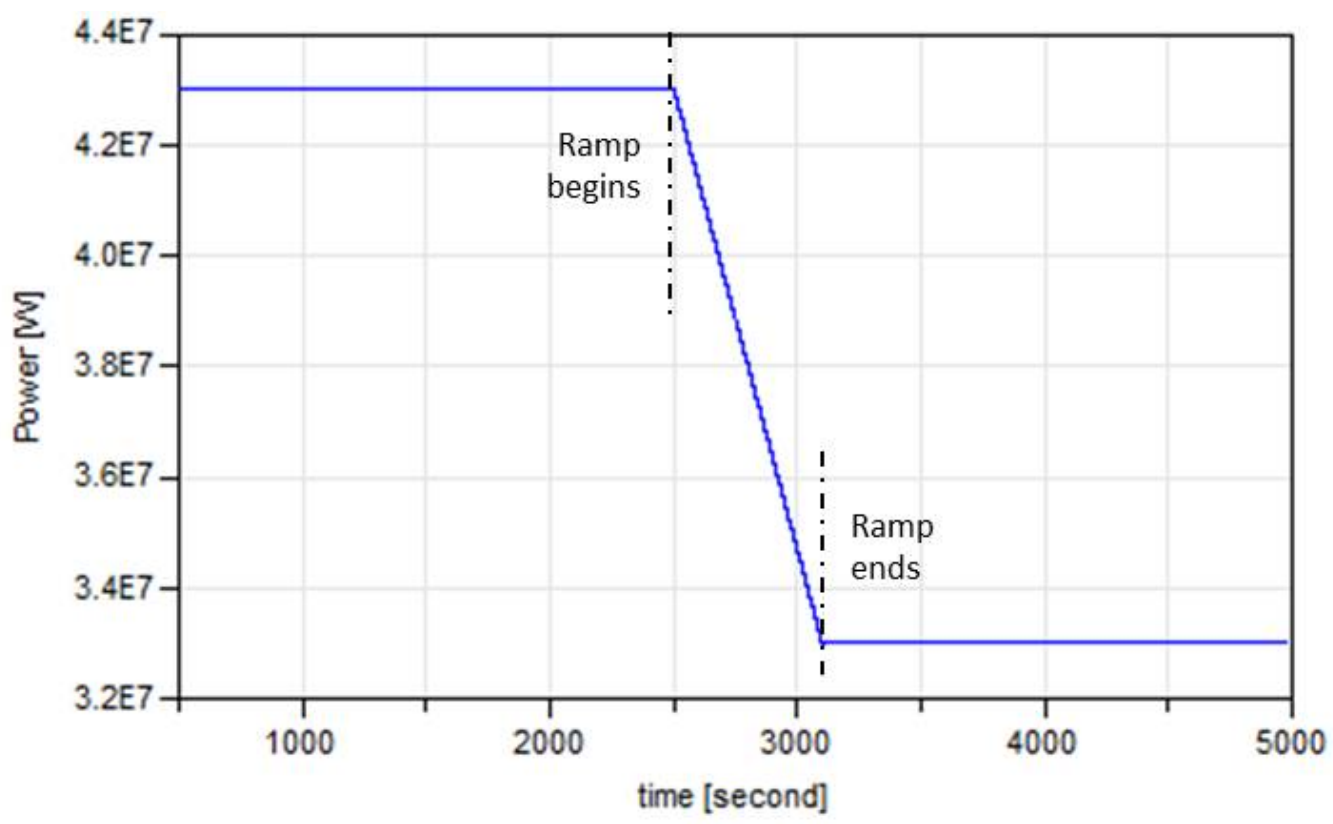

Figure 65. Power consumed by fresh water production plant (NHES_Arizona). 


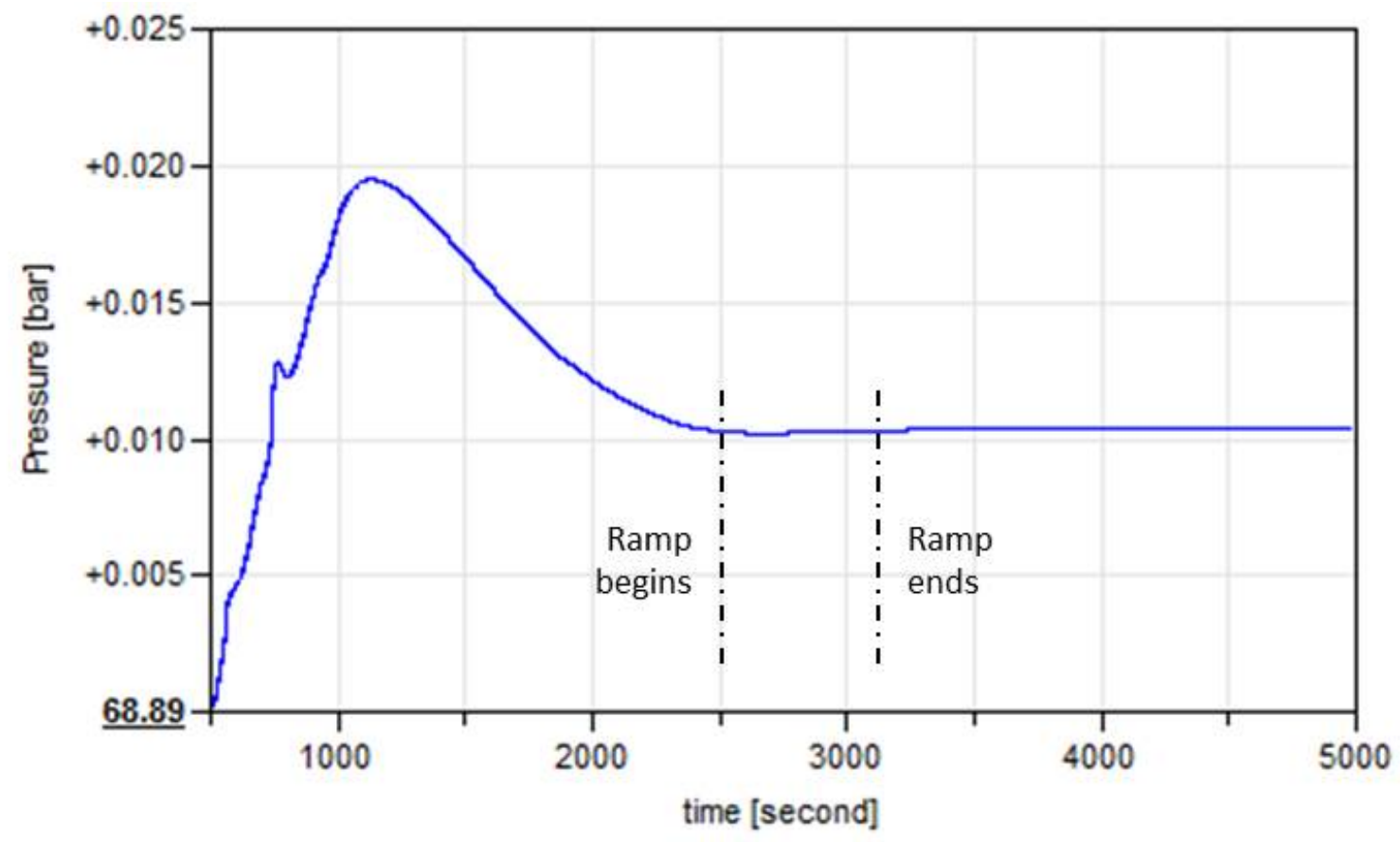

Figure 66. Pressure at steam generator outlet flow (NHES_Arizona).

\subsubsection{Operational flexibility for economic optimization}

In order to demonstrate the controllability of NHES_Arizona for value optimization, two scenarios were considered under variable PV solar power generation. The simulation setup values used in this test are listed in Table 29.

Table 29. Simulation setup for NHES_Arizona: Economic optimization for operations test.

\begin{tabular}{|c|c|c|}
\hline Electrical generation to grid & source & $\begin{array}{ll}\text { 1. } & 165 \text { MWe (constant) } \\
\text { 2. } & \text { adjusted for PGP } \\
& \text { optimization } \\
\text { 3. } & \text { adjusted for NPV } \\
& \text { optimization }\end{array}$ \\
\hline \multirow[t]{2}{*}{ PV solar profile } & source & Arizona region actual \\
\hline & $\begin{array}{l}\text { no. of units (4 } \\
\text { MWe each) }\end{array}$ & 6 \\
\hline \multicolumn{2}{|l|}{ Power smoothing time constant $\left(\tau_{E S E}\right)$} & $7200 \mathrm{~s}$ \\
\hline \multicolumn{2}{|l|}{ Simulation duration } & $31536000 \mathrm{~s}(1 \mathrm{yr})$ \\
\hline \multicolumn{2}{|l|}{ Simulation output interval } & $1200 \mathrm{~s}$ \\
\hline
\end{tabular}

The first scenario uses a constant value for electricity generation, representing the case in which the NHES configuration commits to deliver a constant electricity generation to the electric grid without considering the relative pricing of electricity and gasoline. The other scenarios use economic optimization to determine the most advantageous mix of products, resulting in variable electricity generation as a function of the time-dependent commodity prices. 
In order to compute the value $\mathrm{k}_{0}, \mathrm{k}_{1}$ and $\mathrm{k}_{2}$ for the nonlinear constraint shown in Eq. (12) and Section A.2.1 of APPENDIX A between the power consumption $\mathrm{P}_{\mathrm{RO}}$ and fresh water production $\mathrm{M}_{\mathrm{fw}}$ at the desalination plant, several simulations were conducted to obtain the relationship plotted in Figure 67. Recall that the net load is the remaining demand that must be met by conventional generators (the nuclear reactor in this example) after variable generation is subtracted from the total demand.

$M_{f w}=k_{0}+k_{1} P_{R O}+k_{2} P_{R O}^{2}$

The value for $\mathrm{k}_{0}, \mathrm{k}_{1}$ and $\mathrm{k}_{2}$ are $301.77[\mathrm{~kg} / \mathrm{s}], 442.20[\mathrm{~kg} / \mathrm{s} / \mathrm{MW}]$ and $-2.16\left[\mathrm{~kg} / \mathrm{s} / \mathrm{MW}^{2}\right]$, respectively.

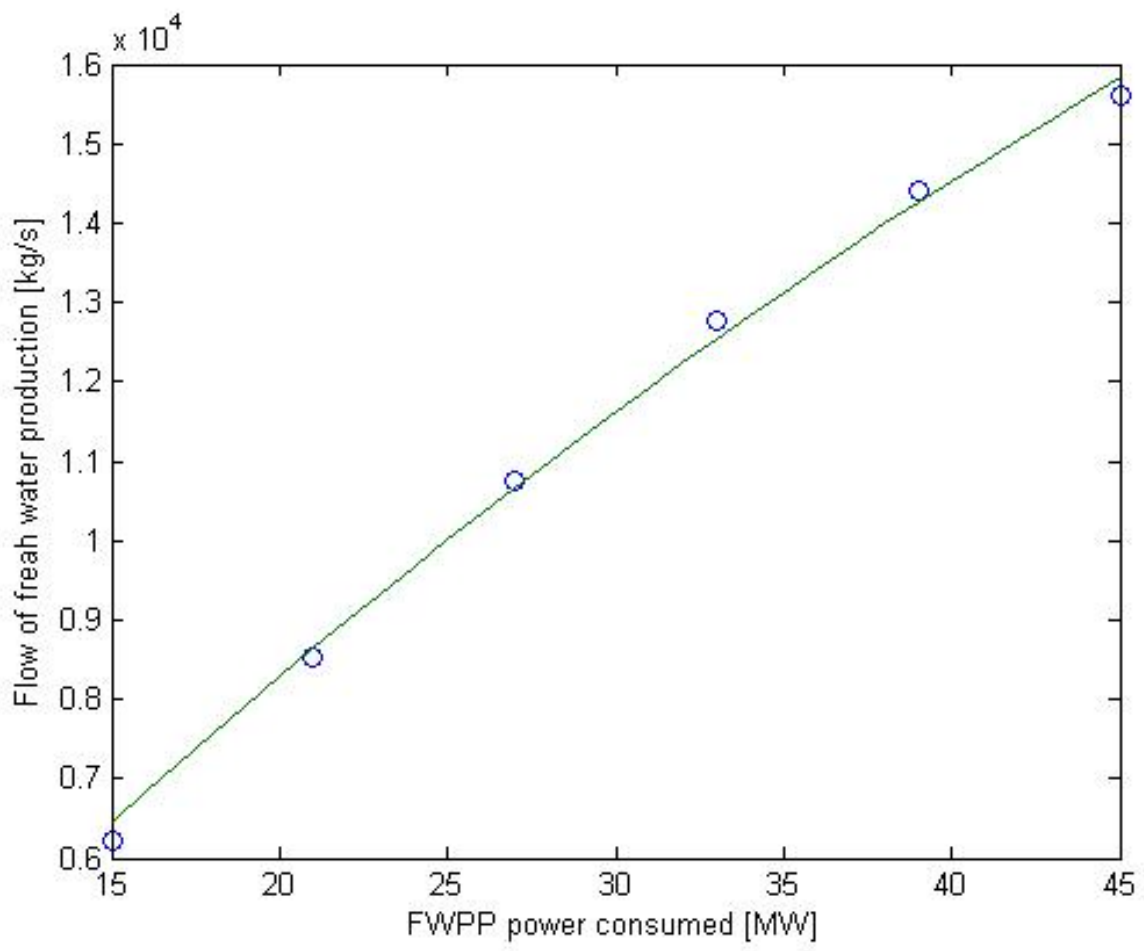

Figure 67. Relationship between power consumed and fresh water produced by the desalination plant.

\section{Economic FOM: Pre-tax Gross Profit}

The resulting optimal electricity production for NHES_Arizona is shown in Figure 68, corresponding to the maximization of pre-tax gross profit (PGP) and assuming the price trends shown in Figures 32 and 33 and the PV solar production in Figure 36. This adjusted electricity generation sold to the electric grid is then input to NHES_Arizona to test the system performance and demonstrate the system's flexibility to operate under this PGP-driven mode. Note that when the fresh water is at a relatively high price, the operations optimizer (supporting economic optimization for operations) diverts electricity to produce fresh water instead of selling it to the electric grid. When the price for fresh water decreases, the revenue of producing fresh water is reduced and selling electricity to the electric grid is hence preferred by the operations optimizer.

The objective function as defined in Section A.2.1 in APPENDIX A (i.e., $J=\int_{0}^{T} P_{e} \beta_{e}+M_{f w} \beta_{f w} d t$ ), which is PGP, is used to analyze simulation results. 


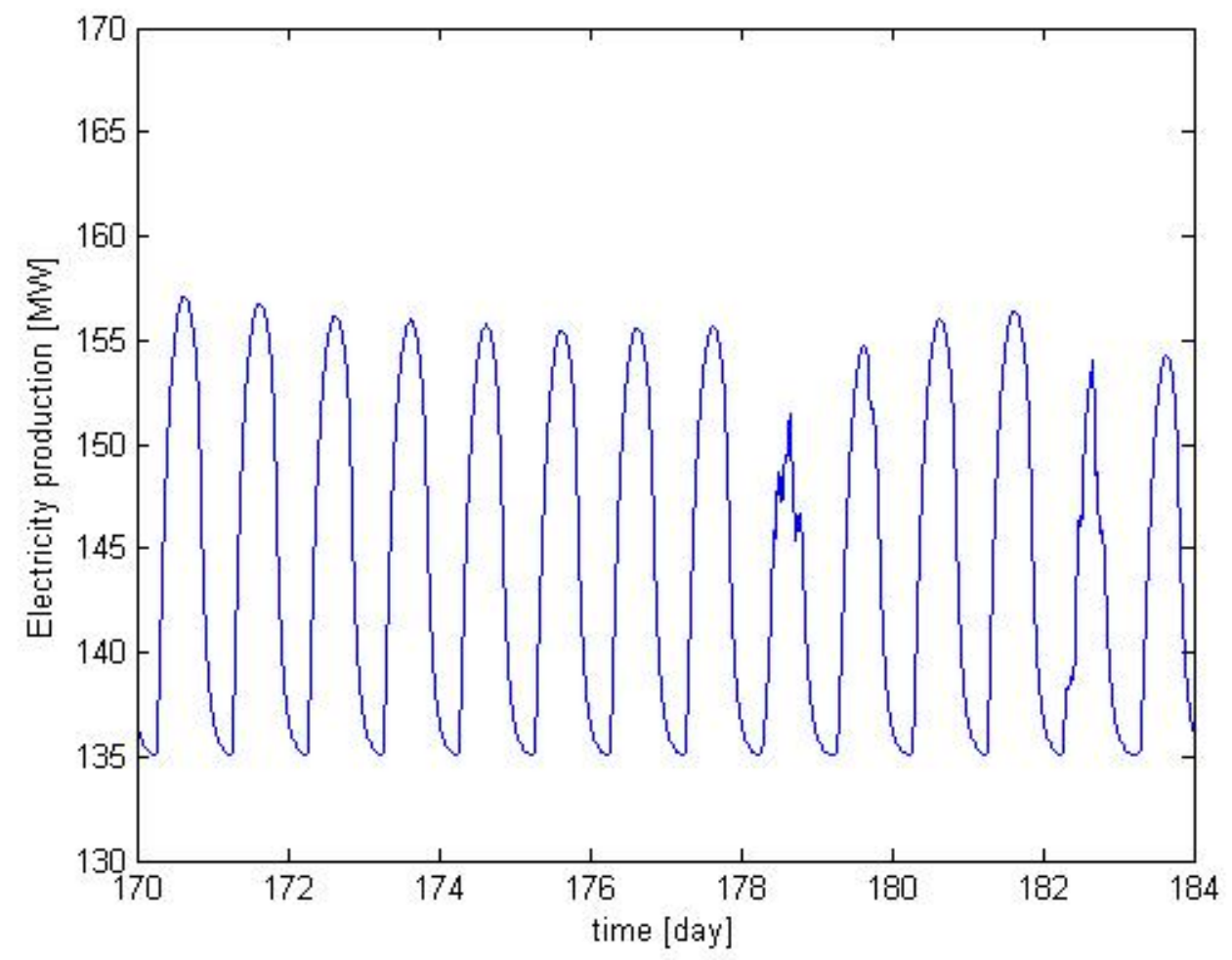

Figure 68. Optimal electricity production for a selected 14 day period for PGP optimization and price trend reported in Figures 32 and 33 (NHES_Arizona).

Based on the cost parameters reported in Table 10, Table 30 reports economic metrics associated with the first year of operation with and without economic optimization. In particular, Table 30 shows that PGP for NHES_Arizona increases from $\$ 221,915,528$ at constant electricity generation mode to $\$ 338,138,744$ (a $52.37 \%$ gain) when considering the modeled commodity market dynamics.

Table 30. Economic values for first year of operation (NHES_Arizona).

\begin{tabular}{|c|c|c|c|}
\hline Economic value & $\begin{array}{l}\text { Optimized Electricity } \\
\text { Generation }\end{array}$ & $\begin{array}{l}\text { Constant Electricity } \\
\text { Generation }\end{array}$ & Gain \\
\hline Revenue - Electricity & $\$ 39,312,438$ & $\$ 44,352,907$ & $-11.36 \%$ \\
\hline Revenue - Fresh Water & $\$ 298,826,306$ & $\$ 177,562,621$ & $68.29 \%$ \\
\hline PGP & $\$ 338,138,744$ & $\$ 221,915,528$ & $52.37 \%$ \\
\hline
\end{tabular}

\section{Economic FOM: $N P V$}

The resulting optimal electricity production for NHES_Arizona is shown in Figure 69, corresponding to the maximization of NPV and assuming the price trend of Figures 32 and 33 and the PV solar production rate of Figure 36. 


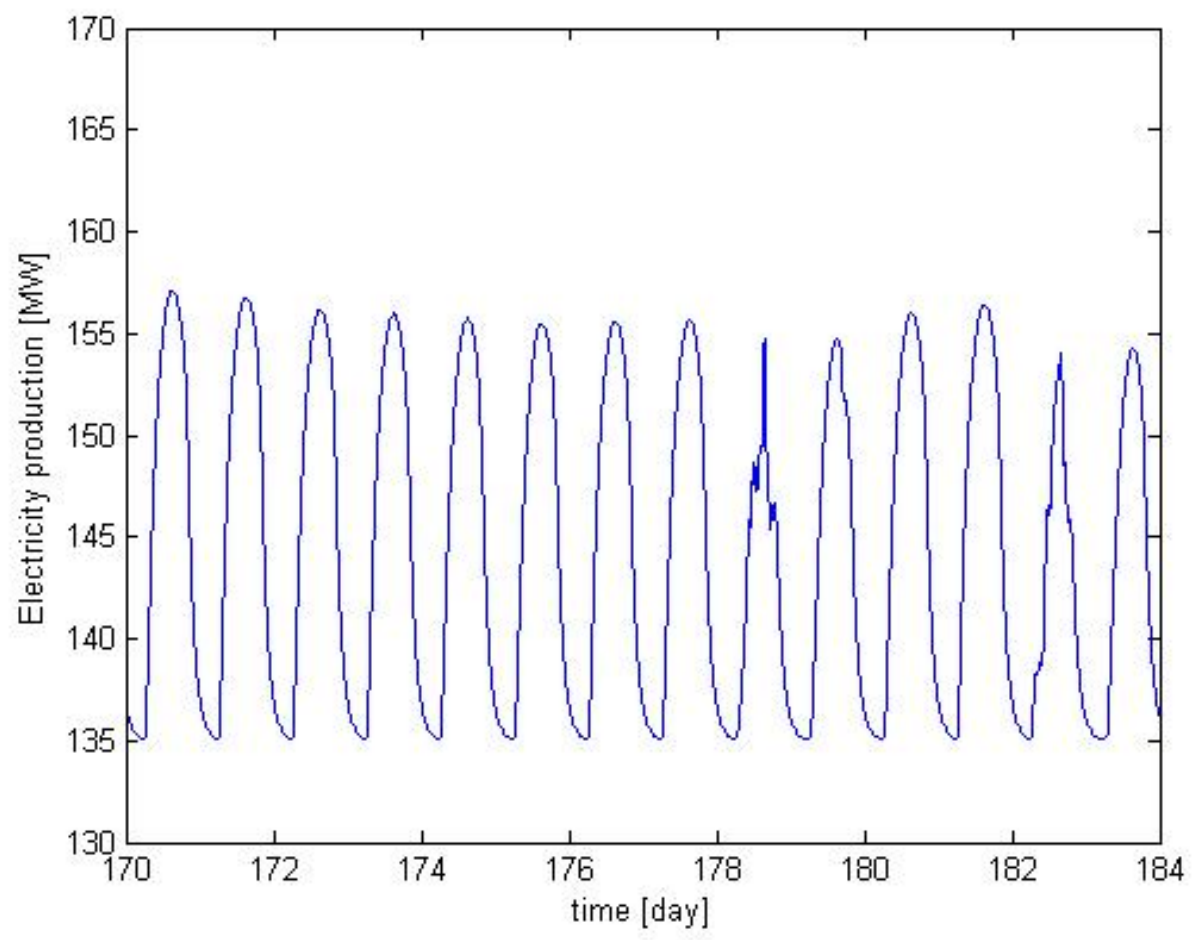

Figure 69. Optimal electricity production for a selected 14 day period for NPV and price trend reported in Figures 32 and 33 (NHES_Arizona).

As before, this adjusted electricity generation profile is then input to NHES_Arizona to test system performance and demonstrate the system's flexibility to operate under this NPV-optimization mode. Table 31 shows that the Real Discounted FCFF for the first year under this NHES configuration increases from $\$ 78,213,987$ at constant operation mode to $\$ 140,004,736$ (a $79.00 \%$ gain) when considering the modeled commodity market dynamics.

Table 31. FCFF for the first year of operation (NHES_Arizona).

\begin{tabular}{|l|r|r|r|}
\hline Economic value & \multicolumn{1}{|l|}{$\begin{array}{l}\text { Optimized Electricity } \\
\text { Generation }\end{array}$} & $\begin{array}{l}\text { Constant Electricity } \\
\text { Generation }\end{array}$ & \multicolumn{1}{c|}{ Gain } \\
\hline Revenue - Electricity & $\$ 39,314,377$ & $\$ 44,352,907$ & $-11.36 \%$ \\
\hline Revenue - Fresh Water & $\$ 298,824,890$ & $\$ 177,562,621$ & $68.29 \%$ \\
\hline FCFF & $\mathbf{\$ 1 4 0 , 0 0 4 , 7 3 6}$ & $\mathbf{\$ 7 8 , 2 1 3 , 9 8 7}$ & $\mathbf{7 9 . 0 0 \%}$ \\
\hline
\end{tabular}

Figure 70 shows the electrical contribution delivered to the electric grid by the nuclear reactor, i.e., the system load minus the output from the renewable generation fleet (or net load, Pe-Pw), for both PGP-optimization and NPV-optimization modes. Results suggest that in both scenarios, the operations optimizer tends to use electricity for fresh water production instead of selling it to the electric grid, and only increases electricity sold to the electric grid when the price for electricity is very high. Considering that the nuclear reactor in this case study can deliver a maximum rated power of $180 \mathrm{MWe}$ and the minimum turndown of the Fresh Water Production Plant (FWPP) is $15 \mathrm{MWe}$, this result suggests that for most of the time NHES_Arizona has a capacity of $30 \mathrm{MWe}$ to participate in operating reserve services, bringing revenue from providing operating reserve service on top of the sale of electricity. Under the current formulation, the electrical contribution increases only as a response to high electricity prices in the day ahead market. The participation in the ancillary service market is not considered in this report. Notice 
that this 30 MWe capacity can be used for fresh water production or accordingly diverted to the electric grid as needed. As this operating reserve capacity value is limited by the rated capacity of the associated flexible load resource (the FWPP in this case), higher capacity values can be achieved by expanding its existing FLR and/or installing additional FLR, such as a hydrogen production plant.

(a) PGP

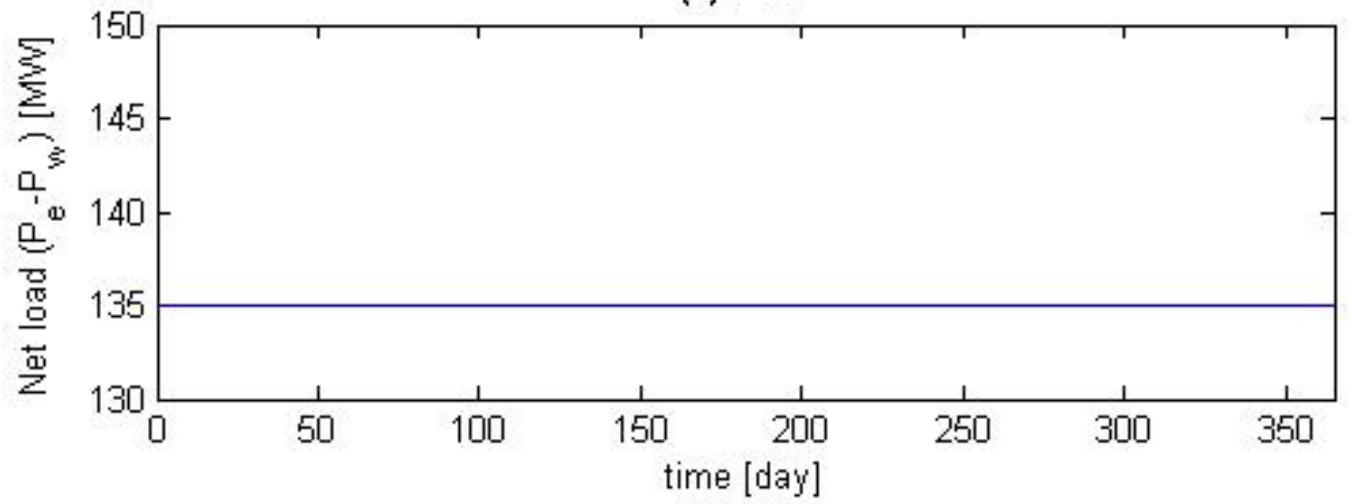

(b) NPV

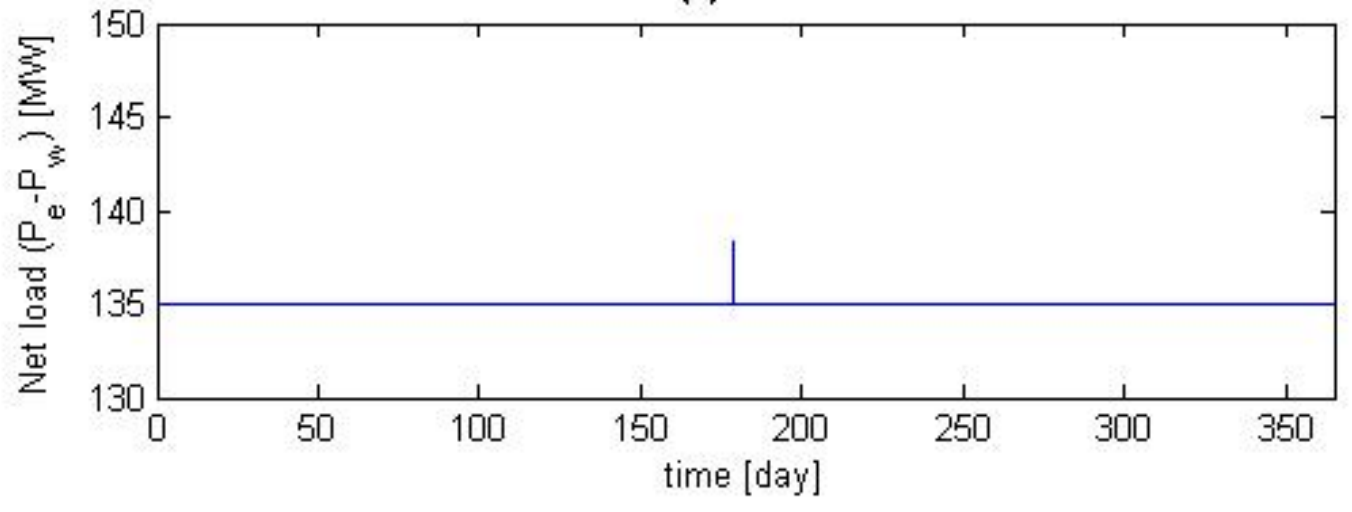

Figure 70. Electrical contribution delivered to the electric grid by the nuclear reactor for (a): PGP and (b) NPV optimization.

Similarly, Figure 71 plots the cumulative NPV as a function of time with and without including economic optimization for operations and assuming that the commodity trends (e.g., price, production, and consumption) in subsequent years are the same as those assumed for the first year. Based on the preliminary cost parameter values reported in Table 10, Figure 71 indicates that the payback time for NHES_Arizona is about 15.45 years when including NPV optimization. The IRR is $8.2 \%$ for 30 years of operation under the optimized case.

These results suggest that NHES_Arizona has the flexibility to be controlled for economic optimization, while maintaining the desired electricity quality and operational requirements. This attractive performance is further magnified when considering that an annual reduction of 1.4 million metric tons in $\mathrm{CO}_{2}$ emission is achieved by using a nuclear reactor as the baseload unit as opposed to using a NG-fired unit. 


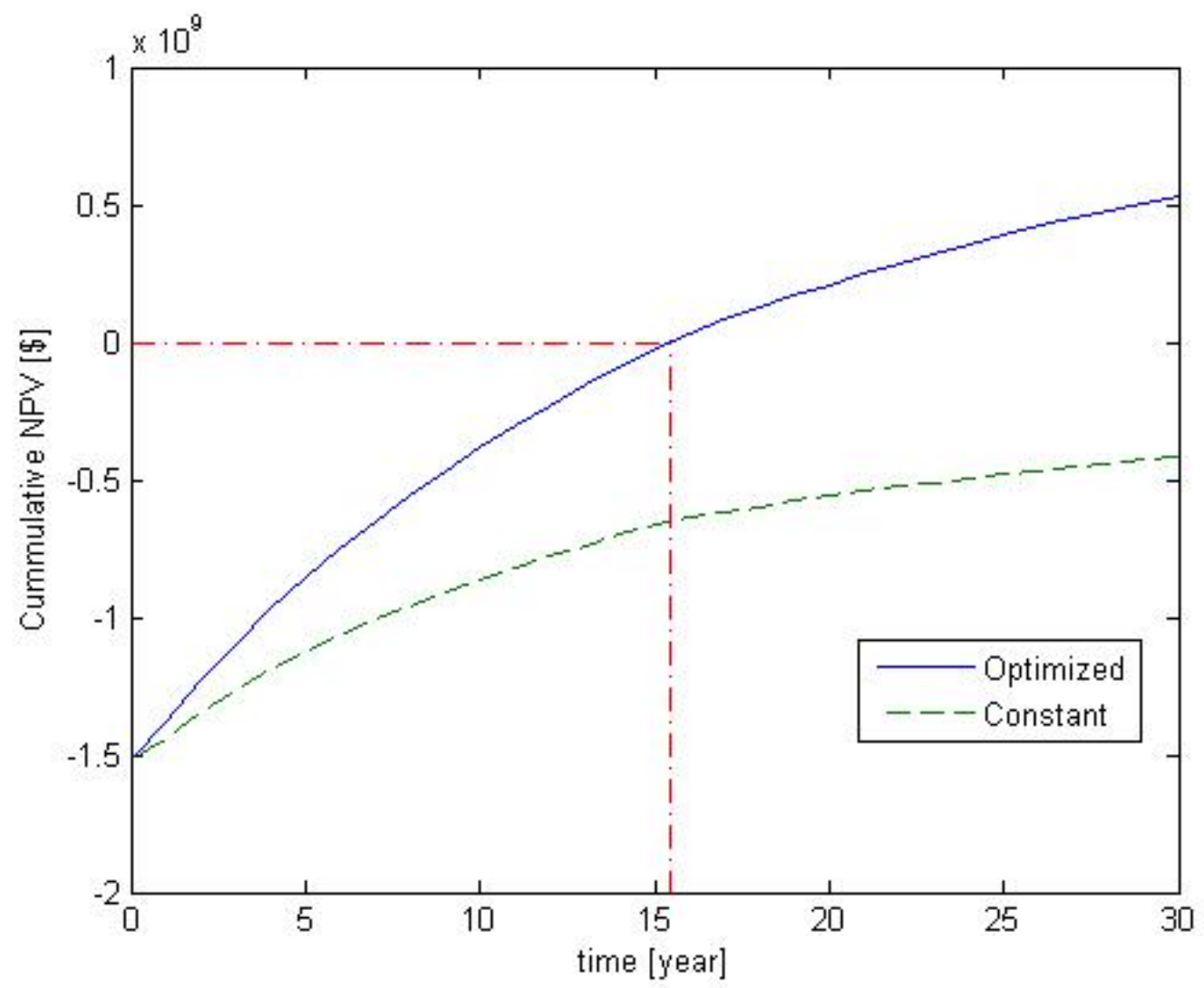

Figure 71. Cumulative NPV as a function of time using cost parameters in Table 10 (NHES_Arizona). 


\section{CONCLUSIONS AND RESEARCH PATH FORWARD}

Dynamic analyses of two NHES configurations were carried out to understand various dynamic challenges and opportunities that may arise from accommodating increasing levels of renewable penetration. The selected NHES configurations include components producing electricity and variable energy generation and utilization components to yield multiple energy commodities, including chemical (e.g., gasoline) and basic (e.g., fresh water) products. Such advanced configurations enable flexible energy and power management, addressing the high variability arising from integrating renewable energy and modern loads into the electric grid. The preliminary results lead to the following findings:

- NHES can be designed in numerous configurations to meet diverse technical specifications, and possibly accommodating various business and financial models.

- NHES can lead to energy use optimization and carbon use reduction for the combined commodity, electric grid, and industrial manufacturing sectors.

- NHES exhibit favorable economic performance due to their ability to produce more than one commodity.

- Preliminary results show that higher economic value is achieved by operating the selected NHES configurations to produce alternative commodities while participating in the electric grid market.

- Preliminary findings suggest that the payback time for NHES_Texas and NHES_Arizona would be approximately 8 and 16 years, while the internal rate of return would be $14.5 \%$ and $8.2 \%$ for 30 years of operation, respectively.

- NHES enable flexible operations to support FOM optimization, uncertainty planning, and real-time energy management.

- Technical and economic FOM may drive the design and operations optimization of selected NHES solutions. This report only considers economic optimization for operations. Efforts to optimize NHES designs are in-progress.

- NHES production of electricity and additional commodities can be controlled to yield maximum economic value to the owner; such evaluations consider operational costs, feedstock costs, and real-time commodity pricing.

- NHES can address high penetration, variability, and uncertainty levels in variable energy resources (VER), which are challenging to accommodate using traditional energy systems that produce electricity only.

- For example, preliminary results show that NHES_Texas can accept levels of renewable penetration and ramp rates greater than $20 \%$ and $0.3 \mathrm{MWe} / \mathrm{s}$, respectively, with these values being 14\% and 2.1 MWe/s for NHES_Arizona. Additional analysis is needed to determine operational limits within defined safety constraints.

- $\quad$ NHES can provide operating reserves to stabilize the electric grid while maintaining the electric grid inertia even with increased renewables penetration, thus supporting more robust transient grid response and addressing the anticipated near term power production transitions in the U.S.

- $\quad$ NHES can be operated as dispatchable flexible energy resources (FER) to smooth the variability and reduce uncertainty within electric grid balancing regions by rapidly increasing or decreasing electricity outputs. As opposed to conventional single-output generators that could require variation in baseload power generation, NHES units could maintain baseload generation by diverting energy to produce alternative commodities at times of reduced grid demand. 
- Having an alternative path for energy conversion, NHES avoid operation at a minimum operating point where units tend to be less efficient. NHES can also be viewed as always in standby, exhibiting zero start up/shut down times from the electric grid perspective.

- NHES can flexibly provide grid services over various time horizons.

- Comparison of NHES transient performance with the requirements for participating in the wholesale electricity service market suggests that the selected NHES configurations can participate in most ancillary service markets, while providing additional economic benefits through the sale of alternative products (such as gasoline or fresh water).

- NHES_Texas and NHES_Arizona can initiate to change their energy distribution quickly following a change in the required electricity generation and settle on the order of seconds based on the current model fidelity. Additional constraints may need to be modeled.

- Although small changes to its current configuration would remove the following limitation, the NHES_Texas can only be operated as a FGR. On the other hand, NHES-Arizona can be operated as both FGR and FLR.

- NHES can increase or decrease its electricity generation over a large range and maintain the change for long time periods.

- NHES_Texas and NHES_Arizona have a capacity of $45 \mathrm{MWe}$ and $30 \mathrm{MWe}$, respectively, for participation in operating reserve services. As their operating reserve capacity values are typically limited by the rated capacity of their associated FLR, higher capacity values can be achieved by expanding their existing FLR and/or installing additional FLR, such as a hydrogen generation plant.

- $\quad$ NHES can significantly reduce $\mathrm{CO}_{2}$ emissions through the use of a nuclear baseload unit and renewables to meet grid demand and the thermal and electrical needs of industrial plants.

- For the selected NHES, an annual reduction of 1.4 million metric tons in $\mathrm{CO}_{2}$ emission is achieved by using a nuclear reactor as the baseload unit as opposed to using a NG-fired baseload unit.

Anticipated future research paths include the following directions:

- Completion and integration of components shown in the framework illustrated in Figure 1, including algorithms for controls and local to global energy optimization, interfaces for intra- and inter-component communication, methods for probabilistic applications including risk assessments, and experimental testbeds for prototype demonstration.

- Identification, analysis, and optimization of NHES configurations for additional regions and markets.

- This effort includes investigating NHES configurations that integrate more than one renewable energy source, such as wind, PV solar, and concentrated solar, and produce more than one product such as gasoline, fresh water, and hydrogen. Such NHES configurations would provide even more flexible energy management and facilitate higher renewable penetration and improved operational control.

- This effort also includes investigating additional ESE, such as pumped-storage hydroelectricity [56], flywheel [57], or super-capacitors [58]. Capital and operational costs associated with each alternative ESE should also be studied for optimal system design.

- Modeling of key operational modes and accident cases to evaluate, understand, and include corrective passive and active measures under diverse normal and off-normal scenarios.

- Although the dynamic models applied in these preliminary analyses exhibit an adequate level of granularity for initial dynamic studies, the level of details currently incorporated in some of the 
models may need to be increased to more realistically characterize critical governing dynamics under both normal and off-normal conditions. This effort includes the modeling of degradation and failure modes and phenomena in key components.

- Synthesis and analysis of more effective control strategies within comprehensive operational scenarios.

- Development of enhanced methods for technical and economic optimization of NHES designs.

- Development of enhanced methods for technical and economic optimization of NHES operations.

- At the time of this report, the optimal distribution of steam for electricity production to the electric grid versus steam to GPP for gasoline production is computed assuming perfect prediction on price trends and renewable resources. Future efforts should include developing online operations optimizers that optimally manage energy production and conversion based on historical and predictive commodity prices and renewable generation. Online optimization algorithms should be devised that consider the real-time market price for each product, consider the operational cost associated with each control action, and determine the optimal control strategy in real-time. The online operations optimizer should also be developed to use predictions on future renewable input, power demand, and market price changes.

- Development of local and coordination control methodologies and algorithms with improved generation and load forecasting for active control of distributed energy resources.

- Development and evaluation of data analytics, big and distributed control paradigms, and intelligent automation approaches for online health assessment, advanced diagnostics/prognostics, flexible, resilient and coordinated controls, and market accommodation under normal and off-normal conditions resulting from natural disturbances and cyber-attacks.

- This effort includes upgrading low level controllers from basic to advanced implementations in order to improve system stability and flexibility for operational/supervisory control.

- This effort also includes extending the nuclear reactor control system as regional cases dictate such that it acts to additionally maintain constant reactor core average temperature while at load, which requires enhancements of the nuclear reactor mode. In addition, the control system for the NSSS will need to be tailored to address BOP control issues unique to each regional NHES.

- This effort also includes developing smart monitoring devices for health monitoring and resilient control.

- Integration of the developed M\&S, controls, and optimization capabilities with physical assets and computational modules running on real-time frameworks and evaluation of the integrated systems under more realistic scenarios.

- Enhanced economic assessment and optimization of NHES design and operation.

- This effort includes conducting more comprehensive analyses that include capital cost, dynamic operational cost, feedstock cost, and financing schemes. 


\section{REFERENCES}

[1] Department of Energy. "Report on the first quadrennial technology review," Tech. rep. Department of Energy. http://energy.gov/sites/prod/files/QTR_report.pdf; Sep 2011 [accessed 30.01.13].

[2] N. Hamsic, A. Schmelter, A. Mohd, E. Ortjohann, E. Schultze, A. Tuckey, et al. "Increasing renewable energy penetration in isolated grids using a flywheel energy storage system." International Conference on Power Engineering, Energy and Electrical Drives 2007:195e200. POWERENG 2007. 2007.

[3] E. Hittinger, J. Whitacre, J. Apt. "Compensating for wind variability using collocated natural gas generation and energy storage." Energy Systems 2010;1: 417-39.

[4] S. Aumeier, R. Cherry, R. Boardman, J. Smith. "Nuclear hybrid energy systems: Imperatives, prospects, and challenges." 2nd International Conference on Asian Nuclear Prospect (ANUP 2010), Nagoya, Japan; 2010.

[5] H.E. Garcia, A. Mohanty, W.C. Lin, R.S. Cherry. "Dynamic analysis of hybrid energy systems under flexible operation and variable renewable generation-part I: Dynamic performance analysis," Energy, 52:1-16, 2013.

[6] H.E. Garcia, A. Mohanty, W.C. Lin, R.S. Cherry. "Dynamic analysis of hybrid energy systems under flexible operation and variable renewable generation-part II: Dynamic cost analysis," Energy, 52:17-26, 2013.

[7] S. Bragg-Sitton, R. Boardman, M. Ruth, O. Zinaman. "Integrated Nuclear-Renewable Energy Systems: Foundational Workshop Report," INL Report INL/EXT-14-32857 Rev.1, NREL/TP-6A20-62778, August 2014.

[8] D. Bruck, H. Elmqvist, H. Olsson, S.E. Mattson. "Dymola for multi-engineering modeling and simulation," $2^{\text {nd }}$ International Modelica Conference, pp. 55.1-55.8, March 18-19, 2002.

[9] Lee. “Texas hits new peak output.” June 23, 2014. Retrieved February 10, 2015, from U.S. Energy Information Administration: Today in Energy: http://www.eia.gov/todayinenergy/detail.cfm?id=16811

[10] McFarland. "Twelve states produced 80\% of U.S. wind power in 2013." April 15, 2014. Retrieved January 10, 2015, from U.S. Energy Information Administration: Today in Energy:

http://www.eia.gov/todayinenergy/detail.cfm?id $=15851$

[11] U.S. Energy Information Administration. “Crude Oil Production.” January 29, 2015. Retrieved February 10, 2015, from Petroleum \& Other Liquids: http://www.eia.gov/dnav/pet/pet_crd_crpdn_adc_mbblpd_a.htm

[12] U.S. Energy Information Administration. "Natural Gas Gross Withdrawals and Production." January 30, 2015. Retrieved February 10, 2015, from Natural Gas: http://www.eia.gov/dnav/ng/ng_prod_sum_a_EPG0_VGM_mmcf_a.htm

[13] Texas Administrative Code: Title 16; Part 1; Chapter 16; Rule 3.32.

[14] B.T. Ewing, M.C. Watson, T. McInturff, D. Liang. "Current and Future Economic Impacts of the Texas Oil and Gas Pipeline Industry.” Lubbock, TX: Texas Tech Univeristy, 2014.

[15] R.A. Wood, R.D. Boardman, M.W. Patterson, "Nuclear-Integrated Methanol-to Gasoline Production Analysis," Technical Evaluation Study, TEV-667, Idaho National Laboratory Idaho Falls, ID 2010. 
[16] power-technology. “Top 10 biggest wind farms." September 2013. Retrieved February 18, 2015, from power-technology.com:

http://www.power-technology.com/features/feature-biggest-wind-farms-in-the-world-texas/

[17] Cielo Wind Power. "Wildorado Wind Ranch." Retrieved February 18, 2015, from Cielo Wind: http://www.cielowind.com/projects/completed-developments/wildorado-wind-ranc

[18] U.S Department of Energy. (n.d.). "North American Electric Reliability Corporation Interconnections." Retrieved February 18, 2015, from ENERGY.GOV Office of Electricity Delivery \& Energy Reliability:

http://energy.gov/oe/downloads/north-american-electric-reliability-corporation-interconnections

[19] Texas Commission on Environmental Quality. "Miscellaneous Barnett Shale Maps and Charts." January 14, 2015. Retrieved February 10, 2015, from Barnett Shale Maps and Charts: http://www.tceq.state.tx.us/assets/public/implementation/barnett_shale/bs_images/txOilGasWells.p $\underline{\mathrm{ng}}$

[20] National Renewable Energy Laboratory. "WINDExchange." October 4, 2010. Retrieved February 10, 2015, from DOE: Energy Efficiency \& Renewable Energy: http://apps2.eere.energy.gov/wind/windexchange/wind resource maps.asp?stateab=tx

[21] Arizona Public Service. “2014 Integrated Resource Plan.” Phoenix: Arizona Public Service, 2014.

[22] Arizona Department of Water Resources. "Arizona's Next Century: A Strategic Vision for Water Supply Sustainability.” Phoenix: Arizona Department of Water Resources, 2014.

[23] L.B. Brug. "emPOWER ARIZONA: Executive Energy Assessment and Pathways 2014." Phoenix: Arizona Govenor's Office of Energy Policy, 2014.

[24] S.B. Worsley. "Arizona's Energy Outlook: Presentation to AZ CAES.” Phoenix, AZ. January 15, 2015.

[25] National Renewable Energy Laboratory. "Arizona Solar Radiation Map from the Western Wind and Solar Integration Study prepared by the National Renewable Energy Laboratory (May 2010)." Retrieved February 10, 2015, from SunZia: Maps: http://www.sunzia.net/resources maps.php

[26] E.L. Montgomery \& Associates, Inc. (n.d.). Retrieved January 2015, from Montgomery \& Associates Water Resource Conulstants: http://www.elmontgomery.net/documents/ahsDesalinationAbstract.pdf

[27] L.F. Greenlee, D. F. Lawler, B. D. Freeman, B. Marrot, P. Moulin. "Reverse osmosis desalination: Water sources, technology, and today's challenges," Water Research 43(9), pp. 2317-2348, 2009.

[28] H-J. Oh, T-M. Hwang, S. Lee. "A simplified simulation model of RO systems for seawater desalination," Desalination 238(1-3), pp. 128-139, 2009.

[29] J. Kirby. "Spinning reserve from responsive loads," ORNL/TM-2003/19. Oak Ridge, TN: Oak Ridge National Laboratory, 2003.

[30] “Spinning reserve and non-spinning reserve," California ISO, January 31, 2006.

[31] Kirby. "Demand Response for Power System Reliability: FAQ," ORNL/TM-2006/565. Oak Ridge, TN: Oak Ridge National Laboratory, 2006.

[32] D.E. Shropshire, et al. "Advanced Fuel Cycle Cost Basis," INL/EXT-07-12 107, Rev. 2, 2009.

[33] Y. Du, J.E. Parsons. "Update on the cost of nuclear power," MIT center for energy and environmental policy Research. Working paper: WP-2009-004, 2009. 
[34] G. Rothwell, F. Ganda. "Electricity Generating Portfolios with Small Modular Reactors," Argonne National Laboratory, May 2014.

[35] Energy information administration (EIA), "updated capital cost estimates for electricity generation plants," tech. rep., independent statistics\& analysis, U.S. Energy Information Administration, 2010.

[36] US. DOE “Carbon capture technology program plan,” January 2013.

[37] S. Tegen, M. Hand, B. Maples, E. Lantz, P. Schwabe, A. Smith. "2010 Cost of Wind Energy Review," Technical Report, NREL/TP-5000-52920, April 2012.

[38] City of Fort Worth, 2014 Water Rates, http://fortworthtexas.gov/water/info/default.aspx?id=117022, accessed on February 5, 2015.

[39] "How to Depreciate Property." Publication 946. Cat. No. 13081F. Department of the Treasury. Internal Revenue Service. 2014.

[40] "U.S. Corporation Income Tax Return." Instruction for Form 1120. Department of the Treasury. Internal Revenue Service. 2014.

[41] G. Barbose, et al. "Tracking the Sun V. An Historical Summary of the Installed Price of Photovoltaics in the United States from 1998 to 2013," Lawrence Berkeley National Laboratory; September 2014.

[42] N. Enbar. "PV O\&M Best Practices," Utility/Lab Workshop on PV Technology and Systems, November 2010.

[43] International Atomic Energy Agency (IAEA), "Economics of Nuclear Desalination: New Developments and Site Specific Studies,” IAEA-TECDOC-1561, July 2007.

[44] U.S Department of the Interior, "Yuma Desalting Plant Pilot Run Final Report," July 2012.

[45] Federation of Tax Administrators, "Range of state corporate income tax rate," February 2015.

[46] M. Lei, L. Shiyan, J. Chuanwen, L. Hongling, Z. Yan. "A review on the forecasting of wind speed and generated power." Renewable and Sustainable Energy Reviews 2009;13(4):915-20.

[47] “Making use of TMY data," PVEducation.org, Retrieved on November 21, 2014.

[48] A.P. Dobos. "PVWatts Version 5 Manual," Technical Report NREL/TP-6A20-6241, September 2014.

[49] R. Landau. "Optimum tilt of solar panels," http://www.solarpaneltilt.com/, retrieved on November 21,2014

[50] "Solar radiation on a tilted surface," PVEducation.org, Retrieved on November 21, 2014.

[51] R. Perez, P. Ineichen, R. Seals. "Modeling daylight availability and irradiance components from direct and global irradiance," Solar Energy, vol. 44, no. 5, pp. 271-289, 1990.

[52] Skoplaki, J. A. Palyvos. "On the temperature dependence of photovoltaic module electrical performance: A review of efficiency/power correlations," Solar Energy, vol. 83, pp. 614-624, 2009.

[53] J. Jie, Y. Hua, H. Wei, P. Gang, L. Jianping, J. Bin. "Modeling of a novel Trombe wall with PV cells," Building and Environment, vol. 42, pp. 1544-1552, 2007.

[54] K. Nishioka, T. Hatayama, Y. Uraoka, T. Fuyuki, R. Hagihara, M. Watanab. "Field-test analysis of PV system output characteristics focusing on module temperature," Solar Energy Materials and Solar Cells, vol. 75, no. 3, pp. 665-671, 2003.

[55] M. Tiller. "Introduction to physical modeling with Modelica," Springer Science \& Business Media, 2001. 
[56] J.A. Suul, K. Uhlen, T. Undeland. "Variable speed pumped storage hydropower for integration of wind energy in isolated grids: case description and control strategies." Nordic Workshop on Power and Industrial Electronics (NORPIE/2008), June 9-11, 2008, Espoo, Finland. Helsinki University of Technology, 2008.

[57] R. Cárdenas, et al. "Control strategies for power smoothing using a flywheel driven by a sensorless vector-controlled induction machine operating in a wide speed range." IEEE Transactions on Industrial Electronics, 51.3 (2004): 603-614.

[58] D.B. Murray, et al. "Supercapacitor testing for power smoothing in a variable speed offshore Wave Energy Converter.” IEEE Journal of Oceanic Engineering, 37.2 (2012): 301-308. 


\section{APPENDIX A \\ Formulation of Economic Optimization of Operations}

\section{A.1 NHES_TEXAS}

This section describes the derivation of equations for the economic (PGP and NPV) optimization of operations as it relates to NHES_Texas.

\section{A.1.1 Economic PGP Optimization: Analytical Approach}

In order to formulate the optimization problem for NHES_Texas, the economic FOM considered is the pre-tax gross profit (PGP), which only includes the revenue from the sale of electricity and gasoline and the cost of using NG and water for gasoline production. Thus, the considered loss/objective function is defined as follows:

$$
J=\int_{0}^{T} P_{e} \beta_{e}+M_{g} \beta_{g}-\left(M_{N G_{-} A H G}+M_{N G_{-} G P P}\right) \beta_{N G}-M_{W} \beta_{W}-M_{C} \beta_{C} d t
$$

where $P_{e}$ is the electrical power sold to the electric grid, $\beta_{\mathrm{e}}$ is the price for electricity, $\mathrm{M}_{\mathrm{g}}$ is gasoline (plus LPG) production rate, which is constant at $45.3 \mathrm{~kg} / \mathrm{s}$ (as the gasoline production plant is operated at full production mode), $\beta_{\mathrm{g}}$ is the gasoline (and LPG) price, $\mathrm{M}_{\mathrm{NG}_{-} \mathrm{AHG}}$ and $\mathrm{M}_{\mathrm{NG}_{-} \mathrm{GPP}}$ is the $\mathrm{NG}$ consumption rate by $\mathrm{AHG}$ and GPP, respectively, $\beta_{\mathrm{NG}}$ is the price of $\mathrm{NG}, \mathrm{M}_{\mathrm{W}}$ is the water consumption rate by GPP, $\beta_{\mathrm{W}}$ is the price of water, $\mathrm{M}_{\mathrm{C}}$ is the greenhouse gas $(\mathrm{GHG})\left(\mathrm{CO}_{2}\right.$ in this case) emission rate, $\beta_{\mathrm{C}}$ is the penalty associated with GHG emission, and $\mathrm{T}$ is the considered time period (e.g., one year). Although all the above variables change with respect to time $t$, they are denoted without subscript $t$ for simplicity. Note that this objective function considers only the revenue and major feedstock costs (i.e., NG used by AHG and GPP and water by GPP). While operational and other feedstock costs are not considered in the objective function described above, it suffices to demonstrate the flexibility of the selected NHES configuration. The constraints for all time $t$ over the variables are as follows:

$$
\begin{gathered}
P_{e}-P_{w}+P_{T}=P_{p h g} \\
0 M W \leq P_{e} \leq P_{p h g} \\
0 M W \leq P_{T} \leq P_{g}
\end{gathered}
$$

where $\mathrm{P}_{\mathrm{w}}$ is the renewable electricity generated by the wind turbines, $\mathrm{P}_{\mathrm{T}}$ is the electrical power equivalent (applying a thermal-to-electrical efficiency of 30\%) generated by the nuclear reactor and consumed by GPP and is denoted in terms of electrical power, $\mathrm{P}_{\text {phg }}$ is the PHG, which is constant at $600 \mathrm{MWt}$ (or 180 $\mathrm{MWe}$ ), and $\mathrm{P}_{\mathrm{g}}$ is the rated power of GPP. In order to characterize the relationship among the decision variables (i.e., $\mathrm{P}_{\mathrm{e}}, \mathrm{M}_{\mathrm{NG}}$ and $\mathrm{M}_{\mathrm{C}}$ ), the following linear relationships are assumed for all time $t$ (See Section 4.1.7 for more detail $)^{\circ}$ :

$$
\begin{gathered}
M_{N G}=k_{0}+k_{1}\left(P_{e}-P_{w}\right) \\
M_{c}=\gamma M_{N G}
\end{gathered}
$$

Combining the above linear relationships with the objective function produces the following equality relationship:

$$
J=\int_{0}^{T} P_{e}\left(\beta_{e}-k_{1} \beta_{N G}-\gamma k_{1} \beta_{C}\right) d t+C
$$

\footnotetext{
${ }^{\mathrm{o}}$ Note that these relationships only hold for ranges such that the above constraints are satisfied.
} 
where $C=\int_{0}^{T}-\left(k_{0}-k_{1} P_{w}\right)\left(\beta_{N G}+\gamma \beta_{C}\right)+M_{g} \beta_{g} d t$ is constant with respect to the only remaining decision variable $\mathrm{P}_{\mathrm{e}}$. Combining for all time $t$ the constraints gives:

$$
\max \left(0 M W, P_{p h g}+P_{w}-P_{g}\right) \leq P_{e} \leq \min \left(P_{p h g}, P_{p h g}+P_{w}\right)
$$

or equivalently

$$
P_{p h g}+P_{w}-P_{g} \leq P_{e} \leq P_{p h g}
$$

Note that the last conversion requires that $P_{p h g}+P_{w}-P_{g} \geq 0$ (equivalently $P_{p h g}-P_{g} \geq 0$ ) and $P_{p h g}+P_{w} \geq P_{p h g}$ (equivalently $P_{w} \geq 0 M W$ ), both of which are true in NHES_Texas. Putting all together, the optimization problem is analytically formulated as follows:

Maximize

$$
J=\int_{0}^{T} P_{e}\left(\beta_{e}-k_{1} \beta_{N G}-\gamma k_{1} \beta_{C}\right)
$$

Subject to

$$
P_{p h g}+P_{w}-P_{g} \leq P_{e} \leq P_{p h g} \text {, for all time } t
$$

Note that the above optimization does not depend on the market price of gasoline. That is because regardless of its market price, GPP is operated at full production mode at all times, producing the gasoline at its maximum rate. However, due to the electricity price variation, the amount of electricity produced to maximize profit. In this case, the amount of NG used to keep GPP at full load mode is changing accordingly, and hence the price of NG needs to be considered in the optimization. By taking the derivative of the objective function with respect to the decision variable $\mathrm{P}_{\mathrm{e}}$, then $d J / d P_{e}=\int_{0}^{T} \beta_{e}-$ $k_{1} \beta_{N G}-\gamma k_{1} \beta_{C} d t$. Therefore, the analytical solution is as follows at each time instant:

$$
P_{e}=\left\{\begin{array}{cc}
P_{p h g} & \text { if } \beta_{e}-k_{1} \beta_{N G}-\gamma k_{1} \beta_{C}>0 \\
P_{p h g}+P_{w}-P_{g} & \text { otherwise }
\end{array}\right.
$$

\section{A.1.2 Economic NPV Optimization: Analytical Approach}

NPV was defined for NHES_Texas (NPV_tx) as follows, where Table 7 lists all the variables used in the optimization problem formulation.

$$
N P V_{t x}=\sum_{k=0}^{N} \frac{F C F F_{R, k}}{\left(1+r_{R}\right)^{k}}
$$

With real discounted Free Cash Flow to Firm for year k, i.e., $\mathrm{FCFF}_{\mathrm{R}, \mathrm{k}}$, defined as:

$$
F C F F_{R, k}=\left(R_{k}-O \& M_{k}-D A_{k}(1+i)^{-k}\right)(1-\operatorname{tax})+D A_{k}(1+i)^{-k}-G H G_{k}-C A P E X_{k}
$$

where $R_{k}$ is the total revenue from sales of electricity and gasoline for year $k$, and is given by:

$$
R_{k}=\int_{0}^{T} P_{e} \beta_{e}+M_{g} \beta_{g} d t
$$

The Capital Expenditure $\left(\mathrm{CAPEX} \mathrm{k}_{\mathrm{k}}\right)$ only occurs when $\mathrm{k}=0$, i.e., year 0 , and is given by:

$$
\text { CAPEX } X_{0}=C_{-} p h g+C_{\_} a h g+C_{-} r e n+C_{-} e s e+C_{-} g p p \text {, }
$$

and $\mathrm{CAPEX}_{\mathrm{k}}=0$ for $\mathrm{k}>0$. Depreciation Amortization for year $\mathrm{k}$ is given by:

$$
D A_{k}=\rho_{d a, k} * C A P E X_{0}
$$


where $\rho_{d a, k}$ is the Depreciation Amortization rate at year $\mathrm{k} . \mathrm{GHG}_{\mathrm{k}}$ is the penalty for GHG emission and is given by:

$$
\mathrm{GHG}_{\mathrm{k}}=\int_{0}^{\mathrm{T}} \beta_{\mathrm{c}} \mathrm{M}_{\mathrm{C}} d t
$$

$O \& \mathrm{M}_{\mathrm{k}}$ is the operations and maintenance $(\mathrm{O} \& \mathrm{M})$ expense for year $\mathrm{k}$, given as follows:

O\&M $M_{k}=$ O\&M_phg + O\&M_ahg + O\&M_ren + O\&M_ese + O\&M_gpp,

and for each component, its O\&M cost would be further divided into fixed and variable O\&M cost. The capital and O\&M expense for the five major components, i.e., Primary Heat Generator \& Power Cycle, Auxiliary Heat Generator, Renewable Energy Generator, Electrical Storage Element and Gasoline Production Plant (GPP), are computed as follows:

1. Nuclear and Power Cycle

Capital cost:

$$
C \_p h g=\alpha \_p h g * P \_p h g \_r a t e d
$$

$\underline{\mathrm{O} \& \mathrm{M} \text { cost: }}$

$$
\begin{gathered}
\text { O\&M_phg }=0 \& M_{-} p h g_{-} f+O \& M{ }_{-} p h g_{-} v \\
O \& M \_p h g_{-} f=\beta_{-} p h g_{-} f * P \_p h g_{-} r a t e d * 8760 \\
O \& M \_p h g \_v=\int_{0}^{T} \beta_{-} p h g_{-} v * P \_p h g d t
\end{gathered}
$$

where $\mathrm{P} \_$phg_rated is the rated maximum output power of the Nuclear \& Power Cycle, $\alpha \_$phg is the capital cost per unit of installed capacity, $\beta \_$phg f is the coefficient for fixed O\&M and $\beta \_p h g \_v$ is the coefficient for variable O\&M, P_phg is the power output of Nuclear \& Power Cycle at time $t$ (note that $\mathrm{P} \_$phg is denoted without subscript $t$ for simplicity).

2. Auxiliary Heat Generation

Capital cost:

$$
C \_a h g=\alpha \_a h g * P \_a h g \_r a t e d
$$

O\&M cost:

$$
\begin{gathered}
O \& M_{-} a h g=O \& M_{-} a h g_{-} f+O \& M_{-} a h g_{-} v \\
O \& M_{-} a h g_{-} f=\beta_{-} a h g_{-} f * C_{-} a h g \\
O \& M_{-} a h g_{-} v=\int_{0}^{T} \beta_{-} a h g_{-} v * M_{N G \_H G} d t
\end{gathered}
$$

where $\mathrm{P} \_$ahg rated is the rated maximum output power of $\mathrm{AHG}, \alpha \_$ahg is the capital cost per unit of installed capacity, $\beta \_$ahg_f is the coefficient for fixed O\&M and $\beta \_$ahg_v is the coefficient for variable O\&M, which is same as the price of natural gas (i.e., $\left.\beta_{\mathrm{NG}}\right), \mathrm{M}_{\mathrm{NG}_{-} \mathrm{AHG}}$ is the $\mathrm{NG}$ consumed by AHG at time $\mathrm{t}$.

3. Renewable Energy Generation (i.e., wind turbines)

Capital cost:

$$
\text { C_ren }=\alpha \_r e n * P \_r e n \_r a t e d
$$

$\underline{O Q M \text { cost: }}$ 


$$
\begin{gathered}
\text { O\&M_ren }=0 \& M \_r e n \_f+O \& M \_r e n \_v \\
O \& M \_r e n \_f=\beta \_r e n \_f * P \_r e n \_r a t e d
\end{gathered}
$$

where $P \_$ren_rated is the rated maximum output power of the wind turbines, $\alpha \_$ren is the capital cost per unit of installed capacity, $\beta \_$ren_f is the coefficient for fixed O\&M. Note that for wind turbines, only the fixed O\&M cost is considered and the variable O\&M_ren_v is assumed to be 0 .

4. Electrical Storage Element (i.e., battery)

Capital cost:

$$
\text { C_ese }=\alpha_{-} e s e * P_{-} e s e_{-} r a t e d
$$

O\&M cost:

$$
\begin{gathered}
\text { O\&M_ese }=0 \& M_{-} e s e_{-} f+\text { O\&M_ese_v } \\
\text { O\&M_ese } f=\beta_{-} e s e_{-} f * C_{-} e s e
\end{gathered}
$$

where $\mathrm{P}$ _ese rated is the rated maximum storage capacity of the battery, $\alpha \_$ese is the capital cost per unit of installed capacity, $\beta$ _ese $f$ is the coefficient for fixed O\&M. Note that same as for wind turbines, only the fixed O\&M cost is considered for battery and the variable O\&M_ese_v is assumed to be 0 .

5. Gasoline Production Plant

Capital cost:

$$
C \_g p p=\alpha \_g p p * M \_g p p \_r a t e d \text {. }
$$

O\&M cost:

$$
\begin{gathered}
O \& M_{-} g p p=0 \& M_{-} g p p_{-} f+O \& M_{-} g p p_{-} v \\
O \& M_{-} g p p_{-} f=\beta_{-} g p p_{-} f * C_{-} g p p \\
O \& M_{-} g p p_{-} v=\int_{0}^{\mathrm{T}} \beta_{\mathrm{gpp}_{\mathrm{v}_{\mathrm{n}}}} * \mathrm{M}_{\mathrm{NG}_{\mathrm{GPP}}} \mathrm{dt}+\int_{0}^{\mathrm{T}} \beta_{-} g p p_{-} \mathrm{v}_{-} \mathrm{W} * \mathrm{M}_{\mathrm{W}} \mathrm{dt}
\end{gathered}
$$

where M_gpp_rated is the rated maximum production rate of GPP, $\alpha \_$gpp is the capital cost per unit of installed capacity, $\beta \_g p p \_f$ is the coefficient for fixed O\&M. $\beta \_g p p \_v_{-} n g$ is the coefficient for variable O\&M cost related to NG consumption, which is same as the price of natural gas (i.e., $\beta_{\mathrm{NG}}$ ), $\mathrm{M}_{\mathrm{NG} \text { GPP }}$ is the NG consumed by GPP at time, $\beta_{-}$gpp_v_w is the coefficient for variable O\&M cost related to water consumption, which is same as the price of water (i.e., $\beta_{\mathrm{w}}$ ) while $\mathrm{M}_{\mathrm{W}}$ is the water consumed by GPP at time $t$.

Now having $\mathrm{NPV}_{\mathrm{tx}}$ well defined, the derivative of $\mathrm{NPV}_{\mathrm{tx}}$ with respect to $\mathrm{P}_{\mathrm{e}}$ gives:

$$
\frac{d N P V_{t x}}{d P_{e}}=\sum_{k=0}^{N} \frac{1}{\left(1+r_{R}\right)^{k}} \frac{d F C F F_{R, k}}{d P_{e}}
$$

where

$$
\frac{d F C F F_{R, k}}{d P_{e}}=(1-\operatorname{tax}) \frac{d\left(R_{k}-O \& M_{k}\right)}{d P_{e}}-\frac{d G H G_{k}}{d P_{e}}
$$

By expanding $\mathrm{R}_{\mathrm{k}}, \mathrm{O \& M} \mathrm{M}_{\mathrm{k}}$ and $\mathrm{GHG}_{\mathrm{k}}$, and substituting the linear relationship from the previous section, then: 


$$
\frac{d F C F F_{R, k}}{d P_{e}}=\int(1-\operatorname{tax})\left(\beta_{e}-k_{1} \beta_{N G}\right)-\gamma k_{1} \beta_{C} d t
$$

Since the same constraints over $\mathrm{P}_{\mathrm{e}}$ still hold, i.e., $P_{p h g}+P_{w}-P_{g} \leq P_{e} \leq P_{p h g}$, the following analytical solution is derived:

$$
P_{e}=\left\{\begin{array}{cc}
P_{p h g} & \text { if }(1-\operatorname{tax})\left(\beta_{e}-k_{1} \beta_{N G}\right)-\gamma k_{1} \beta_{C}>0 \\
P_{p h g}+P_{w}-P_{g} & \text { otherwise }
\end{array}\right.
$$




\section{A.2 NHES_ARIZONA}

This section describes the derivation for addressing the economic PGP and NPV optimization for operations as it relates to NHES_Arizona.

\section{A.2.1 Economic PGP Optimization: Numerical Approach}

Similar to NHES_Texas, NHES_Arizona can also be optimized under operational control for maximum pre-tax gross profit (PGP). In order to formulate the optimization problem, the revenue from the sale of electricity and freshwater is considered as the objective function, defined as follows:

$$
J=\int_{0}^{T} P_{e} \beta_{e}+M_{f w} \beta_{f w} d t
$$

where $P_{e}$ is the amount of electrical power sold to the electric grid, $\beta_{\mathrm{e}}$ is the price for electricity, $\mathrm{M}_{\mathrm{fw}}$ is fresh water production rate, and $\beta_{\mathrm{fw}}$ is the fresh water price. Note that the objective function being optimized considers only the revenue. While operational and feedstock cost is not considered here, the objective function described above suffices to demonstrate the flexibility of the selected NHES configuration. The constraints over the variables are as follows: for all time ${ }_{t}$,

$$
\begin{gathered}
P_{e}-P_{S}+P_{R O}=P_{p h g} \\
0 M W \leq P_{e} \leq P_{p h g}-P_{R O L} \\
P_{R O L} \leq P_{R O} \leq P_{R O U}
\end{gathered}
$$

where $\mathrm{P}_{\mathrm{s}}$ is the renewable electricity generated by the PV solar stations, $\mathrm{P}_{\mathrm{RO}}$ is the electricity consumed by $\mathrm{RO}, \mathrm{P}_{\text {phg }}$ is the nuclear reactor generation, which is constant at $600 \mathrm{MWt}$ (or about $180 \mathrm{MWe}$ ), $\mathrm{P}_{\mathrm{ROL}}$ and $\mathrm{P}_{\mathrm{ROU}}$ are the lower and upper limit, respectively, of the power consumed by the RO. In order to characterize the relationship between the power consumed by the water desalination plant and its fresh water production, the following non-linear relationship is assumed (See Section 4.2.7 for more detail)

$$
M_{f w}=k_{0}+k_{1} P_{R O}+k_{2} P_{R O}^{2}
$$

Combining the constraints yields:

$$
\max \left(0 M W, P_{p h g}+P_{S}-P_{R O U}\right) \leq P_{e} \leq \min \left(P_{p h g}-P_{R O L}, P_{p h g}+P_{S}-P_{R O L}\right)
$$

or equivalently

$$
P_{\text {phg }}+P_{S}-P_{R O U} \leq P_{e} \leq P_{p h g}-P_{R O L}
$$

Note that the last conversion requires that $P_{p h g}+P_{S}-P_{R O U} \geq 0$ (equivalently $P_{p h g}-P_{R O U} \geq 0$ ) and $P_{p h g}+P_{S}-P_{R O L} \geq P_{p h g}-P_{R O L}$ (equivalently $P_{S} \geq 0 \mathrm{MW}$ ), both of which are true in NHES_Arizona. Putting all together, the optimization problem is re-formulated as follows:

Maximize

$$
J=\int_{0}^{T} P_{e} \beta_{e}+M_{f w} \beta_{f w} d t
$$

\footnotetext{
${ }^{\mathrm{p}}$ Note these relationships only hold for ranges such that the above constraints are satisfied.
} 
Subject to (for all time $t$ )

$$
\begin{gathered}
P_{e}-P_{s}+P_{R O}=P_{p h g} \\
M_{f w}=k_{0}+k_{1} P_{R O}+k_{2} P_{R O}^{2} \\
P_{p h g}+P_{S}-P_{R O U} \leq P_{e} \leq P_{p h g}-P_{R O L}
\end{gathered}
$$

\section{A.2.2 Economic NPV Optimization: Numerical Approach}

NPV was defined for NHES_Arizona (NPV_az) as follows, where Tables 7 and 8 list all the variables used in the optimization problem formulation.

$$
N P V_{a z}=\sum_{k=0}^{N} \frac{F C F F_{R, k}}{\left(1+r_{R}\right)^{k}}
$$

with real discounted Free Cash Flow to Firm for year k, i.e., $\mathrm{FCFF}_{\mathrm{R}, \mathrm{k}}$, defined as:

$$
F C F F_{R, k}=\left(R_{k}-O \& M_{k}-D A_{k}(1+i)^{-k}\right)(1-t a x)+D A_{k}(1+i)^{-k}-G H G_{k}-C A P E X_{k}
$$

where $R_{k}$ is the total revenue from sales of electricity and fresh water for year $k$, and is given by:

$$
R_{k}=\int_{0}^{T} P_{e} \beta_{e}+M_{f w} \beta_{f w} d t
$$

The Capital Expenditure $\left(\mathrm{CAPEX}_{\mathrm{k}}\right)$ only occurs when $\mathrm{k}=0$, i.e., year 0 , and is given by:

$$
\text { CAPEX } X_{0}=C_{-} p h g+C_{-} \text {ren }+C_{-} \text {ese }+C_{-} \text {ro, }
$$

and $\mathrm{CAPEX}_{\mathrm{k}}=0$ for $\mathrm{k}>0$. Note that the capital expense for the four major components is explained in more detail shortly. Depreciation Amortization for year k is given by:

$$
D A_{k}=\rho_{d a, k} C A P E X_{0}
$$

where $\rho_{d a, k}$ is the Depreciation Amortization rate at year $\mathrm{k} . \mathrm{GHG}_{\mathrm{k}}$ is the penalty for $\mathrm{GHG}$ emission and for this case it is 0 as no GHG is released. $O \& M_{k}$ is the operation and maintenance expense for year $k$, given as follows:

$$
O \& M_{k}=\text { O\&M_phg }+ \text { O\&M_ren }+ \text { O\&M_ese + O\&M_ro, }
$$

and for each component, its O\&M cost would be further divided into fixed and variable O\&M cost. The capital and O\&M expense for the four major components, i.e., Primary Heat Generator \& Power Cycle, Renewable Energy Generator, Electrical Storage Element and Reverse Osmosis Desalination Plant, are computed as following:

1. Nuclear \& Power Cycle

Capital cost:

$$
C \_p h g=\alpha \_p h g * P \_p h g \_r a t e d
$$

O\&M cost:

$$
\begin{gathered}
\text { O\&M_phg }=0 \& M_{-} p h g_{-} f+0 \& M_{-} p h g_{-} v \\
O \& M_{-} p h g_{-} f=\beta_{-} p h g_{-} f * P \_p h g_{-} r a t e d * 8760 \\
O \& M_{-} p h g_{-} v=\int_{0}^{T} \beta_{-} p h g_{-} v * P \_p h g d t
\end{gathered}
$$


where $\mathrm{P} \_$phg_rated is the rated maximum output power of the Nuclear \& Power Cycle, $\alpha \_$phg is the capital cost per unit of installed capacity, $\beta \_p h g \_f$ is the coefficient for fixed O\&M and $\beta \_p h g \_v$ is the coefficient for variable O\&M, P_phg is the power output of Nuclear \& Power Cycle at time $t$ (note that $\mathrm{P} \_$phg is denoted without subscript $t$ for simplicity).

2. Renewable Energy Generation (i.e., PV solar station)

Capital cost:

$$
\text { C_ren }=\alpha \_r e n * P \_r e n \_r a t e d
$$

$\underline{O \& M \text { cost: }}$

$$
\begin{gathered}
\text { O\&M_ren }=0 \& M \_r e n \_f+O \& M \_r e n \_v \\
O \& M \_r e n \_f=\beta_{-} r e n_{-} f * C_{-} r e n
\end{gathered}
$$

where $\mathrm{P} \_$ren_rated is the rated maximum output power of the PV solar station, $\alpha \_$ren is the capital cost per unit of installed capacity, $\beta$ ren_f is the coefficient for fixed O\&M. Note that for PV solar station, only the fixed O\&M cost is considered and the variable O\&M_ren_v is assumed to be 0 .

3. Electrical Storage Element (i.e., battery)

Capital cost:

$$
\text { C_ese }=\alpha \_ \text {ese } * P_{\_} \text {ese_rated }
$$

$\underline{\text { O\&M cost: }}$

$$
\begin{gathered}
\text { O\&M_ese }=0 \& M_{-} e s e_{-} f+O \& M_{-} e s e_{-} v \\
\text { O\&M_ese_f }=\beta_{-} e s e_{-} f * C_{-} e s e
\end{gathered}
$$

where $\mathrm{P}$ _ese_rated is the rated maximum storage capacity of the battery, $\alpha \_$ese is the capital cost per unit of installed capacity, $\beta$ ese $f$ is the coefficient for fixed O\&M. Note that same as for PV solar station, only the fixed O\&M cost is considered for battery and the variable O\&M_ese_v is assumed to be 0 .

4. Reverse Osmosis Desalination Plant

Capital cost:

$$
\text { C_ro }=\alpha \_r o * M \_r o \_r a t e d \text {. }
$$

O\&M cost:

$$
\begin{gathered}
O \& M_{-} r o=0 \& M \_r o_{-} f+O \& M \_r o_{-} v \\
O \& M_{-} r o_{-} f=\beta_{-} r o_{-} f * C_{-} r o_{\text {rated }} \\
O \& M_{-} r o_{-} v=\int_{0}^{T} \beta_{-} r o_{-} v * M_{f w} d t
\end{gathered}
$$

where M_ro_rated is the rated maximum production rate of GPP, $\alpha$ ro is the capital cost per unit of installed capacity, $\beta$ _ro_f is the coefficient for fixed O\&M. $\beta_{-}$ro_v is the coefficient for variable O\&M cost and $\mathrm{M}_{\mathrm{fw}}$ is the fresh water production by GPP at time $\mathrm{t}$.

Similar to NHES_Texas case, maximizing $\mathrm{NPV}_{\mathrm{az}}$ is the same as maximizing $\mathrm{FCFF}_{\mathrm{R}, \mathrm{k}}$ for each $\mathrm{k}$. Rearrange the equation of $\mathrm{FCFF}_{\mathrm{R}, \mathrm{k}}$, then:

$$
F C F F_{R, k}=\left(\int_{0}^{T} P_{e} \beta_{e}+M_{f w} \beta_{f w}-\beta_{-} r o_{-} v M_{f w} d t\right)(1-t a x)+\text { Const }_{a z}
$$


where Const $_{a z}$ is a lump-sum variable that is not depending on the decision variables (i.e., $\mathrm{P}_{\mathrm{e}}$ and $\mathrm{M}_{\mathrm{fw}}$ ) given as:

$$
\begin{aligned}
& \text { Const }_{a z}=\left(-O \& M \_p h g-O \& M_{-} r e n-O \& M_{-} e s e-O \& M_{-} \text {ro_f }_{-} f\right)(1-\operatorname{tax})+D A_{k}(1+i)^{-k} \text { tax } \\
& \text { - CAPEX } X_{k}
\end{aligned}
$$

Since the same constraints over the decision variables $\mathrm{P}_{\mathrm{e}}$ and $\mathrm{M}_{\mathrm{fw}}$ apply, the optimization problem is re-formulated as follows for any year,

Maximize

$$
J=(1-\operatorname{tax}) \int_{0}^{T} P_{e} \beta_{e}+M_{f w} \beta_{f w}-\beta_{-} r o_{-} v M_{f w} d t
$$

Subject to (for all time $t$ )

$$
\begin{gathered}
P_{e}-P_{s}+P_{R O}=P_{p h g} \\
M_{f w}=k_{0}+k_{1} P_{R O}+k_{2} P_{R O}^{2} \\
P_{p h g}+P_{S}-P_{R O U} \leq P_{e} \leq P_{p h g}-P_{R O L}
\end{gathered}
$$

